S F

751

.266

1906 









\section{DR. DAVID ROBERTS PRACTICAL HOME VETERINARIAN \\ FIFTH EDITION}

Price $\$ 1.00$

Published by DR. DAVID ROBERTS VETERINARY CO.

Waukesha, Wisconsin, U. S. A. 


$$
\begin{array}{r}
\text { SFY51 } \\
. R 6 \\
1906
\end{array}
$$

$$
\text { COPYRIGHT, } 1906
$$

By DAVID ROBERTS, D. V. S.

$$
\therefore
$$

Bo Transfet

\section{FEB $20 \div \angle 5$}




\title{
Dr. David Roberts Practical Home Veterinarian
}

\author{
A BOOK CONTAINING
}

much valuable information on the care and treatment of Cattle, Horses, Swine, Sheep and Poultry, and a review in alphabetical order of the diseases to which they are subject, together with the causes and symptoms, and the most efficient medicines for each.

\section{ALSO A CATALOGUE}

listing the best Disinfectants, Medicines, Stock Foods and Appliances required in the handling and treatment of Live Stock of all kinds.

Written and Compiled by

DAVID ROBERTS, D. V. S.

Cattle Specialist

$\therefore$.

President of

DR. DAVID ROBERTS VETERINARY CO.

WAUKESHA, WISCONSIN. 







\section{General Index of Dr. David Roberts Practical Home Veterinarian}













How to Examine a Sick Animal............................. 21



Never Drench Cattle.................................... 21

How to Give a Cow Medicine.............................. 22





CATTLE SECTION.





























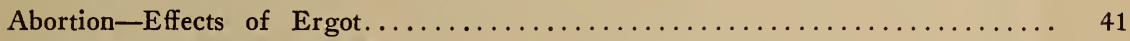













Afterbirth-How to Prevent Retention........................ 49
























Calf Cholerate. Page

Calf Cholera-How to Know It......................... 58

Calf Cholera-How to Prevent It........................... 59

Calf Cholera-How to Treat............................... 60





Casting the Withers, or Expulsion of the Womb.................. 61











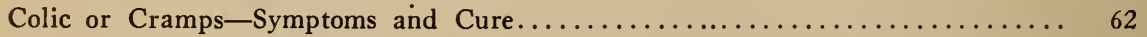

Constipation in Calves................................. 63











Fevers-Use of Fever Thermometer-How to Control Fever............. 64





Founder-How to Know It-The Treatment..................... 65









Gonorrhœa in Bulls-How to Treat........................ 66

Grass Staggers-Treatment for Same....................... 66

Grubs or Warbles $\ldots \ldots \ldots \ldots \ldots \ldots \ldots \ldots \ldots \ldots \ldots \ldots \ldots \ldots \ldots \ldots \ldots \ldots \ldots \ldots$





Inflammation of the Lungs-How to Treat. . . . . . . . . . . . . . . . . . 67

Inflammation of the Womb-How to Treat. . . . . . . . . . . . . . . . . . . . 68



Inflammation of the Testicles-The Treatment $\ldots \ldots \ldots \ldots \ldots \ldots \ldots \ldots \ldots \ldots . \ldots \ldots$



Inflammation of the Joints-The Treatment $\ldots \ldots \ldots \ldots \ldots \ldots \ldots \ldots \ldots \ldots \ldots$



Leucorrhœa or Whites-The Treatment...................... 68

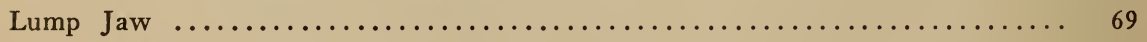

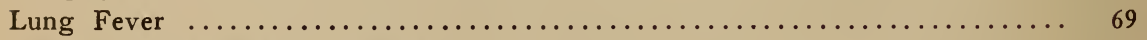

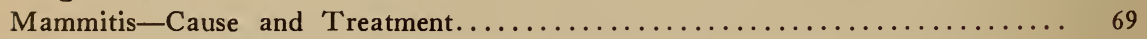

Milk Blue ..... ................................... 69

Milk Fever or Parturient Paresis ............................. 69

Milk Bloody or Stringy-Treatment........................ 70

Navel Diseases of Calves................................ 70

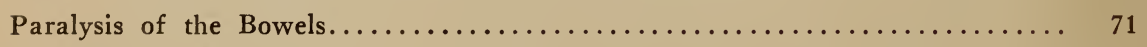










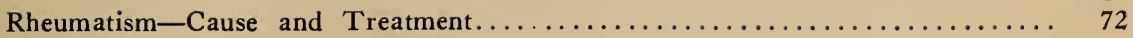

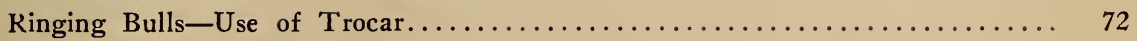

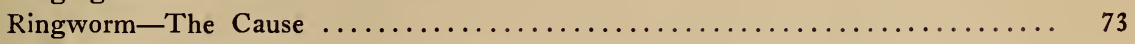

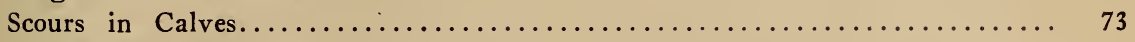

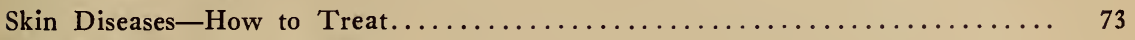

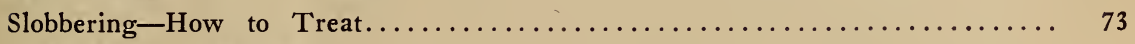

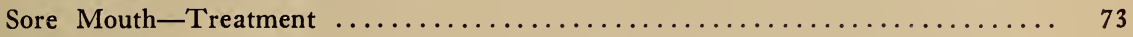





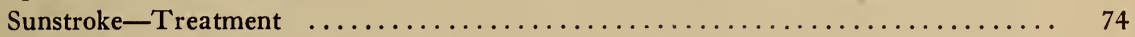

















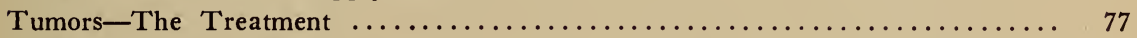

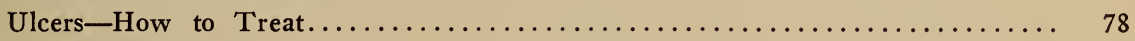



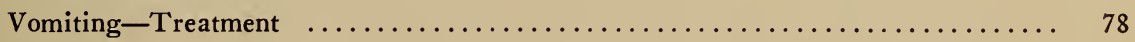



Wounds-How to Heal Them............................... 79

Sworn Testimony Proving Success of Dr. David Roberts' Anti-Abortion Serum.. 81

Prescriptions-For Cattle Ailments-Tabulated................... 145

\section{HORSE SECTION.}

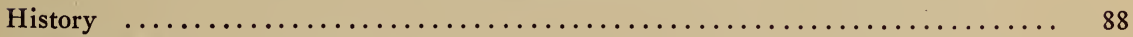

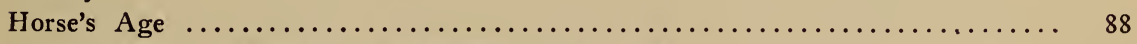

Symptoms and Treatment of Diseases of the Horse................ 89

Abortion in Mares, or Slinking of the Foal..................... 89

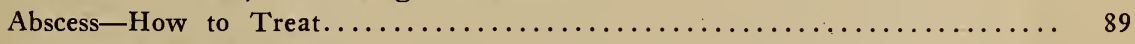



Azoturia, or Paralysis of the Hind Parts, and Treatment of Same......... 89

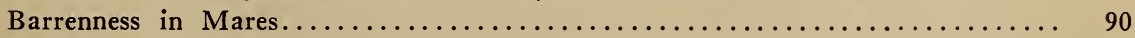

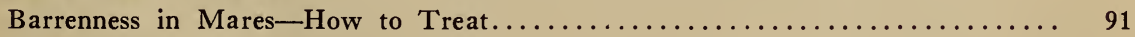

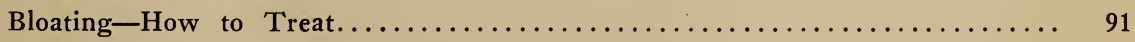

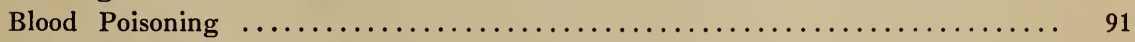

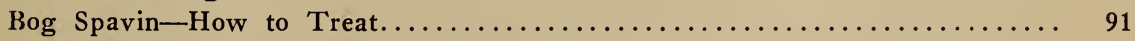

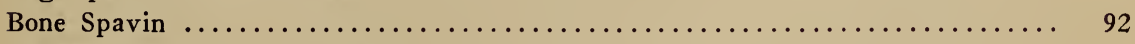

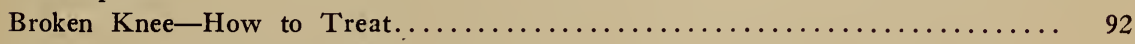

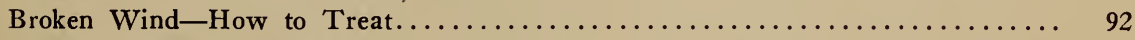

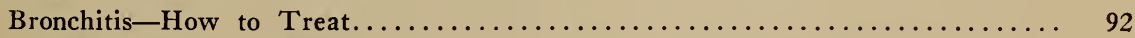

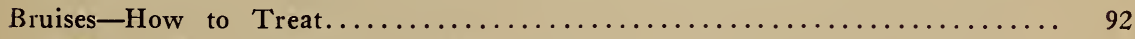

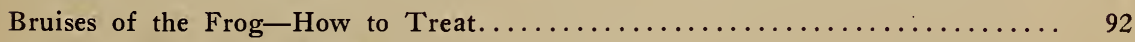

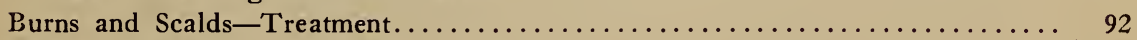

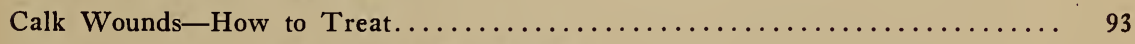

Capped Elbow or Shoe Boil-The Treatment.................... 93

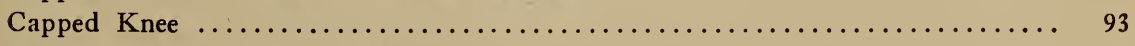

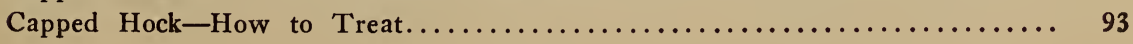


Catration or Cutting Colts $\quad$ Page.

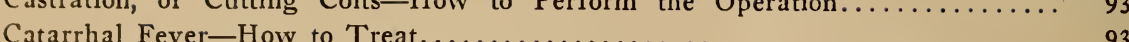







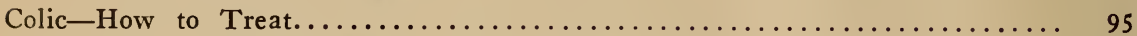

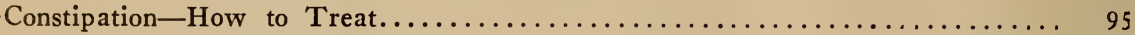



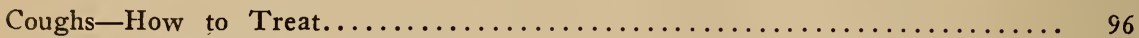



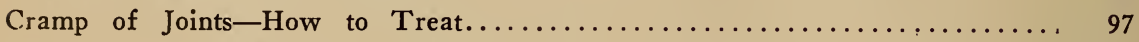

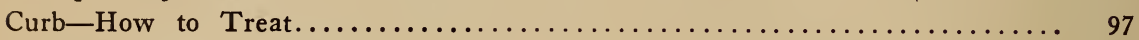







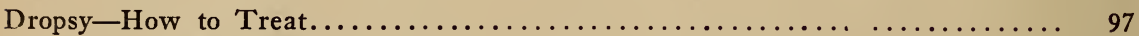



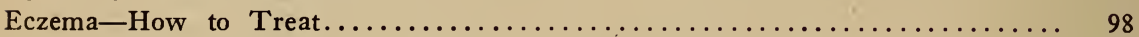

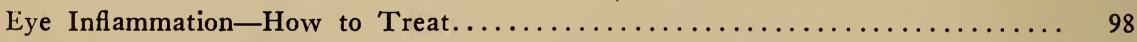

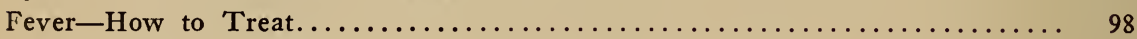

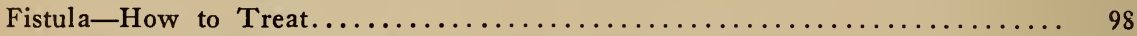

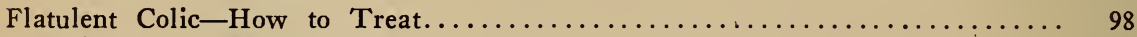

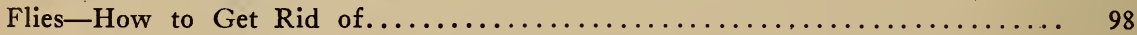

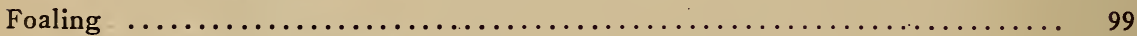

Founder-Cause and Treatment................................... 99

Glanders-An Incurable Disease, How to Know It................... 100

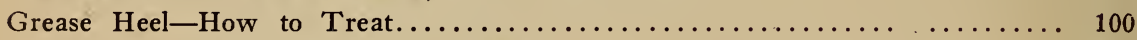

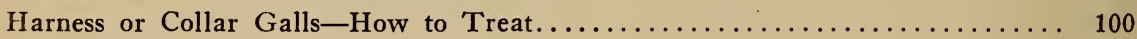

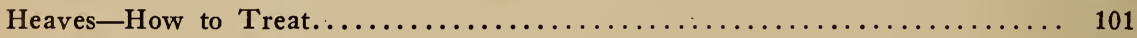

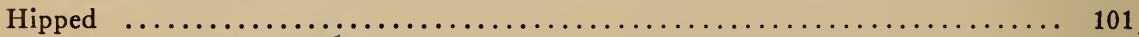





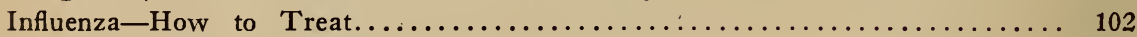

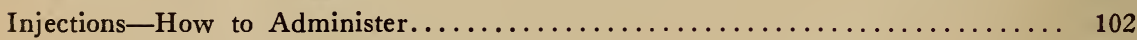

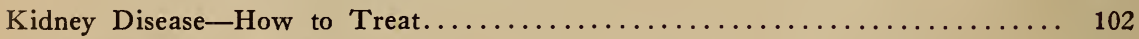

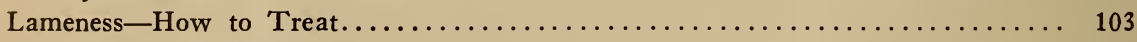

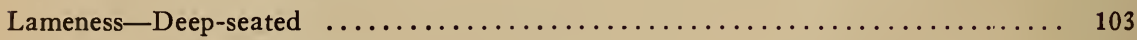

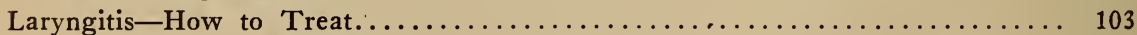

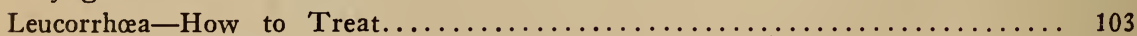

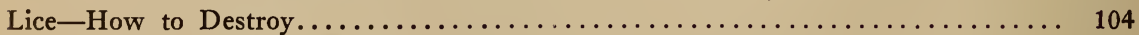

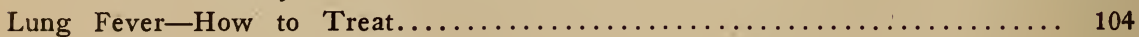

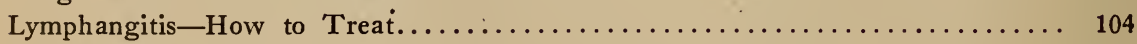

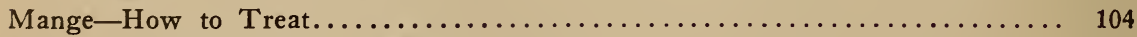

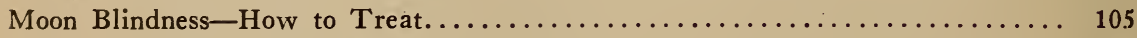

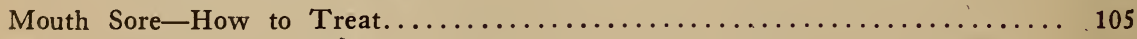





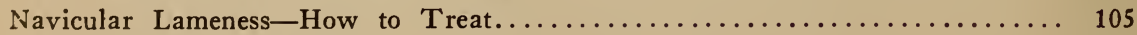








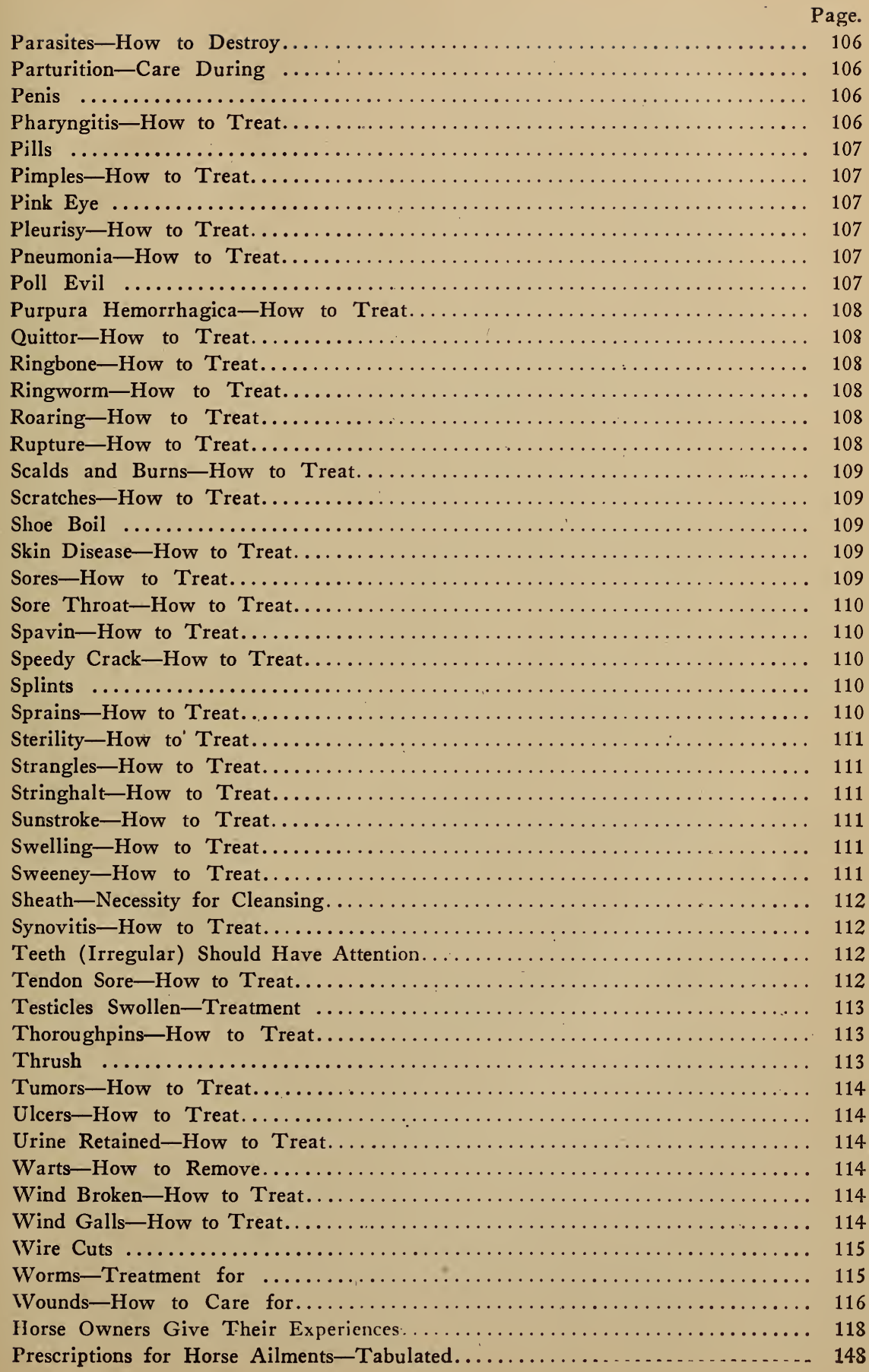




\section{SWINE SECTION.}

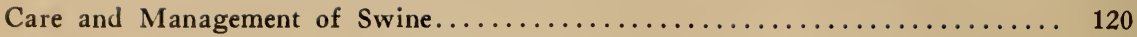

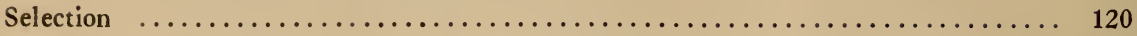

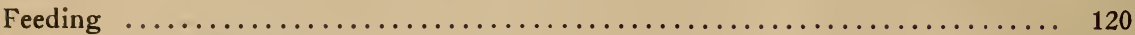

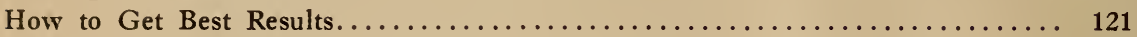

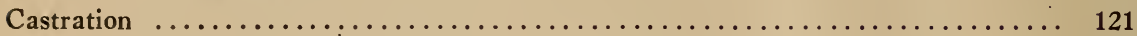

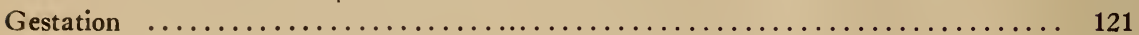

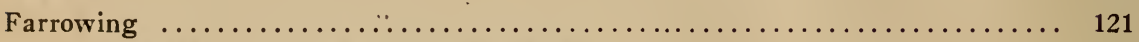

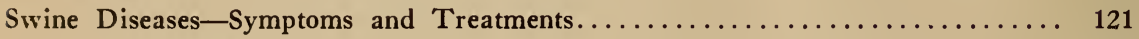

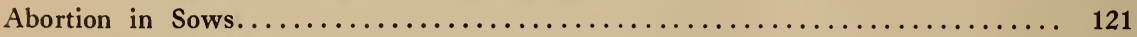

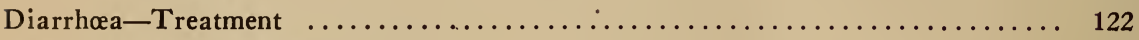



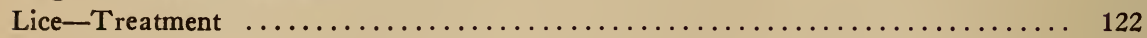

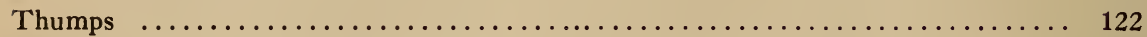

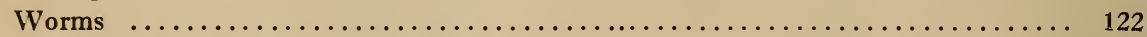

Prescriptions for Swine Ailments-Tabulated.................... 153

SHEEP SECTION.

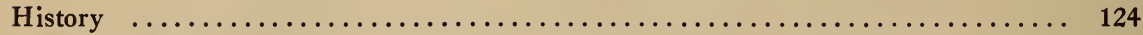



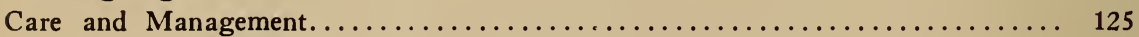



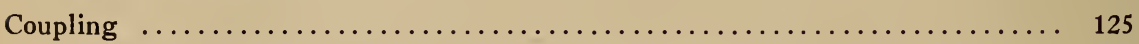

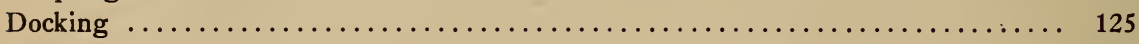

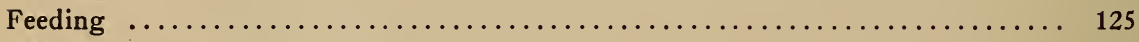



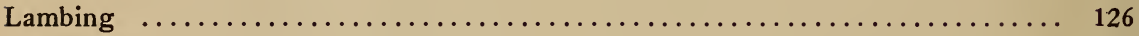

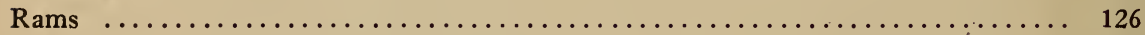

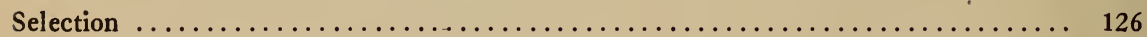

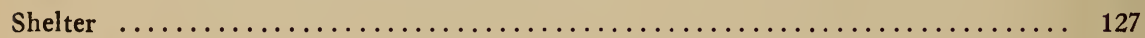

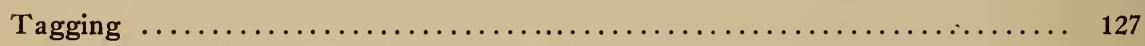

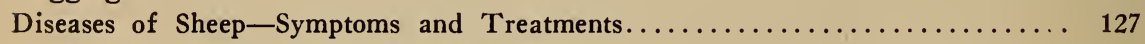

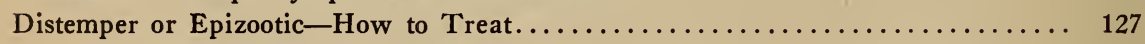

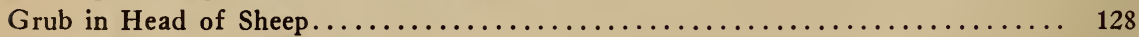

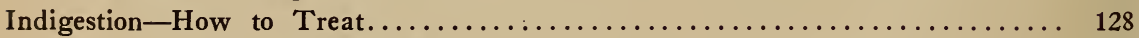

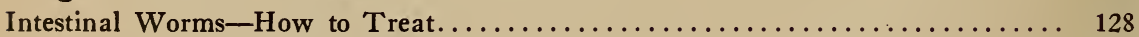

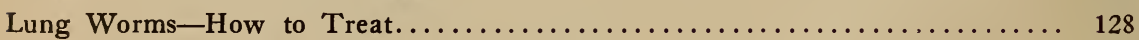

Prescriptions for Sheep Ailments-Tabulated.................... 153

POULTRY SECTION.

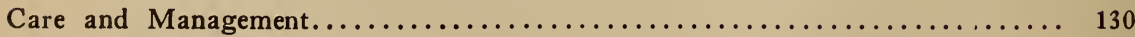

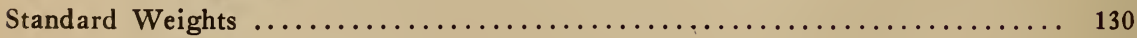

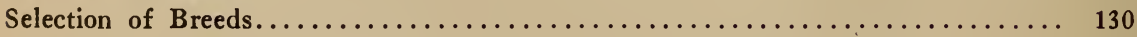

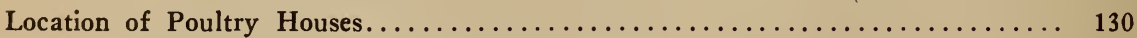

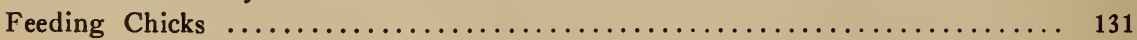

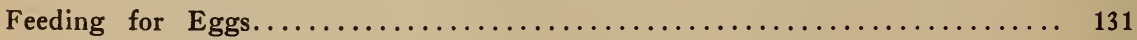

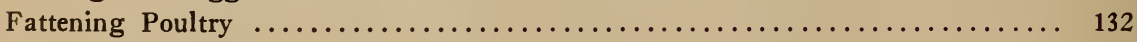

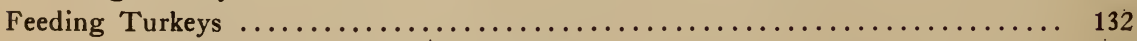

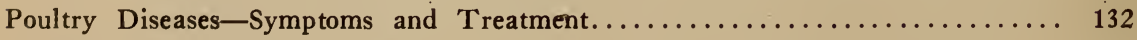

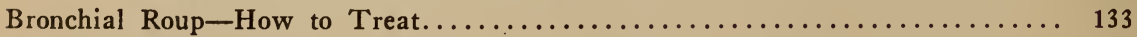

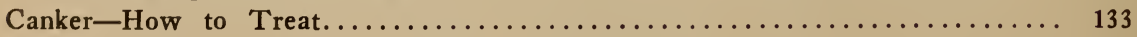

Catarrhal or Diphtheric Roup-How to Treat..................... 133 


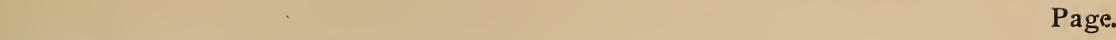

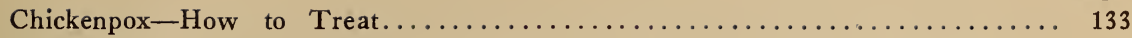

Cholera-How to Treat................................ 133

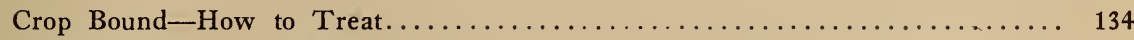

Diarrhœa-How to Treat................................ 134

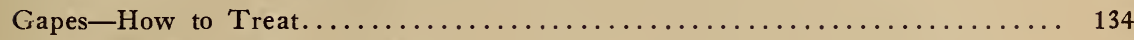

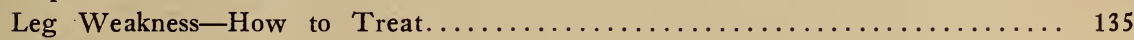

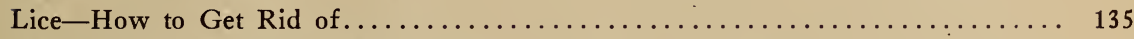



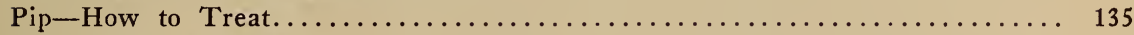

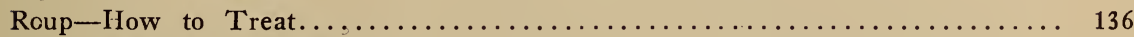

Scaly Legs-How to Treat............................... 136

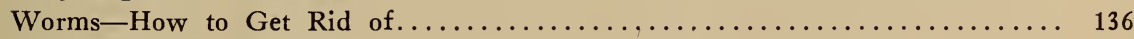

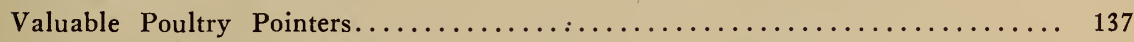

HOW TO MAKE YOUR OWN STOCK TONIC AT HOME............ 139

Catalogue of Dr. David Roberts' Veterinary Medicines................155 to 182

Endorsement of the Waukesha National Bank...................... 144

Prescriptions for Poultry Ailments-Tabulated................... 153

\section{LIST OF ILLUSTRATIONS.}

Home Office and Dr. David Roberts, with His Famous Arabian Team....... 4

Fac-Simile of Dr. Roberts' Diploma from Chicago Veterinary College......... 1t

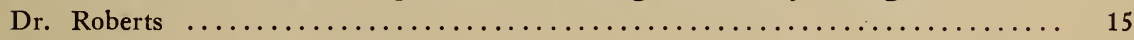

How to Give a Cow Medicine............................ 22

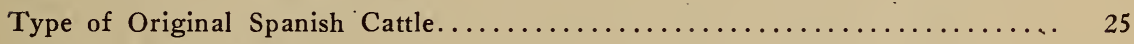

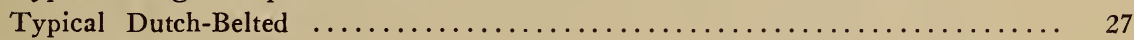

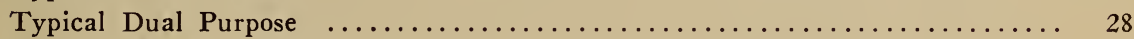

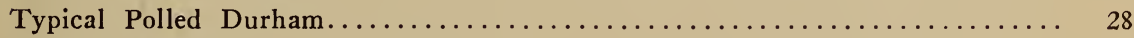

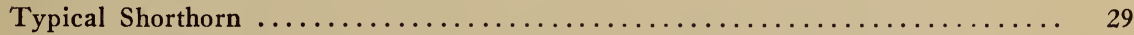

Typical Hereford $\ldots \ldots \ldots \ldots \ldots \ldots \ldots \ldots \ldots \ldots \ldots \ldots \ldots \ldots \ldots \ldots \ldots \ldots \ldots \ldots \ldots \ldots$

Typical Aberdeen Angus................................ 29

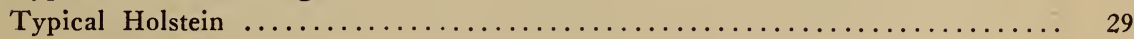

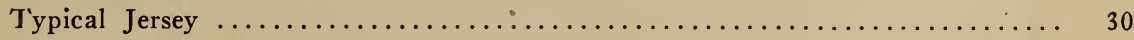

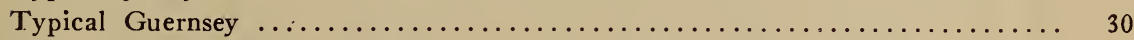

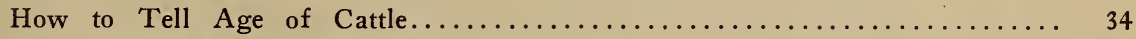

Feet of Cows Severely Afflicted with Ergotism....................41

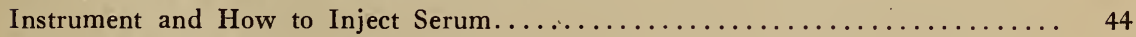

How to Flush Genital Organs of Cow and Bull................... 45

Showing How Easily Serum Can Be Administered in Run............. 45

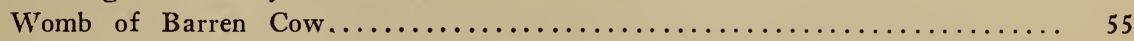

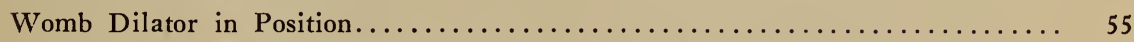

How to Bandage a Cow Suffering from Caked Udder................ 66

Overcoming a Case of Milk Fever......................... 70

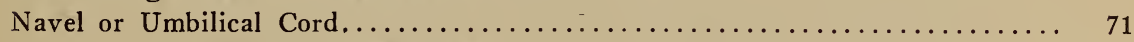

How to Apply Test for Tuberculosis........................ 77

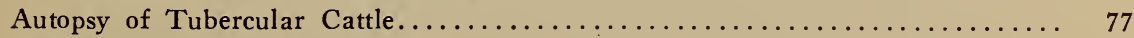

Device for Throwing Cattle............................ 79

Herds of Cattle Treated for Abortion........................ 80

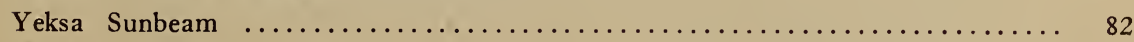

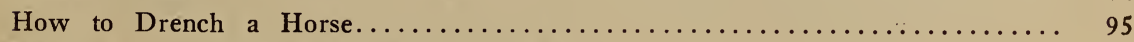

Methods of Applying Antiseptic Poultice....................... 116 


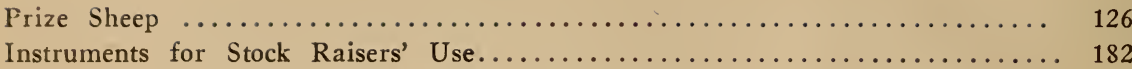

\section{LIST OF DR. DAVID ROBERTS' MEDICINES.}

ANTI-ABORTION TREATMENT OUTFIT, for preventing and curing Abor-

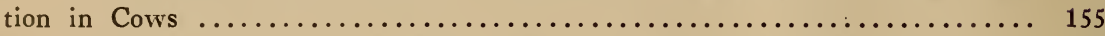

ANTISEPTO, for washing the genital organs of cattle, thus preventing infection 156 BREEDING TONIC, to tone genital organs and overcome barrenness ...... 157 COW CLEANER, for expelling retained afterbirth................. 158 CALF CHOLERA REMEDY, for preventing and curing scours in all live stock 159 MILK FEVER OUTFIT, for preventing and curing milk fever.......... 160 LAXOTONIC, for constipation and paralysis of the bowels in live stock........ 161 C.OW TONIC, for loss of appetite and to increase the flow of milk....... 162 HORN KILLER, for preventing growth of horns in calves............ 175

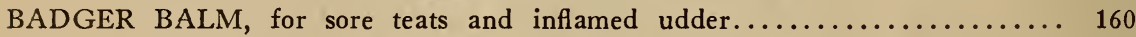
GERM KILLER, for washing wounds and bathing inflamed parts.......... 163 SKIN OINTMENT, for all skin diseases, such as mange, ringworm, etc...... 163 ANTISEPTIC POULTICE, for poulticing swollen and inflamed parts........ 164

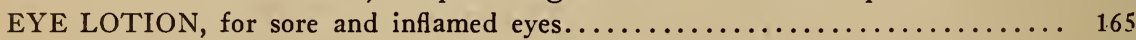

WORM POWDER, for destroying and expelling worms from live stock....... 165

WHITE LINIMENT, for removing muscular soreness in man or beast; also

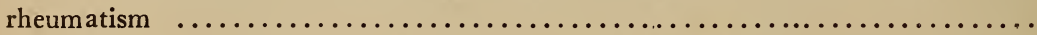

ABSORBENT, for lump jaw, removing unnatural enlargement on body or limbs

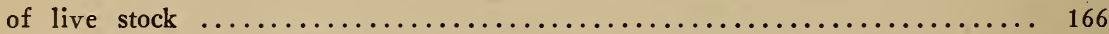

UMBILICURE, for preventing navel diseases in colts and calves.......... 167

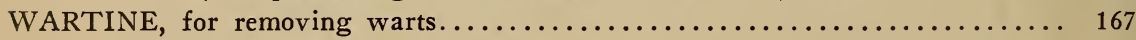

FEVER PASTE, for distemper, coughs, colds and all throat and lung troubles.. 168

HEALING LOTION, for healing old sores and puss cavities, fistula, poll evil, etc 169 HEAVE POWDER, for heaves, asthma, broken wind and irregular breathing. 169 HORSE TONIC, to aid digestion, purify the blood and sleeken the coat...... 170 PHYSIC BALL, for stimulating unthrifty, wormy and hide-bound horses..... 172 COLIC CURE, for spasmodic or wind colic; also water trouble........... 171 HEALING OIL, for collar and harness galls and all superficial wounds....... 172 HOOF REMEDY, for growing new hoofs, overcoming and preventing contraction 173 LUCKY FOUR BLISTER, a penetrating and stimulating blister.......... 173 BONE BLISTER, for bone spavin, ring bone, side bone and splints.......... 173 KIDNEY CURE, for preventing and overcoming kidney diseases, such as Azotura 174 FLY OIL, for protecting stock from flies and insects................. 175 HOG TONIC, for overcoming and preventing diseases and worms in swine.... 176 SHEEP TONIC, to aid digestion, prevent worms and diseases........... 162 POULTRY TONIC, to make hens lay and prevent diseases............ 177 POULTRY CHOLERA CURE, for preventing and overcoming cholera....... 174

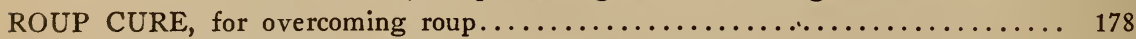
DIOLICE, for destroying lice on live stock and poultry.............. 178 CONDENSED STOCK TONIC, for making your own stock tonic at home.... 179 DISINFECTALL, destroys germs, prevents infectious diseases, such as abortion,

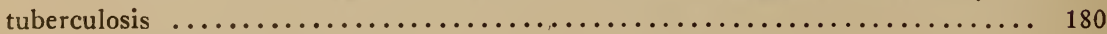

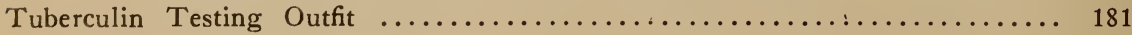

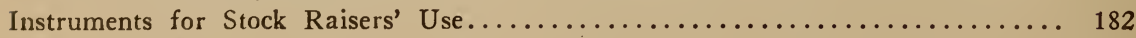

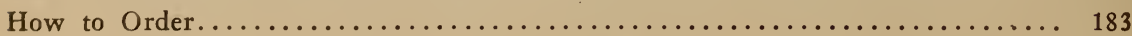




\section{INTRODUCTORY}

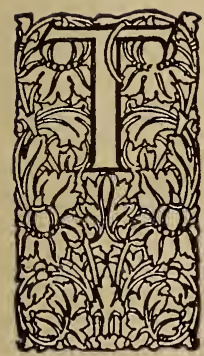

HE only way" by which the farmer, dairyman, poultryman, stock or cattle owner can realize the most from his investment and his labor is by continually guarding the health and welfare of his live stock as a precautionary measure, and to employ the most advanced remedies and discoveries in eradicating disease as soon as it appears. It is the object and purpose of this book to present in clear, concise and simple language, facts with which every farmer and cattle owner should be acquainted. It gives you a brief history of the most important farm animals, also interesting statistics. It tells you how to care for and manage your live stock. How to keep them in good condition so as to always produce the best results. How to prevent disease.

How to know disease when it does appear, and lastly, how to treat and overcome disease. The precautionary measures, to start with, are absolute cleanliness, with conditions and surroundings as sanitary as possible. Then it is necessary at all times to have on hand a sufficient supply of good disinfectants, to destroy parasites and germ life of all kinds, which multiply so rapidly and exist everywhere, especially where cleanliness is neglected.

In this book we make mention of the different diseases to which live stock is subject, and we treat at some length on those for which we have a positive, tried and tested remedy. We make note of other diseases for which we do not claim to have a prepared remedy, and these subjects will be a matter of correspondence direct with Dr. David Roberts, who will give each and every inquiry his careful and personal attention. In regard to the remedies which are offered in this book, we wish to say that they are the results of thousands of experiments and the experience of over twenty years of active veterinary practice in the richest dairy cattle section of the United States. Exceptional opportunities have been offered Dr. David Roberts for studying the cause and effect of such complicated and persistent diseases as Abortion, Barrenness, Retention of the Afterbirth, and Scours in Calves, and on these subjects he is a recognized authority, as hundreds of unsolicited testimonials will prove. The claim, as is often made, that the simple feeding of some of the so-called stock foods is a universal cure for all of these ailments is a rank fallacy and is an insult to the intelligence of the owners of live stock.

Abortion, for instance, is a germ disease; the germ is found in the mother's blood, afterbith and bowels of the fotus, and such conditions can only be corrected by the injection of a serum into the blood which will destroy and eradicate the germ and thus restore the animal to a healthy condition.

We make mention of this to illustrate that the treatment and remedy for many of these diseases is the subject of much deep scientific study, and cannot be successfully handled except by a man of much experience and practice. These things cannot be learned solely from books. The knowledge must be acquired from the most thorough and successful of masters-Experience and Practice. Dr. David Roberts in his 
daily practice administers with unequalled success exactly the same remedies which are offered you here, and with his letter of advice and instructions you can accomplish the same wonderful results in your herd which he meets with wherever he is called. The remedies here offered, in addition to being used by Dr. David Roberts in his practice, have been used to a great extent by live stock owners throughout the country, and have met with marked success. For this reason it is our purpose to now introduce them to every owner of live stock in America, and if you should give them a trial and find them to do what we claim, it would be a move in the right direction and a boon to the suffering animal kingdom if you would recommend them to your friends and neighbors.

With the above remarks we will close our introductory chapter, and would request that you read carefully the following pages, which we are certain will result to your benefit.

We hope after reading this book we will have convinced live stock owners that after all has been said on the subject, the fact cannot be denied that to guard and protect the health and comfort of your animals is, and truly is, "The Only Way."

DR. DAVID ROBERTS VETERINARY CO.,

Dr. David Roberts, Cattle Specialist, President.

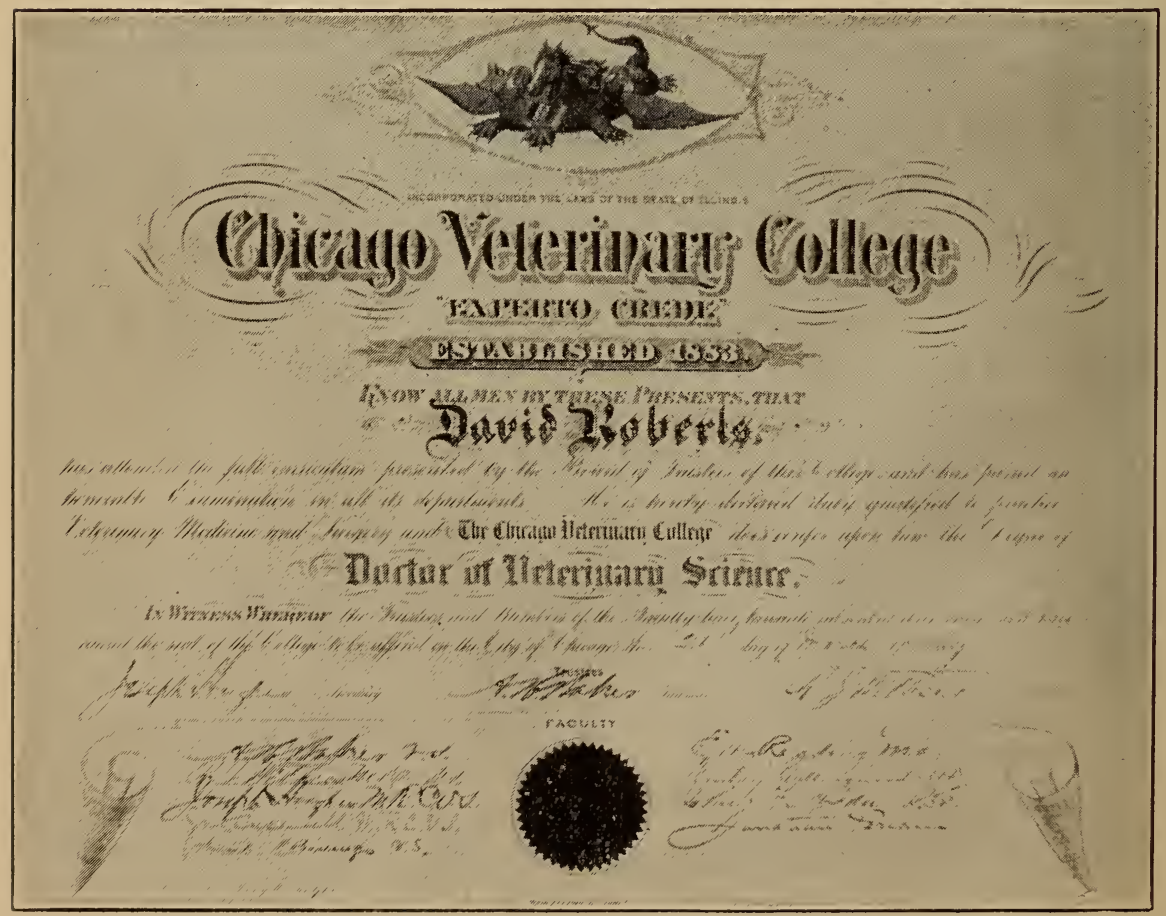

Fac-simile of Dr. David Roberts' Diploma from Chicago Veterinary College. 


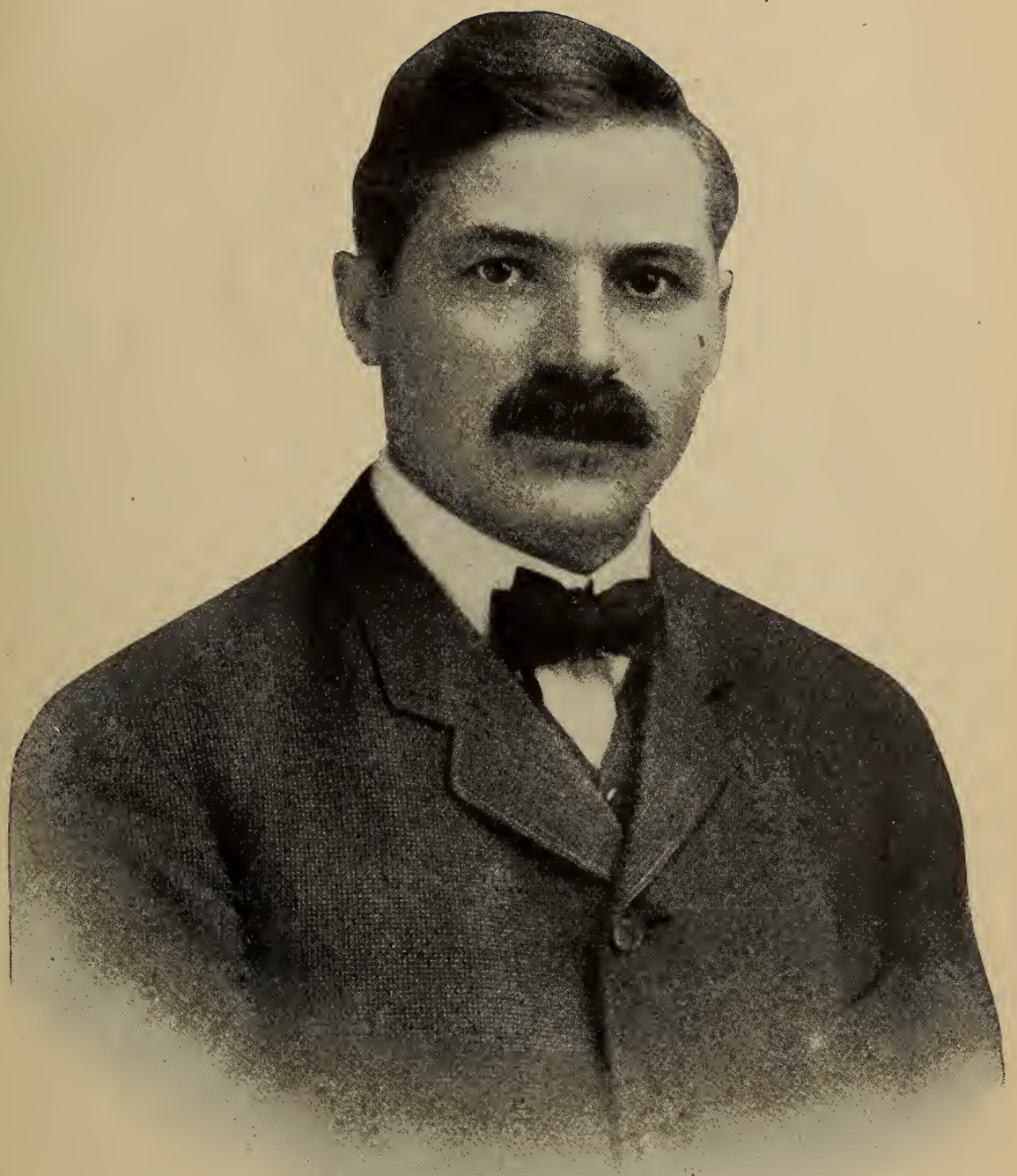

DR. DAVID ROBERTS 


\section{BIOGRAPHICAL SKETCH}

Dr. David Roberts has for years occupied a conspicuous place among the veterinarians of the United States. In appointing him State Veterinarian of Wisconsin, which position he held during the years 1906-07-08, Governor Davidson made the selection from hundreds of applications and his acceptance of Dr. Roberts' resignation on Nov. 1 , 1908, which given in part shows the beautiful record he had established, and won for him the esteem of the state officials. His work has been of unusual importance to the live stock interests of the Northwest. He has traveled widely in the practice of his profession, and through his efforts infectious diseases have been stamped out from among many valuable herds in all parts of the country.

For generations back the Roberts family has been interested in the breeding and treating of live stock. Twenty-five years before any veterinary college had been established in America, J. P. Roberts, the grandfather of Dr. David Roberts, was engaged to some extent in treating horses and cattle. His father, John M. Roberts, was a well-known stock raiser and farrier, his services being in demand even at the present time, owing to his experience and good judgment. fession.

It will thus be seen that Dr. David Roberts was, in a measure, born in this pro-

During the early part of Dr. David Roberts' life he attended the district school and later entered Beloit College. Returning from Beloit he successfully managed his father's stock farm with its extensive milk interests and a side line of draft horses, hogs and sheep. His great natural love of stock, and the success which attended his every effort with them persuaded him to enter the Chicago Veterinary College in order that his usefulness to domestic animals, which serve mankind so faithfully, might be extended.

In 1889 Dr. David Roberts graduated from the Chicago Veterinary College, and his desire of becoming a cattle specialist induced him to leave the larger cities and locate in the beautiful city of Waukesha, which is in the very heart of the large dairy industry of this great state, where he has since 1889 enjoyed a large cattle practice. While he has devoted his time to the general practice of the Veterinary Science, still it must be understood that he is eminently a

\section{CATTLE SPECIALIST,}

and as such is far more competent to handle and treat the complicated diseases of dairy cattle than one who has not paid particular attention to this line of work. On account of the magnitude of the cattle industry in this country, the Doctor places this branch of the practice ahead of all others, and it is with pardonable pride that we refer to his magnificent success in this field.

In the discovery of the Anti-Abortion Treatment, Dr. David Roberts has rendered a service of the highest importance in the cattle industry of the world. It is a matter cf great notice to owners and breeders of live stock that this Treatment, along with numerous other scientific prescriptions that he has employed with such remarkable success in his extensive practice, have been placed on the market in such form as to be readily available.

The Doctor has built up the largest cattle practice in the country, and is prepared to visit any part of the United States on important cases, details of such trips to be arranged with him by correspondence. 


\section{DEPARTMENT OF FREE ADVICE.}

We have a thoroughly equipped organization, all under the direct supervision of Dr. David Roberts, and with the systematic arrangement of our work we can handle an unlimited amount of correspondence. We invite Farmers, Dairymen, Poultrymen, Stock and Cattle Owners and Veterinarians to write Dr. David Roberts on any subject whatsoever pertaining to live stock, and you will receive a prompt, courteous and satisfactory reply by return mail, which may save you many dollars and be of great benefit to you. You may say that this is a rather philanthropic proposition, which it certainly is, but we feel that the cost and labor of such correspondence and free advice is fully offset by the value of the introduction to you and the fact that we will become better acquainted and lasting friends. We know that with our book in your hands you will find occasion at different times to refer to it, and the result of such reference may prove to our mutual benefit. We know that there are many little things that you would like to know from time to time about your stock. The only trouble is, you don't know to whom to apply. Now, write us all about the difficulties you are experiencing with the different live stock you own, and your letter will be treated confidentially and have the prompt attention of Dr. David Roberts. And remember this is absolutely free of charge. From the Doctor's vast experience, he can surely suggest a solution to your problems, and we know the reply will be satisfactory and profitable to you.

Do not delay the matter; but write at once. Delays are dangerous.

DR. DAVID ROBERTS VETERINARY CO.,

Dr. David Roberts, President. 


\section{LABORATORY AND EXPERIMENT STATION.}

We maintain a very extensive Laboratory and Experiment Station, equipped with every modern facility and device for the compounding of our various medicines and the conducting of experimental work in every branch of veterinary science.

Here Dr. David Roberts and his assistants devote a portion of their time to important research work.

In conducting experiments to determine the effect of contagious and infectious diseases, we inoculate guinea pigs, which develop the disease, and post-mortem examinations are held, which enable us to arrive at the absolute facts in every case.

Another department of investigation which is of great value to the live stock industry is the analysis of stock foods, with which the country is being flooded.

Dr. Roberts' analysis of various stock foods shows that there is an alarming tendency on the part of unscrupulous manufacturers to employ black antimony and other dangerous chemicals, the use of which is a danger to the health of live stock, as the effect of same is to cause "quick fattening," which is in reality nothing but bloating or puffing of the tissues.

The animal takes on the appearance of fattening rapidly while "black antimony" foods are being used, but this being merely an unhealthy condition of the flesh, the effects disappear on discontinuing the black antimony foods, leaving the animal in much worse condition than before.

The preparing of Dr. David Roberts' Anti-Abortion Treatment, and the various other medicines for diseases of live stock, is surrounded with every possible safeguard to insure the absolute purity of the product.

All bottles, flasks, tubes and other apparatus are thoroughly cleansed and sterilized.

Throughout the entire establishment every precaution is taken with a view to securing perfect cleanliness.

Before the Treatment goes upon the market it is subjected to physioiogical test upon guinea pigs and also to the most rigid bacteriological tests to prove that it is pure and of full strength. 


\section{TO THE VETERINARY PROFESSION.}

The value of an Anti-Abortion Treatment in preventing, treating and overcoming Infectious Abortion in cows is now established beyond a doubt, and the few veterinarians who do not recognize this as a fact form a very small and constantly decreasing minority of the veterinarians.

For this reason there is a constant large demand for this reliable product.

To meet this demand the Anti-Abortion Treatment is offered, and the universal satisfaction it has given verifies its high standard of quality.

As yet I confine the output of this treatment to Infectious Abortion in cattle only, and do not advise its use on other stock until proved beyond all doubt that it is absolutely reliable in their cases as it in cattle.

I have endeavored to present the facts in such a light that every veterinarian who reads this may get a comprehensive idea of what is meant by the treatment of Infectious Abortion in cattle.

I have purposely avoided technicalities as much as possible, choosing rather to present scientific facts in a clear and intelligible manner.

I believe that when veterinarians familiarize themselves with the treatment, and the results which they can obtain by the use of the same, that they will in time become constant users of this, the most scientific and professional manner in which to handle this dreaded disease, Infectious Abortion in cows, which is costing your clients many hundreds of dollars yearly.

I know that the use of the Anti-Abortion treatment in preventing and overcoming infectious diseases in stock is the correct method. In view of this, I shall exert strenuous efforts to remain in the front rank of scientific and practicable development in this work.

That infectious diseases are caused by germs is admitted by nearly all persons who are at all conversant with what has been done in the world of veterinary science during the last few years.

Infectious Abortion, Calf Cholera, Tuberculosis and several other diseases of infectious forms are known to be caused by the presence of germs, which differ in form, size, mode of growth and microscopic appearance.

By means of these germs we can transmit these diseases from one animal to another, and by taking a small quantity of liquid from a cow afflicted with Infectious Abortion, and injecting it under the skin of a pregnant guinea pig, it will cause her to abort, and if other pregnant guinea pigs be in the same pen they will also abort.

I merely mention this experiment to show the infectious nature of germs of abortion, which produce this disease in cattle.

In the light of such proof, and in accordance with the acknowledgment of the scientific world, the only proper way to control and combat germ diseases is by the proper administration of the Anti-Abortion Treatment, especially prepared for the purpose of destroying the germs which produce the disease. 
In this particular case, we have to contend with germs which produce abortion in cows; it is for this reason that I have prepared a Treatment, part of which if injected underneath the skin, will come in actual contact with and overpower the germs of abortion. Its wonderful effects can best be seen in injecting it under the skin of a cow which is showing every sign of an approaching abortion (such as swelling of the udder and vulva, then watch these symptoms disappear and the cow carry her calf full time. You will then become an eye witness of what power of control the Treatment has over the germs that produce the symptoms, and if they were not disturbed, they would produce abortion, in such a case.

The newest and most improved methods are used in its production. Before being shipped, it is carefully examined, in order to establish its correctness in every particular.

Yours very truly,

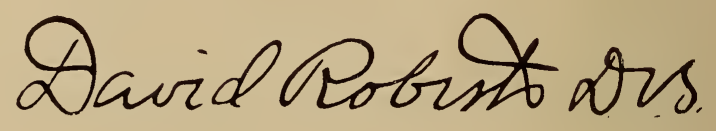




\section{HOW TO EXAMINE A SICK ANIMAL.}

First take the temperature of the animal, by placing a self-registering Veterinary Fever Thermometer into the rectum, allowing it to remain there from three to five minutes. The normal temperature of a cow is 101 degrees (Fahrenheit) and the normal temperature of a horse is 100 degrees (Fahrenheit); hog, 100 degrees; sheep, 101 degrees.

Second, take the pulse of the animal, which can be found at the angle of the lower jaw bone, where it can be felt by pressing the artery against the bone. The normal beat of a cow's pulse is from 40 to 50 per minute, and that of a horse from 33 to 40 per minute.

Third, count the respirations of the animal, or number of times it breathes, by watching the sides of flanks or by pressing the ear to the sides. The normal respiration of a cow is from 15 to 20 per minute, and that of a horse is from 12 to 15 per minute, while resting.

If the temperature, pulse or respiration are found to be higher or faster than the above described you will know that the animal is ailing.

\section{THE CARE AND TREATMENT OF A SICK ANIMAL.}

\section{IMPORTANT.}

Place the sick animal in a well disinfected, ventilated and dry box stall with plenty of bedding and sunlight. (Avoid draughts.) In cold weather put a blanket on, feed sparingly of digestible feed, such as bran mashes made of linseed tea. Keep manger sweet and clean. Water should be pure and clean, and warmed when necessary. (Always necessary for new milch cows.)

An injection of warm water per rectum should be given to all sick animals, excepting those afflicted with looseness of the bowels.

\section{NEVER DRENCH CATTLE.}

\section{REASONS WHY.}

Perhaps the best way of demonstrating the danger of drenching cattle is to advise the reader to throw back his head as far as possible and attempt to swallow. This you will find to be a difficult task and you will find it much more difficult and almost impossible to swallow with mouth open. It is for this reason that drenching cattle is a dangerous practice. However, if a cow's head be raised as high as possible and her mouth kept open, by the drenching bottle or horn, a portion of the liquid is very apt to pass down the wind-pipe into the lungs, sometimes causing instant death by smothering. At other times causing death to follow in a few days from congestion or inflammation of the lungs. 


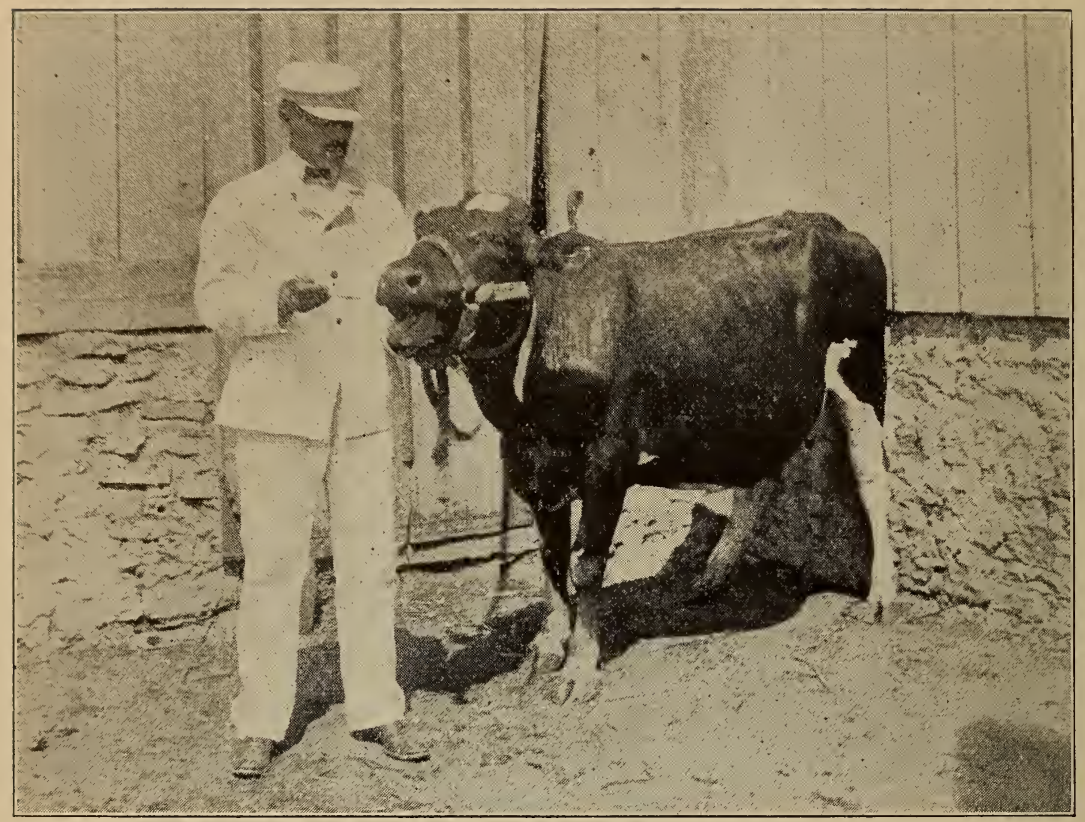

How to Give a Cow Medicine.

HOW TO GIVE A COW MEDICINE.

Give all cattle their medicine hypodermically or in feed; if they refuse feed give it dry on the tongue.

The proper method of giving a cow medicine is to stand on the right hand side of the cow, placing the left arm around the nose, or placing hand under the jaw, at the same time opening her mouth, and with a spoon in the right hand place the medicine, which should be in a paste or powdered form, back on the tongue; she can then swallow with safety.

TABLE OF GESTATION.

\begin{tabular}{|c|c|c|c|}
\hline ANimal. & Average Period. & Early Period to Live. & Late Period to Live. \\
\hline Cows......... & 280 days & 210 days & 336 days \\
\hline Mares.......... & 330 days & 287 days & 409 days \\
\hline Sheep and Goats. & 150 days & 140 days & 160 days \\
\hline Sows............ & 115 days & 105 days & 125 days \\
\hline Rabbits......... & 30 days & $\ldots \ldots \ldots$ & $\ldots \ldots \ldots$ \\
\hline Elephant......... & 730 days & $\ldots \ldots \ldots$ & $\ldots \ldots \ldots$ \\
\hline
\end{tabular}









\section{HISTORY AND STATISTICS.}

The history of the various breeds of cattle with which we are familiar at the present time has been traced back many centuries.

It is reasonably certain that horned cattle first existed in a wild state, long before the dawn of recorded history, and in the Scriptures we find mention of the fact that Jubal, the. son of Lemach, living in the time of Adam, is spoken of as "the father of such as own cattle."

It is a fact worthy of note that as man advanced beyond his primitive state, he found it necessary to domesticate certain wild animals for beasts of burden.

It is evident that the subjugation of wild cattle, not only for beasts of burden, but as means of bodily sustenance, first engaged the attention of primitive man as he struggled upward toward a higher plane of living.

We find that several wild varieties of the bovine tribe were originally widely disseminated in Asia and Europe.

From ancient writings and pictures we learn that these wild cattle were frequentiy the objects of chase by primitive hunters.

It is natural to infer that the animals in their adult state were slain for food, while the young were reduced to domesticity, and by confinement and care lost their wild instincts.

Ultimately these captive animals became fully domesticated, and as the herds increased, and were driven from place to place in search of fresh fields and new pastures, the people who made them captive became nomadic in character-their flocks and herds furnishing them an abundance of food, and the hides affording not only clothing, but shelter for the roving tribes.

The student of racial characteristics and of humanity's upward progress from savagery to civilization finds abundant evidence of the fact that domestic, animals were a most important factor in that advancement.

In primitive America we find surprising confirmation of this fact.

In America, where no cattle existed prior to its discovery by the Europeans, and where there were no animals which were easily domesticable as beasts of burden, the Indians, though able folk, remained savages.

It is a fact worthy of note that the first shepherd and the first farmer were contemporaneous. Likewise, the keeping of live stock and grain growing have gone hand in hand down through the centuries.

Every Celtic nation from the earliest period has raised cattle and they have been regarded by all barbarians and pagan people as the greatest of the divine gifts to man.

With the progress of civilization, the least desirable breeds were exterminated, while the fittest survived in a state of domestication. Descendants of one of these ancient herds are still to be found in the Chillingham cattle of England. They are wild only because all possible means are used to keep them so. The wildest and less frequented tracts of two extensive parks are set apart for their use. These are supposed to be descendants of the best of the ancient cattle of Great Britain.

Cattle were first brought to America by the Spaniards soon after its discovery by Columbus. As these bred and increased, the vast plains of Spanish America were covered with innumerable cattle. As these herds increased many of the cattle escaped and got away from civilization, living in a wild state and roaming over vast tracts 
of territory. As civilization has extended into new territory, these wild herds have gradually been brought under the hand of man or have been destroyed, and domestic cattle have taken their place, until at present there are practically no wild cattle in any section of the world.

The cattle which were originally to be found on the western plains and sections of the United States came from the cattle brought to America by the Spaniards. These cattle were first almost in a wild state, and were only rounded up once or twice a year when the young were branded and the grown animals taken out for shipment.

There are still in the west many large herds of cattle which are kept out on the ranges and only brought up for the branding of the calves and the shipment of the matured stock. But as these western sections of the country are more thickly settled up, these herds are gradually becoming smaller and the ranges are being fenced in so that the cattle are receiving more attention and are gradually being brought up to a higher grade.

These Spanish cattle and their descendants are usually large in size, long legged, various in color, and their distinguishing characteristic is their long and widely extended horns.

The English settlers early introduced cattle in the colonies, bringing them from Great Britain.

In an early day the cattle in the United States were a mixture of various breeds imported by the early settlers, who, for want of good barns, and from habits established in a milder climate, allowed their cattle to suffer severely. Many perished and the survivors degenerated in size and quality. As agriculture advanced and the people became more prosperous the cattle were improved by better care and feeding.

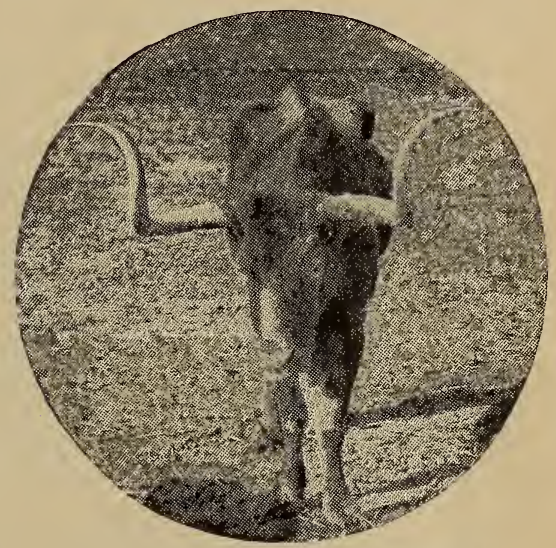

Type of Original Spanish Cattle

As the English breeds gained celebrity, they attracted the attention of enterprising breeders in this country, who began importing the different breeds, and by strict attention and experience in care and breeding, have continued to improve the grade of cattle in the country, so that at the present time all progressive stock owners are introducing pure bred strains in their herds.

It would be interesting to trace the history of cattle, step by step, in their improvement from the earliest time, but from the facts which history gives it would be a hard matter to get any satisfactory information. The first systematic breeder of whom we have any record was Jacob. It is reasonably certain that he understood something of the principles of mating cattle, but did not use his understanding so much in the matter of improving the breed, or to the good qualities for milking or beef, as he did in producing cattle of different colors.

This was with a view to securing a mingling of these colors in the offspring.

There have been many distinctive breeds of cattle known from the beginning of the historical era. Still, it is only within the last two centuries that any careful, systematic breeding has been attempted, and only within the last seventy-five years have greater results been accomplished and the greatest progress toward perfection been made. 


\section{STATISTICS OF THE CATTLE INDUSTRY.}

The cattle industry of the United States is one of the greatest industries of the country. Statistics show that for a period extending over fifty years from 1850 to 1900 the number of cattle consumed by the American people has fallen from twenty-five to twenty for every one hundred of the population, the number consumed in 1850 being twenty-five for each one hundred, and in 1900 the number consumed was twenty for each one hundred.

During this time the number of cattle has increased largely, showing a loss during but one decade, which extended over the period from 1860 to 1870 , covering the time of the Civil War in the United States.

In 1850 the cattle in this country numbered $18,000,000$.

In 1860 the cattle in this country numbered $26,000,000$.

In 1870 the cattle in this country numbered $24,000,000$.

In 1880 the cattle in this country numbered $33,000,000$.

In 1890 the cattle in this country numbered $42,000,000$.

In 1900 the cattle in this country numbered $51,000,000$.

The last three decades, from 1880 to 1900 , inclusive, show a regular increase of nine million each ten years.

During the period from 1890 to 1900 the milk production of this country shows an increase of almost 40 per cent. in the total production. In 1890 the average amount of milk consumed each day by a family of five persons amounted to but little over one pint a day, while in 1900 the average consumption by a family of five persons amounted to one quart a day. This shows the per capita consumption doubled during a period of ten years. During this same year not only the quantity of milk is increased, but also the quality has been steadily improving, so that today one quart of milk contains much more nutriment than it did ten years ago. This increased production and improved quality is due not only to the increase in the number of cows in the country, but also to the improved methods of care and feeding.

The dairy productions of this country show a very marked increase from 1860 up to 1900 . In 1860 they were valued at $\$ 240,000,000$, increasing from that amount to $\$ 605,000,000$ in 1900 , being an increase of over two and one-half times in forty years.

In 1850 the amount of cheese produced annually in the United States amounted to but little over one hundred million pounds, which was four and one-half pounds per capita. Today the annual production is nearly three hundred million pounds, which is a little less than four pounds per capita. This shows an increase of nearly three times in total production, but a decrease of one-half pound per capita.

The statistics as to the production of butter are just the reverse of this, as the production of butter has risen from thirteen and one-half pounds to nineteen and one-half pounds per capita during this time.

These statistics only go to show the immensity of the cattle industry of this country, and the increase which has been made during the time which these statistics cover. That the cattle industry has increased to a marvelous extent is known to all, and it is a foregone conclusion that this increase must continue, as the demands for milk and its products, as well as beef, must increase largely with the better methods 
of living and the increase of the population. The increase must be not only in quantity, but there must also be an improvement in quality. The demand of the present day is for an improvement in everything, and the beef and dairy products cannot be behind the demands of the country. To meet these demands the stock raiser must bend his energies to improve his stock in every way, keeping them in a strong, healthy condition, caring for them in a proper manner, and endeavoring at all times to produce the best quality possible. At the present time there are $61,000,000$ head of cattle in this ountry, consisting largely of the following breeds:

\section{A STUDY OF BREEDS OF CATTLE.}

\section{SUSSEX CATTLE.}

The origin and history of this breed is somewhat obscure, but the common understanding is that their ancestry is closely associated with the Devons. In England they are bred in the counties of Sussex, Kent, Surrey and Hampshire.

They are usually of heavy breed, equal to the Galloways in weight, but with large frame. They are considerably larger than the Devons.

\section{DUTCH BELTED CATTLE.}

Dutch Belted Cattle are a Holland breed, and are so named from the white belt or band which encircles their body. They are now bred to a limited extent in this country, being kept in about twentyfive states in the Union.

Their milking qualities are excellent, and I believe they have a great future.

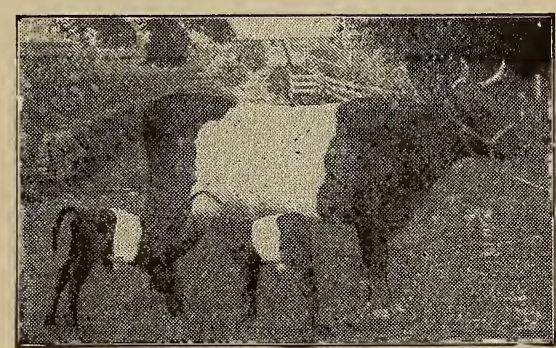

Dutch Belted.

\section{FRENCH CANADIAN CATTLE.}

Were brought by the early settlers of Quebec from France.

As the results of the exposure of this breed to the rigorous climate and long winters of Quebec, they have developed a hardihood that is not found in any other breed of dairy cattle.

\section{KERRY CATTLE.}

This is a pure breed, native to Ireland, and derived their name from the county of Kerry. They are very popular in some parts of England, but as yet have not been extensively introduced into the United States. The quality of their milk is rich, almost equal to that of Guernsey and Jersey in butter fat, and they give a large quantity of milk for their size.

\section{DEVON CATTLE.}

Of all the breeds of cattle found in Great Britain, the Devons are among the purest and most ancient, and they are descendants of the same breeds as the Herefords and Sussex. They are called Devons for the reason that they are originated in Devonshire.

They are smaller in size than the Hereford, Shorthorns, Galloways and the Sussex. They are noted for the quality rather than the quantity of their milk. They are symmetrical in form and very docile in disposition, and mature quickly. They produce an exceptionally fine quality of meat. 


\section{RED POLLED CATTLE.}

This breed of cattle is the result of a mixture of two types, which are known as Norfolk and Suffolk cattle. The Norfolk type was characterized by a blood redcolored body and mottled head, while the Suffolk type was originally a sort of mouse color. For over a century both have been freely intercrossed and have been recognized as one breed since 1846.

\section{POLLED DURHAM CATTLE.}

The Polled Durham is one or the most important of the dual-purpose breeds, and is of American origin.

This breed meets the growing demand for cattle with all the essential characteristics of the Shorthorns, yet without horns.

They are descended from both the Scotch and English Shorthorns.

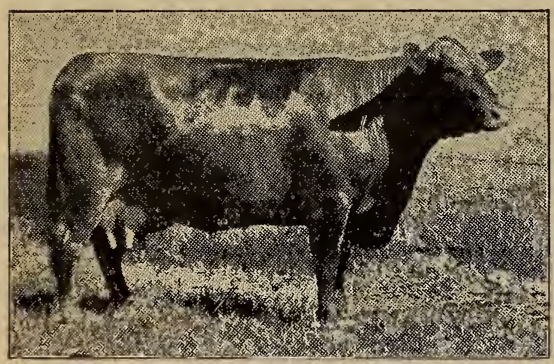

Polled Durham.

Polled Durham are good beef animals, but the development has been largely in the direction of superior milking qualities. They are raised quite extensively in the middle states, and are destined to become a very popular breed.

A man can make a success with any breed if he takes a liking to it, but do not select a brand that you do not like, as you will never take sufficient interest in your work to be successful. Use your own judgment.

\section{DUAL PURPOSE CATTLE.}

Dual Purpose cattle are a mixture of breeds, and produce a reasonably large flow of milk, also grow to sufficient enough size to be profitable as beef animals. They can be easily fattened, should occasion require, to dispose of them for beef. The requirements of a good dual purpose cow are that she be reasonably large in size; that the milk veins show good development, and that she be of amild disposition, and not high strung and

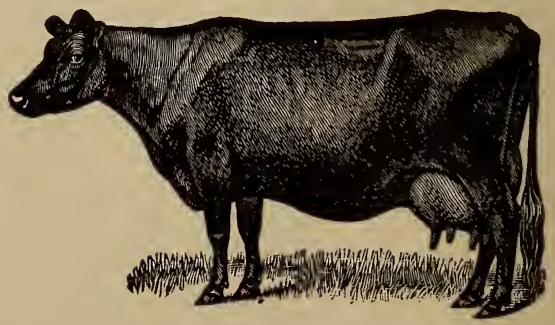

Dual Purpose.

nervous. Other points to be considered are their powers as milk producers, their appearance and size for beef. More profit is to be made by preserving the purity of breeds.

The selection of a breed we leave to the farmer himself, as he best knows his conditions and requirements. 


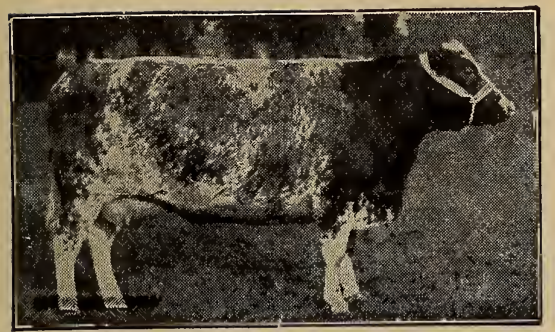

Shorthorn.

\section{HEREFORD CATTLE.}

The Herefords are natives of the shire of Hereford, in England. In color they are red, with white faces and breast, a white stripe along the back, and white legs and belly. They possess the same beef qualities as the Shorthorns, but are better grass cattle.

The Aberdeen-Angus and the Galloways are natives of Scotland. In color they are black, and have no horns.

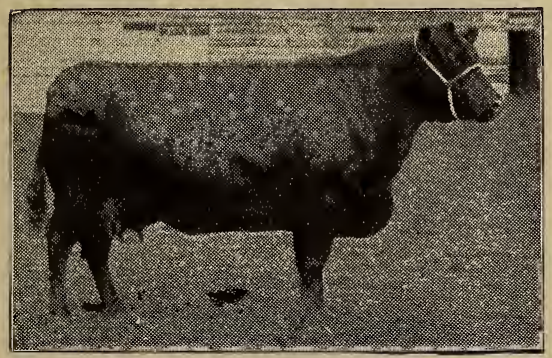

Aberdeen-Angus.

The Holstein, the largest of our dairy breeds, came from Holland. They are black and white in color. They consume a large amount of roughage and coarse fodder. They give a large flow of milk, but the percentage of butter fat is not as high as in some of the other breeds. Their milk is especially adapted to cheesemaking.

Owing to the large amount of milk they give, the Holstein will make as much butter as some of the other breeds; at present they hold the world's record for butter.

\section{SHORTHORN CATTLE.}

The Shorthorns are natives of England and Scotland, where they are still raised in large numbers. They are red, white or roan in color, or may be spotted red and white. They are low down and blocky, with a good coating of flesh of good quality.

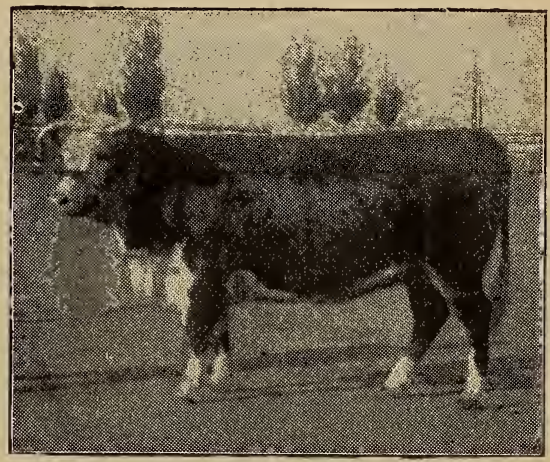

Hereford.

\section{GALLOWAY CATTLE.}

The Galloways are not as large as the other half-breeds and do not mature at such an early age.

In other respects there is little to choose between any of the beef breeds.

\section{HOLSTEIN CATTLE.}

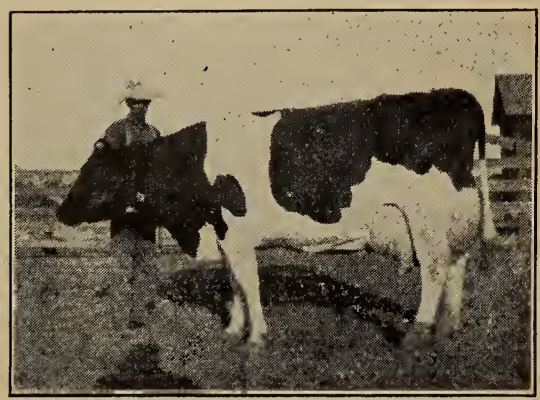

Holstein 


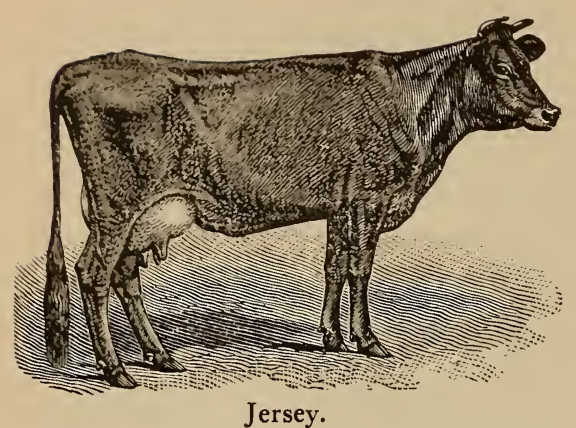

\section{JERSEY CATTLE.}

Jersey cattle come from the Jersey Islands, off the coast of France. In color they are of different shades of fawn, and fawn and white. They give very rich milk, which is especially adapted for butter-making. They cross well with other breeds of cattle for dairy purposes.

\section{AYRSHIRE CATTLE.}

The Ayrshire is a Scotch breed, coming to us from the County Ayr, Scotland. They are good grazers and do well in hilly and rough pastures. Their milk ranks with that of the Holsteins.

\section{GUERNSEY CATTLE.}

The Guernsey, like the Jerseys, are producers of rich milk. They are a little larger and hardier than the Jerseys. Their home was the Guernsey Islands. They are dun o: reddish in color, with white spots.

\section{BROWN SWISS CATTLE.}

The Brown Swiss, as their name indicates, come from Switzerland, and coming from such a mountainous country, are weil adapted to grazing over rough and unbroken

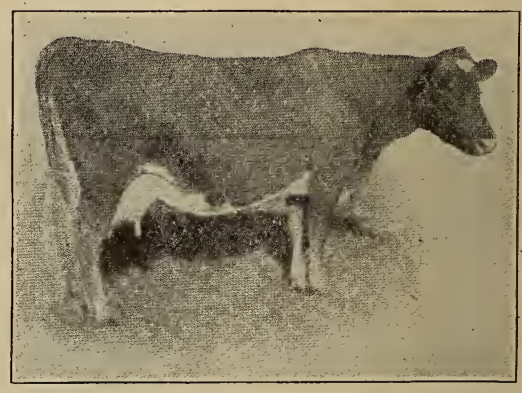

Guernsey. pastures. They are hardy and good size, and of a coarser build than other breeds. They give a good flow of milk of a fair percentage of butter fat.

\section{CARE AND MANAGEMENT OF CATTLE ON THE FARM.}

The cattle barns on the modern farm should be located on a well drained spot. There should be enough windows to allow an abundance of air and sunlight, for these are necessary to keep the animal in the best health.

Then, too, the stable must be properly ventilated so as to, remove foul air and supply fresh, pure air for the animals to breathe.

The temperature of the stables, in winter, should be about 55 degrees (Fahrenheit), and in summer as cool as possible. Provide screens for the windows so they may be left open, and spray daily with some reliable fly oil, and you will not be troubled with flies.

Use a good disinfectant, keep the stables clean, and you will have a sweet smelling stable, free from all bad odors.

Now you have your stables in order and will want to build up a good herd of cattle.

Before deciding on any breed you must take into consideration your location, markets and way in which you wish to dispose of your products.

If you wish beef, select one of the beef breeds, such as the Shorthorn, Hereford, Aberdeen-Angus or Galloway. 


\section{SELECTING A BEEF HERD.}

In building up a herd for beef production, select cows with a broad, deep and square body, cows with a good coating of flesh, for these, if bred to the right kind of bull, will produce a calf that will prove a profitable feeder. Now for the bull. The bull is half the herd. He stamps his qualities on all the calves-not simply on one calf a year, as with the cow.

Get a registered bull of the breed you want, even if you have only grade cows, as then you are sure you are getting a beef breed from beef ancestors. Select a bull that is of good size, with a proud masculine bearing, a good intelligent head, broad and full between the eyes, a short face, and strong, clear eyes, yet with a quiet expression, as a nervous, excitable animal will never fatten to good advantage.

He should be broad and straight across the back, with smooth, even hips. He should have well sprung ribs, heavily covered with flesh.

Spring is the natural season for cows to drop their calves, and the cows should be bred so as to drop their calves in the early spring, and then when the cows are turned to pasture in the spring, the calves are old enough to go with them and thus have advantage for making a rapid growth and require very little attention during the busy summer months.

When the calves are a few weeks old they should be castrated and the wound washed with some good germ killer, so it heals rapidly.

In the fall the calves should be weaned and fed on good, nutritious food.

This should consist of silage and roots, clover or alfalfa hay, oats and branequal parts, with daily allowance of some reliable stock food to aid digestion and promote a quick growth.

The age at which steers should be marketed depends largely on the market prices, but as a rule well fed steers sell best at 14 to 16 months old. But if you do not wish to dispose of your product as beef, then you must choose one of the dairy instead of beef breeds of cattle.

\section{THE DAIRY HERD.}

The principal dairy breeds are Holstein, Jersey, Guernsey, Ayrshire and Brown Swiss.

There are several other dairy breeds, such as the French Canadian, Kerry and Dutch Belted, etc., but these are rather scarce at present.

In buying dairy cows we have a different standard to go by than in selecting a beef animal.

A dairy cow is a machine that turns feed into milk and cream. So we must look for one that will convert the greatest quantity of feed into the most milk and cream. The type of dairy cow we want is a cow weighing about 1,000 pounds. She must have a lean head and neck. Her eyes should be clear and large, indicating health and temperament. Her body should be narrow over the shoulders, and broad at the hip and rump. She should have a large chest, indicating vitality. Her pouch or belly should be large, showing that she is able to consume a large amcunt of rough feed. 
She should have a set of large, branching milk veins leading to a well developed udder on which are placed four good sized teats.

She should carry very little flesh.

Before introducing any new cows into the stable have them tuberculin tested to avoid bringing any cows affected with the germ disease among your healthy herd.

Watch for any discharge which might be due to abortion, as this is another disease you must watch.

If you notice any discharge of this nature, wash out the vagina with a good antiseptic solution and keep cow alone until cured.

\section{FEEDING DAIRY COWS.}

Dairy cows require different feed than beef cattle.

We should not feed much fat-forming foods, as our cows would lay on fat instead of producing milk. Feed more silage or roots in the winter season.

Daily feed for a 1,000 pound cow, give forty pounds of silage, seven pounds clover hay, eight pounds of grain.

The cows that are soon to calve should be fed on succulent feed, such as silage or roots and bran and linseed meal, with a little oats. Keep the bowels open and do not feed very heavy on grains just before or after calving. After calving give a bran mash and warm the drinking water for a few days. Allow the calf to suck for about two days and then feed his mother's milk from a pail for two weeks, about three quarts twice a day; after that reduce it with skim milk or warm water, so that at the end of the fourth week the calf will be getting all skim milk or half whole milk and half warm water, with some reliable stock food to aid digestion. Keep a supply of good clover or alfalfa hay within reach, and also some ground oats with a little linseed meal mixed with it. After the calf eats the ground feed, gradually get him used to eating whole oats, as this is the best feed for him up to six months old. The heifers should not be bred until about 15 to 18 months old.

A good time to do your dehorning is to dehorn the calves with a good dehorner, (see page 100), when they are a few days old. Mark them with a number tag so you can keep a record of them.

Keep a record of the breeding of each cow, so you will know when she is due to calve, and then allow her to go dry for six weeks before calving.

The dairy bull should be fed like a working horse and should receive plenty of exercise. Work him in a tread power.

The milking is one of the most important parts of the dairy business. The cows should be milked quickly, cleanly and quietly. Do not excite your cows, or they will not let their milk down. Don't lick a cow because she kicks. If she kicks, there is some cause for it. Look for the cause and remedy it. It may be a sore teat; it may be an inflamed udder, or it may be that she has been misused and regards her milker as an enemy that she must fight. If such is the case treat her kindly and she will soon learn that you are not going to harm her.

Clip the long hair off the udder and flanks and tail, and wipe off the udder with a damp cloth before milking, and you will be surprised to see how much cleaner the milk will be.

Weigh each cow's milk with an accurate scale and test the milk with the Babcock test, and you will be able to see how many of your cows are paying for themselves. 


\section{TESTING FOR BUT'TER FAT.}

To test milk for butter fat you must have a Babcock Tester and bottles. You measure the milk with a pipette. Measure 17.6 c. c. (cubic centimeters) of milk with the pipette and put in the test bottle. To this add 17.5 c. c. of sulphuric acid and mix by shaking.

Then put it in the tester and run the tester for five minutes and then add enough warm water to bring the butter fat up into the graduated neck of the bottle where. it can be read. Run the tester one minute more and your test is ready to read.

You know how many pounds of milk your cow gives and how much it tests. Now, to find how much butter she is producing: Multiply the pounds of milk by the per cent. of butter fat, and then multiply by one and one-sixth and this will give you the amount. For example, your cow gives in one day 38 pounds of milk testing 4.2 per cent. You multiply 38 pounds of milk by

.042 butter fat.

1.596 pounds butter fat.

One pound of butter fat will make $1 \frac{1}{1} 6$ pounds of butter, so you multiply 1.596 $\mathrm{x} 1 \frac{1}{6}-1.862$ pounds butter.

This shows just how much butter your cow is producing a day.

If you sell your butter at $25 \mathrm{c}$ your cow is earning $46 \frac{1}{2} \mathrm{c}$ a day.

1.862 pounds butter.

$\$ .25$.

9310

3724

$\$ .46550$

From this subtract the cost of feed and you will have the net earnings of your cow. 


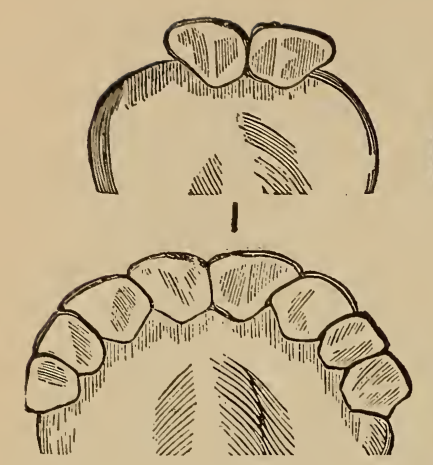

4.

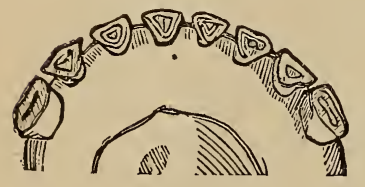

7

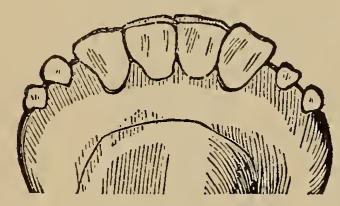

10
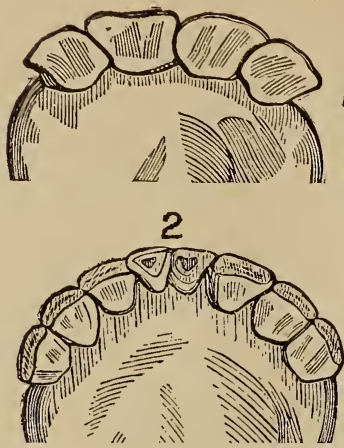

5

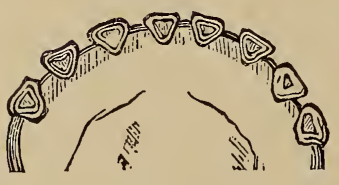

8

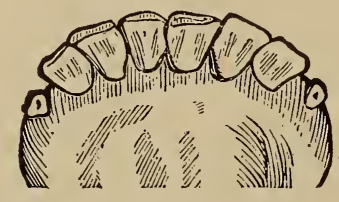

11

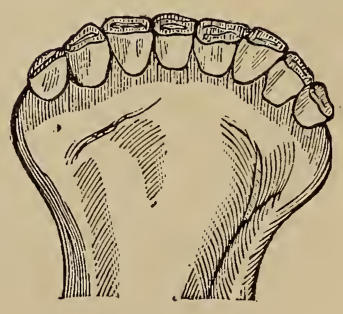

13

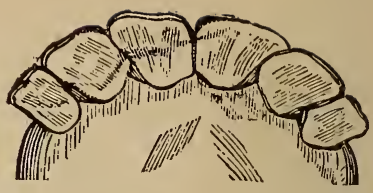

3

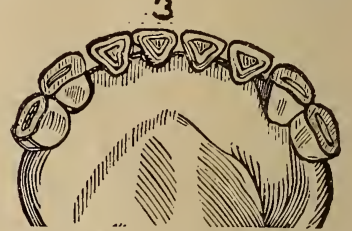

6

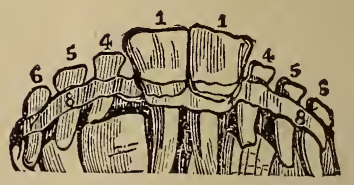

9

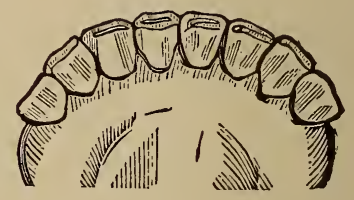

12

Figure 1.-Teeth of calf at birth, showing the first two incisors, milk teeth.

Firgue 2.-Teeth at two weeks old, showing four temporary incisors.

Figure 3.-Teeth at three weeks old, showing six incisors.

Figure 4.-Teeth at one month old, showing eight incisors, or full set.

Figure 5.-Teeth at six or eight months old, showing wear on first two, or central teeth.

Figure 6.-Teeth at ten

months old, showing absorption in first two pair of teeth, and wear of two outside pairs.

Figure 7.-Teeth at twelve months old, showing absorption in all the nippers, except outside pair, and wear in these.

Figure 8.- Teeth at fifteen months old, showing absorption and wear in all the temporary nippers.

Figure 9.-Teeth at eighteen months old, showing two first permanent incisors (1-1) and next two pairs (2-2) and (3-3), growing and pushing upwards toward the surface; also (4-4, 5-5 and 6-6) showing absorption. At. (8-8) is shown the alveali, or cells for the teeth.

Figure 10.- Teeth at two years old past, showing four permanent incisors, and four temporary ones, absorption nearly complete; also marks of wear on two first pairs.

Figure 11.- Teeth at three years past, showing six permanent nippers, and two outside temporary ones nearly gone; also wear on two central pairs.

Figure 12.- Teeth at four years past, showing eight permanent incisors-the full mouth - and complete complement; also wear on all but outside teeth.

Figure 13.-Teeth at five years past, showing wear and dark marks.

Figure 14.-Teeth at ten years old, showing permanent spaces between them; also shape from natural wear by use. 


\title{
SYMPTOMS AND TREATMENT OF CATTLE DISEASES
}

\author{
ABORTION \\ OR \\ SLINKING OF GALF
}

\section{THE NATURE OF THE DISEASE OF ABORTION.}

Abortion has two distinct though related meanings. The word is used to designate the act of prematurely expelling the foetus or, in common cow parlance, "slinking the calf." While this is the first and most common application of the term, the second, and by far the most important designation, is that of the disease which is the cause of perhaps ninety per cent of "calf slinking."

\section{CONTAGIOUS ABORTION.}

Before it was understood or accepted that abortion is a disease, the act of abortion or prematurely expelling the foetus, was attributed to numberless causes and conditions.

Some laid the trouble to loosening feeds, such as flax seed meal and millet hay that was over-ripe when cut. Others were sure that the smell of fresh blood at butchering time would cause a cow to lose her calf.

But the most common theory, and one still widely accepted even by those who recognize abortion as a disease, is that the malady is caused by ergot or smut on grasses, corn and other grains. A little farther on I will take up this last theory.

I shall not deny that abortion may be hastened by the use of certain feeds which act upon the bowels in such a way as to cause undue straining by the cow, and it is quite possible that the smelling of fresh blood may be the immediate cause of the act; for nothing will cause more excitement among cows than the smell of the blood of their kind.

But I am convinced that if every one of these cases of abortion, apparently caused by certain feeds or periods of excitement, could be investigated, it would be found that nearly all, if not all of them, were really caused by the disease of Contagious Abortion, the germs of which were in the system of the animal, working upon and weakening the genital organs and interfering with the functions of reproduction and gestation; and that the feed or excitement only hastened the inevitable.

It is quite possible that, aside from these circumstances of internal or nervous excitement, many such cows would have carried the calves long enough to give them live birth, but in most cases the calves would have come prematurely. Such are termed "living abortions." Some would even carry the calf full time, but the germs of the disease would remain in the system of both the cow and the calf, causing trouble later for both.

In my veterinary practice of twenty years, which has been devoted in large part to cattle, with special reference to the disease of abortion, I have found that in nearly every case of abortion, except such as were caused by a fall, a kick or other absolute violence, the germs of the disease were in both the cow and the foetus.

\section{ACCIDENTAL ABORTION.}

As I have intimated, the act of abortion may be caused by accident to the cow. A fall, a kick by an animal or a brutal attendant, being hooked or otherwise injured, may 
cause the act of abortion, but, unless the cow is predisposed to the act of abortion by the presence of the germs in the system, the violence must be very severe to cause the expulsion of the foetus.

It is, of course, natural for a cow to carry the calf full time, and nature persists in her course against ordinary interference. So when a cow aborts it is indisputable evidence that she has suffered great violence from disease or accident or both.

The purely accidental acts of abortion coming under my care and investigation have been few, and I have used them to establish beyond doubt the contagious or infectious nature of the disease of abortion.

\section{A TEST.}

One of my experiments was selecting a herd of twenty-one cows, seven of which had aborted between the fourth and seventh month of pregnancy. Wads of cotton were soaked in the fluid accompanying the expelled foetus of one, and placed in the vagina of three healthy pregnant cows in another herd at a distance, the cotton being allowed to remain an hour. One of the cows aborted in twenty-three days, the other in twenty-eight days-the first being in the fourth and the second in the fifth month of pregnancy; and the third cow, being in the seventh month of pregnancy, aborted on the fortieth day following the experiment, the calf dying three days later of scours. This last case was a "living abortion," the scours being the result of the germs of abortion in the calf.

To confirm the positive evidence of this experiment, a negative experiment was later carried out. A perfectly healthy cow aborted from an injury caused by falling into an old well. Wads of cotton were soaked in the fluid of this cow and placed in the vagina of healthy pregnant cows, as in the former experiment, and no injurious effects resulted. The cows all carried calves full time, and no germs of abortion were found in the genital organs or afterbirth.

\section{EFFECTS OF ABORTION ON PROFITS.}

Before taking up the relation of contagious abortion to other diseases of cattle, I want to present the practical side of the subject. The interest of dairymen and breeders of cattle in any disease is purely a financial one. If we were not seeking for profits in the business there would be no cattle industry-no cattle. If we were not battling to maintain or increase profits, we should devote little time or effort to eradicating disease.

But since our profits depend absolutely on the healthy condition of the herdstheir freedom from disease-the battle against disease is waged continuously. It is a life and death struggle between the herds and disease, with the chances in favor of the latter, but for the intelligent aid of the breeder.

In this fight against disease, it is but logical to assume that the cattle raiser should give most attention to the malady that is most destructive of his profits, when he is assured what that disease is.

My experience and investigation impel me to declare specifically that Contagious Abortion is the most destructive of all cattle diseases of the profits of the cattle raiser and dairyman of the United States, not even excepting the dreaded and dreadful tuberculosis.

\section{FOUR POINTS OF LOSS.}

\section{THE CALF.}

Abortion prevents the natural increase in the herd by loss of calves. Even when calves from an infected cow are dropped alive, they are weak and diseased, are an 
expense and a source of worry, and very often die in the course of a few days or weeks, of scours, which is the direct result of the abortion germs in their systems. A calf thus borr is a multiplied source of loss; it causes the loss of milk and feed consumed while it exists, a loss of time to the owner, and is a loss itself in the end.

\section{THE MILK.}

A falling off or total cessation of the flow of milk invariably follows abortion. It requires no argument to show the dairyman that this is a direct cut into his profits, in fact, a vital thrust at his only source of income as a keeper of cows.

The loss to beef breeders, though less direct, is just as great proportionately; for besides losing her own calf, the beef cow is unfitted, to the extent of her falling off in milk, for suckling other calves of the herd.

The amount of this loss to the whole cattle industry, in the aggregate throughout the country, is appalling when we come to consider it. From the bases for estimate that I have been able to reach, I figure that the loss is from $\$ 12$ to $\$ 25$ per cow affected, or an average of $\$ 18$ per head per year.

There are in America over 20,000,000 dairy cows, and not less than 10,000,000 beef cows: a total of at least $30,000,000$ cows. It is a low estimate to say twenty-five per cent. of these are suffering more or less from Contagious Abortion. Thus at least $7,500,000$ cows are losing $\$ 135,000,000$ annually, or are failing by that amount to produce what they should produce in healthy condition.

The reader may, at the first flash of such enormous figures, consider them overdrawn, but I am inclined to consider the estimate extremely conservative. There are individual cows in the country which bring in $\$ 250$ to $\$ 300$ gross annually. There are entire herds averaging $\$ 150$ and $\$ 200$. I do not believe a careful dairyman would keep a cow that returned less than $\$ 100$ gross per year. A cow producing less than that amount under average conditions and cost of feed, should be disposed of, or, what is better, put in condition to produce more income. It is entirely within reason, in fact, is proven by close observation and comparison, that a cow with Contagious Abortion will fall off on an average fifty per cent. in her milk, and consume just as much feed or even more than when in perfect condition. This would figure out $\$ 50$ per head per annum; and, on twenty-five per cent. $(5,000,000)$ of the dairy cows alone, would equal $\$ 250,000,000$, not to mention the beef cows. It is certainly, then, a low estimate to put the figure at little more than half that amount $(\$ 135,000,000)$, including both dairy and beef cows.

Note that this tremendous aggregate loss is in milk alone, it being impossible to, make even an approximate estimate on the calves. But 7,500.000 calves constitute a large loss, when their possible value and future usefulness are considered.

\section{THE COW.}

The third source of loss is in the cow herself. Besides becoming profitless as a producer of calves and milk, the aborting cow is a source of expense and trouble. Being usually a cow that has produced well, the owner hopes for her return to former usefulness, and keeps her at an actual loss. Often the final result is barrenness, and too frequently a sacrifice on the butcher's block, with no attempt to restore the cow to breeding condition, which can be done in nearly every case by proper treatment.

\section{THE HERD.}

The fourth source of loss from the abortion-infected cow is the spread of the disease to the entire herd and often to other herds through the services of the bull to which she is bred. Abortion germs are transmitted by all the usual agencies of 
contact in infectious diseases, and by this additional and surest of all agencies, the herd bull.

The germs of the disease vegetate and multiply in the genital organs of both male and female, and are very liable to be transmitted to the cow served by the bull that has previously served an infected cow.

\section{HOW TO. PREVENT THE LOSS, THE GREAT PROBLEM.}

After having proven to my own satisfaction that the enormous loss of scores of millions of wealth to-farmers and breeders was just as real as the losses from fire or flood or drought or chinch-bug or any other pestilence or calamity, I began searching for a means to overcome the trouble. Already convinced that abortion was a germ disease, I reasoned that it would have to be attacked in the animal by injections into the circulation. After repeated experiments covering several years, I found in a prepared "serum" an effective treatment. Gradually, I worked this treatment into $m y$ veterinary practice, where it proved itself to be so effective that owners came to depend on it, and asked for means to administer it themselves. Experience soon proved that the "serum" treatment could be safely and effectively administered by the owners themselves, and its use and demand accordingly spread rapidly.

I was not long, however, in reaching the conclusion that, along with the "serum" for driving the disease out of the blood must go an antiseptic wash for treating locally the delicate affected parts, to bring immediate relief when the disease began to develop.

It was an easy step from this to the next conclusion, that the germs of the disease must be eradicated from the stables where infected animals had been kept, in order to remove this source of contagion.

To rescue a cow from the effects of the disease, while very necessary, is no more important than stopping the source of the disease.

Thus, I added to the "serum" for injection, the Antisepto for treating the genital organs, and to this the Disinfectall to destroy the germs in the stables where the infected animals had been kept.

This is the complete system of treatment, the directions for which are given in the closing pages of this book. The plan was developed and tested in oft-repeated experiments, then put into use in my practice, where it proved its efficiency beyond doubt; and finally, offered to and accepted by the cattle industry as a reliable system for stamping out Contagious Abortion.

To paraphrase Patrick Henry, "Eternal vigilance is the price of profits," in the farming and live stock industry. The struggle is between the unerring instincts of the lowest forms of life and the intelligence of the human or highest form. And human intelligence, to come off conqueror, must not only invoke the aid of science, but must take one lesson from the germ itself: attack at every point whenever opportunity offers.

The germs of Contagious Abortion not only work on the diseased animals, but are found in the barns where diseased cattle have been housed, ready to attack every animal rendered susceptible to attack. They go farther back, and are found to affect calves dropped by cows infected with Contagious Abortion.

\section{WHY ORDINARY MEANS HAVE FAILED TO ERADICATE THE DISEASE.}

The giving of medicine per mouth, by drenching or dosing, disturbs the normal action of the bowels, and fails to reach effectively the sources of the trouble. In fact, this method often weakens the vital activities and thereby increases the susceptibility of the animal to attack, and thus aggravates the condition it was intended to relieve. 
I want to say, in passing, that a cow should never be drenched for any trouble. There are better ways of administering medicines, without the dangers of drenching.

\section{DISPOSING OF THE COW.}

It is a common practice, when Contagious Abortion is discovered in a herd, to sell at a sacrifice those that abort, thereby hoping to banish the disease. But the abortion germ sits in legions upon every yantage point about the stable where this cow has been kept, and is not disturbed by such procedure. And the germs in the cow, if she is sold to another herd, rejoice in the prospects of new and fertile fields.

In selling the aborting cow, of course the dairyman contemplates replacing her. He usually sells her at a sacrifice and cannot purchase her equal, when healthy, for the same money. So he has suffered a direct loss. The cow purchased to replace her will be immediately exposed to infection, both from the rest of the herd and from the stable, where the aborting animal was kept, and will certainly be infected as soon as her condition is favorable. So it is, that the attempt to get rid of the disease by selling off and substitution becomes a means of spreading the malady to other herds, and to new additions to one's own herd.

\section{NEITHER DIRECT TREATMENT NOR DISINFECTION ALONE WILL ACCOMPLISH PERMANENT RESULTS.}

While the "serum" treatment will destroy the germs in the mother's blood, and the Antisepto will destroy the germs in the genital organs of both the cow and the bull, the importance of Disinfectall must not be overlooked, as the means of destroying the germs in the stables occupied by infected cattle.

On the other hand, disinfecting the stables and cleansing the diseased organs will avail nothing permanent, while the disease runs riot through the system of even one animal in the herd.

\section{COMPLETE, COMPREHENSIVE TREATMENT OF THE WHOLE HERD AND INFECTED QUARTERS, THE ONLY EFFECTIVE METHOD.}

The combination of the three effective agencies of germ destruction into one system of treatment will rid any herd of this most dreadful scourge.

Let it be kept in mind that everything in the herd, excepting steers, require watching and treatment.

\section{CALVES.}

The germs often affect caives when dropped, even if they are carried full time, where the cow has the germs in the system. But calves dropped before full time, "living abortions," are sure to carry the germs in the blood; and since these almost invariably have scours, the excrement is a fruitful source of infection for carrying the disease to other calves and cows of the herd.

\section{HEIFERS.}

Apparently healthy heifers may carry the germs in the blood from birth or be infected when calves, and show no signs of abortion until pregnant, when the germs instinctively become active and vegetate rapidly at every vantage point in the system. Close and frequent examinations, according to directions given farther on in this volume, will disclose the early symptoms of the disease, and with prompt action the calf can be saved.

\section{cows.}

A cow that has calved is the most susceptible to attack, and is at the same time the most prolific source from which the disease may spread. This is especially true 
if the afterbirth be retained. In fact, the retained afterbirth is often the source of origin of Contagious Abortion in a herd. At calving time the system of the cow is in an exhausted condition and the genital organs peculiarly susceptible to the invasion and spread of disease. Abortion germs in the system, though in comparatively small numbers and low state of activity, become active and increase rapidly at this time. The retained afterbirth becomes a hot-bed for germ propagation and barrenness often results from the violence of the disease.

The afterbirth, even when dropped within reasonable time, still remains a fertile field of propagation and infection, unless buried or burned at once. The genital organs of the cow should also be given antiseptic treatment as soon as possible.

\section{THE HERD BULL.}

It may seem strange that the bull should become the most dangerous and active source of abortion; but a moment's reflection will show the reason for this. The sheath of the bull, next to the diseased organs of the cow, is the most fertile source of germ propagation. As soon as the bull serves an infected cow, he is in condition to infect the next cow he serves, and the next, to the entire herd, and all outside herds where his service is used. In spreading the disease in one's own herd, and in carrying it abroad to other herds, the bull is therefore the greatest source of danger.

One should not only see that his own bull is free from infection at each service, but that all cows brought to him for service are free from symptoms of the disease.

THE WHOLE HERD.

Thus the necessity of treating the entire herd, except steers, is apparent; for while one infected cow, bull, heifer, or calf remains, the entire herd, and the neighboring herds, are in danger.

Steers are not a source of infection and do not require treatment, for the reason that when an animal is castrated he loses the means of transmitting the disease, and the system having no sources for germ propagation, rids itself of the effects of the disease.

Cleansing the genital organs of cows and bulls with antiseptic treatment, and cleansing the entire systems of cows, bulls, calves, and heifers by the hypodermic injection of Anti-abortion "serum" completes the treatment, so far as the animals themselves are concerned. Thorough disinfection of the stables completes the entire system of treatment, and wipes out the germ at every possible source of propagation.

\section{NOT A THEORY.}

If this system were merely a finely spun theory, I should not be writing this book. But it is the result of experiment and experience through twenty years of practice, and is confirmed by every one of thousands of owners who have followed the plan out in its details.

\section{RELATION OF CONTAGIOUS ABORTION TO OTHER DISEASES.}

\section{ACCIDENTAL ABORTION.}

When a cow aborts solely as the result of an injury, the disorder cannot be called a disease; but unless the cow so aborting is looked after carefully, Contagious Abortion of ten results. For the cow is in the most susceptible condition possible for infection. The retaining of part of the atferbirth or foetus will often result in Contagious Abortion. 


\section{TUBERCULOSIS.}

A striking fact, developed from my experience as a veterinarian, is that fully seventy-five per cent. of all cattle slaughtered because of tuberculosis were also infected with Contagious Abortion.

This observation tends to corroborate a theory at which I had arrived in another way, that Contagious Abortion germs in the system prepare the way for the entrance of other disease germs, and predispose a cow to tuberculosis and other serious disorders.

\section{ERGOTISM.}

When a cow aborts, of course the act must be attributed to some cause. Many simply jump to the conclusion that the cow has been subjected to violence in some way; others attribute it to feeds or periods of excitement, without investigating the case.

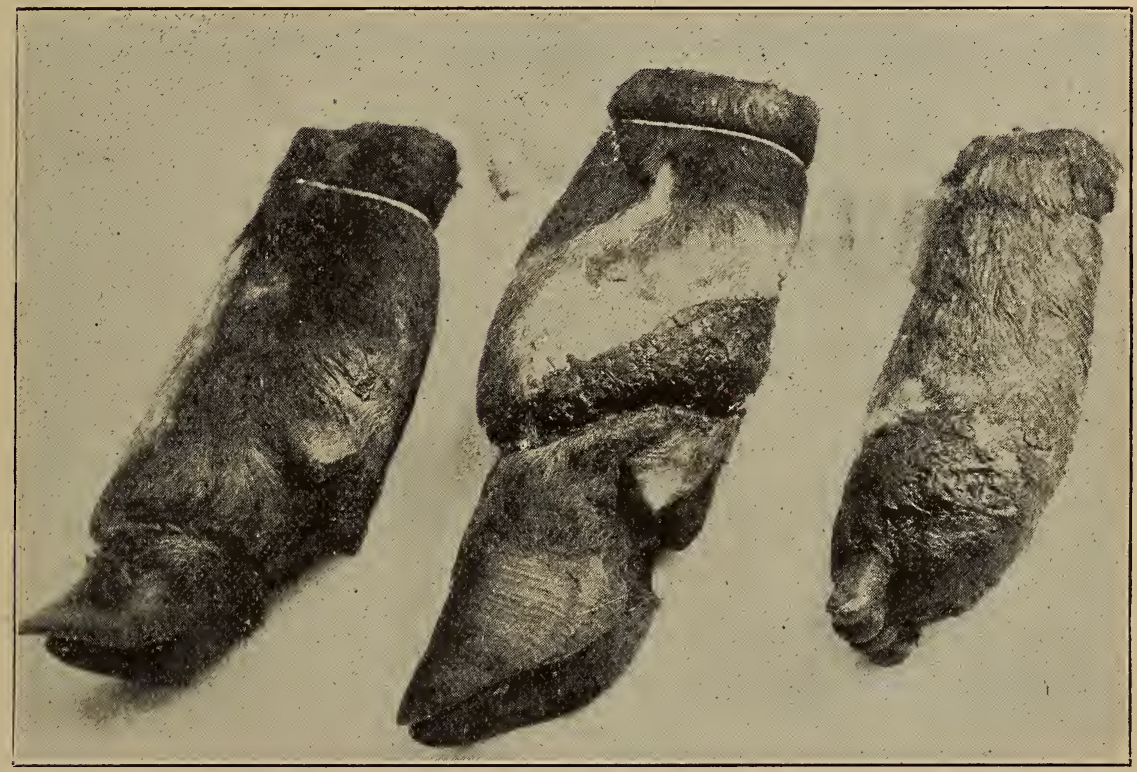

Feet of cows severely afflicted with Ergotism. From a photograph.

Perhaps the most common cause to which abortion has been attributed is ergot.

The action of ergot upon the animal has a tendency to contract the womb upon the foetus and this was thought to be the direct cause of abortion.

The common term for ergot is smut, and this is often seen upon grasses, corn, and other grain, and is more prevalent during some seasons than others.

In the spring of 1893 , my attention was called to a number of cattle afflicted with ergotism, having consumed a large amount of June grass, the June grass being so affected with ergot as to cause this herd of cattle to lose their feet and the ends of their tails. Many of them were seen walking around after the claws and first joints had dropped off. One animal in particular was so affected as to have her feet partly drop off. But upon change of feed and a course of treatment, recovered from the disease. She being pregnant at the time of this trouble and carrying her calf full time, is sufficient evidence that in this case ergot had nothing to do with abortion. 
On the theory that ergot would cause abortion, owners of fine cows accidently getting with calf from grade or mongrel bulls, have tried to bring about abortion by administering large doses of ergot. The failure of such attempts in every case coming to my knowledge or observation is further evidence that ergot does not cause abortion.

The fact that a cow afflicted with ergotism, or any other disease, aborts, does not prove nor indicate that that disease is the cause of the abortion. Examination and test will show in nearly all cases that the cow is suffering from Contagious Abortion, in addition to other ailments, and the act of abortion is the direct result of the activity of the germs of Contagious Abortion.

\section{BARRENNESS.}

Barrenness results from abortion in two ways:

First, the presence and activity of abortion germs in the womb will cause barrenness; the germs causing a catarrhal condition of the womb and destroying the vitality of the semen of the bull, thus preventing conception.

The destruction of the germs of abortion in the system of the cow, by the "serum" treatment, will often overcome this form of barrenness and restore the cow to her former usefulness.

Second, the diseased condition of the genital organs in Contagious Abortion frequently causes the mouth of the womb to become raw and irritated. When the disease is eradicated from the system, the mouth of the womb will heal up in a calloused condition, and become completely closed. This prevents the cow from breeding, and is usually regarded as permanent barrenness. But even this form of barrenness can positively be overcome by a special treatment.

Positive permanent barrenness is far less common than is generally believed. Only the absence or destruction of the ovaries, or other vital parts of the reproductive organs, or constitutional interference. with their functions, will produce permanent barrenness.

No dairyman or breeder should dispose of a valuable cow because she does not breed, until he has thoroughly investigated the cause and made an effort to remove it.

\section{SCOURS IN CALVES.}

I have already called attention to the fact that scours in calves is often the result of Contagious Abortion germs born in the calf. This disease, like all other developments of abortion, is communicable to other members of the herd.

\section{HOUSING OF CATTLE.}

While this subject is not directly under discussion here, I cannot pass on without repeating what is everywhere urged: give cows plenty of sunlight and good ventilation. Damp, dark, poorly-ventilated quarters, partly underground, are absolutely certain to prepare the way for disease to enter, and to spread to the entire herd whatever contagious malady may affect one or more animals. An open shed is preferable to dark, foul basement stalls. No amount of fumigation or disinfection can make up for lack of air and sunlight.

\section{CONTAGIOUS ABORTION CAN BE ERADICATED.}

Procrastination is not only the thief of time, but the purloiner of profits in the live stock business. And there is no disease of cattle, excepting possibly tuberculosis, that advances more stealthily "under cover" than Contagious Abortion. An entire herd may be afflicted without apparent symptoms. Later, the disease may so develop as to render treatment unavailing as far as saving the calves is concerned.

But when careful examinations are made at frequent periods, the first and less 
apparent symptoms will give ample opportunity to drive the disease from the system, save the calf and leave the cow in good condition for milk production.

Nothing is surer than the absolute eradication of abortion, if the system of treatment is persistently pursued.

Even when the disease has advanced so far as to kill the foetus, the cow can be saved and placed in prime breeding condition after the foetus is expelled; while without treatment, she is likely to become barren and worthless, besides being a source of infection to other cows.

\section{DOES THE TREATMENT HURRY ABORTION?}

When Contagious Abortion reaches the stage in which the umbilical cord of the foetus is so diseased as to shut off the circulation from the mother, and, as a consequence, life ceases in the foetus, the treatment has a tendency to cause the act of abortion. And this is one of the good points of the treatment. For the longer the foetus is carried after life is extinct, the greater the damage to the cow and the danger to the herd.

No cattle owner should hesitate to begin the treatment at any stage of the disease; for the final result is always the complete stamping out of the disease, and delays at any time not only defer this desired result, but entail material losses.

If a pregnant cow, not affected by abortion, be treated as a precaution, the treatment has no ill effects on her. Neither is any ill effect produced upon the quality of milk when milch cows are treated.

\section{SYMPTOMS OF CONTAGIOUS ABORTION DESCRIBED.}

Abortion germs may exist for months, or even years, in the system of an animal, in a comparatively inactive state, without making any distinct outward sign of their presence.

A number of cows aborting in a herd should be looked upon with suspicion and any of the following signs looked for: swelling of the udder and vulva; separation from the balance of the herd; dullness; cessation of chewing of cud; restlessness; stamping of the hind feet; passing of a small water bag and a little later a foetus. Sometimes both are expelled together; then again the foetus will be expelled and the afterbirth retained.

The first certain symptom is the appearance of small red patches in the vulva. Frequent examinations should be made in this manner: have a helper hold aside the tail of the cow, heifer, or calf, and, with your two hands, open the lips of the vulva. The appearance of small red patches on the lining membrane of the vulva is unmistakable evidence that the animal is infected and in condition to spread the disease. Service of the herd bull to a cow or heifer showing these symptoms will infect the bull and render him in condition to spread the disease to your entire herd and other herds where he is used.

If in the pregnant cow or heifer there appears with the red patches in the vulva, a secretion of white matter, prompt action should be taken, as she is in bad condition.

Swelling of the udder and vulva at any time before the last month of pregnancy, are advanced symptoms of abortion, and the crisis may come at any time. However, prompt attention will often prevent abortion even at this advanced stage of the disease.

\section{WAITING FOR DISTINCT SYMPTOMS IS DANGEROUS AND EXPENSIVE.}

When the first appearance of the red patches in the vulva is noticed, it is the part of wisdom not only to disinfect the stables and treat the affected parts of the animals 
showing symptoms with the antiseptic wash, but also to administer the "serum" per hypodermic syringe. In fact, this last mentioned treatment should be first, as eradicating the disease from the blood is the only way to render local treatment effective.

Further: the discovery of one diseased animal in your herd is very strong circumstantial evidence that the others are infected. They may only show poor general condition or may appear to be in perfect health, but they should be under strong suspicion and continually watched and frequently examined. Many owners run no risk, but treat the entire herd so as to forestall the disease.

\section{THE TREATMENT AND DIRECTIONS FOR ITS APPLICATION.}

The three preparations named in the following directions, the Anti-Abortion "serum," Antisepto and Disinfectall, are the preparations I have used in this systematic treatment in my practice. They are in use in the hands of hundreds of breeders, large and small, throughout the country. Administered as directed, they constitute a completely effective treatment.

By injecting the Anti-Abortion "serum" in under the skin of the cow, heifer, or bull, with the use of a hypodermic syringe, the germs of this disease in the system of the animal are destroyed. By washing out the sheath of the bull and the vagina of the cow with an antiseptic solution made with Antisepto, the germs that gather in the discharge are entirely removed, and by disinfecting the stalls with Disinfectall, the germs of this disease in the stables are destroyed.

\section{DIRECTIONS.}

Pour the "serum" into a cup and have ready for use. Fill this syringe (Fig. 1). It holds exactly one dose for animals over one year old. Stock under one year and over six months old should receive one-half syringe full, calves from three weeks to six months, one-fourth syringe full, at each injection. Steers need not be treated.

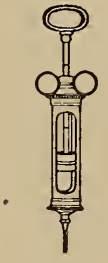

Fig. 1

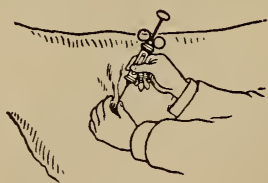

Fig. 2

Pick up the skin of the animal with the left hand directly back of the shoulder blade and in this manner (Fig. 2) with a quick, short jab with the syringe, insert the needel into the skin. Then press in piston.

Cattle can be treated in the stable very easily.

The illustration on the opposite page shows a cow being treated in the barn-yard.

Whether you give treatment in the stable, barn-yard, or pasture, you will find that each animal can be given the Serum in less than one-half minute.

By giving these injections you will eradicate all germs of Abortion from the system of the animal.

After each injection of the Serum, the genital organs of a cow or bull should be treated with the Antisepto according to directions below. 


\section{GERMS IN DISCHARGE.}

Take one tablespoonful of Antisepto to one quart of lukewarm water, and with the hose and funnel flush out the genital organs of the cow, as shown in Fig. 3, inserting the hose about six inches into the vagina, and pouring in the solution as indicated.

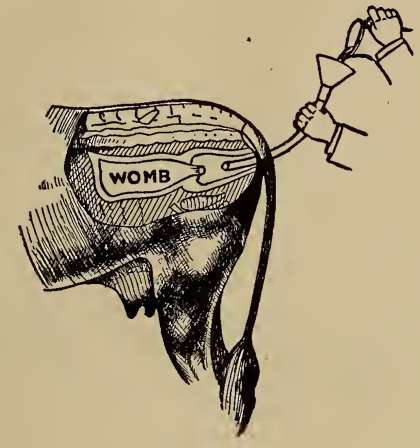

Fig. 3

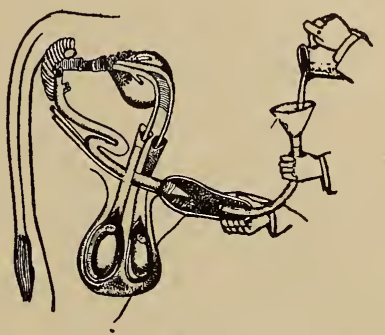

Fig. 4

All cows and heifers having an unnatural discharge from the vagina should have their genital organs washed out once daily with the Antisepto solution, until all discharges cease. This is important, as animals showing a discharge are in a condition to spread the disease.

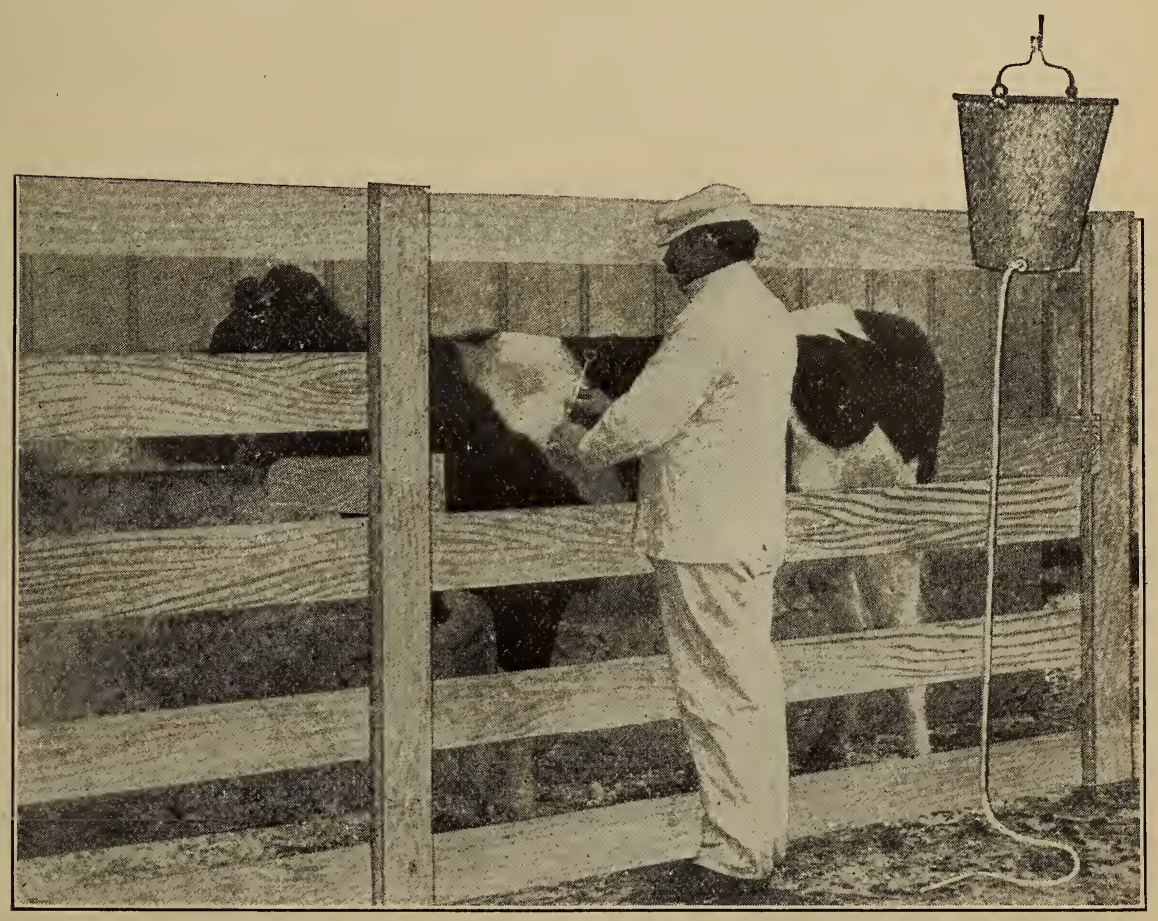

Fig. 5. Attendant administering Hypodermic injection to cow in chute in barnyard. Flushing Tank in readiness to cleanse genital organs with Antiseptic Solution. 
The sheath of the herd bull should be washed out with the Antisepto fluid once a week and after each service. Insert the hose about three inches into the sheath of the bull and pour in the solution, as shown in Fig. 4, a helper holding the sheath to prevent the hose slipping out. This treatment will protect the bull from becoming infected, and will prevent him from infecting cows and heifers bred to him.

Where a large number of animals must be treated with the antiseptic wash, the flushing tank shown in Fig. 5 is a great convenience and saves much time.

The hair on a cow's tail should be kept closely clipped from the tuft or brush up to the body; also the hair at the end of the bull's sheath. When the hair is left long in these places it accumulates pus and other discharges and constitutes a fertile source of germ propagation and infection.

\section{CLEAN YOUR BARN FLOORS.}

One ounce of Disinfectall to one gallon of water will make a powerful disinfectant.

Take an ordinary sprinkling can, fill it with water, put in your Disinfectall, in the above proportion, and sprinkle your stable floors freely. If you use whitewash, add ont or two ounces of Disinfectall to each pail of whitewash.

Use Disinfectall once a week.

\section{CARE OF HERD UNDER TREATMENT.}

A cow in heat should be kept in during that period.

The bull should not be allowed to run with the herd, and should not be permitted to serve cows from other herds; nor should you take your cows to other herd bulls.

A cow that has aborted should not be bred until such time as she would have come in heat if she had carried her calf full time, and not then unless she is perfectly clean and free from any vaginal discharge. This is important, as a disregard of this rule is contrary to nature and hurtful to the cow.

Bury or burn afterbirth or foetus, and thoroughly disinfect the stalls.

Special care should be taken in keeping stables clean and well ventilated. The liberal use of whitewash and plenty of sunlight are desirable; also thoroughly disinfect with Disinfectall.

\section{TAKE IT ALTOGETHER.}

"Serum" treatment once a week to remove the germs from the blood.

Antisepto, as directed, to remove the germs from the discharge.

Disinfectall once a week to destroy the germs in the stables.

This simple treatment, carried out systematically, meets the germ at every turn, and will positively wipe out the disease of abortion.

Sec Prescription No. 1 for treatment for Abortion in Cows, page 145.

The foregoing article is put up in book form and will be sent to any stockman upon request.

NOTE. - On account of the personal services necessary to be rendered the stockman while the herd is under treatment, the treatment for Abortion is not handled by the dealer. We want stockmen to write direct to us for further information and special prices. In writing state number of cows, heifers, calves and li:lls owned. 


\section{This Is What a Few of the High Authorities Have to Say in Regard to Dr. David Roberts' Work.}

Gentlemen: I appreciate very much indeed the copy of your book, which has just been received. I know it will be found exceedingly valuable, and I am turning it over to the Veterinary Department, with the request that it be given a place in the library for the use of our teachers and students. With best wishes, I am,

Very truly yours,

H. J. WATERS,

Dean and Director, University of Missouri.

Gentlemen: I have your letter of the 11th and the book, "Abortion in Cows," which have recently come to hand. I thank you for both and shall give the latter a place in our Station Library for reference. I have read it with interest and profit.

Very truly yours,

\section{Director, Connecticut Agricultural Station.}

Gentlemen: Yours of the 11th has been received, also the interesting little book on Contagious Abortion. I have read this book carefully and find it full of interesting facts. We will gladly give it a place in our library.

$$
\text { Faithfully yours, }
$$

W. L. ENGLISH,

Director, Oklahoma Agricultural Station.

Dear Sir: The writer has received your new book on "Abortion in Cows." We have referred several gentlemen in this state to you, and now desire to have you send your book to another, Mr. James S. Miller, Emory, Va.

Yours cordially,

WALTER J. QUICK,

\section{Dean and Professor of Animal Husbandry,} Virginia College of Agriculture.

Gentlemen: Permit me to thank you for your book, "Abortion in Cows." I shall go over this carefully and give my determination of such. I shall certainly give it a place in my library. Thanking you for the same and for past favors, I remain,

Yours very truly,

WM. H. PEW,

Animal Husbandman, New Hampshire Agricultural Station.

Gentlemen: I beg to acknowledge receipt of copy of "Abortion in Cows." This is a most valuable little work and one that ought to be in the hands of every cattleman. The disease is little understood by the average stockman and anything that will contribute to a better understanding and a more successful treatment of it is a boon to the cattlemen.

Very truly yours,

\section{E. DAVENPORT,}

Gentlemen: I believe that Dr. Roberts, in his little work on "Abortion in Cows," presents a practical common-sense solution of the abortion problem. The germ theory is the correct one, except in special cases, and the Serum, antiseptic and disinfecting treatment of animals appeals to the judgment of thinking men.

Respectfully,

M. W. WILLIAMS,

Editor, The Ohio Farmer.

\section{AFTERBIRTH RETAINED.}

The retention of the afterbirth or placenta (or failure to clean beyond a certain time after the expulsion of the fotus or calf from the uterus) must be looked upon as an unnatural condition which requires attention. The afterbirth should be shed or expelled soon after the fotus is dropped or the calf is born. With ruminants (or animals that chew the cud) retention of the afterbirth is not uncommon, though even in them there is a diffierence in this respect according to species, it being more common in the cow than in the sheep or goat. 
This frequency of retained afterbirth in the ruminant animals is doubtless due to its peculiar conformation or button-like fastenings.

\section{COW RUINED AS A PROFIT PRODUCER.}

While a cow may appear to be a little inçonvenienced by the retention of the afterbirth, at the same time she is, if neglected, being slowly ruined as a milker, breeder, or profit producer.

\section{NEGLECTED COW ENDANGERS THE WHOLE HERD.}

A cow that has retained her afterbirth is not only being ruined as a profit producer by being neglected, her milk will not only be short in quantity, poor in quality, but absolutely unfit for human use. She may be also acting as a hotbed for the propagation of the germs of infectious Abortion and Tuberculosis. These may be brought on by decomposition of the retained afterbirth.

\section{THE HERD BULL LIABLE TO INFECTION.}

As this continues the animal absorbs the poisonous formations of matter which causes her to grow weak and lose flesh rapidly, thus putting her in a condition so that when she is bred to the herd bull she may infect him with the germ of infectious abortion and he is then in a condition to spread the disease.

In this manner the disease of infectious abortion may be introduced into a herd and great loss caused.

\section{DANGER OF TUBERCULOSIS.}

This same cow, in her run-down condition, may also contract tuberculosis, and then expose the entire herd.

\section{HOW TO KNOW IT.}

Usually there is more or less of the fœtal envelopes protruding and hanging from the vulva orifice, though sometimes only the umbilical cord is to be seen. Occasionally the mass is so large as to hang below the hocks with little sacks of liquid at the lower end. If recently expelled, it has a fresh tint, not materially different from that of the intestines; but if exposed for some time, and especially in the summer, it becomes greyish in color.

Decomposition soon sets in, especially in the exposed parts, and as putrefaction progresses the odor becomes very offensive, and thin, bloody, brown tinted discharges, composed of the decomposed parts of the membrane and secretions from the irritated mucous lining of the genital canal, flow from the vulva, soiling the tail, thighs and hocks, and often making them sore.

\section{COW HEALTH IN DANGER.}

As these causes continue, the health of the animal suffers. Oftentimes there is dullness, prostration, decreased flow of milk, loss of appetite, quickened respiration and increased temperature and other indications of illness.

Retention of the afterbirth occurs most frequently in cases of abortion or when birth occurs some days before the proper time. Usually a cow that has retained the afterbirth at its first calf will do so at each succeeding birth.

\section{COW UNDER CONTINUOUS DRAIN.}

Among the breeding cows the consideration of proper care must be made important in order to make either breeding or dairying profitable. The breeding cow must carry a calf every year, and this notwithstanding that she is at the same time suckling another calf. 
The dairy cow must breed every year, and at the same time must give a generous fiow of milk for her owner's profit from nine to eleven months yearly. If her health is lowered thereby, or her life shortened, the question of profit must be considered, and she should yield her place to another when she fails as a profit producer.

\section{HOW TO PREVENT RETENTION OF THE AFTERBIRTH.}

There are certain points, however, in which the care of the cow should be considered. The pregnant cow should have exercise, and as regards both exercise and food, nothing is better than Nature's care, such as she gets while at pasture. She should not be given ice cold water to drink, or be exposed to violent excitement, such as being chased by dogs, riding, or being ridden by cows in heat, driven through narrow gateways, compelled to jump ditches or fences, hooked by other cattle, driven on icy or slippery ground, or being kicked or pounded by vicious attendants.

The diet should be good, clean, wholesome food, such as will produce the greatest amount of strength and yield of milk both for the profit of the owner and the nourishment of the fotus.

Much more is expected from the cow than any other domestic animal. In the breeding cow the value of the calf is the important consideration, and in the dairy cow the yield of milk. In either case the system is at all times under a continuous drain, furnishing blood, muscle, bone and sinews for the fœtus, at the same time producing milk either for another calf by her side or for the profit of her owner.

\section{THE COW A SURE PROFIT PRODUCER.}

For this reason the cow should receive a reasonable amount of care and attention. She is the surest and most reliable of all farm profit producers, the one animal which

\section{MUCH EXPECTED FROM THE COW.}

the owner can bank upon to always produce her share of the income, provided she is given a reasonable amount of care, which consists in pure water, good, clean, wholesome food, and such ingredients as will regulate and control the nervous system, and stimulate the sluggish organs, of which a pregnant cow is usually the possessor. The sluggish organs are one of the greatest causes of the retention of the afterbirth, at the same time being a cause of constipation, which is only a symptom of the former.

\section{NATURE'S DEMANDS.}

To prevent the conditions which cause a cow to retain her afterbirth it is necessary to give such ingredients with the food as will have an affinity for the genital organs, and will enable them to perform each and every function that nature demands them to perform at the trying and critical period of calving, thereby enabling the cow to deliver herself of her calf without an unreasonable amount of exertion, and at a reasonable time after so doing to expel the afterbirth; without mechanical aid.

\section{NATURE NEEDS ASSISTANCE.}

So much is expected of the pregnant cow and the drain upon her system is so great that she should have proper feed and such ingredients added to it, as go to make up a perfect tonic for a pregnant animal.

It is impossible to care for cows as nature would care for them. To a certain extent they are deprived of proper laxative food and water when desired, exercise and sunlight, and such vegetable matter as nature requires to keep her genital organs in a strong, healthy condition. Being deprived of these, it is necessary that they be furnished wila something to take their place, thus enabling the genital organs to perform each and every function required, such as contracting upon the matured 
calf, causing same to be born at the proper time, and expelling the afterbirth within a few hours afterwards, enabling the cow to come in heat at regular intervals, and to get with calf when bred.

\section{BREEDING TONIC ESSENTIAL.}

Breeding Tonic, which is prepared especially for pregnant cows and heifers, should be fed to pregnant cows in small quantities in their feed during the period of pregnancy. This will keep the genital organs in a strong, healthy condition, thereby enabling them to give birth to strong, healthy calves in the proper manner, at the same time preventing retention of the afterbirth, catarrhal discharges, and barrenness.

By keeping the cow in a perfectly healthy condition, you enable her to ward off many diseases that might otherwise be contracted at this critical period. The feeding of this Breeding Tonic to pregnant cows strengthens and invigorates the muscles and all of their genital organs to such an extent that they have no trouble in calving and expelling the afterbirth as Nature intended.

\section{NEVER USE FORCE IN REMOVING AN AFTERBIRTH.}

An afterbirth that can be removed without force or injury to the cow is in a condition to come away of its own accord.

In removing the afterbirth by main force it is only the body of it and such buttons as are torn off that comes away, thus leaving many serious conditions. If the cotyledons or buttons are forcibly torn off, there is great danger of serious internal hemorrhage, as well as leaving a lot of clotted blood in the womb to decompose.

\section{WHEN FORCE IS USED PARTS REMAIN.}

The parts of the afterbirth attached to the buttons are retained and undergo putrefaction, and the buttons torn from the womb leave raw sores, which become infected by the rotting, decomposing, irritating masses of foreign matter of which a large per cent. is absorbed by the system.

\section{DANGER OF EXPELLING THE WOMB.}

By using force the horns of the uterus may be turned inside out. This will cause the cow to strain violently, and by so doing the womb is often expelled, the result of which is serious and often fatal.

The displacement of either or both horns of the womb will cause the cow to strain for some time. This condition may, and often does, cause barrenness.

It is for this reason that barrenness often occurs when the afterbirth is forcibly removed.

\section{DRAINAGE IMPORTANT.}

The afterbirth should be allowed to remain until the buttons are ripe and in condition to release it by its own weight. The afterbirth in this way acts as a drainage by keeping the mouth of the womb open. This allows the contents of the womb to escape, instead of being retained by closure of the mouth of the womb.

\section{DANGER OF POISON.}

In this case, the animal would be compelled to absorb the poisonous matter, consisting of pieces of afterbirth which are always retained when force is used in removing it. Otherwise, the mouth of the womb would close and cause the womb to fill with matter, a portion of which is expelled, causing a catarrhal condition of the vagina, and acting as a hotbed for the germs of infection to propagate and multiply. This is liable to produce Barrenness and Infectious Abortion, and the cow by absorbing a large portion of this matter dries up on her milk, grows thin rapidly, 
and is liable to become a victim of tuberculosis. If she contracts tuberculosis she may then expose the entire herd to the disease.

See Prescription No. 2 for Prevention of Retaining Afterbirth, page 145.

\section{TREATMENT FOR RETENTION OF AFTERBIRTH.}

To overcome this condition the cow should be given a loose box stall, dry, clean, and warm, with plenty of sunlight and good ventilation. A blanket may be placed on her if necessary. Plenty of warm drinks, good, clean, warm, sloppy, nourishing food, containing such ingredients as will loosen the bowels by toning them; and will tone and stimulate the genital organs so as to put the cotyledons or buttons in a perfectly healthy condition. This will enable the cow to naturally expel the afterbirth, which should be removed from the box stall as soon as expelled, so as to prevent the cow from eating it.

The ingredients. which will enable the genital organs to perform their functional duties and will enable a cow to expel her afterbirth in a natural manner are contained in the Cow Cleaner, which is prepared especially for and should be given in all cases of retained afterbirth.

\section{PREVENT BLOOD POISONING.}

In retention of the afterbirth it is very essential to prevent putrefaction, decomposition, and absorption of the decomposing mass; also to prevent and destroy germs, soothe the irritated parts, prevent inflammation and hasten the expulsion of the afterbirth. It is very necessary to use such ingredients in the form of a solution for washing out the vagina while the afterbirth is retained, and even after the expulsion of same and until all discharge ceases, as will accomplish all this. At the same time the solution must be harmless in case the animal absorbs part of it, which she is very liable to do. Many a valuable cow has been ruined or destroyed by absorbing powerful poisonous solutions for washing out the genital organs.

To avoid this danger, use Antisepto for preparing an Antiseptic solution which is to be injected with a hose and funnel into the vagina of all cows afflicted with retention of afterbirth. This Antisepto is an especially prepared remedy for washing the genital organs of cattle.

Antisepto is invaluable for this purpose, as it contains ingredients that prevent and destroy germs, at the same time is healing and soothing to the delicate organs of the cow and is harmless if absorbed.

See Prescription No. 3 for Afterbirth Retained, page 145.

\section{ABSCESS.}

An Abscess may be detected, if situated externally, by heat, pain, redness, and swelling in the early stage.

\section{TREATMENT.}

The opening of an abscess should be encouraged by poulticing with Antiseptic Poultice. However, if lanced, care should be taken not to open too soon. The time to open an abscess is just before it is ready to break.

The cavity should be kept open and syringed out with a solution of Germ Killer once or twice daily, then inject the Healing Oil and Healing Lotion, alternately, as directed.

See Prescription No. 4, page 145.

\section{ANTHRAX.}

The animal without having shown any signs of disease suddenly drops down in the pasture and dies in convulsions; or an animal apparently well at night, is found 
dead in the morning. They stop feeding or ruminating a few hours before death. Chills and fever set in. The temperature runs high-106 to 107.

\section{ANTHRAX TREATMENT.}

Treatment is useless. The only thing to do is to prevent the balance of the herd from getting it. This is done by vaccination. Injecting vaccine under the skin with a syringe, the results of which are very good. Write for particulars.

See Prescription No. 5, page 145.

\section{APPETITE DEPRAVED.}

Cattle thus afflicted have a strong desire to lick the walls, eat dirt and filth, that a healthy animal would have no desire for.

\section{TREATMENT.}

Give good, clean, wholesome feed, and give Cow Tonic, according to directions. Medicate all salt with CONDENSED STOCK TONIC.

See Prescription No. 6, page 145.

\section{BARRENNESS}

Barrenness, sterility, or failure to breed in cows and heifers, is due either to imperfect, unnatural, or diseased genital organs.

\section{IMPERFECTION OF THE GENITAL ORGANS.}

This is one of the causes of barrenness, and may be due to an undeveloped womb or imperfect ovaries.

It is usually the case that when a twin heifer and bull calf are born, and the bull proves to be fruitful, the heifer is barren, and vice versa. If this be the case with the heifer, she is not liable to come in heat at all, and is very apt to take on very masculine appearance; more often having the appearance of a steer than a bull. Ever after she has arrived at breeding age, the breeding organs are undeveloped and there is no sign of an udder, this being proof of imperfect genital organs.

An animal thus afflicted can never be made to breed.

UNNATURAL CONDITION OF THE ORGANS.

Ar unnatural, swollen and inflamed condition of the genital organs may be brought on by a retention of the afterbirth, this being allowed to be retained in a decomposing condition until it rots away, leaving the mouth of the womb irritated, scalded and sore, so that when it does close, it heals closed so firmly that it cannot be opened without mechanical aid in the form of a dilator.

\section{DISEASED ORGANS.}

The genital organs may become diseased from several causes, chief of which is neglect, in cases of retained afterbirth, the same becoming decomposed and converted into matter, causing a catarrhal condition of the mucuous membrane of the womb and vagina.

If a cow be served while in this condition, the semen of the bull will be destroyed by this corrosive discharge, thus preventing conception.

\section{DISEASED BULL MAY CAUSE BARRENNESS.}

If a healthy cow be bred to a bull infected with germs of abortion, she is very liable to become infected. This infection will set up a catarrhal condition of the womb and vagina, and irritate the mouth and neck of the womb to such an extent as to cause same to become sore, and when this sore heals, the scar tissue and cartilage formations are so firm and rigid that they will not open without mechanical aid. 


\section{TUMOROUS GROWTH MAY CAUSE BARRENNESS.}

A slow catarrhal condition of the womb oftentimes causes a gristly, sticky, pliable formation of mucous, called Neoplasm. This renders conception more or less difficult. The formation of small growths, such as tumors, which are liable to form on any part of the genital organs, but are more apt to be at the mouth or in the neck of the womb, often prevent conception.

\section{BARRENNESS MAY BE TRANSMITTED.}

A barren cow, afflicted with a catarrhal discharge of the genital organs may be bred to a perfectly healthy bull; the bull then becoming infected. He in turn may be bred to a perfectly healthy cow, which has never been afflicted with barrenness, and she may in this way become infected and rendered barren.

\section{HOW TO KNOW IT.}

A reasonably healthy cow or heifer that may be bred once or twice at different periods of heat to a reasonably healthy bull, and fails to get with calf, should be looked upon as barren, unless it may be the fault of the bull, which is very seldom the case. This can be determined very easily by breeding the bull to several of the cows and watching the results. If any of them conceive, that proves that the bull is not at fault.

In case a cow does not conceive it is not advisable to take her to outside bulls, as by so doing chances are being taken of introducing into your herd diseases that may prove more serious than barrenness.

\section{SUSPICIOUS SIGNS OF BARRENNESS.}

A cow coming in heat at unreasonable periods and frequent intervals, such as the day following expulsion of the fotus, or the birth of a calf, is another sign of barrenness.

The mere fact of a cow coming in heat at any time after she is bred should be looked upon with suspicion, and should receive proper attention as early as possible, for the reason that the longer the cow remains barren the more difficult it will be to get her with calf.

\section{ALL HEALTHY COWS SHOULD BREED.}

All reasonably healthy cows and heifers should be made to breed.

This can be done with little trouble and slight expense if given proper attention. Many a valuable cow and heifer have been sacrificed or disposed of for the reason that they were not made to breed. This may have been due to a lack of proper information pertaining to this subject.

It is very important that a cow in order to conceive be in a reasonably healthy condition. The genital organs should be in a condition to perform their functional duties as nature would have them. A lack of secretion or an excess of secretion, renders conception difficult. A lack of ambition or vigor, or an over amount of same, renders conception difficult, a lack or an excess of either being an unnatural condition of the genital organs. This should be overcome and controlled by the use of the Breeding Tonic, or ingredients that will regulate and control the genital organs.

First of all, the cow or heifer should be in a reasonably healthy condition. She should not be too thin (emaciated), thus lacking the strength which nature demands; neither should she be too fat (plethoric), or over-stimulated, for in this condition conception would be difficult. 


\section{FAVORABLE SIGNS FOR BREEDING.}

A cow before breeding should be carefully noticed, to make sure that there is no unnatural discharge from the vulva. A natural discharge would be a discharge of mucous that has every appearance of the white of an egg, and at the period of heat usually contains a little blood.

\section{UNFAVORABLE CONDITIONS FOR BREEDING AND DANGER OF INFECTION.}

An unnatural discharge from the vulva may be a discharge of mucous streaked with or containing drops of matter or pus, or a discharge that is all matter or pus, very sticky in nature, adhering to the roots of the tail, at the same time having a very disagreeable odor. This discharge indicates that the organs are very much diseased.

\section{SIGN OF ABORTION.}

Another discharge which is often noticed, and which often follows abortion, is a brownish red, or chocolate-colored discharge, very profuse, having a sweetish, sickening odor. These discharges often stimulate and irritate the genital organs of a cow or heifer, thus causing them to come in heat at irregular periods, such as a day or so after expulsion of the fœtus or calf, and if a cow or heifer in such condition be bred to a perfectly healthy bull it may not only infect him and render him in a condition to infect other cows, but may also produce an acute irritation and inflammation, which may leave his organ in such a sore, irritated condition that he will have no desire to serve a cow until he has been treated with an antiseptic solution.

\section{BULLS SHOULD HAVE ATTENTION.}

The solution, which should be injected into the sheath of the bull, should destroy germs and soothe and heal the irritated and inflamed mucous membrane.

This will enable him to serve a cow when called upon to do so, at the same time preventing him from infecting cows that he may be bred to, also preventing him from becoming infected.

\section{TREATMENT OF BARRENNESS.}

All barren cows and heifers should be given Breeding Tonic in their feed, and their genital organs should be washed out with the Antisepto Solution.

Barrenness is due either to a diseased or weakened condition of the genital organs. It is unreasonable to expect a cow or heifer to breed until this condition is overcome.

The Breeding Tonic contains such ingredients as are necessary to tone, strengthen and regulate the genital organs, in this manner putting them in a strong, healthy, breeding condition.

\section{ANTISEPTIC SOLUTION IMPORTANT.}

The genital organs of all barren cows and heifers should be washed out with this solution until they conceive, whether they have a discharge or not.

This solution will prevent and overcome the acid secretions which kill the semen of the bull and prevent the cow from conceiving.

It will also prevent and destroy germs, soothe and heal all inflamed mucous membranes, thus preventing the formation of germs and the spread of the disease.

If a cow or heifer be cared for according to the demands of nature and fails to get with calf after being bred a reasonable number of times, she should then be classed as a barren animal. Upon examination of the neck of the womb it is usually 


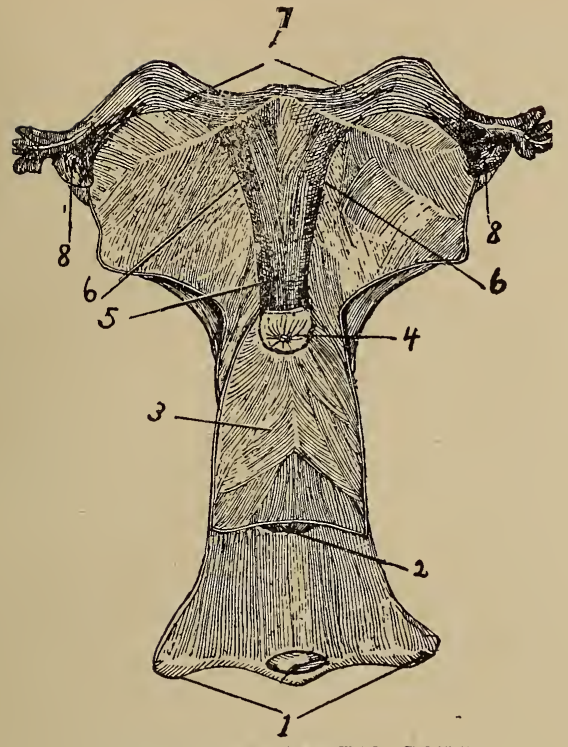

WOMB OF BARREN COW.

1. Vulva (external parts).

2. Uretha (opening into bladder).

3. Vagina (canal leading from vulva to womb).

4. Os (mouth of womb).

5. Neck of uterus (or womb).

6. Body of uterus (or womb).

7. Horn of uterus (or womb).

8. Ovaries (organ which produces ovum) found to be tightly closed. The neck of the womb contains three cartilage rings, which in this closed condition are found to be much contracted. This should be overcome by the use of a womb dilator.

\section{ARTIFICIAL MEANS NECESSARY.}

The use of the Womb Dilators overcome this unnatural diseased condition by being placed as far into the neck of the womb as possible. These dilators contain a preparation which, when it comes in contact with the neck of the womb, or cartilage rings, is absorbed, the result being that the neck of the womb and cartilage rings relax their rigid and contracted condition. The dilator at the same time absorbs moisture, and slowly but firmly expands, and by so doing dilates the neck of the womb, rendering conception easy. In case a cow or heifer does not conceive after the use of one dilator, a second should be used, as perhaps the dilation of the second or third ring had not been accomplished, and in case they do not conceive after the use of the second dilator, a third should be used, as this will open the third and last ring, in this manner overcoming barrenness. After the third dilator has been used the cow should be bred at several different periods of heat, in the natural way, without any artificial means.

\section{DILATOR}

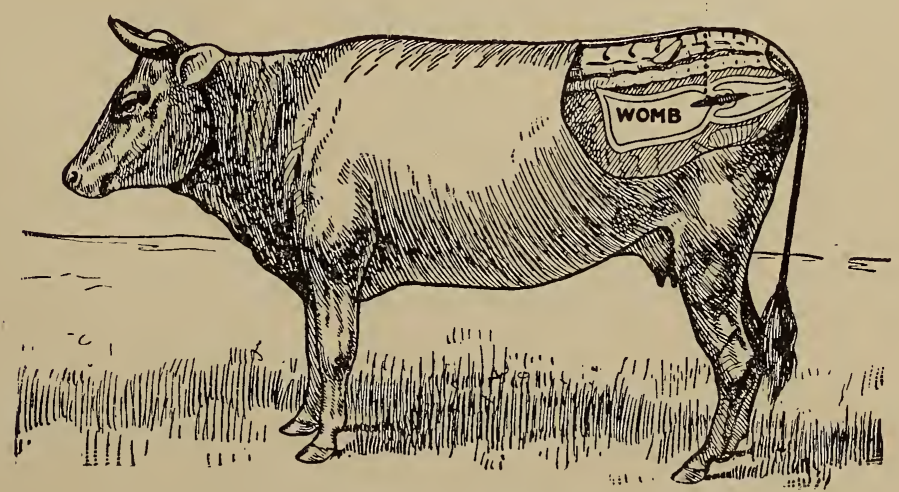

The Above Sketch Shows Womb Dilator in Position. 


\section{DIRECTIONS FOR USING WOMB DILATOR.}

Appiy lard or vaseline to the hand, and introduce it into the vagina of the cow when she is in heat. Dilate the neck of the womb as much as possible with the Womb Sound, then withdraw the hand and introduce the Womb Dilator into the vagina and insert it into the neck of the womb; allow Dilator to remain there for eight or ten hours; then remove it by pulling on the attached cord. After removing Dilator the cow should be bred at once, and kept from the balance of the herd for twenty-four hours.

The Womb Dilator can be inserted by anyone; no professional skill required.

See Prescription No. 7 for Barren Corws, page 145.

\section{BLOATING.}

Bloating may be known by a swelling of the left flank. This swelling rises above the level of the backbone, and when tapped with the finger sounds like a drum.

There is always great danger of smothering. For this reason a Trocar should always be kept on hand.

\section{TREATMENT.}

The animal should be tied up and compelled to stand on a box or platform which will elevate front parts from six to twelve inches; give Laxotonic as directed, and place a gag in the mouth. In very severe cases they should be tapped by the use of a Trocar. The point of this operation is on the left side, just midway between the point of the hip and the last rib. Point the Trocar inward and downward. Give an injection of warm water per rectum ( 2 to 4 quarts). Dip Trocar in Germ Killer solution before tapping.

\section{TO PREVENT BLOATING.}

One box of Condensed Stock Food should be mixed thoroughly with 25 pounds of salt and put in troughs in a sheltered place where the cows can have free access to it in passing to and from the pasture; this will not only prevent them from bloating, but will keep them in a healthy condition.

See Prescription No.'8, page 145.

\section{BLACK LEG.}

Black Leg is a disease that very much resembles Anthrax. The symptoms are very much the same in both cases, excepting that the animal may live a few days longer with Anthrax than with Black Leg.

The most important characteristic of this disease is the appearance of a tumor or swelling under the skin of the affected animal a few hours after the setting in of the disease.

The tumor may be located on the thighs, neck, shoulder, breast, hock joints, flanks or rump. By examining or feeling of the parts a peculiar crackling sound is heard under the skin. This is due to a collection of gas formed by the germs as they multiply. At this stage the skin becomes dry and cool to the touch in the center of the tumor. If the swelling is lanced a frothy, dark red, rather disagreeable, smelling fluid is discharged. The animal manifests little or no pain during the operation.

\section{TREATMENT.}

The treatment of this disease is very unsatisfactory. In fact, it is useless to undertake it. A prevention of the disease is the only wise thing to undertake. This is to render the balance of the herd immune by vaccination with Black Leg Vaccine.

In a case of this kind write us for further particulars.

See Prescription No. 9, page 145. 


\section{BLOOD POISONING.}

This is a condition resulting from the absorption into the system of putrid, poisonous matter or pus, such as follows retention of the afterbirth in animals.

There will be a high fever, rapid but weak pulse and fast breathing. Loss of appetite, staring coat and delirium in the last stages of the disease.

\section{TREATMENT.}

Discover the cause, if possible, and if it is an abscess open it and wash it out with a solution of Germ Killer. Then inject Healing Oil. If it is a sore, wash it with Germ Killer solution and apply Healing Oil. Often internal treatment is very important and consists in reducing the fever and keeping up the action of the heart. This is done by the Fever Paste; give every three hours with two ounces of good whiskey.

See Prescription No. 10, page 145.

\section{BOILS.}

Boils in cattle usually appear about the size of a hen's egg.

The abscess begins as a small, round bunch and gradually increases in size.

\section{TREATMENT.}

Antiseptic poulticing should be done; apply Healing Oil twice daily until the core is formed, when the abscess should be opened and syringed out once or twice daily with the Healing Oil.

See Prescription No. 11, page 145.

(See Paralysis of Bowels, page 71.)

BOWEL STOPPAGE.

See Prescription No. 54, page 147.

\section{BRONCHITIS.}

Bronchitis is an inflammation of the mucous membrane of the bronchial tubes. It is commonly known as catching cold, but it is more often brought on by foreign bodies such as medicine, gruels, salts and oils being given to cattle as a drench. It is for this reason that cattle should never be drenched.

In Bronchitis there is usually a loss of appetite, a rise of temperature (generally 104 to 105), and the breathing is incomplete, short, quick and painful. The pulse is increased and often a painful cough is present.

\section{TREATMEN 1 .}

The animals should be placed in a light, well ventilated box-stall, given feed of a laxative nature, such as grass in season and bran mashes, which latter should be made out of linseed tea. Give the animal plenty of water to drink. Apply white liniment to throat and lungs.

The fever should be reduced with the Fever Paste and the bowels kept open with Laxotonic, while warm water injections per rectum should be given by means of a hose and funnel. After this has been accomplished, the cow may be given Cow Tonic, and well cared for until fully recovered.

See Prescription No. 12, page 145.

\section{CALF CHOLERA.}

This is a catarrhal condition of the mucous membrane of the bowels. It is either a disturbance of the digestive organs or a symptom of some other trouble.

As a disease itself, it is an unnaturally increased action of the bowels, and at first may be nothing more than an attempt of Nature to relieve the stomach and bowels 
of their undigested, fermenting, offensive and irritating contents, which is marked by a thin, profuse, watery discharge from them. This indicates an irritated and overstimulated condition of the excreting glands of the bowels, causing an unnatural increased amount of liquid to be emptied into them, thereby mixing with the undigested fermenting contents, which is irregularly and rapidly expelled from the bowels. Such a condition shows a catarrhal and overstimulated condition of the mucous membrane of the digestive organs, which are very sensitive to irritating, or soothing ingredients taken into the system.

\section{SCOURS DUE TO INDIGESTION.}

The surroundings of the calf have much to do with the cause of this disease. Calves kept indoors suffer to a greater extent than those running in the open air and having the strengthening influences of sunshine, pure air and exercise. Closely crowded, filthy and bad smelling buildings are important factors in causing the disease.

All these causes tend toward reducing the activity of the digestive organs. As scours in calves is the common result of indigestion, it is therefore necessary that the digestive organs be kept in good, strong, healthy condition.

\section{INDIGESTION DUE TO MANY CAUSES.}

Indigestion may occur from many different causes, as costiveness, a too liberal supply of milk; too rich milk; the furnishing of the milk of a cow long after calving to a very young calf; allowing the calf to suck the first milk of a cow that has been hunted, driven by road, shipped by rail, or otherwise violently excited; allowing the calf too long time between meals, so that impelled by hunger it quickly overloads and clogs the stomach; feeding from a pail milk that has been held over in unwashed (unscalded) buckets, so that it is fermented and spoiled; feeding the milk of cows kept on unwholesome food; keeping calves in cold, damp, dark, filthy or ${ }^{\circ}$ bad smelling pens. The licking of hair from themselves or others and its formation into balls in the stomach will cause indigestion in the calf.

\section{SIMPLE SCOURS DEVELOPS INTO INFECTIOUS DISEASES.}

The above are causes of simple diarrhœa or scours. This form in its early stages is not infectious, but is due to indigestion. As indigestion persists, however, the fermentations going on in the undigested masses become steadily more complicated and active, and what was at first the mere result of irritation or suspended digestion, comes to be a genuine infectious disease, in which the organized ferments (bacteria or germs) propagate, multiply and produce an infectious disease which is commonly called scours in calves, but properly called Calf Cholera. It is for this reason that it is transmitted and carried from one animal to another, thus causing untold losses to dairyman and breeder.

\section{DISEASE APPEARS SUDDENLY.}

Scours in calves or Calf Cholera in many instances differs from Diarrhœa in the adults and has special features of its own, taking the form of infectious intestinal catarrh, which is far more serious than the ordinary diarrhœa of the full grown animal. This disease generally appears suddenly. A perfectly healthy calf may be seized all at once, apparently, without any change in food or care. The symptoms of this infantile diarrhœa usually appear during the first two or three weeks of life. In many cases it occurs within a few hours after the animal is born, and the calf may die within from twenty-four to forty-eight hours.

\section{CALF MAY CONTAIN GERMS AT BIRTH.}

It is common for the calf to be afflicted with scours immediately at birth, even before it has had time to suck or take any nourishment whatever. 
The fæces or manure are very thin and watery. They have a sour, disagreeable odor and are usually very light colored. The avacuations are frequent and expelled with force.

\section{PROMPT ATTENTION NECESSARY.}

The first indication of the presence of the disease is usually the soiled condition of the tail, loss of appetite, sunken eyes, sometimes the saliva flowing from the mouth, no attempt being made to swallow it. They have a staring coat, grow thin and lose strength rapidly. Death usually follows in from twelve to twenty-four hours unless prompt measures are taken to check the disease. If allowed to continue for any length of time the scouring will be accompanied by congestion and ulceration of the intestinal mucous membrane caused by the irritating secretions. As a result of this disease partial or total blindness is sometimes brought on.

\section{HOW TO PREVENT CALF CHOLERA.}

To prevent scours in calves proper care should be given to the mother while she is pregnant, that she may be able to give birth to a healthy calf. As it is a germ disease, it is very important that the calf has none of these germs in its system before it is born. Calves from mothers which are affected with the disease of abortion are most apt to die of scours. It is therefore very necessary that the cows be kept free from the disease. Calves born afflicted with the germs of this disease in their system are in a position to spread the disease to other calves that they may come in contact with in the same herd, or if shipped to other herds. This is another proof of its infectious nature.

\section{TO PREVENT LOSS.}

After removing the afflicted calf from the rest of the calves the stable should be thoroughly disinfected with Disinfectall, and the balance of the calves should be given Calf Cholera Remedy once daily with their regular feed, thereby keeping their digestive organs in proper condition so that they may digest and assimilate their food and thus escape the disease entirely.

\section{TO CARE FOR CALF PROPERLY.}

The most important factor in the raising of cattle is their care while young.

Do not think that you are doing the correct thing if you are only managing to keep the life in a calf until it is three months old, and then have it get fat on grass before the winter comes. If you do this you are apt to have a lot of "scraws" with their digestive organs destroyed, and which will never make strong, healthy steers or cows and will not be good for either dairy, beef or breeding animals.

\section{PROFIT IN PROPER CARE OF CALVES.}

It is but little more expense and care to give your calves the attention and food necessary to keep them free from scours and other diseases and start them off with digestive organs in good condition and a strong constitution. This can be done by keeping on hand a package of Calf Cholera Remedy and feeding it to your calves from the time they are dropped until they are fifteen days old, which will carry them past the time when they are most subject to the disease of calf cholera or scours. By doing this you will lay the foundation of a strong constitution upon which you can build a strong, healthy animal, and one which with proper care will make you money in whatever line it is put, whether beef or breeding.

\section{CALVES CONTRACT CHOLERA.}

A calf that is not infected with the germs of Cholera at birth may contract them later on from other causes, such as indigestion, close stabling and coming in 
contact with calves already thus infected. The germs of cholera when once introduced into the system propagate and multiply so rapidly that unless measures are immediately taken to destroy them and stop their ravages in the system death will ensue in a short time.

\section{PROPER FOOD SHOULD BE FURNISHED.}

The calf should reecive proper food, free from fermentation, at regular intervals and in reasonable amounts. To this food should be added a good, reilable Calf Cholera Remedy that will aid digestion and prevent fermentation, thereby preventing the formation of germs and causing a proper digestion and assimilation of the food.

This is an insurance against death by scours or calf cholera.

\section{TREATMENT OF CALF CHOLERA.}

While it is much easier to prevent a disease than it is to cure it, still it is very important to know how to properly care for an animal after it is taken sick. This is certainly the case with a calf which has Calf Cholera or scours, for if it is not taken in hand promptly it will probably be too late to do anything for it, as the disease is apt to prove fatal in a short time.

When it is discovered that a calf has diarrhœa or scours it should be placed in a clean, warm, loose, well disinfected and ventilated stall, free from cold drafts, but admitting plenty of sunlight. It should receive a mild laxative to rid the bowels of the irritating contents, after which it should be given Calf Cholera Remedy. This remedy will arrest fermentation, mildly check the secretions, aid digestion and assimilation, thereby destroying and preventing the formation of germs, thus causing the bowels to be soothed and healed, enabling the calf to pass the fæces in a natural form. Roots of tail and hind quarters should be washed once daily with Solution of Disinfectall.

See Prescription No. 13 for Calf Cholera, page 145.

\section{CALF INDIGESTION.}

\section{HOW TO KNOW IT.}

The symptoms of calf indigestion are dullness, belching of gas from the stomach, sour breath, entire loss of appetite, colicky pains, and at first constipation, which later on develops into diarrhœa, the fæces being very offensive.

If constipation be present at the time of treatment the calf should be given small doses of Laxotonic, but if diarrhœa be present at the time of treatment small doses of Calf Cholera Remedy should be given.

See Prescription No. 14, page 145.

\section{CONSTIPATION IN CALVES.}

Constipation is more often noticed in newly born calves. There may be a continual switching of the tail, uneasiness, and an effort to empty the bowels. If Nature fails to do its part, the treatment is to give on the tongue a small dose of castor oil (from one to three ounces). Give Laxatonic in small doses. And a pint of warm water injection should also be given with a hose and funnel per rectum.

The oil and injection may be repeated once daily until the desired results are obtained.

See Prescription No. 15, page 145.

\section{CALVING.}

The required time of gestation, or the period in which a cow carries her calf, is nine months, at which time special attention should be given the cow. Place her in 
a loose box-stall with plenty of bedding; give her feed of a laxative nature; the drinking water should have the chill taken from it, and her bowels should be kept in a natural condition by giving her Laxotonic.

After the labor pains have appeared it would be well to keep watch of her, and if she does not deliver her calf within a reasonable length of time-say, one hourit would be advisable to make an examination. Upon doing so, if the calf be in a natural position, the nose and front feet are the first to be felt. If such be the case, the attendant may assist the cow in delivering her calf by pulling on the front feet. Any other position would indicate an unnatural condition of calving. When calf is born the navel cord should be tied two inches from the body with a string soaked in Umbilicure; the navel cord should then be cut about four inches from the body, Umbilicure should be applied three times daily to the navel cord until it dries up and drops off. This will prevent calf from becoming infected with navel diseases. The calf should be allowed to remain with the cow three or four days. Important in connection with this article is the article on Navel Diseases in Calves.

See Prescription No. 16, page 145.

\section{CLEAN-FAILURE TO.}

A cow should clean within three hours after calving. In case she fails to do so she should receive plenty of hot mashes, boiled oats, warm water, and given the Cow Cleaner. The vagina should be washed out with Antiseptic Solution and the cow tied up with a halter to prevent eating the afterbirth. After she has cleaned and is through discharging she may be placed with the balance of the herd and her milk be ready for use. (See Retention of the Afterbirth, page 48.)

See Prescription No. 17, page 145.

\section{CASTING THE WITHERS-OR EXPULSION OF THE WOMB.}

This is a weakness which sometimes follows calving. The first sign is that of straining, and later the presence of part or the whole of the womb. In this case the womb should be placed upon a blanket; if the cow is lying down, which she usually is, wash off thoroughly with the Antiseptic Solution; after doing this the womb may be done up in a sheet dipped in the Antiseptic Solution and held up by an attendant, while the operator carefully pushes the womb back into its place. It must not only be placed back, but the full length of the arm must be inserted, so that it turns the horns of the womb back into the natural position, and, unless this is done, the cow will continue to strain.

To prevent the cow from expelling it again she should be placed upon a plank door four feet wide and six feet long, with laths nailed across to prevent her feet from slipping when she stands upon it. The end of the door on which the hind parts are should be raised from six to eighteen inches, and she should be compelled to either lie down or stand up on this door until all straining ceases and she fully recovers, usually requiring from one to three days. During this time her bowels should be kept loose with Laxotonic and her appetite kept up with Cow Tonic.

See Prescription No. 18, page 145.

\section{CASTRATING.}

In castrating calves or bulls the scrotum, or bag; should be washed with the Germ Killer solution. After the operation the scrotum should be well oiled with the Healing Oil.

Calves should be castrated at the age of from one to three weeks. Bulls may be castrated at any age.

See Prescription No. 19, page 145. 


\section{CATARRHAL FEVER OR PINK EYE.}

Catarrhal Fever is usually known as Pink Eye, Distemper and many other diseases of a catarrhal nature. This disease involves the respiratory or breathing organs, the alimentary canal, or digestive organs. The head, eyes and genital organs are frequently affected. This disease usually comes on with a chill, followed by a fever. The head droops, the skin is hot and dry, and the coat staring, frequently very dull in appearance. The secretion of milk usually stops. Loss of appetite and loss of flesh are invariably noticed, and sometimes the eyes become blue, so that the animal may be hardly able to see. In other cases the cow becomes totally blind unless prompt and proper treatment is given. Tears may be noticed running down the face, the lids are swollen and inflamed; sunlight is painful to animals thus afflicted, causing them to close their eyes and keep them closed continuously.

\section{TREATMENT.}

The eyes should be washed with the Antiseptic Solution, full strength, and the Eye Lotion should be injected into the eyes with a small, hard rubber syringe having a soft rubber nozzle. The temperature should be taken, and if found to be high the Fever Paste should be given, and the Cow Tonic should be given during the entire treatment. The stable in which the animal is kept should be thoroughly disinfected with Disinfectall.

See Prescription No. 20, page 145.

\section{CHOKING.}

This means the lodgment of a foreign obstacle in the swallowing tube or gullet. It is known by slobbering, distressed breathing and an accumulation of gas, which may be noticed in the left side or paunch.

\section{TREATMENT.}

Stand the cow with her head down hill, pressing the head downward as much as possible, while the attendant squeezes as much saliva out of the gullet as possible. Then allow her to raise her head and give her half a dose of oil (half pint), giving but one swallow at a time. If she is not relieved in from ten to thirty minutes, a oneinch rubber hose five or six feet long may be passed gently down the gullet. This will force the obstacle into the stomach, at the same time allowing the gas to escape. On account of the extensive stretching of the bowels due to the collection of gas, the Laxotonic should be given to overcome paralysis of the bowels, which usually follows.

See Prescription No. 21, page 145.

\section{COLD.}

A cow may take cold at any time, and it is apt to affect any part of the body, but it usually affects the head, throat or lungs.

\section{TREATMENT.}

If it affects the threoat or lungs apply White Liniment to the throat or lungs, or both, and give the Fever Paste. Keep the bowels open with Laxotonic.

See Prescription No. 22, page 145.

\section{COLIC OR CRAMP.}

This is usually brought on by drinking cold water or eating indigestible food. The animal will be noticed to be uneasy, getting up and lying down frequently, and showing pain.

\section{TREATMENT.}

Give a dose of Laxotonic.

See Prescription No. 23, page 145. 


\section{CONSTIPATION OR STOPPAGE OF THE BOWELS IN CATTLE.}

This is one of the most common ailments that cattle are subject to; at the same time more cattle die from this cause than any other, for the simple reason that constipation is due to paralysis of the bowels.

Constipation is to be regarded as the sign of another disease, rather than a disease of itself. It occurs in almost all general fevers.

In order to overcome constipation the treatment must be applied to overcome the ailment which causes it. Seventy-five per cent. of the cases of constipation are due to partial paralysis of the bowels. In this case the bowels require a laxative and tonic, and not a physic, for if the bowels are paralyzed a physic will have a tendency to cause irritation, congestion and inflammation. For this reason it is dangerous to give a cow salts or oil.

\section{TREATMENT.}

A cow thus afflicted should be given plenty of drinking water with the chill taken from it, bran mashes made from flaxseed tea, and give Laxotonic according to directions. Also inject several quarts of warm water once or twice daily per rectum by the use of a hose or funnel, and give the animal a reasonable amount of exercise.

See Prescription No. 24, page 145.

\section{COW-POX.}

This is a disease communicable from one cow to another. This disease is ushered in by a slight fever, which, however, is usually overlooked, and the first sign is tenderness of the teats. On examination they will be found to be redder and hotter than normal, and at the end of two or three days there appear knobs like little peas, pale red in color, and they gradually grow larger, so that at the end of a week they may be an inch in diameter. The yield of milk is diminshed. From the seventh to the tenth day the eruptions form into blisters with depressions in the center and raised margins. The blister is, however, divided into several pockets, and in order to allow all the contents to escape each pocket has to be opened separately. If the pocket forms on the surface, where there is a thick coat of hair, it does not form a blister, but oozes out through the skin in amber or straw-colored masses. In a few days after this collection forms it turns yellow and the scab dries up and falls off and leaves a distinct pit in the skin. The animal suffers intense agony while being milked, as the scabs are cracked and broken by the hands of the milker.

\section{TREATMENT.}

In severe case give Cow Tonic internally. Badger Balm should be applied to all affected parts of teats and udder, after washing same with a solution of Germ Killer.

See Prescription No. 25, page 146.

\section{DEHORNING.}

As dehorning cattle is rather a cruel but necessary operation, it is advisable to prevent the horns from growing rather than removing them after they have once grown.

To prevent the horns from growing on calves it is necessary to apply a dehorning remedy when the calves are from one to ten days old.

The operation is performed as follows: The little animal is caught and gently laid over on its side, in which position it is easily held by one assistant, while the operator clips the hair off of the little knobs where the horns appear. He then applies 
the remedy thoroughly to a spot not to exceed the size of a quarter of a dollar. The calf is then turned over and the other side treated in a like manner.

If this treatment is propely applied, no horns will ever make their appearance. All cattle should be dehorned, chiefly to protect them from each other. If unfortunately an animal has not been dehorned while still a calf, the dehorning clipper may be resorted to. This operation is performed by placing the animal in a stanchion and fastening the head tightly, then applying the dehorning shears, pretty well down onto the head so as to be sure and remove enough of the horn to prevent any further growth. With one sweep of the dehorning shears the horn should be removed. Apply a little healing Oil after the operation to prevent any bad results from following. Cool weather should be selected fcr this operation.

See Prescription No. 26, page 146.

\section{DIARRHOEA IN CATTLE.}

Diarrhœa in cattle is an indication of indigestion. It comes on at all seasons of the year, but it is more liable to come on during the grass season, and is more prevalent during the wet season rather than the dry, on account of the heavy growth of grass, this being hard to digest.

TREATMENT.

The animal should receive a little ground feed two or three times daily, in which should be given moderate doses of Cow Tonic. The drinking water should be clear and pure, and given warm and sparingly. In bad cases give Calf Cholera Remedy.

See Prescription No. 27, page 146.

\section{EYE DISEASE.}

Sore eyes may be brought on from many different causes. It may be due to injuries or to a catarrhal infection. When due to the latter, the whole herd may be thus afflicted and oftentimes are.

\section{TREATMENT.}

A sore eye due to an injury should be bathed three times daily with a quart of Antiseptic Solution, full strength, and followed with Eye Lotion injected after each bath. This same treatment should be used when sore eyes are due to a catarrhal infection or Pink Eye. And in addition to this treatment the cattle should have free access to a liberal amount of salt, in which should be mixed Condensed Stock Food.

If both eyes of the animal be affected and it be difficult for them to see, it is advisable to keep them in a dark stable during the day and let them graze at night, on account of the strong sunlight being painful to the eyes.

See Prescription No. 28, page 146.

\section{FEVERS.}

In order to detect as to whether an animal has a fever or not, it is always advisable to use a Fever Thermometer, and if the temperature be higher than normal it indicates a fever. It may be due to many causes, such as inflammation of the lungs, inflammation of the throat, inflammation of the udder, etc., etc. However, the fever should be controlled and reduced by giving the Fever Paste according to directions and the bowels should be kept loose with the Laxotonic (per mouth) and injections (per rectum) of from two to four quarts of warm water once or twice daily; also apply the White Liniment to the inflamed parts, such as the throat or lungs, or both.

Every stock raiser should own a Veterinary Thermometer, oftentimes saving him considerable expense.

See Prescription No. 29, page 146. 


\section{FISTULAS.}

A fistula is a pus cavity, containing matter, and is commonly known as a running sore. It may appear on any part of the body, limbs, or feet.

\section{TREATMENT.}

Open the parts so as to allow all the matter to flow freely; wash out the cavity once daily with a solution of Germ Killer (one ounce to a gallon of warm water), and follow by injecting a quantity of Healing Oil and Lotion, alternately, according to directions and according to the size of the cavity. Give Cow Tonic internally according to directions to tone up the system.

See Prescription No. 30, page 146.

\section{FOOT DISEASE OR SORE FEET IN CATTLE.}

Sore feet in cattle may be due to several causes, but the one kind which the ordinary dairyman or breeder has to contend with are sore feet, due to either standing on cement floors or running in wet, boggy pastures. The feet usually crack berween the claws, swell and become inflamed. In either case the treatment is the same, and consists in washing the sore or inflamed feet with a solution of the Germ Killer (one ounce to a gallon of water), and applying both Healing Lotion and Healing Oil, alternately, to all open sores. or inflamed parts. (See remedy list in back part of book.) If a growth of proud flesh appears between the hoofs or on any part of the limb, it should be overcome by frequent use of the Healing Lotion, and the inflamed or sore feet should be placed in antiseptic poultices, once daily, until all inflammation and lameness have been overcome. Use a Poultice Boot.

\section{HOW TO MAKE A POULTICE BOOT.}

Take a round piece of sole leather six or seven inches in diameter and as thick as you wish it; then stitch a heavy canvas to the edges of this sole leather and have it run up about twelve inches.

\section{HOW TO APPLY THE POULTICE.}

Put enough Antiseptic Poultice into the boot to cover the foot nicely, then fasten the canvas or boot on by the use of strap instead of strings, as strings cut in too much.

The Cow Tonic should be given as directed to tone up the system.

See Prescription No. 31, page 146.

\section{FOUNDER.}

Founder is not of frequent occurrence in cattle, but it does occur to overfed or show cattle. It resembles a stiffness, but upon feeling of the hoofs they will be noticed to be hotter than usual; lying down considerably is another symptom.

\section{TREATMENT.}

If this be noticed in the early state it is advisable to bleed the animal by drawing from four to six quarts of blood, according to the size of the animal. The bowels should be loosened up with Laxotonic (per mouth), and warm water injections (per rectum), and the Fever Paste given to reduce the fever. The feet should be poulticed with Antiseptic Poultice, which should be changed once daily. (Use the Poultice Boot for applying poultice.) The animal should be fed sparingly with food of a laxative nature. Exercise should be given as soon as the animal is able to take it.

See Prescription No. 32, page 146.

\section{FROST BITES.}

This should never occur, but sometimes it is unavoidable, and the treatment is to wash the parts thoroughly with a solution of Germ Killer and apply the Badger Balm to the frozen parts.

See Prescription No. 33, page 146. 


\section{GARGET-CAKED UDDER OR INFECTIOUS MAMMITIS.}

Garget or caked udder is a very common but annoying disease, and is due to many causes, the most common being a condition of the blood, and for this reason Cow

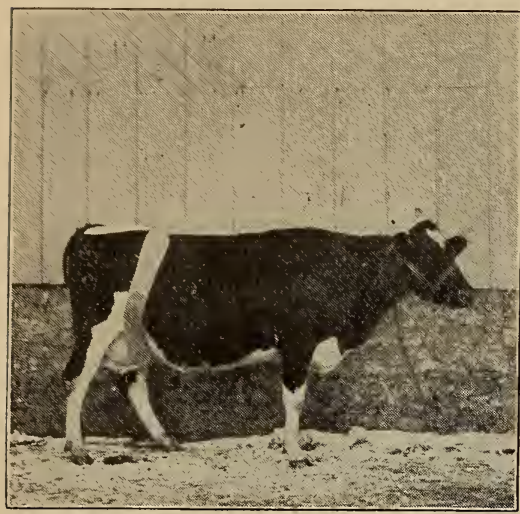

How to Bandage Cow Suffering from Caked Udder.

Tonic (see page 146) should be given freely according to directions. The udder should be rubbed twice daily with an application of Badger Balm or White Liniment, thoroughly rubbed in. In severe cases apply an Antiseptic Poultice by placing a band around the cow's body and udder. Keep the animal well bedded to prevent the udder coming in contact with any dampness. Keep the bowels open by giving warm water injections (per rectum). If the caked udder takes on an infectious form, then the milkers should wash their hands in a solution of Germ Killer after milking each cow, as this will prevent the spread of the disease. Stables should be disinfected with a good germ destroyer, such as Disinfectall.

See Prescription No. 34, page 146.

\section{GENITAL DISEASE.}

As the genital organ diseases are usually due to retention of the afterbirtin, this subject is fully described and the treatment fully given under subject of Afterbirth Retained in foregoing pages.

See Prescription No. 35, page 146.

\section{GESTATION PERIOD.}

As it is pretty well known by most people that the gestation period of a cow is nine months, or 280 to 285 days, it will be needless for much to be said on this subject, as gestation table may be seen on page 22. (A calf born on the 210 th day may live; also 336th.) A cow failing to carry her calf to the period of 280 days may be considered an abortion, and this subject is thoroughly described under heading Abortion.

\section{GONORRHOEA IN BULLS.}

Gonorrhœa is in infectious catarrhal discharge of the genital organs. It is brought on by coming in contact with living germs, such as serving a cow afflicted with infectious abortion, or one that has retained the afterbirth, and comes in heat while she is still discharging.

\section{TREATMENT.}

All herd bulls should have the sheath washed out after each service with a solution of Antisepto to prevent becoming affected and contracting gonorrhœa. It is due to this disease that infectious abortion is spread.

See Prescription No. 36, page 146.

\section{GRASS STAGGERS.}

Grass Staggers is a disease brought on by overloading the stomach with grass. As soon as the stomach becomes overloaded, indigestion sets in, which interferes with the krain, causing the animal to walk with an unnatural and unsteady gait, usually walking in a circle, and oftentimes staggering and falling. If they do so and they are filled with gas they should be tapped with a cattle trocar to prevent death from smothering. 
If they are noticed in time, or before they go down, a dose of Laxatonic should be given according to directions until they recover. A gag may be placed in her mouth.

See Prescription No. 37, page 146.

\section{GRUBS OR WARBLES IN SKIN OF CATTLE.}

Grubs or Warbles in the skin of cattle are caused by a fly which deposits its egg during the summer months in or on the skin of the animal and the egg is retained in the winter months in a little round sack beneath the skin, having a small opening through which the larva escapes in the early part of the following summer and develops into a fly.

TREATMENT.

To overcome and prevent the development or hatching of this fly the grub which is found beneath the skin of the animal along the back and is known by a swelling about the size of a boil, should be opened by squeezing, then inject a little Healing Oil a few times by the use of a small oil-can. The time to do this is during the early part of spring.

See Prescription No. 38, page 146.

\section{HARD MILKERS.}

This is due to an unnatural condition of the sphincter muscles at the end of the teat, and often what might be a valuable cow, on this account, considered a valueless animal, or one of much less value than a nice easy milker would be.

\section{TREATMENT.}

Wash the ends of the teats thoroughly with Germ Killer solution (one ounce to a gallon of water) and dip the Teat Plug into a clean solution of the same strength and insert it into a little Badger Balm and introduce it into the teat clear to the shoulder, so as to pass the enlargement of the teat plug into the teat far enough to admit the bulb which stretches the contracted muscles and retains the plug. The teat plugs should be allowed to remain in the teats from one milking to another until milking is made easy, requiring from three to six days. Do not use the milking tube instead of teat plug, as it will admit the air and is liable to cause infection.

See Prescription No. 39, page 146.

\section{INDIGESTION.}

It is pretty well understood by most stock owners that indigestion may be due to many causes, such as cold water, musty, bulky, fibrous food and irregular feeding. This can be overcome by giving Cow Tonic according to directions, and the bowels should be kept open by giving Laxotonic internally and warm water injections (per rectum).

See Prescription No. 40, page 146.

\section{INFLAMMATION OF THE LUNGS.}

Inflammation of the lungs may be known by the presence of hard breathing. The animal stops as though exhausted and extends the neck and head; dilates the nostrils and turns the limbs or elbows out on either side of the body, while at the same time it will appear to be very much distressed. The breathing may be rapid and short. The temperature should be taken and is usually found high.

\section{TREATMENT.}

Give the Fever Paste according to directions and apply the White Liniment to both sides of the chest. Give warm water injections (per rectum) twice daily, and the bowels may be kept open by giving Laxotonic according to directions. in severe cases apply the Antiseptic Poultice to the chest (both sides) and to the throat if need be. Give bran mashes made of linseed tea.

See Prescription No. 41, page 146. 


\section{INFLAMMATION OF THE WOMB.}

Inflammation of the womb is a very serious and obstinate disease.

The treatment is to give Fever Paste according to directions and warm water injections of Antisepto solution per vagina three times daily; introduce a half pound of lard after each injection. The bowels should be kept open by giving Laxotonic according to directions.

- See Prescription No. 42, page 146.

\section{INFLAMMATION OF THE UDDER.}

Give Cow Tonic according to directions and wash the udder with a warm solution of Germ Killer twice daily, and apply Badger Balm or White Liniment well rubbed in; then apply Antiseptic Poultice. Keep the animal well bedded to protect the udder from coming in contact with any dampness. (See picture "How to Bandage a Cow.")

See Prescription No. 43, page 146.

\section{INFLAMMATION OF THE TESTICLES.}

This may be due to an infection or an injury. In either case the testicles should be washed with a warm solution of Germ Killer and then thoroughly anointed with Badger Balm; then apply Antiseptic Poultice. The animal should receive Cow Tonic according to directions to purify the blood and tone up the system. The animal should not be used for breeding purposes during the treatment.

See Prescription No. 44, page 146.

\section{INFLAMMATION OF THE TONGUE.}

This will be known by a swelling of the tongue, slobbering from the mouth, and inability to swallow naturally.

\section{TREATMENT.}

Fever Paste in small and repeated doses should be given. Give bran mashes made from linseed tea and apply Antiseptic Poultice to the throat.

See Prescription No. 45, page 146.

\section{INFLAMMATION OF THE JOINTS.}

This is very common in all joints, but is more so in the joints of the feet, and the treatment is to wash the affected joints with a solution of Germ Killer; thoroughly rub in Badger Balm and apply Antiseptic Poultice once daily.

See Prescription No. 46, page 146:

\section{ITCH.}

Itch is a disease of the skin and may be due to parasite or other causes. The treatment is to wash the parts thoroughly with a solution of Germ Killer (one ounce to a gallon of water), and apply Skin Ointment according to directions, thoroughly rubbed in. The animal should receive Cow Tonic according to directions to purify the blood and tone up the system.

See Prescription No. 47, page 146.

\section{LEUCORRHOEA OR WHITES.}

Leucorrhœa or whites in cows is a catarrhal disease of the genital organs and is usually brought on by infectious abortion or retention of the afterbirth. They will be noticed to have a white or dirty discharge from the vulva, usually of an infectious nature.

\section{TREATMENT.}

The animal should receive Cow Tonic internally and the vagina should be washed out with a solution of Antisepto until all discharges cease.

See Prescription No. 48, page 147. 


\section{LUNG FEVER.}

(See Inflammation of the Lungs, page 67.)

See Prescription No. 41, page 147.

\section{LUMP JAW, OR ACTINOMYCOSIS.}

The first appearance of Lump Jaw is either an enlargement of the jaw bone or an enlargement of the glands of the throat, which are just back of the angle of the jaw and at first they may be loose from the jaw, but later on become adhered.

These swellings on the jaw or of the glands when broken will discharge a yellowish sticky pus which sometimes contains hard yellow granules or fragments of bone. As a result of the swelling the teeth may be pushed out of their natural position and consequently an animal cannot masticate its food properly and will soon run down in flesh, and the decaying of the bone oftentimes results in the destruction of the tooth sockets and the teeth will often fall out.

Every swelling on the jaws of cattle should be regarded as possibly Lumpy Jaw, if the definite cause for it is not known. The swellings are sometimes noticed to remain for some time of the same size, but sooner or later the inflammation will cause the swellings to increase.

This disease is due to a germ and when pus discharges from any of these enlargements falls on the grass or feed of any other stock, other animals are liable to contract the disease. In this manner a whole herd may be ruined if the treatment is neglected.

\section{TREATMENT.}

When there is no external opening apply Absorbent until the enlargements are all absorbed or an opening produced.

When there is an external opening on the surface of the swelling Absorbent should be injected into the cavity, or a small strip of white cloth may be dipped into the Absorbent and stuffed into the cavity, leaving only the end of it hanging out.

Due to the run-down condition of the animal, on account of the inability to masticate the food which is due to the location of this disease, the Cow Tonic should be given to aid digestion, increase the appetite and hasten recovery.

In extremely bad and stubborn cases a drachm of Iodide of Potash may be given in the drinking water twice daily, but never drench them.

See Prescription No. 49, page 147.

\section{MAMMITIS.}

(See article on Garget or Caked Uudder, page 66.)

See Prescription No. 34, page 146.

\section{MILK BLUE.}

Blue milk is due to an impoverished condition of the blood, and the treatment consists of giving plenty of nutritious food, to which should be added the Cow Tonic.

See Prescription No. 50, page 147.

\section{MILK FEVER, OR PARTURIENT PARESIS.}

The stall which a cow with milk fever occupies should be well drained and plenty of bedding placed under cow. Unless the cow is standing, place her on her broadside and wash off her udder and teats with a solution of Germ Killer (one ounce to one gallon of warm water). Dissolve one tablespoonful of Milk Fever Remedy in two quarts of warm water which has been boiled and cooled to blood heat; then inject this amount (one pint, or one-fourth of this solution) in each of the four teats by the use of the Milk Fever Injector, which must be thoroughly washed in a solution 
of Germ Killer to prevent infection of the teats or udder. After injecting one pint of the solution into each teat, place the lips to the injector and inflate the udder as much as possible by blowing with all the force possible into it until the udder is fully distended; then tie a small piece of tape around the point of the teats to keep the air from escaping. Remove the tape as soon as the cow gets up on her feet. After the udder has been thus treated, raise the cow upon her shoulder and prop her up by the means of bales of hay or bags of grain. Never allow her to lie flat on her side, except while washing and treating the udder. Give her a teaspoonful of Laxotonic, dry on the tongue (never drench a cow), every three hours. until the cow is up and the bowels move naturally; then continue with the Laxotonic every six hours until the contents of

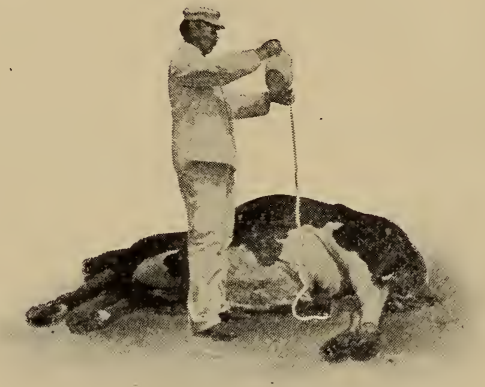

Overcoming a Case of Milk Fever.

one box has been given her, following the Laxotonic with the Cow Tonic to bring her back to her natural flow of milk. Keep a blanket on her until she recovers.

The air should be stripped out of the teats a few hours after she is up, and she may be milked a little twice daily until she gives a natural flow of milk, at which time she should be milked thoroughly dry at each milking. The feed should be of a laxative and nutritious nature, the chill taken from the drinking water for several days and a reasonable amount of exercise should be given her.

See Prescription No. 51, page 147.

\section{MILK BLOODY OR STRINGY.}

Bloody or stringy milk are both due to a derangement of the system, and the treatment consists of giving Cow Tonic as directed, which will alter the condition of the blood to such an extent as to overcome this ailment. Give good, clean, nutritious feed-mashes made of flaxseed tea.

See Prescription No. 52, page 147.

\section{NAVEL DISEASE OF CALVES.}

Navel Disease in calves is a germ disease that affects the navel cord, and takes place oftentimes at birth, due to the parts becoming infected by germs which not only cause the navel to become sore and inflamed, but they enter the body at this point and cause a swelling of the joints; this results in lameness and a gathering of matter or pus, at the same time causing a lack of ambition, dull, sickly appearance, indigestion and scours, and unless proper treatment is promptly given the disease will cause a sloughing of the joints or death by scours. 


\section{TREATMENT FOR NAVEL DISEASES OF CALVES.}

It is better to prevent this disease than to treat it after it has appeared. This can be done by thoroughly disinfecting the stall in which the cow calves, and when the calf is born the navel cord should be tied with a string dipped in Umbilicure, and Umbilicure should be applied to navel cord until it dries up and drops off and the wound heals.

See Prescription No. 53, page 147.

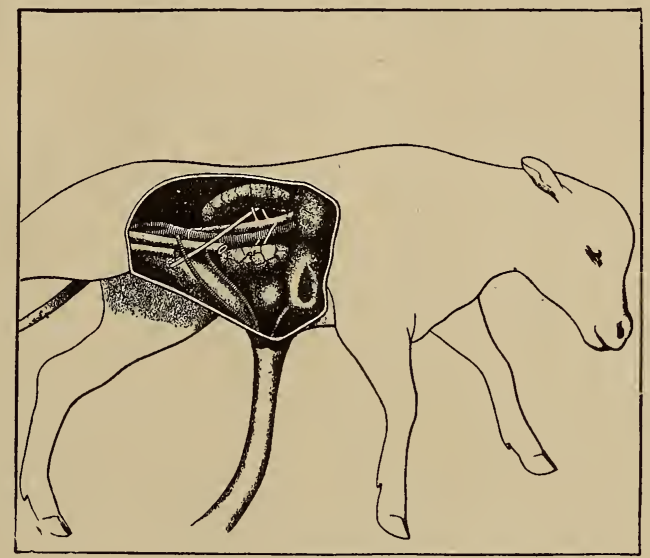

Navel or Umbilical Cord.

\section{PARALYSIS OF THE BOWELS.}

Paralysis of the bowels in cattle is a very common but seldom recognized ailment, even by the most skilled persons, and is the result of an overloaded and overworked condition of the bowels, and in nine times out of ten it is mistaken for constipation, for the reason that it appears very much like constipation and is difficult for any one but a skilled hand to recognize the difference until it comes to the treatment, which is entirely different. For instance, "A remedy that will overcome constipation will not overcome paralysis, but a remedy that will overcome paralysis will overcome constipation."

As 75 per cent. of the cases of stoppage of the bowels is due to paralysis and only 25 per cent. due to constipation, it would be advisable for all stock owners to be on the lookout for paralysis when stoppage of the bowels is met with.

If a cow afflicted with paralysis of the bowels be given a physic it will have a tendency not only to irritate the bowels, which are unable to throw off the already poisonous, irritating contents, but will oftentimes produce inflammation of the bowels and death will soon follow. While, on the other hand, if a cow be afflicted with paralysis of the bowels and she be given a laxative and tonic which loosens the bowels by toning them without any irritation whatever, the results will be favorable; and in case it should be constipation without paralysis the bowels will be loosened by being toned just the same.

\section{TREATMENT.}

In all forms of stoppage of the boewls in cattle, whether due to constipation of paralysis, give Laxotonic according to directions, at the same time give from two to four quarts of luke-warm water per rectum once or twice daily to empty the small intestines.

Give the animal bran mashes made of linseed tea, feed sparingly, remove the chill from the drinking water and give moderate exercise when able to take same.

See Prescription No. 54, page 147. 


\section{PARALYSIS OF THE HIND PARTS.}

This is a disease of the nerves which is usually present and follows milk rever, but does sometimes occur independent of anything else, and the treatment consists in giving Laxotonic, both to keep the bowels open and to overcome the paralysis. The animal should be given warm water injections (per rectum); should be turned several times daily from side to side. Apply White Liniment to the spine. Give nourishing and laxative food and plenty of water. The urine should be drawn if she is unable to pass it.

See Prescription No. 55, page 147.

\section{PINK EYE.}

(See Catarrhal Fever, page 62.)

See Prescription No. 20, page 147.

\section{RED WATER IN CATTLE.}

This is a common affection among cattle in certain localities, and is more common in Europe than anywhere else. It may be caused by injuries of the back; eating irritating plants; being exposed to low, damp districts, etc. But the most common form or. red water usually infects the whole herd. This is the form that most breeders have to contend with. The symptoms are bloody urine, associated with a high fever, usually, and a milking cow may be troubled with a frothy condition of the milk, this having a reddish tinge.

TREATMENT.

Rid the bowels of the irritating contents, and by so doing relieving the kidneys, which are always overtaxed. It is their overtaxed condition which produces the hemorrhage, and the result is red urine or red water. To relieve the kidneys of their irritated and overtaxed condition, the Kidney Cure should be given. The bowels should be emptied by giving two to four quarts of warm water (per rectum). A complete change of feed is necessary; this should be of a nutritious and laxative nature; giving plenty of bran mashes, made from linseed tea and allowing the animals to drink all the linseed or slippery elm tea that they want.

See Prescription No. 56, page 147.

\section{RHEUMATISM.}

Rheumatism is a disease due to an acid in the blood, and usually affects either the muscles or joints, or both.

The treatment consists in giving Cow Tonic as directed and applying White Liniment to affected parts. The feed should be nutritious and of a laxative nature. In bad cases, poultice joints with Antiseptic Poultice.

See Prescription No. 57, page 147.

\section{RINGING BULLS.}

The animal should be placed in a stanchion, a rope placed around the neck or horns and a loop around the nose; then fasten the rope to one side or the other so as to keep him from swinging his head from side to side. The operator then takes the cattle trocar and passes it directly through the partition between the nostrils. The bull ring should be dipped in Healing Oil, then passed through the opening and joined in the usual manner.

See Prescription No. 58, page 147. 


\section{RINGWORM.}

Ringworm is due to a parasite which affects the skin only. It has the appearance of a gray, crusty condition of the skin, which soon destroys the hair follicles and the hair falls out, leaving the skin in a dirty and scabby condition.

\section{TREATMENT.}

Give Cow Tonic internally, and wash off the affected parts with the Germ Killer solution and apply Skin Ointment, thoroughly rubbing it in.

See Prescription No. 59, page 147.

\section{SCOURS IN CALVES.}

(See Calf Cholera, page 58.)

See Prescription No. 13, page 147.

\section{SKIN DISEASE.}

There are several forms of skin disease, such as itch, ringworm, mange, eczema, etc., etc., and it is hard for an inexperienced person to distinguish one from another.

The treatment consists in giving Cow Tonic internally; washing all the affected parts with a warm solution of Germ Killer (one ounce to a gallon of water), and applying the Skin Ointment, thoroughly rubbed in. Continue this until the skin heals and all signs of itching or irritation have passed away.

See Prescription No. 60, page 147.

\section{SLOBBERING.}

Slobbering is not a disease, but an ailment which is due to several causes, such as an inflamed condition of the tongue, ragged edges of the teeth, or an overloaded stomach.

\section{TREATMENT.}

If due to ragged edges of teeth, they should be filled. If due to swollen condition of the tongue, give Fever Paste. If due to an overloaded stomach, give Laxotonic.

See Prescription No. 61, page 147.

\section{SORE MOUTH.}

This may be due to several causes, such as sharp teeth, inflammation of the tongue.

\section{TREATMENT.}

Dress the teeth and wash out the mouth thoroughly with a solution of Antisepto, and give small and often repeated doses of Fever Paste.

See Prescription No. 62, page 147.

\section{SORE THROAT.}

May be due to taking cold or infection, such as catarrhal fever.

\section{TREATMENT.}

Give fever Paste internally and apply the White Liniment to the throat externally from ear to ear. The bowels should be kept open with Laxotonic and warm water injections (per rectum) and soft and nutritious feed. Apply Antiseptic Poultice to throat if needed.

See Prescription No. 63, page 147.

\section{SPRAINS.}

Sprains are brought on by violent injuries and usually affect the tendons, joints and muscles. The treatment is to wash the parts off thoroughly with a warm solution of Germ Killer (one ounce to a gallon of water) and apply the Antiseptic Poultice, 
continuing this until all fever and swelling have disappeared. If the lameness remains, the parts should be blistered with Lucky Four Blister, applied according to directions. See Prescription No. 64, page 147.

\section{SUNSTROKE OR OVERHEATED.}

This is uaually brought on by over-exertion, such as too fast driving, etc., etc. The treatment consists in sponging the animal with cold water. Keep in the shade where the air is fresh and pure. Give Fever Paste to reduce the temperature, and small sips of water at short intervals. Give linseed tea to drink, if animal will drink. Do not drench.

See Prescription No. 65, page 147.

\section{SUPPRESSION OF MILK.}

This is not a disease, but a condition which exists more often in cold weather than in warm weather, and is often due to some derangement of the system. The treatment consists in giving Cow Tonic according to directions until the natural flow of milk is brought back.

See Prescription No. 66, page 147.

\section{SURGICAL OPERATIONS.}

All surgical operations should be performed in a careful and cleanly manner. Knives and instruments should be thoroughly cleansed and dipped into a strong solution of Germ Killer, and the seat of the operation should be thoroughly washed with the same solution. Then apply Healing Oil to the hands, instruments and the parts to be operated upon, and the results will always be favorable.

See Prescription No. 67, page 147.

\section{TEAT STOPPAGE OR STRICTURE.}

This is a very common, annoying and complicated ailment. There are two forms of stricture or stoppage; one at the point of the teat, and one at the basis of the teat. In either case the treatment is to wash the teats off thoroughly with a solution of Germ Killer. Teat Plug (see illustration, page 182) should also be washed in the same solution. If the stoppage be at the point of the teat, dip the point of a Teat Plug into the Badger Balm and pass it into the teat far enough to cause the little bulb to enter the teat. When this is done the plug will be retained and should be allowed to remain from one milking to another. The treatment continued until milking becomes perfectly natural and easy.

If the stricture be higher or at the base of the teat, a Teat Expander (see illustration) must be passed up through the stricture. After it is in position, the center part of the expander must be pressed upon. This will spread the upper part of the expander sufficiently to expand the stricture. However, this instrument should not be allowed to remain more than from one-half an hour or an hour at a treatment. A Teat-Bistoury may be used in the same manner. Badger Balm should be applied to the instrument before inserting. The hands of the operator and whole udder of the cow should be thoroughly washed before the operation is begun. Cleanliness must be given strict attention in these cases or the results will not be favorable.

See Prescription No. 68, page 147.

\section{TEAT SORE.}

This common form of sore teats may be treated by applying Badger Balm. This should be done after milking, leaving the teats in a nice, clean condition so as to heal between milkings.

See prescription No. 69, page 148. 


\section{TEAT WARTS.}

Teat Warts are small appendix which may adhere to the teats in a small or great number. Treatment consists in touching the little warts with Wartine, according to directions.

See Prescription No. 70, page 148.

\section{TUBERCULOSIS}

Tuberculosis or Consumption in cattle is an infectious and communicable disease known by the formation in the glands and other parts of the body of small bunches called tubercles. It is from these tubercles that the disease receives its name, Tuberculosis. The germs of tuberculosis enter the body by way of the nostrils in the air breathed, or by way of the mouth or digestive tract in feed, also through the genital organs by conception. As soon as the germs enter the body they begin to multiply, slowly but surely, until the entire body of the animal becomes affected; such animals spread the disease to other animals stabled with them and calves or pigs consuming milk from a tuberculous cow are liable to become affected as are human beings.

All germ diseases, and especially tuberculosis, are more liable to affect animals that are in a run-down condition, such as cows afflicted with infectious abortion or retained afterbirth, than those that are in a strong, healthy condition, for the reason that the animal that lacks vitality acts as a hot-bed for the germs of diseases to propagate or multiply, while the healthy, strong, vigorous animal may ward off the disease to some extent.

\section{HOW TO PREVENT TUBERCULOSIS.}

Tuberculosis being largely a house or stable disease due to artificial life, such as being housed or stabled, every possible precaution must be taken to prevent disease: One tuberculosis cow in a close, foul, hot, badly ventilated stable will infect all other cattle in the barn. Even in the best of barns where the presence of any weakening disease, such as infectious abortion, contagious mammitis, dysentery, retained afterbirth exists, there is danger of these diseases inviting the entrance and spread of tuberculosis and destruction of the herd. To prevent and guard against such disease, it is necessary to maintain absolute cleanliness.

\section{THOROUGHLY DISINFECT ALL STABLES.}

Allow plenty of sunlight, perfect ventilation to remove foul gases, and allow fresh air to enter. Stamp out contagious abortion and such other debilitating diseases as above mentioned.

\section{DETECTING THE PRESENCE OF TUBERCULOSIS.}

By means of the tuberculin test it is an easy matter to quickly and surely tell whether tuberculosis is present in a herd. It is a reliable method of detecting tuberculosis, even in its early stages. All herds should be tuberculin tested. Every animal in every herd of cattle should be tested, as tuberculosis affects a herd to such an extent as to render it unprofitable, although it may be the picture of health.

The owner can easily and safely apply the test himself after receiving proper instructions, instruments and a reliable tuberculin, which is a very important part of the test. The test should be applied to a herd, and if any diseased animals are found, they should be removed. The balance of the herd should be tested again in three months. Repeat the test every three months, removing after each test all infected cattic until all tuberculous animals are wiped out of the herd. The remainder of the herd should then be tested every six months, or at least once a year to be on the safe side. 
At the same time, all cattle affected with contagious abortion or other diseases should be treated until perfectly well, as they are in condition to attract tuberculosis.

In conducting the tuberculin test each animal in the herd should be marked by a number tag; the number on the tag should correspond with the number on the tuberculin chart or certificate, showing a record of the test of each animal in the herd.

The tuberculin certificate referred to will protect the reputation of the owner and insure the acceptance of the cattle he has for sale and also the product of his dairy, which will command the highest market price, and the extra profits will return many times the cost of testing. Test each new animal before it is allowed to mix with the herd.

\section{STATE DOES NOT MAKE TEST UNLESS TUBERCULOSIS EXISTS.}

Test your herd without waiting for the state to do it. The state officials only test a herd when tuberculosis is known to be present, when someone has complained that the cattle are, diseased, and by that time the reputation of the herd may be ruined. Make the test at once on general principles for your own information and benefit, whether tuberculosis is, or is not known to be in your herd. If you make the test at once, you will save all cows that are not affected; if you put the test off, the cows which you could save now will sooner or later become diseased and a loss to you. Learn to make the test yourself so that you may apply the test every six months, or at least once a year.

Stock owners should urge their neighbors to test their cattle at least once a year so as to keep the community free from tuberculosis.

See page $165^{\circ}$ for further information.

\section{HOW TO APPLY THE TEST.}

Before commencing the test, each animal should be tied up in the stable for at least three hours. Do not test a sick animal, or one in heat or otherwise greatly excited, twenty-four hours before or after calving, or one just having aborted or retained her afterbirth. Avoid testing in extra hot weather. Make no sudden changes of food at any time of test and do not give cold water just before taking temperature. Do the work as gently and quietly as possible to prevent unduly exciting the cattle.

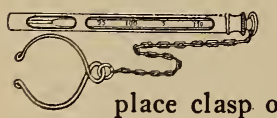

This Thermometer is to be inserted in the rectum of the animal to be tested, thus:

place clasp on tail so that thermometer cannot fall

out and break. Leave thermometer in place for five minutes, remove and read figures, and then jot them down on record sheet or chart (included in each outfit) opposite the number of the animal to be tested, as shown by the tag. These number tags are supplied free of charge with each outfit. Begin at cow No. 1 and test each animal in turn, taking each temperature in the same way, being careful to shake the mercury down below 100 before inserting the thermometer. This is done by holding the thermometer tightly, then giving it a quick jerk. A little vaseline applied to the rectum of each animal at beginning of test makes it easy to insert the thermometer.

\section{FIRST TEMPERATURES (First Day).}

Temperatures should be taken at 3 p. m., 5 p. m. and 7 p. m.

Tuberculin should be injected after the 7 o'clock temperature. 


\section{INJECTING THE TUBERCULIN.}

Fill this Hypodermic Syringe On with Tuberculin.

Pick up the skin of the animal, with the left hand directly back of shoulder blade in this manner: and with a quick, short $\mathrm{j} a b$ with the syringe insert the needle into the skin. Then press in piston to first notch in piston, this being half dram- $2 \frac{1}{2} \mathrm{C} \mathrm{C}$, or one dose for a full grown animal. The entire herd should be watered and returned to their places.

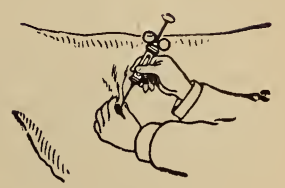

NEXT TEMPERATURES (Second Day).

Temperatures should be taken 10 hours after injection of Tuberculin and following every two hours. These are the hours: 6 a. m., 8 a. m., 10 a. m., $12 \mathrm{~m}$. and 2 p. $\mathrm{m}$.

See Prescription No. 71, for Testing Cattle for Tuberculosis, page 148.

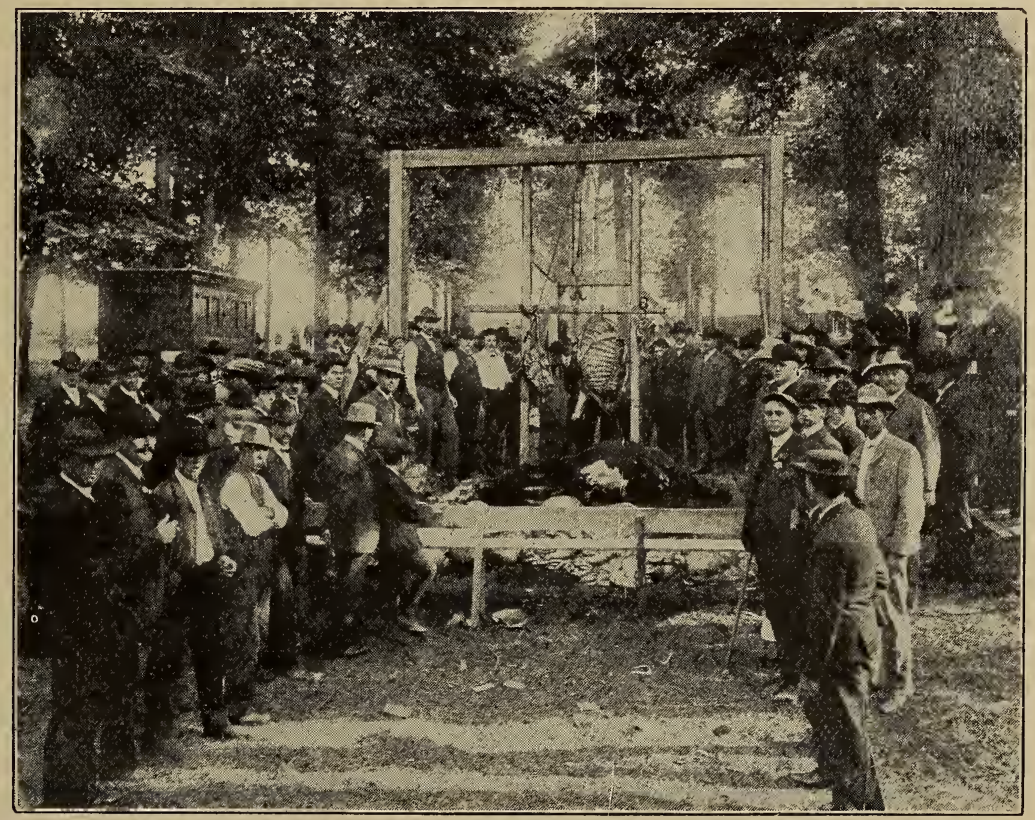

AUTOPSY OF TUBERCULAR COWS AT WISCONSIN STATE FAIR. A-Shows Healthy Lung. B-Shows Diseased Lung.

\section{TUMORS.}

As tumors come under the head of operations, it is needless to say that in their treatment absolute cleanliness, both of hands and instruments, is essential. The parts should be thoroughly washed with a solution of Germ Killer, and this followed with applications of Healing Oil. To heal the wound use alternately Healing Oil and Healing Lotion.

See Prescription No. 72, page 148. 


\section{TICKS.}

Cattle Ticks are small parasites which attach themselves to the skin of cattle, and they are frequently the means of spreading Texas Fever, which is a fatal disease unless the Ticks can be destroyed before the last stages of it are reached.

\section{TREATMENT.}

The treatment consists in washing the whole animal thoroughly with a warm solution of Germ Killer; then applying to all parts of the body and thoroughly rubbing in the Skin Ointment. All affected and exposed animals should be treated in this manner until all danger is past. Give Cow Tonic internally to tone up the system.

See Prescription No. 73, page 148.

\section{ULCERS.}

Ulcers may be an inflamed condition of any part of the body. The treatment consists in washing the parts thoroughly with a warm solution of Germ Killer and applying the Healing Oil to all affected parts, alternating with Healing Lotion.

See Prescription No. 74, page 148.

\section{URINE RETAINED.}

Retention of the Urine is usually brought on by any form of paralysis of the hind parts, such as occurs in Milk Fever. The treatment consists in passing a Catheter, which is a silver-plated tube about a foot in length and a quarter of an inch thick, into the bladder. This will allow the urine to flow freely. This instrument should be passed in all cases of paralysis of the hind parts, as there is usually a retention of the urine.

See Prescription No. 75, page 148.

\section{VOMITING.}

\section{SYMPTOMS.}

In the first place there is a loss of appetite, and the animal only takes part of its feed. Later on it fails to eat at all; and finally vomits what it has eaten. In other cases, the animal may be in a poor condition, and perhaps has been given food sparingly, then allowed to eat an over amount. In this case it is liable to eject or vomit from five to ten pounds; and will then oftentimes go on eating as though nothing had occurred. In either case, vomiting is due to indigestion, and the treatment consists in giving Cow Tonic to overcome indigestion, and to tone up the system; and the bowels, which contain a lot of undigestible material, should be toned up and emptied by giving Laxotonic (per mouth), and from two to four quarts of warm water (per rectum). The animal should be given bran mashes made from linseed tea. To prevent the whole herd from becoming thus afflicted, mix Condensed Stock Food with salt and place in sheltered trough where the cattle can have free access to same.

See Prescription No. 76, page 148.

\section{WARTS.}

Are little tumors, and often appear very suddenly and are liable to appear at any part of the body or limbs, angles of the mouth, corners of the eyes or tips of the ears. For this reason they are difficult things to remove, and great care should be taken in removing them. The only safe and reliable method is to apply Wartine, once daily, to warts of all kinds until they disappear. The large warts should be pulled out by the roots with the fingers or forceps; then apply the Wartine and Healing Lotion alternately to the wound thus made.

See Prescription No. 77, page 148. 


\section{WOUNDS.}

There are many different kinds of wounds, both external injuries, and by an improper condition of the blood.

Wounds of every nature, both surface and deep-seated, should be washed with a solution of Germ Killer.

Use both Healing Oil and Healing Lotion, alternately. Apply and inject same in the following deep-seated wounds, and into abscesses and fluid sacks, after they have been opened: capped knees; blood blisters (or bruises); fistulas, lump jaw abscesses, or abscesses of the udder; punctured or lacerated wounds, such as are often caused by barb-wire, tin, glass, nails or slivers; sore feet due to cracking, and formation of ulcers between the claws; wounds left after removing large warts.

It is difficult and important in all deep-seated wounds to keep proud flesh from forming, and to cause the wounds to heal nicely without a scar. This can be done if the above directions are carefully and closely followed.

GERM KILLER cleanses the wound.

HEALING LOTION prevents proud flesh.

HEALING OIL soothes and heals.

Above are listed in back part of book.

Use Healing Oil for superficial or surface wounds such as cracked or inflamed skin; cracked heels; bruises or irritated skin, such as is often noticed on the knees, ankles, hocks, and hips, from lying on cement floors; cracked or sore teats; sore mouth, both around the mouth and inside; bites of insects; poisoned or inflamed condition of the skin, and all superficial irritations of the skin.

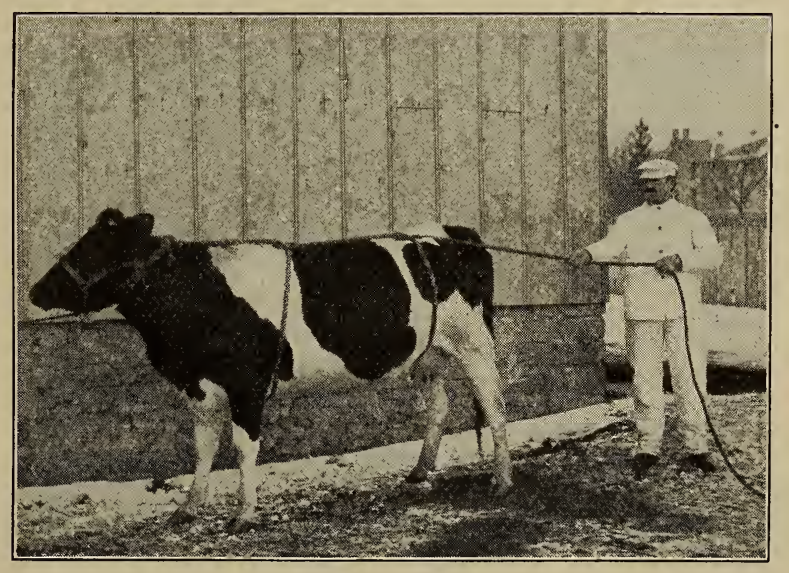

\section{DEVICE FOR THROWING CATTLE.}

Healing Oil should be used freely on the instruments and hands of the operator. It should also be applied to the scrotum of al! live stock castrated, such as calves, colts, lambs and pigs.

Healing Oil is invaluable to the veterinarian, or to parties who make a business of castrating stallions, bulls, boars, or rams, as it will prevent infection and blood poisoning in all surgical operations.

See Prescription No. 78, page 148. 


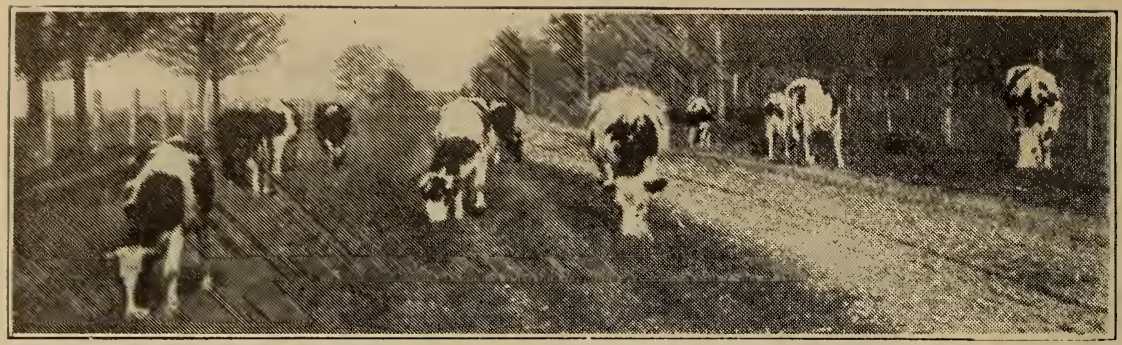

Group from the Holstein-Friesian Herd of St. John's Military Academy, Delafield, Wis., from which the Roberts Treatment Completely Stamped Out Contagious Abortion.

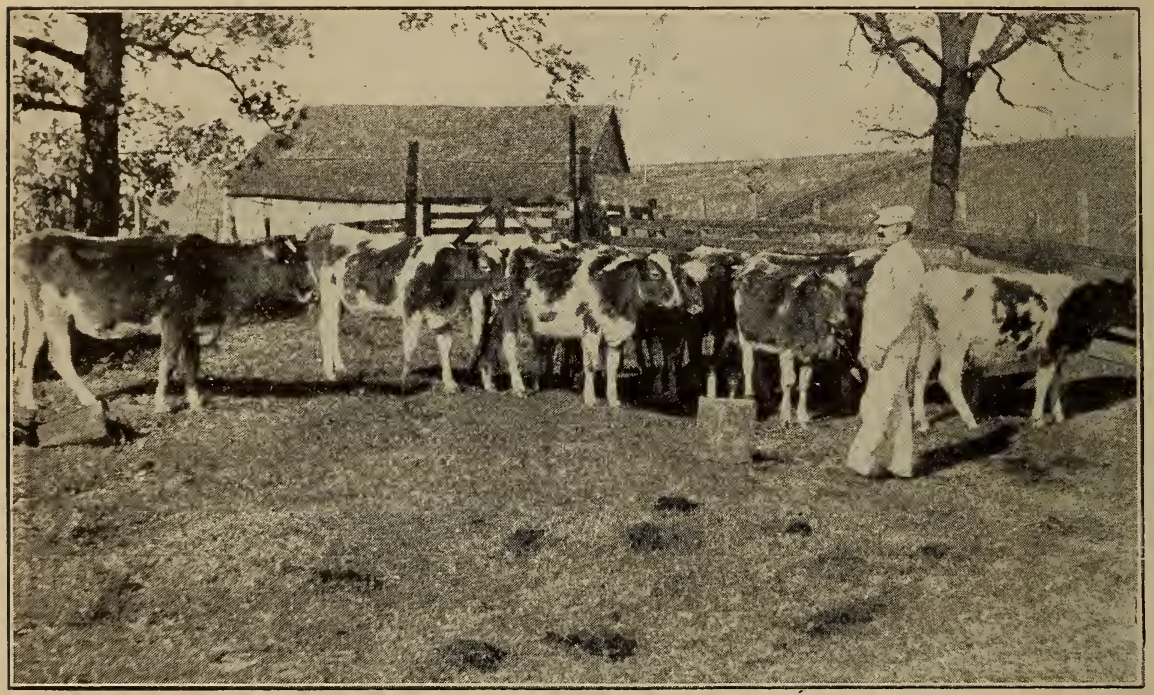

Herd of Cows Shipped to Waukesha for Treatment for Abortion Returned Home Cured.

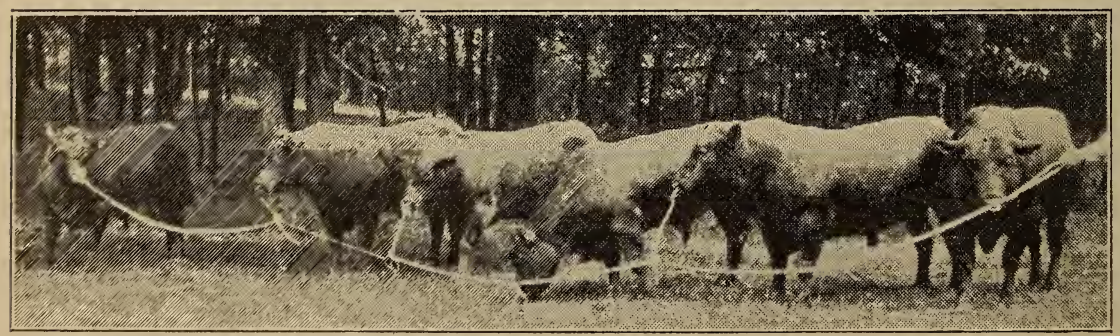

Herd Bulls of Northern Indiana Land Co. Dr. Roberts' Treatment Stamped Out Contagious Abortion from this Herd, consisting of 425 Head. See testimonial, page 86. 


\section{SWORN TESTIMONY REGARDING SUCCESS \\ of \\ Dr. David Roberts' Anti-Abortion Serum.}

\section{The Most Impressive Array of Legal Evidence Ever Presented in Behalf of Veterinary Medicines.}

This book may reach some who are not familiar with the remarkable achievements of Dr. David Roberts in stamping out Infectious Abortion by means of his AntiAbortion Treatment.

For this reason, we take pleasure in submitting testimony in the form of affidavits legally sworn to before properly constituted authorities, which any stock raiser must accept as absolute proof of every claim we make for this Treatment. This testimony is supplemented by many other signed statements from men well known in the cattle industry, whose reputation for truth and veracity is unquestioned.

\section{WISCONSIN EXPERIMENT STATION}

\section{Recognizes and Endorses Dr. David Roberts' Anti-Abortion Serum-Mr.} Baird's Herd Saved from Ruin.

State of Wisconsin,
Waukesha County. ss.

To Whom It MAY CONCERN:

S. A. Baird, being first duly sworn, on oath deposes and says, as follows:

My herd of cows was afflicted with Infectious abortion for at least six yearslosing a large number of calves each year-at the same time trying to get rid of the disease by selling the cows or heifers that aborted and buying new ones in their places, but the new ones would abort very soon after being brought into my herd. In this way the disease seemed to increase, my loss being greater each year. I used various remedies advertised for the cure of this disease, but they all failed to even improve my herd. I began to think it was an incurable diesase and was very much discouraged, when I happened to think that the Wisconsin Agricultural Experiment Station at Madison might be able to give me some information in regard to the disease or a treatment for same. So I wrote to Professor W. A. Henry, who is president of the Wisconsin Agricultural Experiment Station, and $w$ as answered by Professor W. L. Carlyle, who was at the head of the Animal Husbandry, and who advised me to consult Dr. David Roberts of my own city in regard to my afflicted herd, which I did. The doctor advised me to treat my herd with his ANTI-ABORTION SERUM, which I began doing on the 19th of December, 1899, and gave them a full treatment according to directions with the best results. I am positive the SERUM cured my herd and it prevented some of my cows from aborting after they had showed symptoms, such as swelling of the udder and vulva. The symptoms would disappear in about ten days, and the cows would carry their calves full time. It has done all that DR. ROBERTs claims for it and I cannot speak too highly of it. It has given me both pleasure and profit.

\section{Signed:}

S. A. BAIRD, Waukesha, Wis.

Subscribed and sworn to before me this 20th day of November, 1903. Notary Public, Wis.

Professor A. S. Alexander, M. D., C. V. S., Veterinarian of the Wisconsin Agricultural Experiment Station, Madison, Wis., permits me to refer to him as a believer in the efficiency of DR. ROBERTS' ANTI-ABORTION SERUM, and in giving advice by mail to a Wisconsin correspondent some months ago, said: "I must confess, however, that I cannot prescribe anything for contagious abortion that gives as good results as those 
obtained from the use of Dr. David Roberts' Anti-Abortion Serum, which to my knowledge has succeeded where thorough application of an antiseptic treatment advised by me had failed to stay or prevent the disease. His other remedies are also reliable and worthy of extended use by stockmen."

Dr. David RoBerts.

\section{YEKSA SUNBEAM HOLDS WORLD'S RECORD.}

Dr. David Roberts, Waukesha, Wis.

Athens, Wis.

MY DEAR Doctor:- It is now just a year since you went over my logging horses. While they are much better than in former years before you gave them attention, it is to be nevertheless presumed that in a bunch of fifty there will be some that need their teeth dressed again and other ailments looked after.

My Gurnseys should also have their annual tuberculin test applied, so when you come bring tuberculin enough to test 80 head. We might do the testing ourselves, but I will feel safer to have it done by a skilled hand.

And I think you will want to see Yeksa Sunbeam after taking the world's record on both milk and butter fat production, 14,920 pounds of milk and 857.15 pounds of butter fat, equal to 1,000 pounds of butter. This is a large amount for a cow to produce in one year; but she is not alone in the herd that has done or is doing fine work. The cows are all doing well and the whole herd is doing fine.

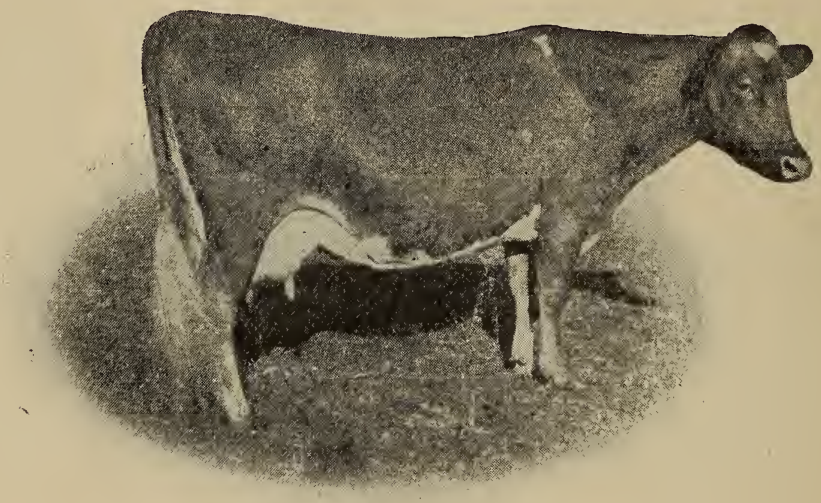

YEKSA SUNBEAM 15439 A. G. C. C.

Dropped April 2, 1895. Helendale Herd, Athens, Wisconsin.

Fred Rietbrock, Proprietor, Milwaukee, Wis.

There has not been a case of abortion since March last. Cows and heifers are carrying their calves full time and drop sound and healthy calves. We have used your ANTI-ABORTION SERUM, as directed, with great effect, and have also had splendid results with your Laxotonic, given with a spoon dry on the tongue, also with the Healing Oil on the horses' shoulders.

In one word, I am satisfied that your veterinary remedies are excellent and are effective for the purposes recommended.

Now, if a trip of 230 miles is not too far to come on such short notice, come while I am here, as I expect to stay till about the 28 th or 29 th inst. Let me know when you will be here.

Yours truly,

FRED RIETBROCK.

State of Wisconsin,

Waukesha County. $\}$ ss.

Dr. H. H. Smith of New Munster, Wis., being first duly sworn, on oath deposes and says as follows: 
I have used Dr. ROBERTS' ANTI-AbORTION SERUM in my practice for the past three years and have found it all that is claimed for it.

I cheerfully recommend it to other veterinarians. Signed:

DR. H. H. SMITH, New Munster, Wis.

Subscribed and sworn to before me this 17 th day of January, 1903.

A. L. BLAcKstone.

$\left.\begin{array}{l}\text { State of Illinois, } \\ \text { DeKalb County. }\end{array}\right\}$ ss.

I. Vandeburg, being duly sworn, on oath deposes and says as follows:-

My herd of twenty-two cows being afflicted with Abortion in 1902, I decided to try Dr. Roberts' Anti-Abortion Serum, which I did with results satisfactory, and I believe if used according to directions is a sure cure every time. Signed:

I. VANDEBURG, Kingston, Ill.

Subscribed and sworn to before me this 2d day of January, A. D. 1904.

[SEAL]

J. A. McCollon, Notary Public, Wis.

\section{AN ILLINOIS ENDORSEMENT.}

$\left.\begin{array}{l}\text { State of Illinois, } \\ \text { Johnson County. }\end{array}\right\}$ ss.

This is to certify that I have used Dr. Roberts' Anti-Abortion Serum and find it to be all that is claimed for it.

I take great pleasure in recommending it to anybody whose herd is afflicted with Infectious Abortion.

Signed:

Subscribed and sworn to before me this 31st day of August, 1903.
J. E. Arnold,

Vienna, Ill.

[SEAL]

S. A. VAN KIRK,

Notary Public, Ill.

\section{WILL USE NOTHING ELSE.}

Dr. David Roberts, Waukesha, Wis.

Marengo, Ill.

DEAR Sir:- The ANTI-ABORTION SERUM and syringe which I bought of you last January came all right. I did not use it on mv full herd, but just on those cows and heifers which showed signs of aborting, about eighteen head. All excepting one heifer carried their calves the full time, and that one aborted the third day after I got the Serum, so I am sure that your remedies did for us all we could expect of them, and I will not use anything elese in case I am in need of such medicine.

Respectfully yours,

Jos. BERNER.

\section{WANTS TEN MORE BOTTLES.}

Dr. David Roberts.

- Washington, Pa.

DEAR SIR:- Please send me ten more bottles of your Serum for abortion in cows. I think it is simply a wonderful medicine. Before using your remedies my cows were badly afflicted with contagious abortion, not one in twenty that would not abort and afterwards would not get with calf. I beg $n$ using your Serum last April, and have had no trouble of any kind with them since. One cow in particular that showed every symptom of aborting, I used the medicine as directed, the symptoms left, and she carried her calf the full term.

Please send this at your earliest convenience to Washington, $\mathrm{Pa}$. Very truly yours, Clark T. Harsha,

R. D. No. 5. 


\section{HE RECOMMENDS SERUM.}

Dr. David Roberts, Waukesha, Wis.

MINIER, ILL.

DEAR SIR:-I have used your ANTI-ARORTION SERUM and some of your other remedies and I am more than pleased with them. They will do all that you claim and I can recommend them to any one.

Yours truly,

Clarence Wilson.

\section{SERUM DID ALL YOU CLAIMED IT WOULD.}

Dr. David Roberts, Waukesha, Wis.

WINDSOR; Wis.

DEAR SiR:-Your ANTI-Abortion SERUM did all that you claimed for it for me. I know that all my cows would have aborted if I had not used it. Four had aborted in one week previous to using it. I had only one abort after I commenced using it, though five more showed every symptom of abortion. The twenty cows in my herd had their calves alive and all right.

Yours truly,

S. D. B. MOONEY.

\section{A HERDMAN'S ENDORSEMENT.}

Dr. Roberts Veterinary Co., Waukesha, Wis.

Osнкоsн, Wis.

DEAR SIRS:-We have used several of your cattle remedies with excellent results and would cheerfully recommend them to Cattlemen and Veterinarians. The Cow Tonic and Laxotonic have produced marvelous results in severe cases of indigestion, constipation and loss of appetite. Your Condensed Stock Food, when mixed with ground flaxseed, makes a Stock Food that is an excellent conditioner for cattle, and we have also used it with good results for the prevention and cure of scours and indigestion in calves. Your Cow Cleaner should do away entirely with the dangerous practice of removing the afterbirth by hand, as it does the work surely and thoroughly and leaves the genital organs in a healthy condition; it is a wonderful remedy.

Yours very truly,

Albert Portz, Herdsman.

\section{COW CLEANER REMOVES RETAINED AFTERBIRTH.}

Dr. David Roberts, Waukesha, Wis.

WHEELING, W. VA.

DEAR SIR:- I have used a number of your remedies and find them all that you claim for them. I have used your Cow Cleaner and find that it will remove a retained afterbirth and leave the cow in condition to breed without any trouble. I have also used your Laxotonic, and for constipation or stoppage of the bowels it is the best remedy I have ever found.

Truly yours,

M. T. MONTGOMERY.

$\left.\begin{array}{l}\text { State of Wisconsin, } \\ \text { Waukesha County. }\end{array}\right\}$ ss.

\section{STOPPED LOSS OF CALVES.}

J. A. Griswold, being first duly sworn, on oath deposes and says as follows:-

My herd of 25 cows was afflicted with Infectious Abortion in 1898. After losing a number of calves, I began treating them with Dr. Roberts' Anti-Abortion Serum. I gave them a full treatment with very satisfactory results. I feel that they were permanently cured, for I have not lost any since that time.

The herd is in excellent condition, and I take great pleasure in recommending Dr. Roberts' ANTI-ABORTION SERUm to any one whose herd is thus afflicted. I cannot speak too highly of it.

$$
\text { Signed: }
$$

J. A. Griswold.

Duplainville, Wis.

Subscribed and sworn to before me this 10th day of August, 1903. 
$\left.\begin{array}{l}\text { State of Wisconsin, } \\ \text { Waukesha County. }\end{array}\right\}$ ss.

\section{VERY SATISFACTORY RESULTS.}

Henry Clausing, being duly sworn, on oath deposes and says as follows:-

My herd of cows was afflicted with Infectious Abortion in 1902. After losing a number of calves, I began treating them with Dr. RoberTs' ANTI-ABortion SERUM. I gave them treatment with very satisfactory results. I feel that they were permanently cured, for I have not lost any since that time.

The herd is in excellent condition, and I take great pleasure in recommeding Dr. Roberts' Anti-Abortion Serum to any one whose herd is afflicted. I cannot speak too highly of it.

\section{Signed:}

Henry Clausing, Grafton, Wis.

Subscribed and sworn to before me this 4th day of November, 1903.

[SEAL]

Charles C. WirTh, Notary Public, Wis.

State of Colorado,
El Paso County.

\section{DISEASE WIPED OUT.}

H. Botting; being first duly sworn, on oath deposes and says as follows:-

My herd of cows was afflicted with Infectious Abortion in 1901, and after having lost a number of calves, I began treating them with DR. ROBERTs' ANTI-ABORTION SERUM with the best of success. The disease was checked and was entirely wiped out of my herd. I cannot speak too highly of this treatment, and can cheerfully recommend it to any one whose herd is thus afflicted.

$$
\text { Signed: }
$$

Henry Botting,

Colorado Springs, Colo.

Subscribed and sworn to before me this 26th day of October, 1903.

[SEAL]

JAMES W. COFFEY, Notary Public, Colorado.

Dr. David Roberts.

\section{A BOON TO DAIRYMEN.}

It is with pleasure that I make the following statement:-

For some time I was bothered with abortion in my herd. I used a number of different kinds of other medicines and they all failed. At last I began to use your Serum, and have found it does what you warrant. It not only prevents abortion, but cures it. I have not had a case of abortion since I began to use your Serum. It is a boon to dairymen and my stable will never be found without it hereafter.

I will be pleased to answer any questions in regard to my experience with your Abortion Serum.

Signed:

E. R. Frank, Mindoro; Wis.

Subscribed and sworn to before me this .12th day of January, 1905. GEORGE S. HewitT,

My commission expires April 6, 1908. Notary Public, La Crosse Co., Wis.

To Whom It May Concern:

I have used Dr. David Roberts' cattle remedies with excellent success.

For cows that do not clean properly after calving, Dr. David Roberts' Cow Cleaner is a sure, safe and economical remedy.

The Laxotonic moves the bowels gently, yet effectually.

Abortion, one of the greatest contagious diseases among dairy cattle, is under control by the use of Dr. Roberts' treatment.

I have found the remedies for cattle to do all that is claimed for them and have no hesitancy in recommending them to stockmen whose stock needs attention. 


\section{WIPED OUT THE DISEASE FROM 17 HERDS.}

\section{Experimental Station, University of OHio.}

\section{Dr. David Roberts' Veterinary Co.}

Aug. 7, 1908.

The 17 herds that were treated with Dr. Roberts' Anti-Abortion Serum, over which I had supervision, have fully recovered from the disease and in every way the treatment has proved to be a success.

(Signed)

$$
\text { Yours very truly, }
$$

O. ERF,

Professor of Dairying.

\section{LOST 1,000 CALVES IN ONE YEAF.}

De MotTe, Ind.

Replying to your letter of the 14th regarding the abortion in our cows, and as to the benefits derived from your treatment, will say I have watched these cows very carefully and notice their condition is much improved from last year. Last year we lost nearly 1,000 calves and some of the cows, while we have been very successful in saving our calves this year, and our cows are in much better condition than they were a year ago, and we believe that is due to Dr. David Roberts' Abortion Treatment. I have great confidence and am well assured, with Dr. David Roberts' Abortion Treatment (by the use of the Serum and washing out the genital organs) that Abortion can be entirely cleaned out of any herd.

\section{NORTHERN INDIANA LAND Co.}

By C. D. Shook, Supt.

Dr. Roberts Veterinary Co., Waukesha, Wis.

Montclair, Colo.

DEAR SIR:-It is a pleasure for me to inform you that abortion is eradicated from my herd of 65 cattle by the use of your Anti-Abortion Serum.

If you should meet with any persons who are in doubt as to the merits of your remedies, you are at liberty to refer them to me, as I think it would be a crime not to let those meeting with losses (as I have) know that there is relief for them through your remedies.

Yours. respectfully,

JONAS WASHBURN,

\section{WE HAVE MANY TESTIMONIALS.}

On account of the dread many breeders have of the disease, we refrain from using some of our strongest letters as testimonials, as breeders dislike to have it known that their herd has been afflicted.

All inquiries will be treated as strictly confidential. Treatment will be shipped in a concealed form on request.

Please give express office address. 


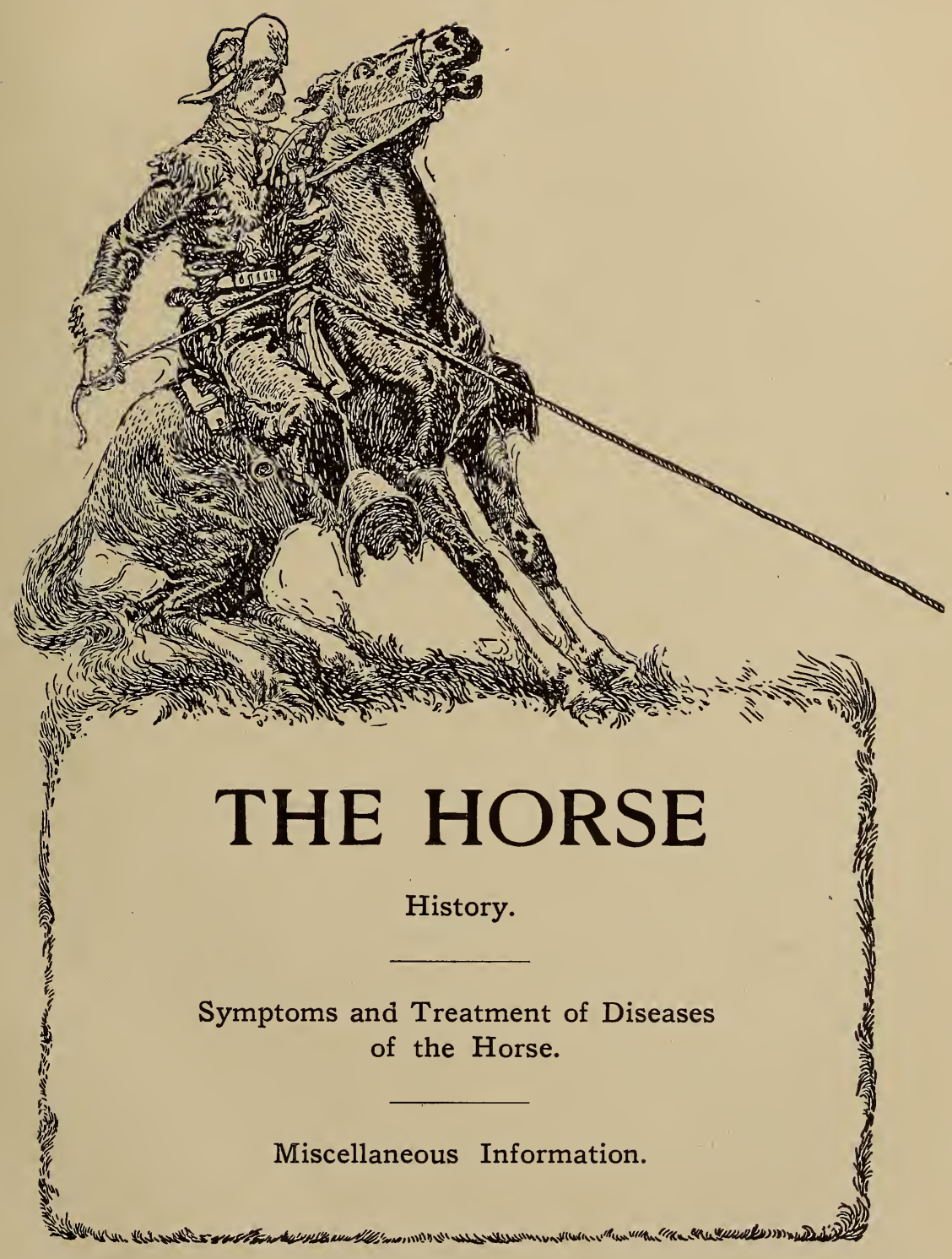




\section{HISTORY.}

As far back as history goes, we find that the horse was the servant of man. The first mention of the horse is as a domestic animal, and not as a wild animal.

The Arabs are renowned as early breeders of fine horses, and history tells us they considered their horses their companions, being kind in their treatment and holding them high in their affections. Great care and attention were bestowed upon breeding. In this manner they produced a breed of horses noted for its high intelligence, great speed and remarkable endurance. While they were always careful and considerate of their horses, still they expected always that a horse would do its best for them, and that it would endure many hardships. They were the first to establish pedigrees, and the line of breeding in their day was considered as important to them as it is today among high-class breeders. Breeders of horses at the present time are following in their footsteps closely, guarding carefully the pedigrees of their horses, giving them better care and closer attention, and in this way producing a better grade of horses and endeavoring at all times to reach the highest mark possible.

To get the best results out of a horse it is necessary that he be treated with kindness and given the best care and attention.

\section{HORSES' AGE.}

To tell the age of any horse,

Inspect the lower jaw, of course;

The six front teeth the tale will tell,

And every doubt and fear dispel.

Two middle nippers you behold

Before the colt is two weeks old;

Before eight weeks two more will come,

Eight months the corners cut the gum.

The outside grooves will disappear

From middle two in just one year.

In two years from the second pair-

In three years "corners," too, are bare.

At two the middle "nippers" drop;

At three the second pair can't stop;
When four years old the third pair goes, At five a full new set he shows.

The deep black spots will pass from view At six years, from the middle two;

The second pair at seven years;

At eight the spot each corner clears.

From middle "nippers" upper jaw

At nine the black spots will withdraw;

The second pair at ten are bright;

Eleven finds the corners light.

As time goes on the horsemen know

The oval teeth three-sided grow;

They longer get-project-before

Till twenty, when we know no more. 


\section{Symptoms and Treatment of Horse Diseases}

\section{ABORTION IN MARES OR SLINKING OF THE FOAL.}

From the third to fifth month of pregnancy there is danger of mares aborting, and to avoid this danger they should receive good, clean, nutritious feed, stables should be well lighted, well ventilated and well drained, and a good germ-destroying disinfectant should be used to overcome and allay all foul odors, which usually indicate that there are germs present.

The system of a mare at this time is in a very delicate condition, and if there be any time during the entire period of pregnancy that she requires a tonic it is at this period. The Breeding Tonic is especially prepared for this purpose and is invaluable for pregnant mares.

See Prescription No. 79, page 148.

\section{ABSCESS.}

An abscess is a gathering of pus or matter in a sack and it may develop in any part of the body. The most common locations for them to form is between the lower jaw. This may be due to Distemper, or it may form on the withers, and is then known as Fistula Withers. If on the head, it is then known as Poll Evil.

Abscesses are caused by either impure blood or bruises.

If due to impure blood, this should be overcome by giving Physic Balls and Horse Tonic.

\section{HOW TO TREAT ABSCESSES.}

An application of Antiseptic Poultice (see page 148) should be placed upon the seat of any abscess, continuing this treatment until the abscess comes to a head, at which time it should be opened with a sharp, clean, pointed knife, at the lower part of the abscess, making a cut so as to allow all matter to flow out freely. The knife should first be dipped in a solution of Germ Killer and then in Healing Oil to prevent infection. Then make a solution of Germ Killer and wash out the cavity by the use of a syringe or an overhead flushing tank with a rubber hose connected.

After the abscess is thoroughly washed out, inject Healing Oil or Healing Lotion. See Prescription No. 80, page 148.

\section{ASTHMA.}

Asthma is similar to Heaves. (See Heaves, page 101.)

See Prescription No. 81, page 148.

\section{AZOTURIA OR PARALYSIS OF THE HIND PARTS.}

This is a disease which comes on suddenly and is due to an acid condition of the blood. It sometimes affects the front parts as well as the hind parts, and the animal may come out of the barn feeling fine, ambitious, willing to go and often go faster than usual, but before it has gone very far it begins to lose its spirits, hang back, sweat profusely, breathe hard and begin to knuckle over behind, get lame in one or both hind limbs, and in a short time is unable to go any farther and often falls helpless on the road. 


\section{TREATMENT.}

Roll the animal on a stone boat and haul to the nearest warm, comfortable stable; place it in a large box stall, never in a single stall. Give one bottle of Colic Cure and follow with Kidney Cure according to directions. Half a bushel of dry, hot salt may be placed upon the kidneys. The body should be kept warm by placing a blanket on. Give four quarts of warm water injection (per rectum) by the use of a hose and funnel (and the urine should be drawn by means of a catheter). The animal should be turned from side to side as long as it is unable to rise, and it should be kept down by hobbles until it is able to get up and stand alone. This will keep it from injuring itself by floundering.

Give the animal all the water it wants to drink, with the chill taken off, and very little feed, if any, should be given during the first twenty-four to forty-eight hours. The animal should receive light food for several days.

See Prescription No. 82, page 148.

\section{BARRENNESS IN MARES.}

Barrenness, sterility or failure to breed in mares is due either to imperfect, unnatural or diseased genital organs. Imperfection of the genital organs may be due to an undeveloped womb or ovaries.

\section{UNNATURAL CONDITION OF THE ORGANS.}

An unnatural, swollen and inflamed condition of the genital organs may be brought on by a retention of the afterbirth, this being allowed to be retained in a decomposed condition until the mouth of the womb becomes irritated, scalded and sore, so that when it closes it heals closed so firmly that it cannot always be opened without mechanical aid.

\section{DISEASED ORGANS.}

The genital organs may become diseased from several causes, the main cause being neglect when they become affected with a catarrhal discharge. This disease is called Leucorrhœa, or Whites, and if a mare be served while in this condition the semen of the stallion will be destroyed by this corrosive discharge, thus preventing conception.

\section{ALL HEALTHY MARES SHOULD BREED.}

All reasonably healthy mares should be made to breed. This can be done with little trouble and slight expense if given proper attention. Many a valuable mare has been sacrificed or disposed of for the reason that they would not breed. This may have been due to a lack of proper information pertaining to this subject. It is a very important thing that a mare, in order to conceive, be in a reasonably healthy condition. The genital organs should be in a condition to perform their functional duties as nature would have them. A lack of secretion or an excess of secretion renders conception difficult. A lack of ambition or vigor, or an over amount of same, renders conception difficult. This should be overcome and controlled by the use of the Breeding Tonic, which contains ingredients that will regulate and control the genital organs. A mare should not be too thin (emaciated), thus lacking the strength which nature demands. Neither should she be too fat (plethoric), or over stimulated, for in this condition conception would be difficult.

\section{FAVORABLE SIGNS FOR BREEDING.}

A mare before breeding should be carefully examined to make sure that there is no unnatural discharge from the vulva. An unnatural discharge from the vulva may be a discharge of mucus streaked with or containing drops of matter or pus having a disagreeable odor, being of a very sticky nature, adhering to the tail or thighs. This 
would indicate the diseased condition of the genital organs and should be given prompt attention.

\section{ANTISEPTO SOLUTION IMPOR'TANT.}

The genital organs of all barren mares should be washed out with this solution until they conceive, whether they have a discharge or not. This solution will overcome the acid secretion which kills the semen of the stallion and prevents the mare from conceiving. It will also prevent and destroy germs, soothe and heal all inflamed mucous membranes, thus preventing the formation of germs and the spread of the disease. If a mare be cared for according to the demands of nature and fails to get with foal, after being bred a reasonable number of times, she should have the mouth of the womb opened. This is done while the mare is in heat by inserting from one to two fingers. This will dilate the neck of the womb and make conception easy.

\section{TREATMENT OF BARRENNESS.}

Barren mares should be given Breeding Tonic in their feed and their genital organs should be washed out with the Antisepto Solution.

As barrenness is either due to a diseased or weakened condition of the genital organs, it is unreasonable to expect a mare to breed until this condition is overcome. The Breeding Tonic contains such ingredients as will tone and strengthen and regulate the genital organs, in this manner putting them in a strong, healthy breeding condition. The neck of the womb can be opened by the fingers, if necessary, after this treatment.

See Prescription No. 83 for Treatment of Barren Mares, page 148.

\section{BLOATING.}

Bloating is due to indigestion and is caused by feed that is hard to digest. In order to avoid this trouble, which often proves fatal, see that your horses are digesting their feed. Their teeth should be well dressed.

This bloating is more often called Wind Colic. It usually comes on rather suddenly and continues, if not checked, until the animal's abdomen becomes very much distended, and unless the horse receives a dose of Colic Cure it may be necessary to resort to tapping. This is done on the right side of a horse, and the left side of a cow, and the seat of operation is located a little below the point of hip and the last rib. The instrument used is a trocar and a canula, which is usually a little smaller than a cattle trocar.

Before the operation the parts should be washed with a solution of Germ Killer. A small slit one-fourth of an inch long through the skin is necessary before attempting to insert the trocar. The instrument should be thoroughly washed with a solution of Germ Killer and dipped in Healing Oil. This will prevent infection. An injection of four quarts of warm water (per rectum) should be given by the use of a hose and funnel.

See Prescription No. 84, page 148.

\section{BLOOD POISONING.}

See Blood Poisoning in Cattle, page 57.

See Prescription No. 10, page 148.

\section{BOG SPAVIN.}

This is a distension of the synovial bersa and is located just in front and to the inside of the hock joint and is usually caused by strains.

The treatment, which is very effectual in colts, consists in washing off the hock thoroughly with soap and water, allowing it to dry. Clip off the hair and apply the 
Absorbent according to directions. The animal should rest during the treatment, but good results have followed even when the treatment has been applied and the animal worked.

See Prescription No. 85, page 148.

\section{BONE SPAVIN.}

Bone Spavin in horses is known by the enlargement and the limp. A hard, bony growth on the inner side of the hock joint, usually low down and a little forward of the center of the leg. In tarveling there will be a quick hitch with the sound leg and a stiff movement of the lame leg, bearing the weight on the toe, most noticeable in starting. The enlargement is due to a growth between the outer edges of the hock joint bones.

\section{TREATMENT.}

The proper way to treat this is to absorb the growth between the edges of the bone by the use of Bone Blister. When this is, done the lameness will cease.

See Prescription No. 86, page 148.

\section{BROKEN KNEE.}

Broken knee means that a horse has fallen on his knees and broken the tissues, oftentimes so extensively as to cause the joint oil to flow.

The treatment consists in washing the parts thoroughly with a solution of Germ Killer. Then apply the Healing Oil around the wound to the bruise, and apply the Healing Lotion to the wound itself.

Keep the animal quiet and free from exercise. If the animal has a desire to bite the sore, its head should be tied up.

See Prescription No. 87, page 148.

\section{BROKEN WIND.}

Broken Wind is similar to Heaves and should be treated in the same manner.

See Prescription No. 88, page 148.

\section{BRONCHITIS.}

Bronchitis is similar to Pneumonia or Lung Fever and should be treated in the same manner.

See Prescription No. 89, page 148.

\section{BRUISES.}

Bruises and swellings affecting any part of the body should be treated by thoroughly rubbing in Badger Balm and thoroughly apply Antiseptic Poultice. This should be repeated and continued until all heat and swelling have disappeared.

See Prescription No. 90, page 148.

\section{BRUISES OF THE FROG.}

This is usually due to traveling on stony roads, and the treatment consists in applying the Antiseptic Poultice and continuing same until all soreness, heat and lameness have disappeared.

See Prescription No. 91, page 148.

\section{BURNS AND SCALDS.}

All burns and scalds should be treated by applying Healing Oil or Badger Balm, then followed with Antiseptic Poultice.

See Prescription No. 92, page 149. 


\section{CALK WOUNDS.}

A calk wound is usually caused by one horse stepping on another one; and a horse may calk itself.

\section{TREATMENT.}

The hair should be clipped from the injured parts and the parts washed off with a Germ Killer solution; then by the use of the blacksmith's knife all parts of the broken hoof should be trimmed down as close as possible to give the wound a good drainage and prevent the formation of pus or matter which usually forms there. Lack of drainage will have a tendency to cause the horse to lose its hoof.

Apply Healing Oil around the wound and touch the wound with Healing Lotion. Then apply Antiseptic Poultice to the entire wound. The animal should receive laxative and soft feed during the treatment.

See Prescription No. 93, page 149.

\section{CAPPED ELBOW OR SHOE BOIL.}

This is an enlargement usually due to bruising of the point of the elbow where a collection of liquid gathers in the form of a large sack. If the sack is quite large and very soft it should be opened and thoroughly washed out with a solution of Germ Killer; then inject the Healing Oil. If the shoe boil is not ready to open it may be removed by applying the Absorbent.

See Prescription No. 94, page 149.

\section{CAPPED KNEE.}

Capped Knee may be treated in the same manner as Capped Hock.

See Prescription No. 95, page 149.

\section{CAPPED HOCK.}

This is an enlargement due to bruising of the point of the hock and should always be looked after and treated in its earliest stage. The treatment consists in clipping off the hair, washing off the parts and when dry applying Absorbent. One washing is usually sufficient. If a blister is required, apply the Bone Blister according to directions.

See Prescription No. 95, page 149.

\section{CASTRATION OR CUTTING COLTS.}

This is an operation which the owner of horses very seldom undertakes, but in case he should desire to do so, the parts should be thoroughly washed with a solution of Germ Killer and then apply a little Healing Oil. All the instruments used, and the operator's hands, should first be thoroughly washed in a solution of Germ Killer and dipped in Healing Oil to prevent infection.

See Prescription No. 96, page 149.

\section{CATARRHAL FEVER OR PINK EYE.}

Catarrhal Fever is similar to Distemper or Strangles, affecting the mucous membrane, especially the air passages, and if neglected often causes Pneumonia and Bronchitis. There is usually a discharge from both nostrils. First it is a thin, watery discharge and often becomes a thick, matter-like discharge, and in many instances the horse may have Catarrhal Fever without discharging from the nostrils. There will be a soreness of the throat, inability to swallow, and loss of appetite. 


\section{TREATMENT.}

If the temperature does not exceed 103 degrees the animal should be given a Physic Ball. If it should, omit the Physic Ball.

Apply White Liniment to the throat from ear to ear. If there be loud breathing apply Antiseptic Poultice from ear to ear to allay the inflammation. Give Fever Paste to reduce the temperature (in bad cases add one ounce of good whiskey to each dose of Fever Paste), and give Horse Tonic to keep up the appetite, and warm water injections to loosen up the bowels. Make a solution of Germ Killer or Disinfectall and dip gunny sacks in it and hang them around the stables to destroy the germs.

Allow the animal plenty of cold water to drink, and laxative food, such as bran mashes and grass in season.

See Prescription No. 97, page 149.

\section{CHOKING.}

This is a stoppage of the food in the swallowing tube or gullet. Usually the obstruction stops just before entering the stomach, and as the animal swallows, each swallow is stopped in the tube until the tube or gullet is filled up with saliva and food. It will then begin to come out of the horse's nostrils in the form of feed, froth and saliva.

The animal, in its effort to swallow, appears to have a spasm, often squealing in a desperate effort to pass the food down.

\section{TREATMENT.}

Lead the animal down a steep embankment, stopping him at the steepest place, where the hind parts will be very much elevated above the front part. Then, by pressing the head downward, a great part of the matter will pass out through the nostrils. You are then to lead him back into the stable; back him into a single stall, and by the use of a Drenching Hook draw his head up gently and give him half a dose of Colic Cure, but only give him one swallow at a time, and that through the mouth, never through the nostrils. Then turn him loose in a large box stall. He should not be allowed to eat a mouthful of food of any kind. Neither should he be allowed to drink any water.

In an hour lead him down the embankment, and after so doing give him another dose of Colic Cure. This should be repeated in the manner described every hour until the horse recovers. Feed sparingly after he recovers.

See Prescription No. 98, page 149.

\section{COCKED ANKLES.}

To prevent and overcome Cocked Ankles, the toe cork should be left off; the heel of the shoe-raised with heel corks. Apply White Liniment to the tendons from the hock or knee to the ankle. This should be continued until the proper results are obtained.

See Prescription No. 99, page 149.

\section{COLD IN THE HEAD.}

A cold in the head may be thought by most attendants to be Distemper, but as the treatment is like that of Distemper, it does not matter.

The treatment consists of applying White Liniment to the throat from ear to ear, giving the Fever Paste to reduce the temperature, and giving the Horse Tonic to keep up the appetite. Warm water injections should be given (per rectum) to empty the bowels.

See Prescription No. 100, page 149. 
COLIC.

There are only two kinds of Colic, Spasmodic and Wind Colic. They are often caused by a disturbance of the stomach and bowels, viz., indigestion and fermentation of feed.

Wind Colic does not cause the animals to be in such intense pain as Spasmodic Colic, but in both cases they look around to their sides. There is pawing, stamping and kicking at the stomach; frequent getting up and lying down; rolling from side to side and oftentimes lying on the back.

Colic is usually an easy ailment to detect, and unless it is given proper and immediate attention it often terminates in rupture or inflammation of the bowels, in which case death follows.

\section{TREATMENT.}

Back the horse into a single stall and by the use of a Drenching Hook drench him (see cut) with a dose of Colic Cure.- Turn him into a loose box stall with plenty of bedding and give him an injection of four quarts of warm water (per rectum) by the use of a hose and funnel. Place a blanket on him. Give another dose of Colic Cure in from one to three hours if necessary, and follow with Laxotonic; apply a quarter of a pound of mustard thoroughly mixed with a little warm water, making a thin paste, which should be thoroughly rubbed onto the abdomen or belly. Apply lard over the mustard in 12 hours to prevent its blistering.

Always allow a horse with Colic to lie down if he so desires. Never walk, trot or exercise a horse with Colic. A horse that is supposed to be subject to Colic should have his teeth examined and be given a Physic Ball and Tonic several times during the year, as this will prevent the horse from having Indigestion and Colic.

See Prescription No. 101, page 149.

\section{CONSTIPATION.}

Constipation in itself is not a serious ailment, but frequently leads on to more dangerous conditions and should be prevented and overcome by the use of a Physic Ball and four quarts of warm water injections (per rectum) by the use of a hose and funnel. The animal must receive laxative food and regular exercise.

See Prescription No. 102, page 149.

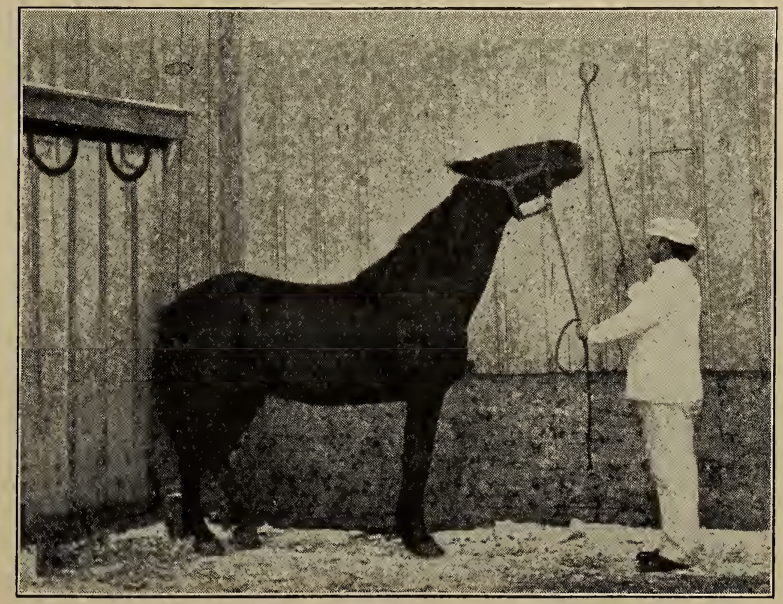

HOW TO DRENCH A HORSE.

¿ce "Hcw to Drench," page 96. 


\section{CORNS.}

Corns are brought on by improper shoeing and bruises of the feet, and the treatment consists in removing the barring of the shoe, poulticing the foot with Antiseptic Poultice, trimming out the diseased and bruised tissues and applying the Absorbent according to directions.

See Prescription No. 103, page 149.

\section{COUGHS.}

A Cough is due to an irritation of the throat and is often brought on by taking cold or coming down with a catarrhal disease, such as Distemper, Influenza, etc.

\section{TREATMENT.}

Apply White Liniment to the throat from ear to ear and give the Fever Paste as directed; in stubborn cases a Physic Ball should be given, as in some instances the cough may be due to an irritation caused by Indigestion.

See Prescription No. 104, page 149.

\section{CRACKED HEELS.}

Cracked Heels may be due to several causes, such as an impure condition of the blood, stocking and swelling of the limbs, driving in cold, slushy mud, or snow water.

\section{TREATMENT.}

Give the horse a Physic Ball and follow with the Horse Tonic. Wash the affected parts of the heels with warm water and soap. After they are clean and dry apply the Badger Balm. Avoid washing as much as possible. After the parts are once washed, then washing should be ommitted entirely, as water has a tendency to irritate and aggravate the Cracked Heels.

See Prescription No. 105, page 149.

\section{DRENCH.}

A drench means a liquid dose of medicine which is given to a horse by pouring same down the throat. While this may be a simple act, it, however, is accompanied by great danger, and a little knowledge and good advice may be very beneficial to the one who does the drenching.

Never drench a horse with a sore throat.

Never drench a horse through the nostrils.

\section{HOW TO DRENCH.}

Back the horse into a single stall. Fasten a Drench Hook to the rafters just above the horse's head, by means of a rope place a loop around the front upper teeth and gently draw the horse's head up.

The medicine should be well shaken before giving. Drench the horse slowly, by giving him one swallow of the medicine at a time, allowing him sufficient time to swallow before pouring more medicine into his mouth.

A horse that is unable to swallow should have the medicine given to him in the form of a powder or paste, on the tongue, by the, use of a spoon.

Great care should be exercised in examining a horse's throat to determine whether it is in a condition to be drenched or not. This can be determined by pinching the throat with the thumb and finger, and if by being pinched the horse will cough, then great care should be taken in drenching the animal. 


\section{CRAMPS OF JOINTS.}

This is an ailment which is frequently seen in young horses, and when present will be noticed when an attempt is made to back the animal out of the stall. One of the feet will appear as if bolted to the floor. If you are able to back him out it will be with difficulty, and when you start him up he may be unable to lift that foot from the floor, but all of a sudden, in some cases, the limb will snap and crack and he will walk off sound, but on standing will experience the same trouble, which is invariably located in the hock joint, but is often mistaken for stifle trouble.

\section{TREATMENT.}

Apply White Liniment all around the hock joint. See Prescription No. 106, page 149.

\section{CURB.}

A Curb is an enlargement which makes its appearance back of the hock just a little below the joint of the hock and is usually due to a bruise or strain.

\section{TREATMENT.}

During the hot or inflamed stage the parts should be thoroughly poulticed with Antiseptic Poultice until all the inflammation has subsided, then apply the Bone Blister according to directions. In stubborn cases it is well to alternate the Bone Blister with Absorbent according to directions upon the packages. This treatment will remove Curbs of every nature. The animal should not be worked or strained during the treatment.

See Prescription No. 107, page 149.

\section{DISTEMPER.}

(See Catarrhal Fever, page 93.)

See Prescription No. 97, page 149.

\section{DIARRHOEA.}

Diarrhœa is an unnaturally loose condition of the bowels, where the fæces or manure passes away in a liquid condition, indicating a disturbance of the mucous membrane of the bowels. It may be caused by bad or irregular teeth, indigestion, worms and unwholesome food.

\section{TREATMENT.}

Have the teeth examined and dressed if need be, and give liberal doses of Herse Tonic and dry feed, such as bran and ground oats. Give the horse a reasonable amount of water, and it is better that the chill be taken off. Give Calf Cholera remedy in small doses.

See Prescription No. 108, page 149.

\section{DROPSY.}

Dropsy is a watery condition of the blood and is known by heavy swellings in the limbs and abdomen. The treatment consists in giving a Physic Ball and following with Horse Tonic. Give nutritious food and proper exercise.

See Prescription No. 109, page 149.

\section{DYSENTERY.}

Dysentery is a watery condition of the bowel contents, similär to Diarrhœa, and is treated in the same manner.

See Prescription No. 110, page 149. 


\section{ECZEMA.}

Eczema is a disease of the skin and exists in various forms, but the most serious form of Eczema is known as Mange. This form is due to a parasite which is very hard to destroy, and the disease is equally hard to overcome, but all forms of Eczema and Mange can be permanently overcome and cured.

\section{TREATMENT.}

Give a Physic Ball and follow with the Horse Tonic internally. After the effects of the Physic Ball have passed away, the animal should be clipped (if the season will permit) and thoroughly scrubbed with soft soap and a solution of Germ Killer. After the parts become thoroughly dry the animal should be thoroughly rubbed with the Skin Ointment. This treatment should be repeated every few days until the disease is completely cured.

Sce Prescription No. 111, page 149.

\section{EYE INFLAMMATION.}

Inflammation of the eye may be due to an injury or to moon blindness. The treatment consists in bathing the eye with warm antiseptic solution several times daily, and injecting into the eye after each bathing some of the Eye Lotion.

The animal should be kept in a dark stable during a very aggravated case of sore eyes.

Sec Prescription No. 112, page 149.

\section{FEVER.}

A fever is an elevation of the temperature and is caused by a disturbance of one or more organs of the body, and the treatment consists, if taken in the early stages before the temperature rises above 103, in giving a Physic Ball and follow with the Fever Paste. Bran mashes and a liberal amount of cool water should be given.

See Prescription No. 113, page 149.

\section{FISTULA.}

A Fistula may occur on any part of the body, and the treatment for it is the same, no matter where it may be located. But it is more often located on the withers and is generally called Fistulous Withers. The treatment consists, when it first makes its appearance, in repeated applications of Antiseptic Poultice until the fever and inflammation have been reduced; then wash off parts thoroughly and clip off the hair and mane, and apply a good application of Lucky Four Blister. This may be repeated every two weeks, or until the enlargement has disappeared or been brought to a head. In the latter case it should be opened at the lowest point and thoroughly drained, the operator making an incision from two to three inches long. The cavity then is to be thoroughly washed cut with a solution of Germ Killer and the Healing Lotion injected once daily. In this manner any. Fistula can be permanently cured.

See Prescription No. 114, page 150.

\section{FLATULENT COLIC.}

(See Wind Colic, the treatment of which is the same.)

\section{FLIES.}

It is needless to say that flies are a nuisance to stock owners. However, they are not only a nuisance, but they are dangerous insects, and often are the means of carrying and spreading disease, thereby causing heavy losses to stock raisers and owners. They annoy horses to such and extent as to keep them in one continual fret and worry. It is impossible to keep a horse in flesh when thus continually disturbed. 
Milking cows are often so disturbed by flies as to cause their owners serious loss, owing to the shortage of milk. It is for this reason that all horse and cow stables should be darkened during the fly season each morning, and the stables thoroughly sprayed with Fly Oil (see page 159). And this should be sprayed upon the cows while they are in the stable and a few minutes before milking time. When this is done the cow will quiet down to her natural condition, and will give her milk down freely and naturally, and will give enough extra milk to many times pay for the Fly Oil. It is for this reason that a good Fly Oil is an invaluable preparation to have on hand during the fly season. "A word to the wise is sufficient."

See Prescription No. 115, page 150.

\section{FOALING.}

The required time of gestation, or the period in which a mare carries her coit, is eleven months, at which time special attention should be given the mare. Place her in a loose box-stall with plenty of bedding; give her feed of a laxative nature; the drinking water should have the chill taken from it, and her bowels should be kept in a natural condition by giving her laxative food.

After the labor pains have appeared, it would be well to keep watch of her, and if she does not deliver her colt within a reasonable length of time-say, one hour -it would be advisable to make an examination. Upon doing so, if the colt be in a natural position, the nose and front feet are the first to be felt. If such be the case, the attendant may assist the mare in delivering her colt by pulling on the front feet. Any cther position would indicate an unnatural condition of foaling.

When colt is born the navel cord should be tied two inches from the body with a string soaked in Umbilicure, the navel cord should then be cut about four. inches from the body. Umbilicure should be applied three times daily to the navel cord until it dries up and drops off. This will prevent the colt from becoming infected with navel diseases. Important in connection with this article is the article on Navel Diseases in Colts.

See Prescription No. 116, page 150.

\section{FOUNDER.}

Founder is a congested condition of the feet, and so affects them as to leave them in a diseased condition unless properly treated. An animal may be foundered by being overfed, by being watered or fed when in too warm a condition for receiving same, or by overdriving.

The first thing noticed will be an inability to move, especially their feet. They will stand with their hind feet pretty well forward and under the body, and if they are compelled to turn around suddenly, they will show evidence of great pain and lameness.

\section{TREATMENT.}

Bleed the animal by tapping the blood vessel in the neck. The seat of bleeding is about 12 inches from the angle of the jaw, and the operation should be performed by the use of a bleeding Flem on the left under-side of the neck.

The blood vessel may be raised by tying a string around the neck three to four inches below the point of bleeding. This should be drawn up rather snug. By so doing the blood vessel will fill rapidly with blood. The Flem should be placed and struck with a piece of heavy wood about 12 inches long. Always tap the blood vessel lengthwise. After you have let out from two to four quarts of blood, the string on the neck should be loosened and a pin passed through both edges of the opening in the 
skin and a small string of mane wound around the pin in the form of a figure 8 . This will prevent the animal from further bleeding.

Give the animal a Physic Ball and reduce the temperature with Fever Paste. Keep the appetite up with Horse Tonic.

Good big applications of Antiseptic Poultice should be placed on each foot. They should be kept moist in front and behind by pouring water on them every few hours, and place a blanket on the animal if in cold, and a fly sheet if in warm weather. Give soft feed and plenty of water.

If the animal shows signs of soreness in the feet in the course of 15 to 30 days an application of Lucky Four Blister should be made around the upper part of the hoof, and especially on the front feet.

See Prescription No. 117, page 150.

\section{GLANDERS.}

Glanders is a contagious disease and is incurable. It is a very dangerous disease to handle. If a person's judgment is not good enough to detect a case of Glanders, or if the case is not sufficiently developed to prove beyond a doubt that it is Glanders, the test should be applied, which consists in taking several temperatures, then injecting a dose of Mallien into the skin then taking a few temperatures afterwards and later, if the temperatures rise and do so above a certain number of degrees, it is evident that the horse has Glanders. Further particulars will be given on application.

See Prescription No. 118, page 150.

\section{GREASE HEEL}

Is a swelling of the legs and a breaking out of the skin, extending from hock to knee to hoof, and is more often due to a bad condition of the blood than anything else.

\section{TREATMENT.}

Give a Physic Ball and follow with Horse Tonic. Apply Badger Balm to all inflamed parts and in all severe cases apply Antiseptic Poultice over the Balm until the inflammation is gone, then continue with the Balm. Give the animal soft feed, such as bran mashes, grass, plenty of water, and keep him out of mud.

Do not wash off the leg unless you have to, and if you do, use a solution of Germ Killer, as water alone has a tendency to aggravate the case.

See Prescription No. 119, page 150.

\section{HARNESS OR COLLAR GALLS}

Are brought on from a chafing of the parts by the harness or collars. The parts chafed will first become hot, sore and inflamed; later on a scab will form and if neglected when scab comes off, there is danger of a sore being left under which pus cavities often form and cause no end of trouble.

If they reach this stage it will necessitate opening of the pus cavities, and in this case requires from 20 to 30 days to heal.

\section{TREATMENT.}

In ordinary cases of Harness and Collar Galls, apply Healing Oil; it will positively prevent and cure all Galls. It matters not at what stage they are in, if pus has collected, open up the sack and wash out the cavity with a solution of Germ Killer, then inject Healing Lotion.

See Prescription No. 120, page 150. 
HEAVES.

Heaves is a derangement of the blood vessels and air tubes of the lungs. The most common cause is Indigestion, or the animal may be out of condition. As soon as a horse gets out of condition there is great danger of an attaci of Heaves.

\section{TREATMENT.}

Give a Physic Ball and keep the animal from eating from 12 to 24 hours, then give Horse Tonic to tone up the system and digestive organs, and follow treatment by giving a moderate amount of feed with Heave Powder in it: Give water sparingly, and a reasonable amount of hay. Dampen all the feed.

After you have given a Physic Ball, Horse Tonic and one package of Heave Powder you can easily see how much you have improved him, and if he is not entirely cured, continue with the Heave Powder until he is well, giving a Physic Ball every two weeks.

See Prescription No. 81, page 150.

\section{HIPPED.}

The term "hipped" means the knocking down of the points of the hip bone. This can be done without injury to any joint, and for this reason the animal usually recovers from all lameness, but is always left deformed, though still useful.

\section{TREATMENT.}

Apply Badger Balm to all hot or inflamed parts around the hip until all heat, swelling and inflammation have disappeared. Then make an application of Lucky Four Blister between hip and stifle, every two weeks until the animal has fully recovered.

See Prescription No. 121, page 150.

\section{IMPACTION OF THE BOWELS.}

Impaction of the bowels means a stoppage of the bowels and the most frequent cause is overloading the stomach and bowels with bulky feed, such as straw or overripe hay. Another cause is paralysis of the bowels. It is for this reason that salts or oil should not be given a horse in this condition.

You will know this trouble by noticing that the horse acts as if he had the Colic. He will lie down, get up, perhaps pass a little water and a little manure, but only enough manure to deceive you. He will stretch himself, look around to his sides, and perhaps keep on eating.

\section{TREATMENT.}

Give a dose of Colic Cure and follow in three or four hours with a dose of Laxotonic. Repeat the Colic Cure and Laxotonic every six hours, giving them at intervals of three hours. Give four quarts of warm water (per rectum) three times daily, by the use of the hose and funnel. If the animal be in great pain, one-fourth pound of powdered mustard, mixed with a little warm water to make a thick paste, should be applied to the abdomen or belly. Apply lard over the abdomen in 12 hours, to keep the mustard from blistering. A Physic Ball should not be given unless in the early stage of impaction.

See Prescription No. 122, page 150.

\section{INDIGESTION OR "OUT OF CONDITION."}

This is a derangement of the stomach and bowels and is brought on by eating too much when the stomach is not in condition to digest food. You will know this trouble 
by the horse getting out of condition. He will eat plenty, but will not do well. There will be a rough coat, lack of ambition, bowels either too dry or too loose.

\section{TREATMENT.}

Give a Physic Ball and follow with the Horse Tonic. Repeat the Physic Ball every two weeks, and continue with the Horse Tonic until the animal has fully recovered, becomes fleshy, sleek, ambitious and able to do a good day's work. Give ground oats, bran and good tame hay, and see that he has regular exercise.

See Prescription No. 123, page 150.

\section{INFLUENZA.}

Influenza is a Catarrhal affection of the air passages, usually of the head and throat, but if neglected the disease will affect the lungs. It is similar to Distemper, and the care and treatment are much the same.

\section{TREATMENT.}

If the animal be treated in the early stages of the disease, a Physic Ball should be given, but if the temperature is higher than 103, don't give a Physic Ball.

Give Fever Paste and apply the White Liniment to the throat from ear to ear.

Keep up the appetite of the horse by giving Horse Tonic. Keep bowels loose by injections of four quarts of warm water (per rectum) by the use of hose and funnel.

In very severe cases of influenza, one ounce (two tablespoonfuls) of good whiskey should be added to the Fever Paste. If there be loud breathing, apply Antiseptic Poultice to the throat. Disinfect stables with Germ Killer or Disinfectall, hanging sacks around the sick stall that have been dipped in the solution, three times daily.

See Prescription No. 124, page 150.

\section{INJECTIONS.}

The usual method is to inject warm water into the rectum of an animal by the use of the hose and funnel, and this is a very important thing to do in all ailments and diseases except where the bowels are already too loose.

An injection makes it possible and easy for an animal to empty and expel the contents of the rectum without straining enough to injure itself in any way. The amount of warm water used is from two to six quarts and is injected into the rectum by the use of the hose and funnel, placing the hose from four to twelve inches into the rectum, at the same time holding the funnel up as high as the hose will permit, and pouring warm water into it as fast as it will run into the animal.

\section{KIDNEY DISEASE.}

The chief work of the kidneys is to expel all impurities from the system, and if they fail to do this, you will soon have a sick animal, and you will know it by a stiffened gait on the hind parts, the horse taking very short steps and being stiff in turning, showing an inclination to stretch as if wanting to pass water. This is a very serious disease and must receive prompt and proper attention.

\section{TREATMENT.}

In the early stage of the disease give a Physic Ball and follow with the Kidney Cure. Give warm water injections, bran mashes, good hay and plenty of drinking water. All horses should receive Kidney Cure daily to prevent diseases.

See Prescription No. 125, page 150. 


\section{LAMENESS.}

Lameness is a disease or an injured condition of a joint, ligament, tendon, hoof or muscle of an animal, and can be located usually by heat, swelling, inflammation, enlargements, and lack of action in any part of the body or limbs. The signs of location are as follows:

Hoof lameness improves with exercise. In cases of splint lameness a horse walks as though sound, but trots lame. In shoulder lameness a horse stumbles considerably. Joint lameness is usually indicated by heat and swelling. Tendon lameness the same. In ligament lameness there is no swelling, no heat and there will be no recovery unless the trouble is located and treated. In ringbone and curb lameness there is always an enlargement present. Bone spavin lameness sometimes appears without enlargement. Animal starts off on the points of his toes, and warms out of it as he is exercised. Bog spavin or thoroughpin always shows an enlargement.

\section{TREATMENT.}

Apply Antiseptic Poultice until all heat and inflammation are gone from the seat of the injury; then the parts should be clipped, washed, dried and Absorbent thoroughly applied in each of the following ailments: Ligament Lameness, Bog Spavin, Thoroughpins, Capped Elbows, Wind Puffs, Corns, and all unnatural enlargements on the body or limbs. In other forms of lameness the parts should be prepared as above mentioned and Bone Blister applied to the following ailments: Splints, Curbs, Ringbones, Bone Spavins and Capped Hock.

See Prescription No. 126, page 150.

\section{DEEP-SEATED LAMENESS.}

The parts should be clipped, washed, dried and Lucky Four Blister thoroughly applied where the following ailments exist: Shoulder Lameness, Sweeney, Stifle Lameness, Hip Joint Lameness, Sprained Joints, Tendons, also Curbs, and all parts requiring good, deep, stimulating blister. Hoof lameness due to nail wounds, gravel or bruises, should be thoroughly poulticed with the Antiseptic Poultice, and all cavities washed out with a solution of Germ Killer, after which inject Healing Oil. Plug all holes in bottom of hoof with absorbent cotton dipped in Healing Oil to prevent foreign matter from getting into the wounds. The poultice. should be applied after the hoof is thus treated, as it keeps down inflammation and lessens the danger of Lockjaw

See Prescription No. 127, page 150.

\section{LARYNGITIS}

Is an inflammation of the lining of the throat and is often accompanied by a swelling which causes the animal to breathe very hard. Unless proper care and treatment is given there is great danger of the horse smothering to death. It is in these cases that the silver tube, placed in the windpipe by cutting a hole into it, is so often necessary.

\section{TREATMENT.}

Give Fever Paste. Apply White Liniment to the throat from ear to ear, and if there is hard breathing, apply the Antiseptic Poultice to the throat from ear to ear. Keep up appetite with Horse Tonic. Keep bowels open by warm water injections, disinfect stalls with solution of Germ Killer or Disinfectall.

See Prescription No. 128, page 150.

\section{LEUCORRHOEA.}

This is a catarrhal or inflamed condition of the mucous membrane or lining of the genital organs, and is a very dangerous disease if neglected. It often prev nts mares from getting with foal. 


\section{TREATMENT.}

Give a Physic Ball and follow with Horse Tonic. Wash out the vagina with a solution of Antisepto, by the use of the hose and funnel.

See Prescription No. 129, page 150.

\section{LICE.}

Lice are small insects which infect live stock and do a great deal more damage to stock than the average stockman realizes.

It is a positive fact that if a stock owner knew just how much untold agony, to say nothing of the loss of flesh, that lice cause, he would not sleep until he had done all in his power to destroy the restless pests.

\section{TREATMENT.}

Diolice should be thoroughly applied and dusted into the hair on all parts of the animal.

See Prescription No. 130, page 150.

\section{LUNG FEVER.}

It is also called Pneumonia and is inflammation of the lungs. It may be caused in various ways, but the most common cause is taking cold and being neglected.

A horse with Lung Fever may or may not have a cough. He will stand with his elbows turned out most of the time, and seldom ever lays down.

\section{TREATMENT.}

Apply White Liniment to both sides of the chest over the ribs and also the throat.

Give Fever Paste to reduce the fever. Give Horse Tonic to keep up the appetite. Give one gallon of warm water as an injection (per rectum) to keep the bowels open. Dip gunny sacks in a solution of Germ Killer or Disinfectall three times daily and hang them around the sick stall to kill the germs which are always present.

The stall should be ventilated. Plenty of sunlight. Keep stall warm in winter and cool in summer. Place a blanket on the animal if needed. Keep the stall clean, well drained and use plenty of bedding. Give plenty of cold water, bran mashes and grass in season.

See Prescription No. 131, page 150.

\section{LYMPHANGITIS.}

This is inflammation of the lymphatic glands of the body or limbs, and is more commonly known as "Monday Morning Disease." Comes on from Sunday rest and high feeding. It is more often seen in the hind limbs than in the front ones, and is more liable to affect the left leg than the right.

\section{TREATMENT.}

Give a Physic Ball and follow with Horse Tonic. If the fever be high, give Fever Paste. Apply the Badger Balm to all swellings of the limbs or body and rub it in thoroughly. Give soft feed, such as bran mashes, grass in season, and lots of exercise when the animal is able to take it.

See Prescription No. 132, page 150.

\section{MANGE.}

Mange is a skin disease which comes under the head of "Eczema."

See Prescription No. 111, page 150. 


\section{MOON BLINDNESS.}

This is a disease of the eyes, and it is also known as Periodical Opthalmia. It gets both of the names from the fact that it affects a horse at regular periods and was formerly supposed to be controlled by the moon. It may affect one or both eyes at any time.

\section{TREATMENT.}

Remove wolf teeth, if any, by pulling them, instead of breaking them off. There is no treatment that will cure this disease, but improvement has been effected by giving the animal a Physic Ball and following with Horse Tonic.

Bathe the eyes with a solution of Antisepto three times daily and then inject the Eye Lotion as directed, until all inflammation is gone. Keep animal in dark stable during the stage of intense inflammation.

See Prescription No. 133, page 150.

\section{MOUTH SORE.}

If the animal's teeth need dressing, have them dressed and apply Healing Oil to all sore or inflamed parts. Change bits if necessary.

See Prescription No. 134, page 150.

\section{NASAL GLEET}

Is a Catarrhal Discharge from one or both nostrils and is often caused by a bad cold or Distemper.

\section{TREATMENT:}

Give a Physic Ball and follow with the Horse Tonic. Apply White Liniment to the nostril or nostrils affected, as high up as to come even with the lower part of the eyes, and within three inches of the hole of the nostril. This treatment should be continued until the animal is entirely cured.

See Prescription No. 135, page 150.

\section{NAVEL DISEASE IN COLTS.}

This is a disease that affects the navel cord, and this takes place oftentimes at birth, due to the part becoming infected by germs which not only cause the navel to become sore and inflamed, but they enter the body at this point and cause a swelling of the joints of colts. This results in lameness and a gathering of matter or pus, and unless proper treatment is promptly given, the disease will cause a sloughing of the joints and death will follow.

\section{TREATMENT.}

It is better to prevent this disease than to treat it. This can be done by applying Umbilicure to the end of the navel cord for several days immediately after birth.

\section{TREATMENT OF THE DISEASE AFTER IT HAS CAUSED THE JOINTS TO SWELL.}

Give Fever Paste internally and apply Badger Balm and Antiseptic Poultice externally. Keep colt from lying on damp ground or wet stalls.

See Prescription No. 136, page 151.

\section{NAVICULAR LAMENESS.}

This is caused by continual pounding on hard surfaces, such as pavements, and the treatment is not very satisfactory. Removing a part or severing the nerves of the 
feet will enable an animal to do work for some time without limping, but there is great danger of the foot dropping off.

\section{OPEN JOINT.}

This means an injury to a joint to such an extent as to cause the joint water to flow out. The joint water forms as fast as it flows out, so as soon as the flow is stopped the joint fills up again with as much of the fluid as Nature requires to lubricate the joints.

\section{TREATMENT.}

Clip off the hair and wash the joint and wound with a solution of Germ Killer. When dry, apply Lucky Four Blister to the entire joint, as per directions given on Blister. Apply Healing Lotion to the wound. Do not disturb the scab or wash the wound after the first washing. If the discharge of joint water does not cease in four days, one pint of the Antisepto Solution, which is made by dissolving one tablespoonful of Antisepto in a pint of water which has been boiled and cooled to blood heat, should be injected once daily into the joint until discharge ceases. Follow with Healing Lotion.

See Prescription No. 137, page 151.

\section{PARALYSIS.}

This is a loss of power, both of motion and of sensation, but one may occur without the other. The kind of Paralysis which is most common is due to Azoturia or an excess of uric acid in the blood, and must be treated the same as Azoturia.

See Prescription No. 138, page 151.

\section{PARASITES}

Is a term applied to a small living organism which lives on other animals, burrowing into the skin and producing irritation and a disease such as Mange in animals, or the Itch in human beings. For treatment see article on "Eczema."

See Prescription No. 139, page 151.

\section{PARTURITION.}

This is the act of giving birth to the offspring. The animal should be placed in a loose box-stall and given plenty of bedding. After the mare has labored for several hours, she should be examined to see if everything is all right. If she is not, she should be given special attention. After colt is delivered, she should be washed out with a solution of Antisepto (two quarts), then place one pound of lard (in chunks) into the womb. Do this once daily until she has recovered.

See Prescription No. 140, page 151.

\section{PHARYNGITIS.}

This is very much like "Laryngitis" and the treatment is the same. (See page 104.) See Prescription No. 141, page 151.

\section{PENIS}

This is the genital organ of the male and should be given some attention, such as washing out the sheath with a solution of Germ Killer every sixty days, and if the penis be sore, apply Healing Oil. 


\section{PILLS.}

Mean Physic Balls, of which all horses should receive no less than four eacil year, and at most, one every two weeks, until put in good condition.

Whenever the blood is out of order, the skin rough or covered with pimples, or the animal has a staring coat, no gloss to it, or is unthrifty in every way, you will know he needs a Physic Ball and it should be followed with Horse Tonic.

\section{PIMPLES.}

Pimples are only an indication that the blood is out of order, and the proper method of treatment is to give a Physic Ball and follow with the Horse Tonic, if the pimples do not disappear readily. Apply Skin Ointment to all parts affected.

See Prescription No. 142, page 151.

\section{PINK EYE.}

(See Catarrhal Fever, page 93.)

See Prescription No. 97, page 151.

\section{PLEURISY.}

Pleurisy is usually brought on by taking cold. It is an inflamed condition of the covering of the lungs and resembles Lung Fever. Give Fever Paste internally and apply White Liniment externally to both sides of the chest, also to the throat. Give warm water injections (per rectum) to keep bowels open, and care for the animal the same as you would in the case of Lung Fever.

See Prescription No. 143, page 151.

\section{PNEUMONIA.}

Is "Lung Fever" and the treatment is the same. (See page 104.)

See Prescription No. 131, page 151.

\section{POLL EVIL.}

Poll Evil is a large, hot, painful swelling on the forward and upper part of the neck just between and back of the ears, and is usually caused by bruises or violence of some form, such as jamming the head against the ceiling of the stable, or rearing up and falling over backwards, the result being the same, regardless of the cause. After the parts become hot, inflamed and swollen, pus or matter usually forms, and, unless it is overcome by absorption, the cavities become filled with pus and later on break open unless they are opened before.

The treatment cousists, when it first makes its appearance, in repeated applications of Antiseptic Poultice until the fever and inflammation have been reduced; then wash off parts thoroughly and clip off the hair and mane, and apply a good application of Lucky Four Blister. This may be repeated every two weeks, or until the enlargement has disappeared or been brought to a head. In the latter case it should be opened at the lowest point and thoroughly drained, the operator making an incision from two to three inches long. The cavity then is to be thoroughly washed out with a solution of Germ Killer and the Healing Lotion injected once daily. In this manner any Poll Evil can be permanently cured.

See Prescription No. 144, page 151. 


\section{PURPURA HEMORRHAGICA.}

This is an intense swelling of the limbs, head and under the belly, including the sheath or udder. The swelling comes on slowly but steadily and must run its course, causing the eyes to close from the intense swelling.

\section{TREATMENT.}

Give a Physic Ball at once and give Fever Paste to reduce the fever. Give Horse Tonic to keep up appetite. Give warm water injections (per rectum) to keep bowels open and apply Badger Balm, well rubbed in, to all swollen parts. If the heels crack, use Healing Oil and Healing Lotion-first one, then the other, as directed.

See Prescription No. 145, page 151.

\section{QUITTOR.}

Is like a Fistula, only it is located in the foot, and is often caused by nail pricks, bruises or gravel in the foot.

\section{TREATMENT.}

Wash part with Germ Killer solution and poultice the feet with the Antiseptic Poultice until most of the fever is gone, then inject Healing Lotion.

See Prescription No. 146, page 151.

\section{RING BONE.}

A Ring Bone is an unnatural growth of the bone, which takes place at the pastern joints and is liable to appear on any foot, but generally on the hind foot.

\section{TREATMENT.}

In the early stages of Ring Bone, clip off the hair, wash the parts thoroughly with soap and warm water. When dry, apply Bone Blister to the ring bone or any enlargement of like nature, and continue the treatment until all lameness is gone.

See Prescription No. 147, page 151.

\section{RING WORM.}

Ring Worm is a skin disease and is due to parasites which live just beneath the skin and must be destroyed before the disease can be cured.

The treatment is the same as for Skin Disease and Eczema. (See "Eczema," page 98.)

See Prescription No. 148, page 151.

\section{ROARING.}

Roaring is a disease of the throat and is caused by a neglected case of Distemper. It is very hard, and in fact, almost impossible to cure this disease.

\section{TREATMENT.}

Apply Lucky Four Blister to the throat from ear to ear according to directions. Repeat. every two weeks until at least four treatments have been given.

See Prescription No. 149, page 151.

\section{RUPTURE.}

Rupture is a term generally applied to an injury to the tissues which hold the bowels in their natural position.

A rupture of this kind may appear in different locations, but the rupture which the ordinary person has to contend with, and the only one which he can treat and improve the condition, is a rupture in a suckling colt, where the bowels come down 
into the scrotum. This may occur at any time from the day of birth to full maturity. It will be detected by an unnaturally enlarged condition of the scrotum.

The treatment is to apply Healing Oil once daily to the entire scrotum until it regains its natural size.

See Prescription No. 150, page 151.

\section{SCALDS AND BURNS.}

Scalds usually occur from having water applied to any part of the animal when it is too hot.

The most common way in which Burns occur, and the kind of burns that horse raisers have to contend with, are caused by the horse getting tangled up in a rope, either by being tied too long or staked out to grass. This is called a rope burn and if neglected, often results in a serious inflamed wound, which may leave a thick, diseased scar or ridge.

\section{TREATMENT.}

For either Scalds or Burns, apply the Badger Balm, and if it be where a poultice can be used, apply the Antiseptic Poultice. This can be continued until all heat and inflammation have gone. Then this should be discontinued, but continue with the Badger Balm until the parts are healed.

See Prescription No. 151, page 151.

\section{SCRATCHES.}

Scratches or cracked heels is an inflamed, irritated and diseased condition of the skin, usually at the fetlock of either front or hind limbs, but more often the hind ones. If this be neglected, it is liable to terminate in what is called Grease Heel. Scratches may occur at all seasons of the year, but are more liable to come on in the spring of the year. This goes to show that in many cases they are due to a bad condition of the blood.

\section{TREATMENT.}

Give a Physic Ball and follow. with the Horse Tonic. Wash the legs and feet off thoroughly with a solution of Germ Killer. See back part of book for remedies. The washing should not be repeated after the limbs are once clean. Then apply the Badger Balm, and if it be a very sever case, apply the Antiseptic Poultice until all heat and swelling have disappeared. Continue with the Badger Balm until the skin is healed. The animal should be kept out of the mud and snow water, as all water and moisture are irritating to the skin when thus afflicted.

See Prescription No. 152, page 151.

SHOE BOILS.

(See "Capped Elbow," page 93.)

See Prescription No. 94, page 151.

\section{SKIN DISEASE.}

Skin disease comes under the head of "Eczema" (see page 98).

See Prescription No. 111, page 151.

\section{SORES.}

There are various kinds of sores, some being superficial, and others deep seated. Both superficial or surface sores and deep seated sores or pus cavities may be caused by bruises, punctures, wire cuts, etc. 


\section{TREATMENT.}

In all cases of sores, the first thing to be done is to cleanse them. This should be done with a solution of Germ Killer. If it be a deep seated sore, the cavity should be thoroughly syringed out with this solution, and then Healing Lotion should be injected.

If a surface sore, it should be cleaned in the same manner, then treated with the Healing Oil. If proud flesh appears, apply Healing Lotion.

See Prescription No. 153, page 151.

\section{SORE THROAT.}

Is an inflamed condition of the mucous membrane lining the throat, and it may be due to taking cold, inhaling smoke, or to Distemper or Catarrhal Disease.

\section{TREATMENT.}

Apply the White Liniment to the throat from ear to ear for three to four days, discontinuing for a few days and resuming the treatment later if needed.

Give Fever Paste on the tongue. The appetite may be kept up by the use of Horse Tonic. The bowels should be kept open by giving four parts of warm water (per rectum) as an injection, using a hose and funnel.

The animal should be allowed plenty of cold water and soft and nutritious feed, such as bran mashes; and flaxseed teá may be given freely.

See Prescription No. 154, page 151.

\section{SPAVIN.}

(See Bog and Bone Spavin, pages 91 and 92.)

See Prescriptions Nos. 85 and 86, page 152.

\section{SPEEDY CRACK}

Is similar to "Scratches" or "Cracked Heel," and the treatment is the same (see page 109 ).

See Prescription No. 152, page 152.

\section{SPLINTS.}

A Splint is a bony enlargement which develops on the (canon) or shin bone of the horse between the knee and hock, and the (fetlock) or ankle joint. They usually form on the inside of the limb, but do occasionally appear on the outside of a limb. They vary in size from that of a hickory nut to a small kernel. They can usually be seen or felt very readily. Splint lameness has a peculiarity of its own, inasmuch as the horse is apt to walk perfectly sound and trot lame and the horse usually grows worse by exercise. Splints are usually caused by hard road work or injuries. Either will produce a growth of bone beneath the thin tissue paper like covering of a bone; it is this growth that produces lameness and the treatment of a splint consists in the application of ingredients such as are contained in Bone Blister. When this growth or enlargement is absorbed, it disappears and so does lamesness if the animal is thus afflicted.

See Prescription No. 155, page 152.

\section{SPRAINS.}

A Sprain is an injury to the joint, ligament, tendon or muscle, and is usually detected by heat, swelling, soreness or lameness. . All heat, swelling and soreness should be overcome by applying the Antiseptic Poultice and if there be lameness after the heat 
and swelling have been relieved, the Absorbent or Lucky Four Blister should be applied.

See Prescription No. 156, page 152.

\section{STERILITY.}

(See Barrenness in Mares, page 90.)

See Prescription No. 83, page 152.

\section{STRANGLES.}

Strangles is the same disease as Catarrhal Fever or Distemper (see page 93).

See Prescription No. 97, page 152.

\section{STRING HALT}

Is an injured condition of the nerves of the hind limbs, and is known by an unnaturally high lifting of the limbs. This trouble is incurable.

A horse out of condition will show this disease more than one in a good, healthy condition, so the only thing to do is to get the animal in a healthy, strong condition. This may be done by giving Physic Ball and Horse Tonic until the condition of the animal is improved.

See Prescription No. 157, page 152.

\section{SUNSTROKE}

Is simply prostration from heat, and usually occurs in very hot weather.

The animal may be going along as usual, but will suddenly get dizzy, weak and sweat profusely, then suddenly stop sweating and begin to pant. His nostrils get large and he will hang his head, and it is at this point that he is liable to go down.

\section{TREATMENT.}

Cold water should be applied to all parts of the body and head by the use of a light spray or by sponging. This should be kept up until he cools off. Move him to a shady place, where he may get fresh air, and give him one tablespoonful of Fever Paste and eight ounces of good whiskey as one dose, and follow every three hours with a tablespoonful of the Fever Paste and two ounces of good whiskey as one dose, until he recovers.

Give a gallon of tepid water (per rectum) by the use of the hose and the funnel. Allow the animal to drink tepid water, and as he recovers, give him bran mashes and soft foods.

See Prescription No. 158, page 152.

\section{SWELLING.}

Swelling is a hot, inflamed condition, and the treatment consists in giving a Physic Ball internally, following this with the Horse Tonic. Apply Badger Balm well rubbed in, and if possible to use a poultice, use the Antiseptic Poultice.

See Prescription No. 159, page 152.

\section{SWEENY.}

Sweeny is a shrinking of the muscles and is caused by an injury to the point of the shoulder; for this reason the hair should be clipped from the entire shoulder blade, and the point of the shoulder, and an application of Lucky Four Blister or White Lini- 
ment to both the point of the shoulder and to the depression at the shoulder blade.

In many cases it is an advantage to use first one of these remedies, then the other.

The animal should receive daily exercise; sometimes a little light work may be beneficial, but heavy work is out of the question.

Sce Prescription No. 160, page 152.

\section{SHEATH.}

The sheath is the cover of the penis of the male, and the only attention that is usually required is to occasionally wash out with soap and warm water, the collection of dust and dirt in the sheath, which sometimes produces bad results if negiected. It may cause portions of the skin to slough off, leaving raw surfaces, which come in continual contact with the balance of the unclean parts. If there be signs of soreness, the dirt from the sheath should be washed out at the point of the penis, and should be examined, as there is frequently a collection of cheesy-like material collecting just in front of the urethra, where there is a little blind sack that favors the collection of foreign matter. This gathering is commonly known as a bean. It should be examined and the sheath washed no less than four times per year. If there be soreness of any nature on the penis, the Healing Oil should be applied to the inner parts of the sheath.

\section{SYNOVITIS.}

This is inflammation of the synovial and joints, the parts of the joints which come in contact with one another. This is commonly know as inflammation of the joints, and may be recognized by heat, swelling and intense lameness. Bruises, slips or strains are frequent causes of synovitis.

\section{TREATMENT.}

Apply Badger Balm thoroughly rubbed into the parts of the inflamed joints, then apply the Antiseptic Poultice. Continue this treatment until all heat and swelling have disappeared. If lameness continues, apply Lucky Four Blister according to directions, and repeat every two weeks until lameness is overcome.

See Prescription No. 161, page 152.

\section{TEETH (IRREGULAR).}

All owners of horses should examine their horses' teeth and should be able to tell by examination whether they should be dressed or not.

The way to examine them is to back the horse into a single stall, remove the halter or bridle, and if need be put a neck strap on the animal, and by standing directly in front of the horse and reaching into the mouth, grasping the tongue and pulling it out and to one side with one hand, and lifting the sides of the cheeks with the other. In this way you will be able to see the full set of molars or grinders. If they need dressing, the inside edges of the lower teeth and the outside edges of the upper teeth will be ragged, rough and sharp.

Sometimes in examining a horse in this manner you will find one or more teeth considerably longer than the othe:s, in which case, or where the edges are sharp, the teeth should be properly dressed by a qualified veterinarian who thoroughly understands dentistry. In fact, all horses should be thus examined, and especially horses that are out of condition.

\section{TENDON SORE.}

When a horse has a sore or lame tendon and when inflamed so as to produce lameness, it should first be thoroughly rubbed with Badger Balm. Then apply the 
Antiseptic Poultice until all heat and swelling have disappeared, after which remove the lameness by applying Lucky Four Blister as directed.

See Prescription No. 162, page 152.

\section{TESTICLES.}

Swollen testicles may occur as the result of bruises, kicks or stings, and the trouble frequently happens to stallions during breeding season.

Bathe parts with warm water, then apply Badger Balm, thoroughly rubbed in, and follow by the use of the Antiseptic Poultice. This is done by placing a wide bandage around the belly, just in front of the hips, then another strip attached to it just at the point of the sheath, then brought up between the thighs and along the side of the tail and fasten to the other strip just over the loins or kidneys. In this manner a poultice may be applied easily, and its use is very important in such cases.

\section{THOROUGHPINS}

Is an unnatural enlargement of the hock, and is indicated by a puff in front and outside of the hock, passing entirely through the hock. This trouble may happen to horses of any age, but the treatment is very much more satisfactory in young horses than in old ones, and is as follows:

\section{TREATMENT.}

Clip off the hair from all parts and wash with warm,water and soap. A few hours later apply Absorbent to the puffs, both in front and at the sice of the hock. In this manner all curable cases of Thoroughpins can be cured.

See Prescription No. 163, page 152.

\section{THRUSH IN FEET.}

Thrush is known by a dark gray, unhealthy secretion of matter oozing from the middle or either side of the frog of a horse's foot. This discharge, if neglected, is liable to eat its way through the sole of the foot, oftentimes involving the joints and sometimes causing intense lameness, swelling of the limbs. It is at this stage of the disease that blood poisoning is liable to set in and death occurs.

This disease affects both horses and mares, more often affecting the front feet of geldings or stallions and the hind feet of mares; this being due to the filth and moisture caused by the urine.

\section{TREATMENT.}

Thrush is to be treated by cleanliness-the removal of all direct causes and a return of the frog to its normal condition. The diseased or ragged condition of the frog should be pared away and in severe cases the foot should be poulticed for a few days with the Antiseptic Poultice. The center of the frog and the grooves on either side are then to be cleaned and well filled with wads of cotton soaked in Germ Killer (full strength). The foot should be dressed in this manner once daily. If there be intense fever in the feet and swelling of the limbs, this will indicate that the horse requires internal treatment, and for this give a Physic Ball and follow with Horse Tonic; but in all mild cases of Thrush in the feet pack the frog and affected parts with wads of cotton soaked in Germ Killer (full strength) and you will overcome the disease.

See Prescription No. 164, pagè 152. 


\section{TUMOR.}

The only possible way for stock owners to remove Tumors is by use of the Absorbent. If that should fail to accomplish the result, the knife must be resorted to.

See Prescription No. 165, page 152.

\section{ULCERS}

Are deep seated sores, usually of a very disagreeable character, occurring in any part of the body or upon the limbs.

\section{TREATMENT.}

Wash them out thoroughly with a solution of Germ Killer and apply Healing Lotion. Most ulcers should be touched up with Absorbent to get them in a condition that they will heal.

See Prescription No. 166, page 152.

\section{URINE RETAINED.}

The retention of the urine in mares may be easily overcome by passing a female catheter, which is a silver plated tube a little larger than a lead pencil and about twelve inches long, into the neck of the bladder, which is located on the floor of the vagina. But the retention of the urine in a gelding or stallion is a difficult matter to overcome, as an inexperienced person would be liable to have trouble in passing the male catheter, which is usually about three feet long. However, if there be retention in the mare or horse, a bottle of Colic Cure should be given, as this contains ingredients which act upon the urinal organs, and by so doing may overcome the necessity of drawing the water.

See Prescription No. 167, page 152.

\section{WARTS}

Are little tumors which often appear very suddenly on any part of the body or limbs, angles of the mouth, corners of the eyes, tips of the ears, etc. For this reason they are difficult to remove, and great care should be taken in their removal. The only safe and reliable method is to apply -Wartine to warts of all kinds, until they are removed. It requires a longer time to remove some kinds of warts than others. The large warts should be pulled out by the roots with the fingers or forceps, and then apply the Wartine to the wound thus made.

See Prescription No. 168, page 152.

\section{WIND BROKEN.}

This trouble is very much like Heares and should be treated in the same manner. (See Heaves, page 101.)

See Prescription No. 81, page 152.

\section{WIND GALLS.}

Wind Galls are sometimes called Wind Puffs, either term being correct. They are enlargements of the synovial bursa, and usually appear on the fetlock joint of the front or hind limbs, but more often on the hind limbs. 


\section{TREATMENT.}

Clip off the hair over the wind gall, wash the parts thoroughly with warm water and soap, and in a couple of hours apply Absorbent. Do this daily until the trouble disappears. Do not repeat the washing.

The animal will improve more rapidly if kept from doing hard work, and kept off the pavement.

See Prescription No. 169, page 152.

\section{WIRE CUTS.}

Wire Cuts are usually caused by wire containing barbs or sharp prongs. These barbs or prongs are usually in a rusty condition, and for this reason a wire cut is considerably more dangerous and harder to handle than most any other wound; but wire cuts may also be produced by smooth or woven wire, but the animal, in such cases, must come in contact with such wires with considerable force. When this occurs the bruise is usually as serious as the cut, and both have to be properly treated in order to obtain the best results.

Barb wire cuts are also very dangerous for the reason that when the animal comes in contact with a fence with sufficient force to produce an ugly gash there is great danger of the sharp, rusty barbs passing considerably deeper into the flesh than the wire itself, and by so doing oftentimes penetrate the joints in that vicinity. When this occurs you have to contend with both a wire cut and an open joint. The open joint means the escaping of snobia, or joint water, from the joint.

\section{TREATMENT.}

All wounds should be thoroughly washed with a solution of Germ Killer. When the skin and muscles are cut to more than two or three inches in length it is advisable to stitch up with silk or linen thread, bringing the skin together. This may be done successfully in several ways, but it is advisable to make stitches about one-half or one inch apart, passing the needle through both edges of the skin, then cutting the thread sufficient in length to be tied in a hard knot. These are called interrupted sutures.

Another method would be to begin at one end of the cut, passing the needle through the skin and back through the end of the thread, then to the opposite side of the wound, and in this manner drawing the edges of the skin together, sewing the entire wound without cutting the thread. This is called uninterrupted sutures. The entire wound should then be dressed with Healing Oil once daily. Daily washings of the wound with Germ Killer solution and Healing Oil are necessary. After the stitches are removed the wound may be washed once daily with Germ Killer solution. Apply Absorbent with a small brush to the wound itself, using Healing Oil to keep the skin moist. In this manner any wound may be treated with success, regardless of its size.

See Prescription No. 170, page 152.

\section{WORMS.}

There are several classes of worms, but the same treatment applies to the various kinds.

It is a very important thing to rid your horse of worms and keep the animal from having them. In order to do this a package of Worm Powder should be given. It should be followed with a Physic Ball, which expels all destroyed and stupified worms.

In connection with this treatment, two to four quarts of Germ Killer solution, half strength, should be given (per rectum) as an injection by the use of a hose and funnel, 
two or three times per week. This will rid the rectum of the little pin worms, which are sometimes very hard to be gotten rid of. This treatment can be repeated if necessary.

Sce Prescription No. 171, page 152.

\section{WOUNDS.}

There are many different kinds of wounds, which are caused in different ways. Most wounds are caused by external injuries, while others may be caused by improper condition of the blood.

Wounds of all nature, both surface and deep seated, should be washed with a solution of Germ، Killer; after they are thoroughly cleaned by injecting this solution into the cavity, use both Healing Oil and Healing Lotion alternately.

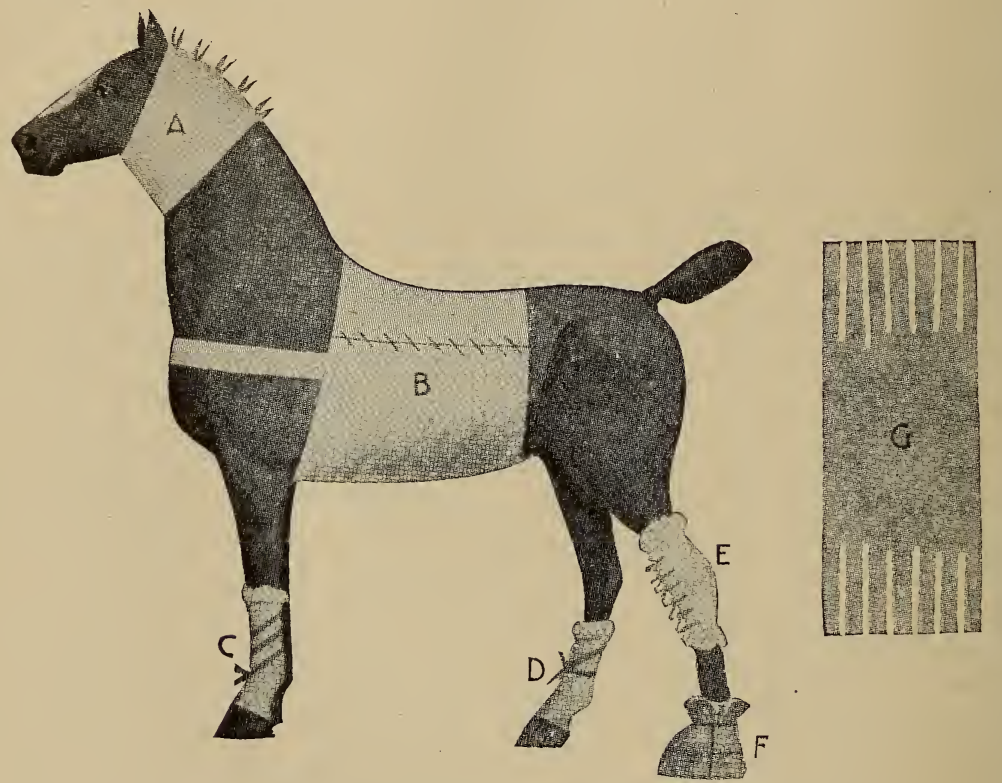

METHODS OF APPLYING ANTISEPTIC POULTICE.

A-Throat Pad.

B-Pneumonia Jacket.

C-Fetlock Pads.

D-Fetlock Pads.

E-Hock Bandage, Manytail.

F-Poultice Bandage.

G-Manytail Bandage.

Apply and inject into the following deep seated wounds, and into Abscesses and Pus and Fluid Sacs, after they have been opened, such as Poll Evil, Fistulas, Withers, Capped Elbow, Capped Hock, Distemper, Abscesses on any part of the body, open collar or harness Galls, Blood Blisters (or bruises), often seen at the point of the breast bone, abscess of the udder, punctured or lacerated wounds, such as are often caused by barb wire, tin, glass, nails or slivers; sore feet due to rope burns, wounds left after removing warts. 
It is a difficult and important thing in all deep seated wounds to keep proud flesh from forming, and to cause the wound to heal nicely without a scar. This can be done if the above directions are clearly and carefully followed.

GERM KILLER cleanses the wound.

HEALING LOTION prevents proud flesh.

HEALING OIL heals the wound.

See back part of book for these medicines.

Use Healing Oil for superficial or surface wounds, such as Collar Galls, Harness Galls, Cracked or Inflamed Skin, Cracked Heels, Speedy Cuts (or Scratches), bruises or irritated Skin, such as is often noticed on the knees, ankles, hocks, and hips from lying on cement or rough floors without much bedding. Sore mouth, both around the mouth and inside; bites of insects, poisoning or inflamed condition of the skin, and all superficial irritation of the skin.

Healing Oil should be used freely on instruments and hands of operator, also applied to the scrotum of all live stock castrated, such as calves, colts, lambs and pigs.

Healing Oil is invaluable to veterinarians or to parties who make a business of castrating stallions, bulls, boars and rams, as it will prevent infection and blood poisoning in all surgical operations.

See Prescription No. 172, page 152. 


\title{
HORSE OWNERS GIVE THEIR EXPERIENCE.
}

\section{Dr. David Roberts' Absorbent Saves Valuable Race Horse.}

\section{Dr. David Roberts,}

Waukesha, Wisconsin.

Milwaukee, Wis.

DEAR SIR:-Electric Maiden, 2:131/2, was afflicted with two large goitres on her neck. I had great fear, and in fact had made up my mind that she was ruined as a race horse on account of these unnatural growths, but upon learning that you had an Absorbent specially prepared to remove unnatural enlargements from the body and limbs of a horse, I was determined to try it, so I purchased one bottle and applied it according to directions, and in a remarkably short time it reduced the enlarged glands to their natural and normal condition.

I consider that your Absorbent has done more than I ever expected of any remedy. I take great pleasure in recommending this valuable remedy to other horsemen.

$$
\text { Yours truly, }
$$

T. J. DUNBAR, Milwaukee, Wis.

\section{WISCONSIN STATE INDUSTRIAL SCHOOL USES OUR REMEDIES IN ITS LIVE STOCK DEPARTMENT WITH GREAT SUCCESS.}

\author{
STATE INDUSTRIAL SchOOL, \\ WAUKESHA, WIS.
}

\section{DR. DAVID ROBERTS,}

Waukesha, Wisconsin.

DEAR SIR:-At one time I was superintendent and manager of the Captain Pabst stables in the city of Chicago. Later I conducted a livery business at the Aldine Square Livery on Vincent Avenue. At times I had as high as ninety head of boarding horses, and as a rule each owner or family employed their own veterinarians and used different veterinary remedies in the care and treatment of their animals. This necessitated the calls of many different veterinarians and the use of a great many different veterinary remedies, and it gave me a good opportunity to witness the different methods of treating animals, and the most interesting of all things was to watch the results of different remedies, such as Condition Powders and Colic Cures, and with this experience I must say of all the Colic Cures I saw administered or administered myself to these different boarders, that of Dr. David Roberts' Colic Cure has in my opinion, saved more horses and brought about better results than any that $I$ have witnessed or experienced, and I take pleasure in recommending your Colic Cure for all forms of colic.

I have had considerable experience with your Horse Tonic, and like it very much and can highly recommend it for all horses out of condition.

K. C. Dousman, Manager of the Live Stock Dept. of the Wisconsin State Industrial School. 


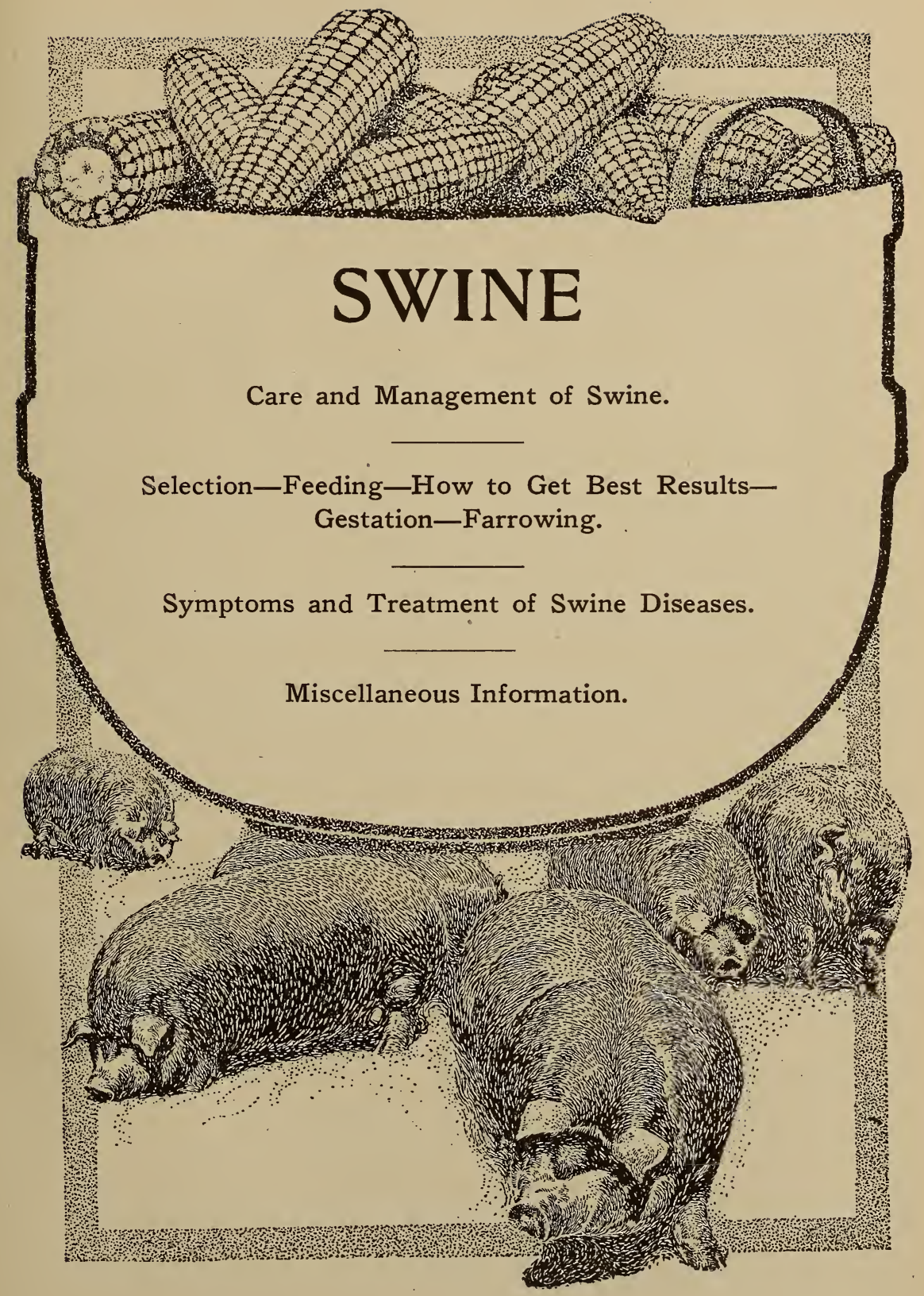




\section{Care and Management of Swine}

\section{SELECTION.}

No money can be made by selecting a half-wild breed of hogs. Nor can success be achieved by selecting a good breed and starving the hogs or allowing them to shift for themselves. Hogs of the improved breeds are not so well able to take care of themselves as those of a half-wild breed, but when well cared for, will pay fifty per cent more profit than the other breed, for the grain fed. This is because they are more quiet and assimilate their food more perfectly.

However good the breed may be, care should be taken in the selecting or coupling of animals, otherwise degeneration of the offspring will result.

In the selection of stock for breeding, look first to the constitutional vigor. Without this, no matter what the beauty of form may be, disaster will come to the herd. Next examine the form, with regard to what you require. Then comes the question of early maturity and easy fattening qualities. In all farm animals tractability and quietness of disposition are essential. In swine this is especially so, as on the disposition of the animal largely depends the quality of fattening quickly and easily.

\section{FEEDING.}

The question of feeding swine comes under two heads, viz., that of feeding swine for breeding purposes and feeding for fattening only.

In feeding the breeding animal attention should be given to feeding for a strong constitution, a more active animal, and perfect health. True economy in this will dictate that they have the warmest possible shelter in winter and that they be kept cool in summer, with some place where they can escape from insect enemies. They should have range sufficient for them to exercise their instinct in rooting for such underground vegetation as their nature may require. This promotes health and strengthens their constitution.

These animals which are intended for fattening (and which are the very great per cent. of swine in the country), and whose lives do not extend to beyond 15 months at most, are fattened, ready for sale, within ten months, and do not require this range and exercise.

If the breeding stock have been kept healthy they should transmit health to the offspring, giving them a strong constitution on which to build.

The young pigs should be weaned when about six weeks old, allowing them plenty of skimmed milk and buttermilk, mixing at seven or eight weeks old a fair portion of corn-meal mush, or, better still, light wheat and rye screenings ground together. Give them grass also as soon as they will eat it, and at three months old they may be put on clover. In addition to clover, give the young pigs all the milk and other slops of the house, and also give what corn they will eat. The older pigs will do well on clover and corn without the slops. The summer and early fall is the best season for fattening hogs. The gain during this time will be more rapid than at any other season. In the late fall, winter and spring the hogs should be housed in dry, warm sheds or barns.

The fact should never be overlooked that it requires a certain percentage of the food to supply daily animal waste. The young animal converts into flesh more of the food given than a full grown one; no matter how long the animal is kept, the daily waste goes on constantly. True economy is therefore to feed strong from birth and keep them growing as fast as possible. In this way you shorten the feeding period and get them to market quickly. Do not neglect the hogs. Feed them regularly and often enough so that they will not overeat, as this is apt to cause trouble with the hog as with the human being. 
Further, see that they have plenty to drink. Neglect to furnish abundance of pure water is a common source of loss and favors the outbreak of disease. Impure and germ laden water invites disease.

Hogs which are being fattened are not given their natural exercise, neither are they at liberty to root in the ground, where they could get the roots and herbs necessary to their digestion. They are, therefore, on account of their confined condition, liable to contract disease. To aid their digestive organs and supply them with the proper ingredients to aid in digesting and assimilating their food, they should be given a small amount of stock tonic each day by mixing Dr. David Roberts' Condensed Stock Tonic with linseed meal and giving this to them in their feed.

\section{HOW TO GET BEST RESULTS.}

The care of young hogs is important in getting the results, and "best results" are what every one is striving for. After you have used care in selecting and feeding your hogs, do not lose' the benefit of it by not properly caring for them.

A boar will be ready for service when six or eight months old, but it is better to wait until he is about ten months of age at least. The sow is capable of breeding at seven or eight months old. However, it is better to wait until she is ten or twelve. One litter of pigs per year is enough for the average.sow, although some will raise two. If the sow has a warm place for farrowing, the earlier in the season the pigs are produced the greater will be the profit from them.

\section{CASTRATION.}

Pigs should be castrated at from two to three weeks old. Never delay it later than the age of four weeks. This operation should not be performed in cold, damp weather.

Give your hogs the best 'of care and attention, for without these the finest bred hogs in the land will soon degenerate and become only scrubs.

See Prescription No. 173, page 153.

\section{FARROWING.}

The sow should have a quiet, dry, warm place and plenty of bedding. Rich food should not be fed for a few days before and after farrowing.

\section{GESTATION.}

The average period of gestation in a sow is four months. This varies sometimes several days. Whenever you have a good breeding sow keep her as long as you can, as young sows are often bad mothers. A sow will remain a good breeder for about eight years, unless she becomes overloaded with fat. This should be guarded against.

\section{DISEASES DF SWINE}

Diseases of swine are usually classed as infectious and contagious. The infectious form is known as Epizootic Catarrh. The contagious form usually appears as Hog Cholera, Pneumœnteritis.

In the care of swine the prevention of disease is of the utmost importance. They are indeed subject to comparatively few ailments; but these few are generally of the most serious kind. In such cases the great difficulty is in administering the medicine, as the animals are usually too sick to take it in their feed. For this reason it is much more important to keep hogs in a healthy condition, and prevent them from having disease than it is to treat them after they have been taken sick.

Abortion in sows may be divided into two forms, infectious abortion and accidental 
abortion; either one is a loss and a detriment to the stock owner. It is pretty thoroughly understood that the infectious form is the one which produces the greatest loss. Accidental abortion in sows may be brought on by injuries usually received by sows heavy with pig passing to and from pens or pastures in which there might be sills or boards under gates which they are compelled to either jump over or drag themselves over in this heavy pregnant condition. Infectious abortion may be brought on by breeding sows having a weakened or catarrhal condition of the genital organs to a boar used on all sows. If the boar becomes infected he is then in a condition to infect all sows bred to him.

The treatment for infectious abortion in sows consists in the giving of Breeding Tonic and washing the genital organs of both sow and boar with a solution of Antisepto. The pens should be thoroughly disinfected with Disinfectall.

See Prescription No. 174, page 153.

\section{DIARRHOEA.}

Small pigs are frequently taken with diarrhœa, in which case the pens should be disinfected by thoroughly using the Disinfectall, after which Calf Cholera Remedy should be added to a little sweet milk as directed and given to them.

See Prescription No. 175, page 153.

\section{HOG CHOLERA.}

While there are two forms of Hog Cholera, both are due to germs and the treatment is the same for each. The bowels of the animals may be loose or they may be constipated. In either case the Hog Tonic acts as a regulator, and should be fed the year around.

To prevent the diseases to which swine are subject $\mathrm{Hog}$ Tonic should be giren according to directions. To overcome such diseases as Hog Cholera; the Hog Tonic should be given in a little larger doses, and the pens, floors and in fact everything pertaining to the hog-pen should be thoroughly disinfected by the liberal use of a solution of Disinfectall. Gunny sacks should be dipped in this same solution and hung around the pens.

If one or more animals are attacked, the ones that are apparently well should be removed at once to another pen and the infected pen should be disinfected. In all cases where well hogs have been removed, the balance of them should be kept in a well ventilated, dry pen, and receive the best of care, including medicine, wholesome food, and pure water. If any more of them get sick the hogs that have not yet shown signs of sickness must again be removed to another pen, and so on until the disease has been controlled.

\section{See Prescription No. 176, page 153.}

\section{LICE ON HOGS.}

The hogs should be thoroughly washed with Disinfectall, one to two ounces to a gallon of water. Older hogs can stand it a little stronger. After they have been thoroughly scrubbed with this solution, and a few applications of Diolice have been thoroughly sprinkled in, you will have no further trouble with these pests.

See Prescription No. 179, page 153.

\section{THUMPS.}

Is an ailment due to contraction of the diaphragm and often affects the heart, and is more often noticed in pigs which are afflicted with indigestion.

Treatment consists in giving Hog Tonic to overcome indigestion.

See Prescription No. 177, page 153.

\section{WORMS.}

For worms give Hog Tonic or Worm Powder according to directions.

See Prescription No. 178, page 153. 

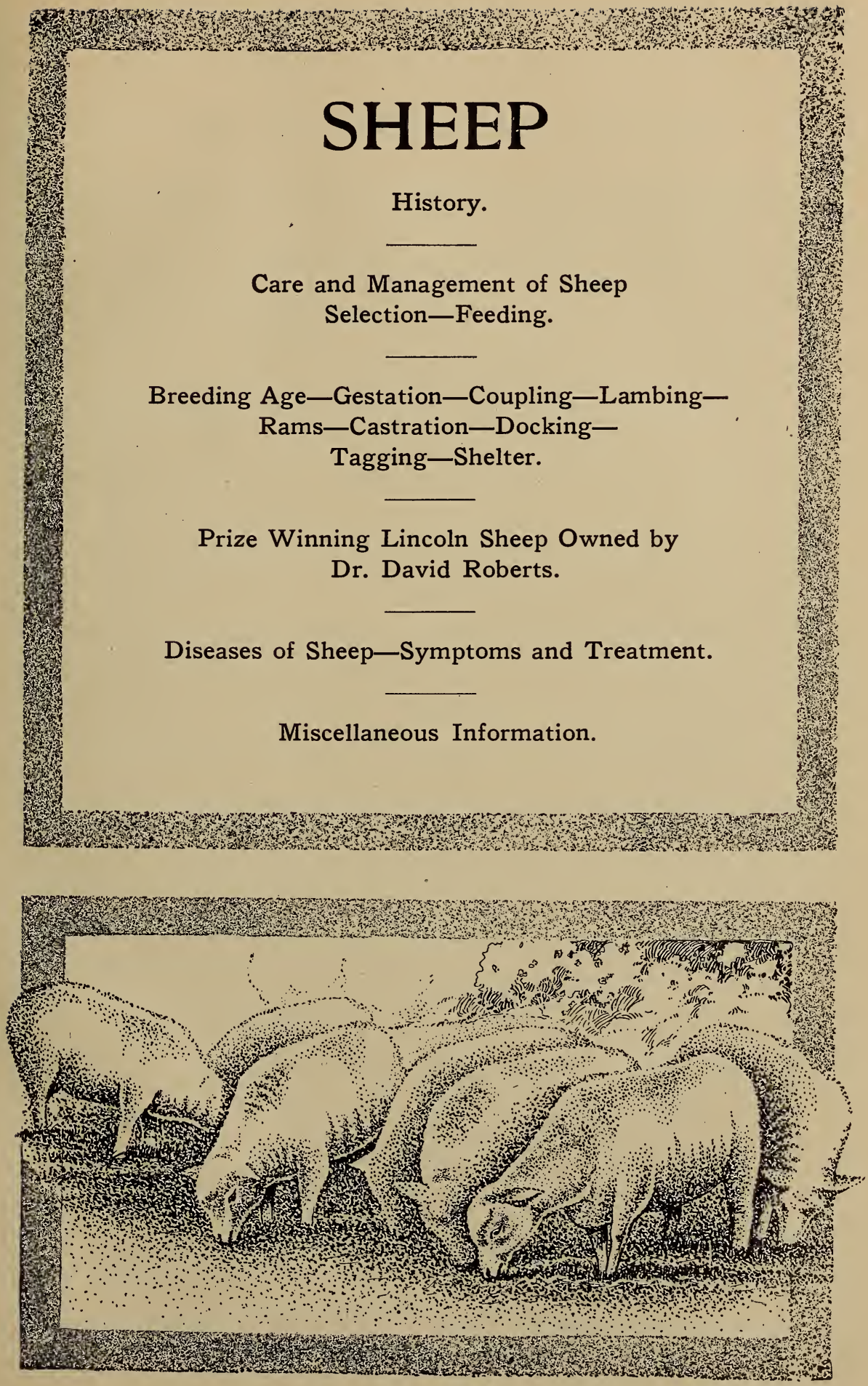


\section{History}

Domesticated sheep were first introduced on the American continent by Spanish discoverers and conquerors. On the second voyage of Columbus to the new world he brought with him some animals with which to stock the island of Hispaniola; among them were some sheep. His live stock was landed about the middle of December, 1493, at Isabella, where was founded the first Christian city of the new world. The vessels that followed from Spain from time to time brought supplies for the Colonies, including in their cargoes sheep which were landed at Hispaniola and Cuba. From these islands sheep were carried to the Isthmus of Panama.

On Cortes' return from Spain to the City of Mexico in 1530, misunderstandings arose between him and the magistrates, and he left the capital, taking up his residence in the City of Cuernavaca, on the southern slope of the Cordilleras overlooking a wide expanse of country. Here he devoted himself to agriculture and the improvement of his estate. Among other live stock, he imported large numbers of Merino sheep, which flourished and increased rapidly on the abundant pastures in the country around Tehuantepec. From these two localities, Panama and the City of Cuernavaca, went forth sheep in large numbers. From these Spanish sheep originated the immense herds in Mexico, New Mexico, Utah and Texas.

Sheep were introduced into the Eastern States by the early settlers, and much attenion was paid to the raising of them. The increase was slow, as there were many difficulties to overcome in caring for them, the principal one being that of protecting the sheep from wolves which abounded in that country in its early settlement. With the approaching of the Revolution more attention was paid to the raising of sheep. A feeling of independence was felt throughout the country, and showed itself in the increase of flocks, that the domestic manufacture might be carried on, and there was an increased demand for homespun garments from those who had usually worn the finer products of the British looms. The press of the country urged upon the population the importance of increasing the number of sheep and improving them by selecting the best and disposing of the poorest, and one who continued to wear a coat made of English material $w$ as not considered a patriot.

The Revolutionary War caused a backward step in the character of the sheep at that date, and also retarded the increase. As large numbers of the citizens were in the army, the flocks were neglected, and many of the sheep were destroyed by the armies. Upon the close of the war many breeders endeavored to improve their flocks by importations from abroad, as well as by giving those which they still had better care and attention. Much was done toward improving the sheep by better care and attention, but as England was too jealous to permit her improved sheep to be exported for the purpose of improving the sheep of the United States, she passed stringent exportation laws which practically prohibited the exporting of any sheep from England. Although means were found for evading this law, yet the number which the citizens of the United States succeeded in importing was but few, and left but a small mark upon the native flocks.

George Washington, after the close of the Revolutionary War, was the first to improve the breed of his native sheep. He usually kept a flock of from seven to eight hundred sheep, and paid particular attention to their care and breeding, fully realizing that to get the most income from his flock they should be kept up to as high a standard as possible. From the time of the Revolutionary War the sheep industry has gradually increased, though it has oftentimes met with reverses of different kinds. 


\section{Care and Management of Sheep}

Constant attention is necessary in the care and management of sheep. They are timid, without self-reliance, an easy prey to dogs. The necessity of keeping them in large flocks causes them to be especially liable to contagious and epidemic diseases. This care and attention should be given from the time the lamb is born. Oftentimes a little attention to a young lamb which is weak will enable it to take on a robust constitution and become one of your best sheep.

\section{BREEDING AGE.}

The proper breeding age for sheep is two years, and may continue until ten years old. From the age of three to eight years the best lambs will be produced.

\section{CASTRATION.}

Lambs should be castrated at from two to four weeks old.

\section{COUPLING.}

November is the season for coupling, but if breeding for mutton or wool it may be later than this, as the lambs will be better if not dropped until after the time for grass. If the object be to sell lambs, the earlier in the season they are produced the more money they will bring.

\section{DOCKING.}

This should be done as soon as they recover from castrating, generally about three or four days afterwards. This should be done with a single stroke of a sharp knife, care being taken to sever the tail at a joint. The skin of the tail should be drawn to the body so that the end will cover the stub. Allow the flock to lie down to keep quiet so that they may lose the least amount of blood possible.

\section{FEEDING.}

Sheep eat a variety of vegetation other than the true grasses and will pick a living on pastures where other stock would starve. They can be turned into rough pastures and where brush is growing and will enjoy eating the nutritious shrubs, brush and tufts of grass, in this way helping to clean up the land while getting a good living. The feeding of grain and other feed to sheep should be taken up early enough in the fall so that they will not fall off in flesh before going into winter quarters. A good allowance of corn, oats and bran should be fed, together with plenty of good, clean hay, clover being preferable. There should also be plenty of good clean water to drink. A trough with salt in should be provided so that the sheep may get it at will.

The general diseases of sheep are as follows:

Distemper or Epizootic Catarrh, Indigestion, and Paralysis or Stoppage of the Bowels. These are forms of disease that are the most troublesome, and need the most prompt attention.

\section{GESTATION.}

Ewes carry their lambs on an average of 152 days. This time may vary a few days. 


\section{LAMBING.}

At lambing time the ewe should be provided with warm quarters so that the lamb may dry off and take the teat as soon as possible. Ewes are very apt to become indifferent to a weak lamb.

\section{RAMS.}

There should be one ram for each one hundred sheep or less. In the beginning of the season do not let the ram serve more than two or three ewes a day, increasing the number as necessity demands. As the season draws to a close, restrict him again, as an exhausted male cannot get strong offspring.

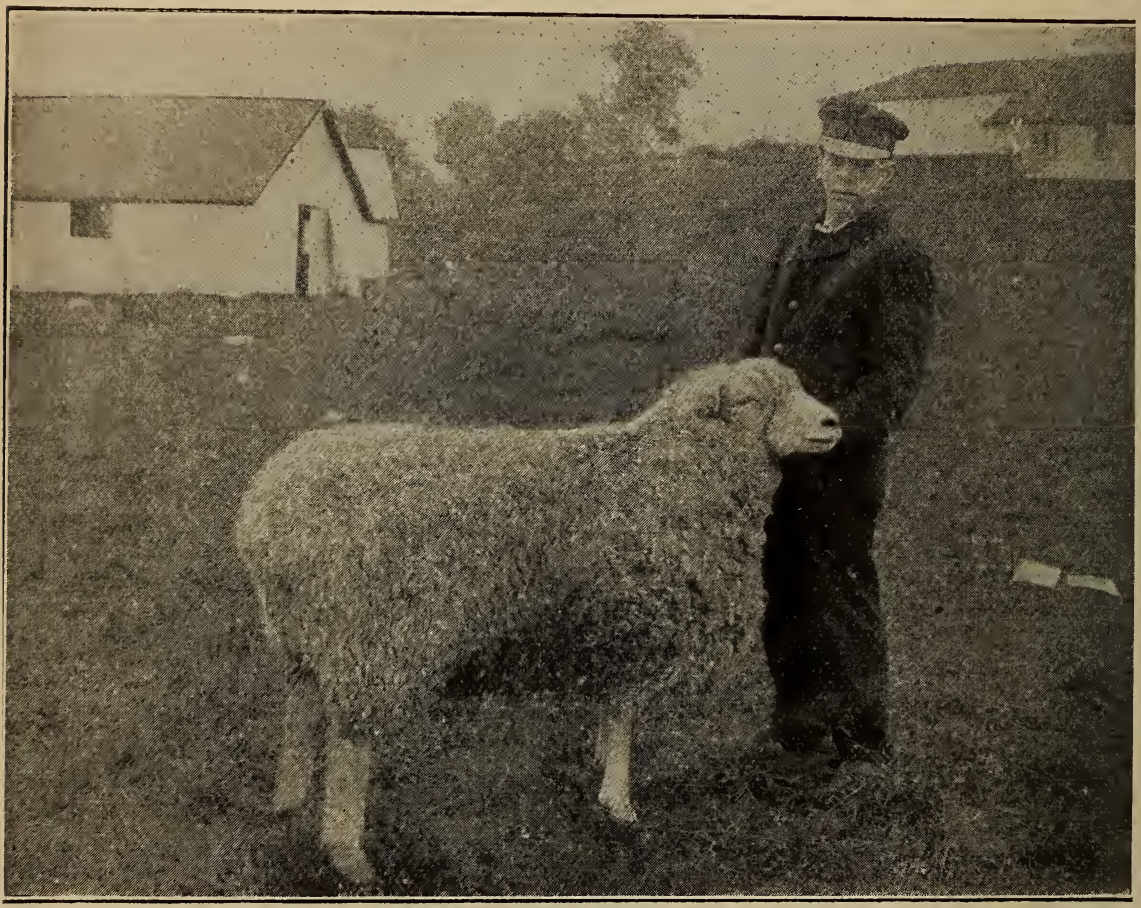

ONE OF OUR PRIZE-WINNING LINCOLN SHEEP.

Dr. David Roberts Veterinary Company exhibited a bunch of Lincoln Sheep at the following State Fairs: Wisconsin, Illinois, Missouri, Minnesota, Indiana, Iowa and Kentucky, and won 57 (fifty-seven) prizes.

6 Championship prizes,

32 First prizes,

18 Second prizes,

1 Third prize.

\section{SELECTION.}

In the selection of sheep for the foundation of a flock the first question to be settled is whether you are going to breed principally for wool or for mutton, and the next is the question of what breed to adopt. In deciding both of these questions your own inclinations should be considered, for you are apt to be more successful when your own inclinations are followed, as more interest will be taken. It is also advisable 
in deciding these questions to study up on good authorities the sheep industry and also to seek the advice of some well posted sheep raiser who has had experience in handling sheep.

After these questions have been settled, the selections of the individuals follow. In this the same as with other stock, only strong, healthy, vigorous animals should be used for breeding. When you succeed in raising a particularly fine animal, one which shows the best points, keep that animal for your own use in breeding and dispose of some not as good in quality. By following this rule you will soon have a fine flock of vigorous and healthy sheep.

\section{SHELTER.}

Sheep barns or sheds need not be expensive structures, as it is only necessary to provide shelter that will keep out wind and water, and at the same time admit of proper ventilation. About three to three and one-half square feet of shed room should be allowed for each sheep. Sheds opening to the south are preferable, as they provide the most protection.

By giving your sheep such care and attention as they need, together with good feed and breeding, they will produce wool and mutton of the best quality, and in large quantities, and be a flock in which their owner will take much pride.

\section{TAGGING.'}

This is important and should be performed as early in the spring as possible, certainly before the sheep are turned to grass.

\section{DISEASES OF SHEEP}

\section{DISTEMPER.}

In Distemper, there is a slight watery discharge from the nostrils and eyes-there is a depression and more or less loss of appetite. The breathing is not changed unless the bronchial tubes are affected; the animals seldom cough. At the end of a week, unless the animal gets relief, the discharge from the nostrils becomes thick and puslike, and sometimes tinged with blood. The eyes are half closed and the lids are gummed with a yellow secretion. There is a loss of appetite, and the animal will die unless promptly treated.

\section{TREATMENT.}

Immediately upon noticing the first animal affected with Distemper, the entire flock should promptly receive Sheep Tonic as a preventive treatment. The Sheep Tonic should be thoroughly mixed with their salt, and placed in a sheltered trough, to which they may have free access. No salt should be given in any other form during the treatment. A solution of Disinfectall (one oz. to a gallon of water) should be used to sponge out their eyes and nostrils. The sheds should be thornughly disinfected ( $2 \mathrm{oz}$. Disinfectall to a gallon of water). Gunny sacks dipped in this solution should be hung around through the sheds, and a sack half full of shavings saturated with Disinfectall (full strength), and hung over the sheep, is of great benefit in such cases.

Sic Prescription No. 180, page 153. 


\section{GRUBS IN THE HEAD OF SHEEP.}

This is caused by the eggs of the gadfly being deposited in the nostrils of the sheep in July and August. From the nostrils they find their way (in a maggot form) through the sinuses, causing much pain. When the gadflies are seeking the sheep the animals will crowd together with their noses to the ground, stamping violently at times, and will run from one place in the pasture to another. When the maggots reach their resting place they attach themselves by their hooks and are easily dislodged.

TREATMENT.

Treatment consists of an operation which none but a competent veterinarian should attempt, and as this is not practical excepting upon valuable sheep, it is for this reason that a more simple and cheaper treatment is required, which consists in giving the sheep, which are usually in a nervous, run-down condition, the Sheep Tonic and the dipping of gunny sacks and hanging them just above the heads of the sheep and thoroughly spraying the sheds with a strong solution of Disinfectall.

See Prescription No. 181, page 153.

\section{INDIGESTION.}

Give Sheep Tonic according to directions and medicate all salt given.

See Prescription No. 182, page 153.

\section{INTESTINAL WORMS.}

The presence of intestinal worms is seldom known to the ordinary observer, until after the death of a sheep. They can be detected by a post mortem examination. If worms are found in this one animal, the presumption is good that other sheep are seriously infected.

\section{TREATMENT.}

Mix the Worm Powder thoroughly, according to directions, with their salt, and place in sheltered troughs where they may have free access to same. They should not receive salt in any other form.

See Prescription No. 183, page 153.

\section{LUNG WORMS.}

These worms are usually found in wind-pipe, or bronchial tube, and sometimes in the lungs. They are small, thread-like, and long.

There will be a husky cough, rapid breathing, loss of appetite and flesh. The sheep will rub their noses on the ground. There may be dysentery, with a bad smelling odor.

\section{TREATMENT.}

Give the Worm Powder according to directions, in the salt or in a little feed. Disinfect the sheep pens thoroughly with a strong solution of Disinfectall (2 oz. to a gallon of water). Gunny sacks dipped in the same solution should be hung around the pens, and a half sack of shavings saturated with Disinfectall (full strength) should be hung around at different points, over the sheep. The breathing of this medicated air destroys the worms. The sheep should receive good, nutritious feed, both during and after the treatment.

See Prescription No. 184, page 153. 


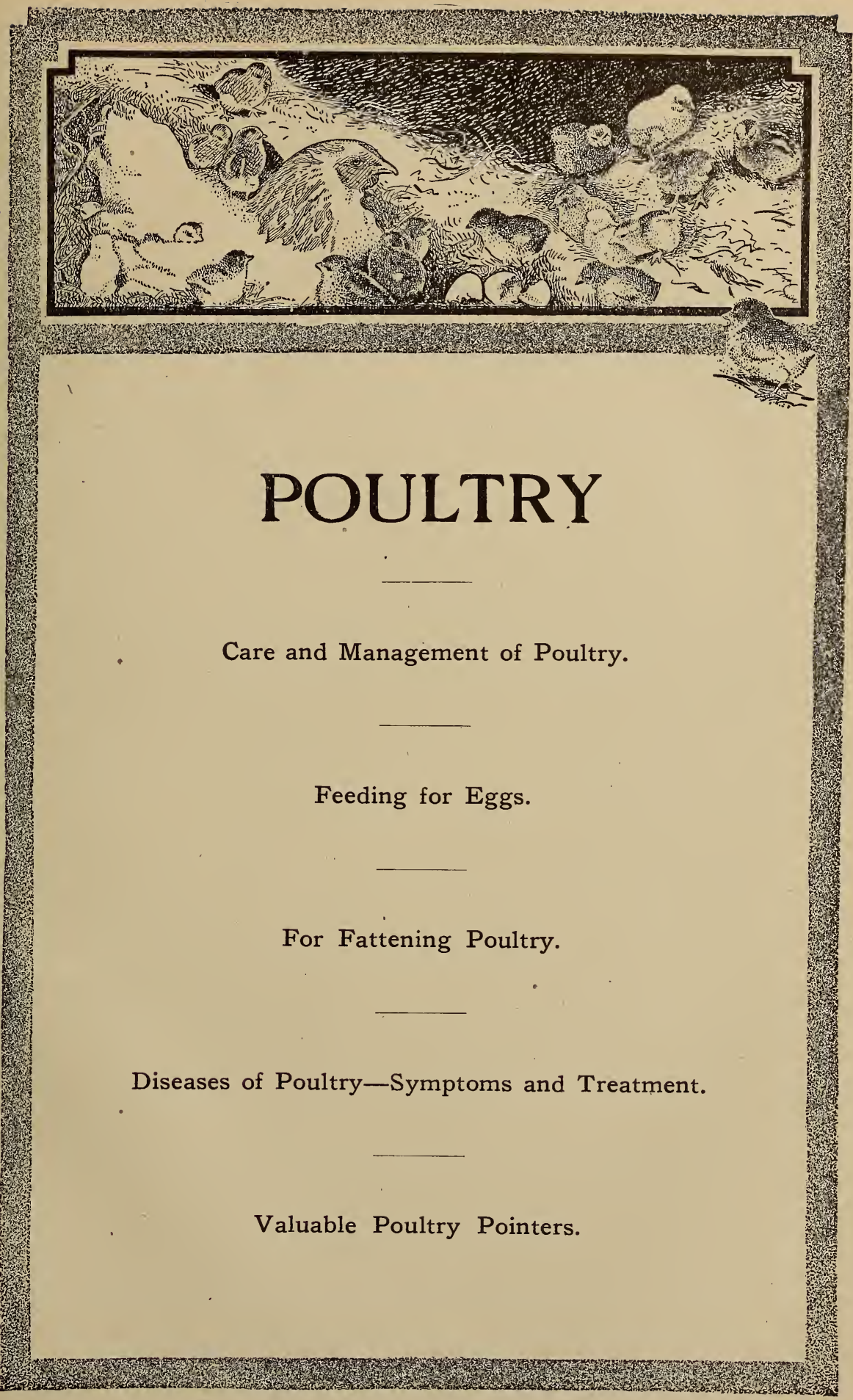




\section{Care and Management of Poultry}

STANDARD WEIGHT.

\begin{tabular}{|c|c|c|c|}
\hline $\begin{array}{c}\text { Cock } \\
\text { lbs. }\end{array}$ & $\begin{array}{c}\text { Cockerel } \\
\text { lbs. }\end{array}$ & $\begin{array}{l}\text { Hen } \\
\text { lbs. }\end{array}$ & $\begin{array}{l}\text { Pullet } \\
\text { lbs. }\end{array}$ \\
\hline Light Brahma ............. 12 & 10 & $91 / 2$ & 8 \\
\hline Dark Brahma and All Cochins....... 11 & 9 & $81 / 2$ & 7 \\
\hline Langshan $\ldots \ldots \ldots \ldots \ldots \ldots \ldots . \ldots \ldots$ & 8 & 7 & 6 \\
\hline Javas and and Plymouth Rocks....... $91 / 2$ & 8 & $71 / 2$ & $61 / 2$ \\
\hline All Wyandottes ................. $81 / 2$ & $71 / 2$ & $61 / 2$ & $5 \frac{1}{2}$ \\
\hline American Dominique $\ldots \ldots \ldots \ldots \ldots$ & 7 & 6 & 5 \\
\hline Bull Orpingtons $\ldots \ldots \ldots \ldots \ldots \ldots 10$ & $81 / 2$ & 8 & 7 \\
\hline Minorcas and Spanish $\ldots \ldots \ldots \ldots \ldots 8$ & $61 / 2$ & $61 / 2$ & $51 / 2$ \\
\hline Aandalusians $\quad \ldots \ldots \ldots \ldots \ldots \ldots \ldots$ & 5 & 5 & 4 \\
\hline Rhode Island Reds............. $81 / 2$ & $71 / 2$ & $61 / 2$ & 5 \\
\hline
\end{tabular}

\section{SELECTION OF BREEDS.}

For meat: Brahma, Cochins and Langshans.

For general purpose: (Meat and eggs combined.) Plymouth Rocks, Wyandottes, Rhode Islands Reds and Orpingtons.

For eggs: Leghorns, Minorcas, Hamburgs or any of the smaller active breeds.

\section{CARE AND MANAGEMENT.}

To be on a paying basis, poultry must be properly managed. This latter clause covers many essentials, viz.:

1. Suitable quarters.

2. Healthy conditions.

3. Proper feed.

4. Correct feeding.

\section{LOCATION OF POULTRY HOUSE.}

The Poultry House should always be so situated that it has good drainage, a South or Western slope being preferable. It should be well lighted and ventilated. Windows should be placed not to exceed eighteen inches from the floor. Nests and roosts should be made removable, so they can be taken out and thoroughly cleaned. The proper size for roost is $2 \times 2$ timbers with the uppermost corners rounded. And the best plan is to construct dropping boards under your roosts, easy of access so they may be cleaned out every morning. A box for dust bath should be placed in one corner and kept filled with ordinary road dust, as this is one of the best materials obtainable for the purpose.

If possible, have a scratching shed in connection with your poultry house, otherwise keep the floor of your poultry house covered with some kind of litter. One of the best and most serviceable houses constructed is built by using $2 \times 4$ timbers for the frame, covering inside and outside with building or tar paper and then using ship-lap or tongue-and-groove siding, giving you a dead air space of four inches as a protection against frost. 
Mix the above with warm water or milk (not hot) until it becomes a crumby mass, not sloppy.

Use one gallon of the mash for every twenty-five fowls, and to this amount add two tablespoonfuls of Poultry Tonic, mixing same with mash thoroughly, before the water or milk is added.

Do not feed too much mash. While chickens are eating their mash scatter some oats in their scratching shed or litter.

At noon, feed wheat. In the evening feed corn. All grain should be fed in litter so as to encourage exercise. This is one of the essentials, as exercise gives a good appetite. Keep plenty of grits and fresh water constantly before the poulry.

\section{FOR FATTENING POULTRY.}

To fatten an animal or fowl, one must furnish a feed that is rich in carbohydrates and fat, instead of being rich in protein, as carbohydrates and fats are changed to fat whenever the fowl is fed more than enough to keep it warm and keep it strong enough to perform the work it has to do. This being the case, a fowl should be kept inactive as much as possible, so the food will go to fat instead of bone and muscle.

Here is a good morning mash for fattening: Equal parts of oat meal and corn meal, mixed with sweet milk. Feed all they will eat up clean. To every gallon of the mash, add one tablespoonful of Poultry Tonic, and one-fourth pound cheap sugar.

Feed cracked corn at noon, whole corn at night. Place fowl in slat bottom coop, that can be darkened with a curtain of some sort. Have a trough to place all the food in.

\section{FEEDING TURKEYS.}

Raising young turkeys is considered one of the most difficult things in poultrydom. But with Poultry Tonic this is made easy.

The first day's food should be the yolks of hard-boiled eggs, sprinkled with a small amount of Poultry Tonic. After this period feed up to the tenth week as follows: Make cottage cheese from sour milk-make it dry. Mix one tablespoonful of Poultry Tonic to every pint of the cheese. Feed cheese mornings and noon, and hulled oats at night.

In the summer time poultry get bugs, insects, worms, grass, etc. In the winter time, Poultry Tonic supplies all these elements in a concentrated form. To prevent diseases and avoid loss, feed Poultry Tonic the year round.

"An ounce of prevention is worth a pound of cure." This is an old axiom and nowhere is it more applicable than in the poultry yard. Disease is usually the result of carelessness or lack of knowledge of how to care for poultry properly. Bear in mind, if our foregoing system is followed, there will be no disease.

\section{POULTRY DISEASES}

\section{CATARRHAL OR DIPHTHERIC ROUP.}

Make a solution of one part of Disinfectall and two parts water (one drop to the ounce), and wash head, eyes, nostrils and throat thoroughly. Then apply Dr. David Roberts' Roup Cure by rubbing same into the nostrils, over head and comb, and well into the mouth. Feed nourishing soft food, reduce corn and increase meat foods. In order to effect a permanent cure, one must use a good tonic in connection with the above treatment. The best tonic extant is made by taking equal parts of wheat flour and Poultry Tonic, mixing same with just enough water so you can form it into pills about 
the size of a large pea, and administer one or two of these pills three times a day until a cure is effected.

See Prescription No. 185, page 153.

\section{BRONCHIAL ROUP.}

Take a tail or wing feather, strip the web from it excepting just at the point. Dip feather into some Roup Cure, insert feather into the trachea (wind pipe) and give a quick turn. This is a delicate operation, but if you are careful there is no danger.

See Prescription No. 186, page 153.

\section{CANKER.}

Associated with Roup, the symptoms being similar and the treatment is the same.

SYMPTOMS.

A cheesy matter collects on the tongue, roof of the mouth and around the opening of the windpipe. Fowl usually breathe with mouth open.

\section{TREATMENT.}

Apply Disinfectall direct to the canker with a small brush or feather. Feed same as for Roup.

See Prescription No. 187, page 153.

\section{CHICKEN POX.}

Caused by neglect or improper feed.

\section{SYMPTOMS.}

Small bunches of hard substances appear just under the skin on the comb, face and wattle, and in a short time they exude a liquid matter which dries and gives the head a scabby or scaly appearance.

\section{TREATMENT.}

Feed same as for Roup. Wash affected parts with a solution of one part of Disinfectall to nine parts of warm water, dry with a cloth and apply Roup Cure.

See Prescription No. 188, page 153.

\section{CHOLERA.}

This disease is very often seen among poultry, although many diseases are diagnosed as such. The cause of 'this disease is filth. It is one of the most contagious diseases. At the first appearance of Cholera one should kill and burn the fowl to check spread of the disease.

\section{SYMPTOMS.}

Fowl has at first a watery discharge from the bowels, lacking in color as the hours go by. The bird sits around with its feathers ruffled, head and neck drawn up close to the body, eyes closed, is very feverish and thirsty. It is inclined to remain standing just where it is. As the disease increases in violence the discharge increases, and the ability of the bird to move decreases.

\section{TREATMENT.}

Put one tablespoonful of Cholera Cure to every quart of mash, feed twice a day until all symptoms of the disease disappear. If the fowl is unable to eat, make pills 
of the Cholera Cure by dampening it and administering one every four hours until a cure is effected. Follow up after a cure is effetced by using Poultry Tonic in your regular feed.

See Prescription No. 189, page 153.

\section{GAPES.}

This is a parasitic disease prevalent among chicks. The worm that causes the disease is hatched from an egg containing embryo, and they attach themselves to the lining of the windpipe. They live and flourish until they become so numerous as to choke the chick, if nothing is done to hinder their progress.

\section{SYMPTOMS.}

The chicks go around with their mouths open, gasping for breath and making a gasping noise. Feed Poultry Tonic to your chicks and keep them free from lice, and they will never have Gapes. In case the chicks already have them, use the same treatment as for Bronchial Roup.

See Prescription No. 192, page 153.

\section{CROP BOUND.}

Impaction of the crop is a condition known to many poultrymen. This is caused by the retention and swelling of grain by the accumulation of dead gases or by some obstruction of the outlet of the crop. It is also caused by poor digestion, and occasionally a bird has had a fast, then when allowed all it will eat it stuffs its crop to the utmost capacity.

\section{SYMPTOMS.}

Swelled crop. Fowl stretches its neck occasionally as though choked or trying to swallow.

\section{TREATMENT.}

Take ordinary baking soda (saleratus), dissolve a tablespoonful in one pint of warm rain water, flush crop by pouring the water down the fowl's throat. Knead crop gently between thumb and finger until the mass is broken up. Tie fowl by feet, lay its head downward, hold mouth open, work crop gently, and in this manner the crop may be emptied. In extreme cases, the knife must be resorted to, and when this is done the incision should be as high up as possible. After the mass is taken out, the opening should be sewed. Feed nothing but soft feed for eight or ten days, and a mixture of Poultry Tonic. It is a rare case when the fowl dies from the operation.

See Prescription No. 190, page 153.

\section{DIARRHOEA}

In chickens and adult fowls is caused from too coarse food, filthy water, improper temperature, etc.

\section{SYMPTOMS.}

Discharge or looseness of the bowels.

\section{TREATMENT}

Use Cholera Cure as prescribed for Cholera, using half the amount for chicks.

See Prescription No. 191, page 153. 


\section{LEG WEAKNESS.}

Caused from in-breeding, lack of nourishing food, overcrowding, damp quarters and sometimes from too wide a perch to roost upon.

\section{SYMPTOMS.}

Unsteady gait. Bird will attempt to walk and topple over, either forward or backward, and in advance stages is wholly unable to walk. The feet and legs become feverish and dry.

\section{TREATMENT.}

Rub legs with Oil of Camphor and add fifteen grains of Iodide of Potassium to every quart of drinking water. Feed nourishing food, containing double the amount of Poultry Tonic that is usually given.

See Prescription No. 193, page 153.

\section{LICE.}

These pests are the cause of more deaths among poultry than any disease. In fact, they are the cause of many of the diseases and ailments among poultry. One must wage a constant war against vermin to keep the fowls free from them.

To keep the fowls free from vermin the following method should be followed: To every gallon of whitewash add one-fourth pint of Disinfectall. Whitewash inside of poultry house and nests. Use Disinfectall in its purity on the roosts and dropping boards. Apply same with a paint brush or spray pump. Dust the poultry thoroughly with Diolice Powder, and the most effective way of doing this, if you have no machine, is to place fowls' legs between your knees, the head toward your body, raise the feathers with your left hand and dust the powder with right, being careful that the powder gets to the skin.

To keep the air pure and healthful in your poultry house all the time, fill a burlap bag with shavings or excelsior thoroughly saturated with Disinfectall and hang the same in poultry house.

See Prescription No. 194, page 153.

\section{MOULTING.}

This is not a disease, but may be touched on just here. This change takes place once a year and if properly cared for, poultry will begin to moult in late summer. Then by early winter they will be through, and will have their entire coat of new feathers, and be ready to start in on their winter lay of eggs. This is a vital period for the hen, and it is important that she should be fed Poultry Tonic, as there is nothing better to aid in the growing of new feathers.

See Prescription No. 195, page 154.

PIP.

Caused by the fowl being in a feverish condition.

\section{SYMPTOMS.}

The tongue becomes very dry and parched, the point of it becoming almost like horn.

\section{TREATMENT.}

Give fowl two drop dose of tincture of aconite every two hours until the sixth dose has been given. Use same treatment in connection as prescribed for Diphtheric Roup.

See Prescription No. 196, page 154. 


\section{ROUP.}

This is a disease that comes from sudden changes of the weather or may be due to birds being exposed to drafts. It may be the result of hereditary tendencies, overcrowding, contagion, filth, etc.

There are several forms of Roup, known as Catarrhal, Diphtheric, Cankerous, Bronchial and Pulmonic.

\section{SYMPTOMS.}

Sneezing, discharge at the nostrils, difficult breathing, wheezing, rattling in the throat. Any one or several of these symptoms may be present, accompanied by a bad odor about the nostrils or mouth. Fowls thus affected want to sleep most of the time with their heads under the wings.

\section{TREATMENT.}

All birds affected as above should be separated from the rest of the flock and the premises should be given a thorough cleaning and disinfecting. Especially should the drinking vessels and feed troughs be carefully attended to. To prevent the spread of the disease, use a teaspoonful of Disinfectall to every gallon of drinking water, also use Poultry Tonic, giving twice the amount prescribed for ordinary use.

See Prescription No. 197, page 154.

\section{SCALY LEGS.}

Caused from a small parasite propagated by filth, burrowing under the scales on the legs.

\section{SYMPTOMS.}

Legs are very rough and unsightly.

\section{TREATMENT.}

Apply kerosene to the affected parts, then anoint with lard or vaseline.

\section{WORMS.}

There are more than a dozen different kinds of worms that infest domestic fowls, yet there are but three that are common enough to warrant suggesting means of getting rid of them. They are the tape-worm, round-worm and pin-worm. The tapeworms are jointed, the same as are found in man, only much smaller. They have small hooks arranged so that they cling to the wall of the bowels and thus subsist on the nourishing elements of the food found there. Round-worms take their name from their appearance. They are seldom passed in the droppings. They multiply very rapidly and are often present in great numbers. Pin or thread worms are very small, being about the size of a thread, white in color, and from one-half to one inch in length. These are quite often found in the gizzard, having eaten through the lining and into the gizzard proper.

\section{SYMPTOMS.}

Symptoms of the different worms are essentially the same. Indigestion, sometimes accompanied by looseness of the bowels. Fowls sit around, drawn up, feathers ruffled, comb becomes pale, fowl feverish. The surest sign is where the fowl "goes light," i. e., eats well but seems to gain no weight, and in fact decreases in weight all the time. 


\section{TREATMENT.}

Let the birds fast for twenty-four hours, then feed a bran mash twice a day, to which has been added some Worm Powder for Poultry. Use one tablespoonful to twenty-five head of poultry.

As a preventive, use one-half of the amount once every two weeks.

In extreme cases, coop the bird and do not feed it for twenty-four hours. Make a pill about the size of a pea from Worm Powder, and give to the fowl. Give light feed of bran mash, and in three hours give the bird a teaspoonful of Epsom Salts dissolved in water.

See Prescription No. 198, page 154.

Do not overfeed.

\section{POULTRY POINTERS.}

Vermin, filth and lice propagate disease.

Diolice keeps out vermin.

Always dust a hen thoroughly with Diolice before setting her on eggs.

Supply your poultry with green food in winter, by feeding cabbage, beets, rutabagas, etc.

Feed a variety. Your poultry tire of one food, just the same as you do.

See that all the cracks in your poultry house are stopped up before winter sets in, as the draft from a nail hole will do more damage than an open window.

Roup Cure is a positive cure for Roup, Canker, Cold, etc. filled.

Supply your poultry with plenty of fresh water, good grits, and keep dust box well feeding.

Clean your poultry house every morning, if possible, and be systematic in your

Cholera Cure never fails.

Keep the poultry house sweet and clean by the use of Disinfectall. 



\title{
How to Make Your Own Stock Tonic at Home
}

\author{
B y D R. D A V I.D R O B E R T S \\ Cattle Specialist
}

The Originator of Condensed Stock Tonic.

\section{IMPORTANCE OF HEALTHY STOCK.}

It is a well-known fact that successful stock raising and dairying depend entirely upon the health and condition of your animals. If they be in a strong, healthy condition this is evidence that they are digesting and assimilating all the feed that they consume. A milch cow requires a certain percentage of the feed she eats to sustain her, the balance should go to the milk pail. This will be the case if she is in a good, healthy condition and digesting and assimilating her feed.

\section{NATURE'S CARE OF THE COW.}

A cow at pasture depends entirely upon nature to supply and regulate her feed and it is during this season of the year that a cow produces the greatest amount of milk. This is because she is furnished with such ingredients as are required by nature to perfectly digest and assimilate her feed. She can only receive the feed that nature has provided for her, in its natural condition, during the grass season.

\section{COW UNDERGOES GREAT CHANGE.}

At the close of the grass season the cow is compelled to go into winter quarters, thereby, undergoing a great change as to sunlight, fresh air, water, exercise and feed. While being in her winter quarters she is to a certain extent deprived of sunlight, and sometimes fresh air. She is usually watered at stated intervals. While at pasture she can partake of water in such quantity and at such time as she desires, the temperature of which is regulated by nature. This is a great advantage over the ice cold water which she is oftentimes compelled to drink or go without until the following day, at which time she is so thirsty that she is apt to partake so freely of cold water as to cause a chilling of the digestive organs, thus causing indigestion. Another common cause of indigestion is the lack of exercise. During the winter months, while a cow is shut in the stable so much of the time, it is impossible for her to get the exercise which it is her nature to have and which she gets during the summer months, while going to and from and roaming in the pasture while hunting her feed. The last and greatest cause of indigestion is the great and complete change that the cow is compelled to undergo, when required to change from the feed which nature provides in its natural form to the dry, fibrous and hard to digest fodders, which it is necessary that she be fed upon, not only to sustain her, but also to make a profit for her owner.

\section{A WINTER PROFIT PRODUCER.}

If a cow during the winter months can be made a profit producer, it can only be done by furnishing her with something to stimulate her digestive organs and keep them 
in a healthy zondition, so that she may thoroughly digest and assimilate the feed that she eats. This san be done by adding to her regular ration such ingredients as she may need to tone up her system and thereby furnish her with a substitute for nature. A cow can produce more by receiving little feed and digesting it well, than by receiving lots of feed and only digesting part of it.

\section{MAKE YOUR OWN STOCK TONIC.}

A good Stock Tonic can be prepared at home at very small cost and fed to a herd so that the saving of feed will pay for the Stock Tonic, and the increase in milk and the health of the herd will be clear gain, the latter being a very essential and important thing to consider. If this alone $w$ as the only benefit derived by feeding the Stock Tonic, it would be considered a good investment. This stock food and Tonic is not only a bone and muscle builder, a flesh and milk producer, but is also valuable as a health preserver and a preventive of disease.

\section{ONE DISEASED COW ENDANGERS THE WHOLE HERD.}

It is a well-known fact that a cow in a run-down condition is a hotbed for the germs of disease to lay hold on and multiply, not only becoming a dead loss to the owner, but endangering the health of the whole herd. From this source many infectious diseases originate in herds and in this manner cause great loss to the owner.

\section{A COW'S YEARS OF USEFULNESS PROLONGED.}

Every dairyman owes it to himself to see that his cows are kept up to the highest point of productiveness. He should not be satisfied with the amount of milk that he is getting from a cow until he knows that she cannot be made to give any more. A cow can be kept up to her highest point of productiveness for many years, provided she digests and assimilates her food; on the other hand, when she fails to properly digest and assimilate her food her years of usefulness are very much shortened. A cow is similar to a machine, the more you feed the more she produces, the better care she receives, the longer she lasts-this Tonic to a cow is as oil to a machine. Therefore, when you have a good cow, why not take proper care of her and make her last for years in service instead of neglecting her, thereby shortening her period of usefulness, making it necessary to replace her with another cow which you are not sure is going to be a profit producer? In replacing a neglected cow which might otherwise be good for many years you are not only taking chances on getting a profit producer, but you are also taking chances on introducing into your herd, with every new cow you buy, diseases which might cause you great loss.

\section{DISPOSE OF NON-PROFIT PRODUCERS.}

If you have a number of cows in your herd which have passed the years of usefulness, dispose of them and give the balance of your herd the attention necessary to enable them to give the richest, highest test and largest flow of milk that it is possible for them to produce.

In disposing of the cows in your herd that have proved themselves to be non-profit produces and those that have passed their years of usefulness, and bringing the balance of your herd up to the highest degree of productiveness you are getting and saving all the profits from your herd, instead of putting part of the profit back in feeding and caring for the cows that have proved themselves to be non-profit producers, and those 
HOW TO MAKE YOUR OWN STOCK TONIC AT HOME.

that have passed their age of usefulness. A few cows well kept are more profitable than a larger number poorly kept.

\section{QUICK MONEY IN BEEF.}

Beef cattle should be given such attention as to cause them to fatten quickly, shorten the feeding period and produce the highest and best grade of beef that is possible to be produced. To obtain these results the best of attention should be given to them and such ingredients added to their feed as to cause perfect digestion and assimilation, thus enabling the animal to obtain a larger per cent. of flesh and fat-forming elements from a certain amount of grain.

\section{HEALTHY INDIVIDUALS.}

To be successful in the breeding of cattle, and especially show cattle, much attention should be given in order to produce strong, robust, healthy, superior individuals. In order to expect this the calf from the moment that it drops should receive proper care and such food as will be digested and assimilated so as not to overtax the digestive organs. To avoid this, such ingredients should be added to the feed as will aid digestion and assimilation, thus causing rapid development of bone and muscle and the result will be a perfect animal.

\section{PROFIT SAVED.}

Profit can be made easy and saved by the regular use of a good Stock Tonic, in the form of a pure, unadulterated Stock Tonic, which you can make at home and know positively that it is absolutely pure.

\section{WHERE YOUR PROFITS GO.}

All the bulky portions of Stock Tonic are products of the farm. You raise these products and sell them to your buyer; he then in turn sells them to the large grain dealer at a profit. The large grain dealer sells to the buyers for the different mills at a profit. In these mills your products are ground up, sold and shipped to the Stock Tonic factories at a profit, where it is medicated, then put up in packages and pails and labeled Stock Tonic. It is then sold to the wholesaler at a profit. The wholesaler sells to the retailer at a profit, and you buy from the retailer, paying him a profit. You, being the consumer, must pay all these different profits, together with all freight charges. These freight charges, where the goods are shipped so many times, amount to considerable, for each time that the goods change hands a new freight charge is made and they are most all made for short hauls, and you well know that a number of short haul charges amount to more than one single long haul.

\section{HOW TO SAVE YOUR PROFIT.}

You can save the middleman's profit and the freight charges from one dealer to another on your products and back to the farm by buying your ground flaxseed from your home dealer in such quantities as to assure you of getting it at a reasonable price, or better still, buy or raise your own flaxseed and grind it yourself if you have a mill; if not, have it ground at your nearest home mill. You are then sure that you are getting the very best and purest ground flaxseed meal that can be had. By adding to this ground flaxseed meal such roots, barks, herbs and seeds as nature demands for stock, you have a complete and perfect tonic in the form of a pure Stock Tonic. By feeding this Stock Tonic to your cattle in small quantities with their regular feed you will keep their 
digestive organs in good condition, so that they can thoroughly digest and assimilate their feed, which will enable them to produce you a profit and also to keep in a sleek, healthy condition. This when given to a milch cow will cause her to give the richest and greatest flow of milk that it is possible for her to give.

When given to beef cattle with proper feed it will enable them to obtain a larger percentage of flesh and fat-forming elements from a certain amount of grain, causing them to fatten quickly, thus shortening the feeding period and producing the highest and best quality of beef possible to be produced.

If you are in the breeding business, not only the prices which you can demand, bur also your sales depend upon the strong, robsut and healthy appearance of your stock.

\section{HOW TO MAKE YOUR OWN STOCK TONIC AT HOME.}

To prepare your own Stock Tonic at home, it is only necessary for you to have the medical parts (such as powdered roots, barks, herbs and seeds) to mix with the ground flaxseed meal. These powders we can furnish you at the lowest cost and with a perfect guarantee of purity.

We buy our roots, barks, herbs and seeds direct from the drug mills in large quantities, thereby getting the very lowest prices possible. They are shipped direct to our factory under a positive guarantee that they are absolutely pure. They are then carefully and scientifically mixed and placed in sealed cans, the contents of which we guarantee to be absolutely pure. This is the ConDENSED STOck Tonic, by the use of which you are enabled to make an absolutely pure Stock Tonic.

\section{DIRECTIONS FOR MAKING YOUR OWN STOCK TONIC.}

Dr. David Roberts' Condensed Stock Tonic, 2 pounds.

Ground Flaxseed Meal, 25 pounds.

Place such amount of Ground Flaxseed Meal as you wish to use in large shallow box, spread over it the Condensed Stock Tonic, in the proportion of 2 pounds to each 25 pounds of Ground Flaxseed Meal. Then with a hoe or shovel turn back and forth five or six times, or until the Condensed Stock Tonic is thoroughly mixed with the Ground Flaxseed Meal.

\section{DIRECTIONS FOR FEEDING YOUR OWN STOCK TONIC.}

For milch cows-Give two tablespoonfuls twice daily in feed of any kind.

For fattening steers or show cattle-Give two or three tablespoonfuls twice daily in feed.

For raising or fattening calves-One teaspoonful twice daily in feed or milk.

For horses-Give two tablespoonfuls twice daily in feed of any kind.

For brood mares-Give two or three tablespoonfuls twice daily in food.

For colts-Give one or two tablespoonfuls twice daily in feed.

For hogs-For every pig of 50 pounds or less give one teaspoonful twice daily in feed or milk. For hogs over that weight give one tablespoonful twice daily in feed.

For brood sows, suckling pigs-Give two tablespoonfuls twice daily in feed.

For sheep-Give two tablespoonfuls twice daily in feed.

For fattening sheep-Give two tablespoonfuls twice daily in feed.

This Stock Tonic will aid digestion, increase the flow of milk, save milk in raising calves, keep hogs healthy and fatten them quickly, sleeken and fatten horses. It is a bone and muscle builder and for this reason all young stock as well as matured animals should receive it. 
Calves and pigs receiving skim or separator milk should be given this Stock Tonic, as it aids digestion and prevents scours. Medicate all salts given stock.

Two pounds of Condensed Stock Tonic mixed thoroughly with 25 .pounds of salt and put in troughs in a sheltered place where the cows can have free access to it in passing to and from the pasture will keep them in a healthy condition.

This stock tonic is prepared especially for cattle, but has been used with such good results on other stock that we do not hesitate to recommend its use for all animals.

\section{Successful Stockmen Highly Endorse Dr. David Roberts' Condensed Stock Tonic.}

Stockmen everywhere are warm in their praise of DR. DAVID RoBerTs' ConDENSED STOCK ToNic, which not only has the advantage of greater economy than Stock Tonics of large bulk, but is backed by the reputation of one of the greatest living veterinarians, under whose personal direction it is prepared.

\section{WISCONSIN INDUSTRIAL SCHOOL MAKES TEST-GIVES STRONG ENDORSEMENT.}

We gave your Stock Tonic a fair trial on all our horses and half of our herd of Holstein cows, and the difference between those receiving the tonic and those not receiving it was very marked, the former being very sleek and thrifty. After this experiment we feel we cannot speak too highly of your tónic, and take pleasure in recommending it to all in need of a first-class stook tonic.

Wisconsin IndUSTRIAL School.

Per K. C. Dousman, Supt. Stock Dept., Waukesha.

\section{DROPS ALL OTHER FOODS AND USES DR. DAVID ROBERTS' CONDENSED STOCK TONIC.}

Dr. David Roberts, Waukesha, Wis.

Monroe, Iowa.

DEAR SIR:-Enclosed find draft for which please ship to Prairie City, by freight, one dozen packages of your Condensed Stock Tonic.

After giving your tonic several tests I am ready to recommend it to others. I have used stocks tonics at different times for the past eight years and some of the best I could get, but I must admit I got much the best results from yours. I am feeding nine calves on separator milk and adding your Stock Tonic, and they are doing fine, as good as some that are sucking the cow and no stock tonic.

I have fed it to fattening hogs, to sows and to pigs with excellent results, better than anything I ever tried. I also had a chance to give it a severe test on my horses, especially on our family horse. She got in bad shape, coat of hair was rough, and she was not doing well. I fed her two different makes or stock tonic at different times, but did not help her. Last spring I fed yours to all my horses, her with the rest, and it caused her to shed off and get a nice coat of hair, and get fat so that several of the neighbors mentioned to me how well she was doing now. I used the oil meal to mix with it to save expense. I also mixed your tonic with salt and fed it to my cattle when I turned them out on pure clover pasture that had a good growth and not one bloated. I shall drop all other tonics and use yours. Truly yours,

C. FAhrney. 


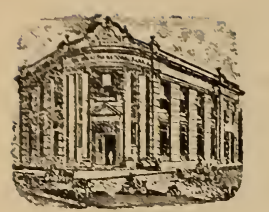

Dr. D. Roberts,

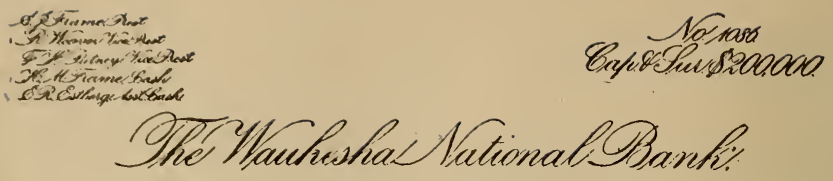

Maureshastlis

Nov. 20 th., 1903.

C1ty.

You ask if you can refer to this Bank in placing before the public

your Veterinary Remedies,

Most certainly you can. One who can concoct remedies which evidentIy gives great relief to the distressed dumo animal, is entitled to be called a benefactor.

Your testimonlals, which I have seen, from stock raisers, not only in the United States, but from Europe as well, are conclusive evidence as to the value of your remedies.

Your record and manly efforts command approbation. If this short letter is of any service to you, then use 1 t. sincerely yours,

ฟ

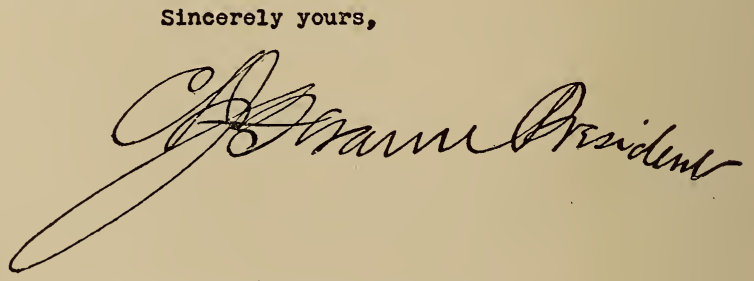

"YOU HAVE STRUCK THE KEYNOTE!"

Dr. David Roberts, Waukesha, Wis.

DEAR SIR:-I have used your Condensed Stock Tonic with highly satisfactory results. Think you have struck the keynote, as there is no chance for adulteration where a stockman buys the ingredients of a stock tonic and mixes them himself.

F. W. Harding. 


\section{PRESCRIPTIONS}

\section{CATTLE}

\section{ABORTION IN CATTLE.}

R No. 1.

Anti-Abortion

Hypodermic Syringe

Antisepto

Disinfectall

Flushing Outfit

AFTERBIRTH-RETENTION

PREVENTIVE.

R No. 2.

Breeding Tonic

AFTERBIRTH RETAINED

R No. 3.

Cow Cleaner

Antisepto

ABSCESS.

R . No. 4.

Antiseptic Poultice

Germ Killer

Healing Oil

Healing Lotion

ANTHRAX.

R No. 5.

Anthrax Vaccine

APPETITE DEPRAVED.

R No. 6.

Cow Tonic

Condensed Stock Tonic

\section{BARRENNESS}

R No. 7.

Breeding Tonic

Antisepto

Flushing Outfit

Womb Sound

Womb Dilator

BLOATING.

R No. 8.

Laxotonic

BLACK LEG.

R No. 9.

Black Leg Vaccine

BLOOD POISONING.

R No. 10.

Germ Killer

Healing Oil

BOILS.

Fever Paste

R No.' 11.

Antiseptic Poultice

Healing Oil

BRONCHITIS.

R No. 12.

Fever Paste

Laxotonic

Cow Tonic

White Liniment
CALF CHOLERA.

R No. 13.

Calf Cholera Remedy.

Disinfectall

CALF INDIGESTION.

R No. 14.

Laxotonic

Calf Cholera Remedy

CONSTIPATION IN CALVES.

R No. 15.

Castor Oil

Laxotonic

CALVING.

R No. 16.

Laxontoic

Umbilicure

CLEANING.

R No. 17.

Cow Cleaner

Antisepto

CASTING THE WITHERS.

R No. 18.

Antisepto

Laxotonic

Cow Tonic

CASTRATING.

R No. 19.

Germ Killer

Healing Oil

CATARRHAL FEVER OR PINK EYE.

R No. 20.

Antisepto

Eye Lotion

Fever Paste

Cow Tonic

Disinfectall

CHOKING.

R No. 21.

Half Pint Raw Linseed Oil

Laxotonic

COLD.

R No. 22.

White Liniment

Fever Paste

Laxotonic

COLIC OR CRAMPS.

R No. 23.

Laxotonic

CONSTIPATION OR STOPPAGE

OF"THE BOWELS IN CATTLE.

R No. 24.

Laxotonic 
COW POX.

R No. 25.

Cow Tonic

Badger Balm

Germ Killer

DEHORNING.

R No. 26.

Horn Killer

or

Dehorning Clipper

Healing Oil

DIARRHOEA IN CATTLE.

R No. 27.

Cow Tonice

Calf Cholera Remedy

EYE DISEASE.

R No. 28.

Antisepto

Eye Lotion

Condensed Stock Tonic

FEVERS.

R No. 29.

Fever Thermometer

Fever Paste

Laxotonic

White Liniment

FISTULAS.

R No. 30.

Germ Killer

Healing Oil

Healing Lotion

Cow Tonic

FOOT DISEASE OR SORE FEET

IN CATTLE.

R No. 31.

Germ Killer

Healing Lotion

Healing Oil

Antiseptic Poultice

FOUNDER.

R No. 32.

Laxotonic

Fever Paste

Antiseptic Poultice

FROST BITES.

R No. 33.

Germ Killer

Badger Balm

GARGET-CAKED

INFECTIOUS MAMMITIS.

R No. 34.

Cow Tonic

Badger Balm

White Liniment

(In severe cases use in addition.)

Antiseptic Poultice

Germ Killer

Disinfectall

GENITAL DISEASE.

R No. 35.

Cow Cleaner

Antisepto

GONORRHOEA IN BULLS.

R No. 36.

Antisepto
GRASS STAGGERS.

B No. 37.

Laxotonic

GRUBS OR WARBLES IN SKIN

OF CATTLE.

R No. 38.

Healing Oil

HARD MILKERS.

R No. 39.

Germ Killer

Teat Plug

Badger Balm

INDIGESTION.

R No. 40.

Cow Tonic

Laxotonic

INFLAMATION OF THE LUNGS. R No. 41.

- Fever Paste

White Liniment

Laxotonic

INFLAMMATION OF THE WOMB.

R No. 42.

Fever Paste

Antisepto

Laxotonic

INFLAMMATION OF THE UDDER.

R No. 43.

Cow Tonic

Germ Killer

Badger Balm

White Liniment

Antiseptic Poultice

INFLAMMATION OF THE TESTICLES.

R No. 44. 。

Germ Killer

Badger Balm

Antiseptic Poultice

Cow Tonic

INFLAMMATION OF THE TONGUE.

R No. 45.

Fever Paste

Antiseptic Poultice

INFLAMMATION OF THE JOINTS.

R No. 46.

Germ Killer

Badger Balm

Antiseptic Poultice

ITCH.

R No. 47.

Germ Killer

Skin Ointment

Cow Tonic 
LEUCORRHOEA OR WHITES.

R No. 48.

Cow Tonic

Antisepto

LUNG FEVER.

R No. 41.

Fever Paste

White Liniment

Laxotonic

LUMP JAW. OR ACTINOMY-

COSIS. R No. 49.

Absorbent

Cow Tonic

\section{MAMMITIS.}

R No. 34.

Cow Tonic

Badger Balm

White Liniment

(In severe cases use in addition

Antiseptic Poultice)

Germ Killer

Disinfectall

MILK BLUE.

R No. 50.

Cow Tonic

MILK FEVER OR PARTURIENT

PARESIS.

R No. 51.

Germ Killer

Milk Fever Remedy

Milk Fever Injector

Laxotonic

Cow Tonic

MILK BLOODY OR STRINGY.

R No. 52.

Cow Tonic

NAVEL DISEASES OF CALVES. R No. 53.

Umbilicure

PARALYSIS OF THE BOWELS. R No. 54.

Laxotonic

PARALYSIS OF THE HIND

PARTS.

R No. 55.

Laxotonic

White Liniment

PINK EYE.

R No. 20.

Antisepto

Eye Iotion

Fever Paste

Cow Tonic

Disinfectall

RED WATER IN CATTLE.

$R$ No. 56.

Kidney Cure
RHEUMATISM.

R No. 57.

Cow Tonic

White Liniment

Antiseptic Poultice

RINGING BULLS.

R No. 58.

Healing Oil

RINGWORM.

R No. 59.

Cow Tonic

Germ Killer

Skin Ointment

SCOURS IN CALVES.

R No. 13.

Calf Cholera Remedy

Disinfectall

SKIN DISEASE.

R No. 60.

Cow Tonic

Germ Killer

Skin Ointment

SLOBBERING.

R No. 61.

Fever Paste

Laxotonic.

SORE MOUTH.

R No. 62.

Antisepto

Fever Paste

SORE THROAT.

B No. 63.

Fever Paste

White Liniment

- Laxotonic

Antiseptic Poultice

SPRAINS.

R No. 64.

Germ" Killer

Antiseptic Poultice

Lucky Four Blister

SUNSTROKE OR OVER-

HEATED.

R No. 65.

Fever Paste

SUPPRESSION OF MILK.

R No. 66.

Cow Tonic

SURGICAL OPERATIONS.

R No. 67.

Germ Killer

Healing Oil

TEAT STOPPAGE OR STRIC

TURE. R No. 68.

Germ Killer

Teat Plug

Badger Balm

Teat Expander

Teat Bistoury 
TEAT SORE.

R No. 69.

Badger Balm

TEAT WARTS.

R No. 70.

Wartine

TUBERCULOSIS IN CATTLE. R No. 71.

Testing Outfit Complete Disinfectall

TUMORS.

R No, 72.

Germ Killer

Healing Oil

Healing Lotion

TICKS.

R No. 73.

Germ Killer

Skin Ointment

Cow Tonic
ULCERS.

R No. 74.

Germ Killer

Ilealing Oil

Healing Lotion

URINE RETAINED.

R No. 75.

Catheter

VOMITING.

R No. 76.

Cow Tonic

Laxotonic

Condensed Stock Tonic

WARTS.

R No. 77.

Wartine

Healing Lotion

WOUNDS.

R No. 78.

Germ Killer

Healing Lotion

Healing Oil

\section{HORSES}

ABORTION IN MARES OR SLINKING OF THE FOAL.

R No. 79.

Breeding Tonic

Antisepto

Flushing Outfit

ABSCESS.

R No. 80.

Germ Killer

Healing Lotion

(In severe cases use in addition.).

Physic Ball

Horse Tonic

Antiseptic Poultice

Healing Oil

ASTHMA OR HEAVES.

R No. 81.

Physic Ball

Horse Tonic

Heave Powder

AZOTURIA OR PARALYSIS OF THE HIND PARTS.

R No. 82.

Colic Cure

Kidney Cure

BARRENNESS IN MARES.

R No. 83.

Breeding Tonic

Antisepto

Flushing Outfit

\section{BLOATING.}

R. No. 84.

Colic Cure

(In severe cases use in addition.)

Trocar

fierm Killer

Ifealing Oil
BLOOD POISONING.

R No. 10.

Germ Killer

Healing Oil

BOG SPAVIN.

R No. 85.

Absorbent

BONE SPAVIN.

R No. 86.

Bone Blister

BROKEN KNEE.

R No. 87.

Germ Killer

Healing Oil

Healing Lotion

BROKEN WIND.

R No. 88.

Physic Ball

Horse Tonic

Heave Powder

BRONCHITIS.

R No. 89.

Fever Paste

White Liniment

Laxotonic

BRUISES.

R No. 90.

Badger Balm

Antiseptic Poultice

BRUISES OF THE FROG. R No. 91.

Antiseptic Poultice 
BURNS AND SCALDS.

R No. 92.

Healing Oil

Badger Balm

Antiseptic Poultice

\section{CALK WOUNDS.}

R No. 93.

Germ Killer

Healing Oil

Healíng Lotion

Antiseptic Poultice

CAPPED ELBOW OR SHOE BOII.

R No. 94.

Germ Killer

Healing Oil

Absorbent

\section{CAPPED KNEE.}

R No. 95.

Absorbent

Bone Blister

CAPPED HOCK.

R No. 95.

Absorbent

Bone Blister

\section{CASTRATION OR CUTTING}

COLTS

R No. 96.

Germ Killer

Healing Oil

CATARRHAL FEVER OR PINK EYE.

R No. 97.

Physic Ball

White Liniment

Antiseptic Poultice

Fever Paste

Horse Tonic

Germ Killer

\section{CHOKING.}

R No. 98.

Drenching Hook

Colic Cure

COCKED ANKLES.

R No. 99.

White Liniment

SOLD IN THE HEAD.

R No. 100.

White Liniment

Fever Paste

Horse Tonic

COLIC.

R No. 101.

Drenching Hook

Colic Cure

\section{CONSTIPATION}

R No. 102.

Physic Ball
CORNS.

R No. 103.

Antiseptic Poultice

Absorbent

COUGHS.

R No. 104.

Physic Ball

White Liniment

Fever Paste

CRACKED HEELS.

R No. 105.

Physic Ball

Hor'se Tonic

Badger Balm

CRAMPS OF JOINTS.

R No. 106.

White Liniment

CURB.

R No. 107.

Antiseptic Poultice

Bone Blister

Absorbent

DISTEMPER.

R No. 97.

Physic Ball

White Liniment

Antiseptic Poultice

Fever Paste

Horse Tonic

Germ Killer

DIARRHOEA.

R No. 108.

Horse Tonic

Calf Cholera Remedy

DROPSY.

R No. 109.

Physic Ball

Horse Tonic

DYSENTERY.

R No. 110.

Horse Tonic

Calf Cholera Remedy

ECZEMA.

R No. 111.

Physic Ball

Horse Tonic

Germ Killer

Skin Ointment

EYE INFLAMMATION.

R No. 112.

Eye Lotion

FEVER

R No. 113.

Physic Ball

Fever Paste 
FISTULA.

$\mathrm{R}$ No. 114.

Antiseptic Poultice

Lucky Four Blister

Germ Killer.

Healing Lotion

FLIES.

R No. 115.

Fly Oil

FOALING.

R No. 116.

Umbilicure

FOUNDER.

R No. 117.

Physic Ball

Fever Paste

Horse Tonic

Antiseptic Poultice

GLANDERS.

R No. 118.

Mallien

GREASE HEEL.

R No. 119.

Physic Ball

Horse Tonic

Badger Balm

Antiseptic Poultice

Germ Killer

HARNESS OF COLLAR GALLS. R No. 120.

Healing Oil

Germ Killer

Healing Lotion

HEAVES.

R No. 81.

Physic Ball

Horse Tonic

Heave Powder

HIPPED.

R No. 121.

Badger Balm

Lucky Four Blister

IMPACTION OF THE BOWELS. R No. 122.

Colic Cure

Laxotonic

Physic Ball

INDIGESTION OR OUT OF CON-

DITION.

R No. 123.

Physic Ball

Horse Tonic

INFLUENZA.

R No. 124.

Physic Ball

Fever Paste

White Liniment

Horse Tonic

Antiseptic Poultice

Germ Killer
KIDNEY DISEASE.

R No. 125.

Physic Ball

Kidney Cure

LAMENESS.

R No. 126.

Antiseptic Poultice

Absorbent or Bone Blister

DEEP SEATED LAMENESS.

R No. 127.

Lucky Four Blister

Germ Killer

Antiseptic Poultice

Healing Oil

LARYNGITIS.

B No. 128.

Fever Paste

White Liniment

Antiseptic Poultice

Horse Tonic

Germ Killer

LUECORRHOEA.

R No. 129.

Physic Ball

Horse Tonic

Antisepto

LICE.

R No. 130.

Diolice

LUNG FEVER.

R No. 131.

White Liniment

Fever Paste

Horse Tonic

Germ Killer

LYMPHANGITIS.

R No. 132.

Physic Ball

Horse Tonic

Fever Paste

Badger Balm

MANGE.

R No. 111.

Physic Ball

Horse Tonic

Germ Killer

Skin Ointment

MOON BLINDNESS.

R No. 133.

Physic Ball

Horse Tonic

Antisepto

Eye Lotion

MOUTH SORE.

R No. 134.

Healing Oil

NASAL GLEET.

R No. 135.

Physic Ball

Horse Tonic

White Liniment 
NAVEL DISEASE IN COLTS. R No. 136.

Umbilicure

Fever Paste

Badger Balm

Antiseptic Poultice

OPEN JOINT.

R No. 137.

Germ Killer

Lucky Four Blister

Antisepto

Healing Lotion

PARALYSIS.

R No. 138.

Colic Cure

Kidney Cure

PARASITES.

R No. 139.

Physic Ball

Horse Tonic

Germ Killer

Skin Ointment

PARTURITION.

R No. 140.

Antisepto

PHARYNGITIS.

R No. 141.

Fever Paste

White Liniment

Antiseptic Poultice

Horse Tonic

Germ Killer

PIMPLES.

R No. 142.

Physic Ball

Horse Tonic

Skin Ointment

PINK EYE.

R No. 97.

Physic Ball

White Liniment

Antiseptic Poultice

Fever Paste

Horse Tonic

Germ Killer

\section{PLEURISY.}

R No. 143.

Fever Paste

White Liniment.

PNEUMONIA.

R No. 131.

White Liniment

Fever Paste

Germ Killer

Horse Tonic

POLL EVIL.

R No. 144.

Antiseptic Poultice

Lucky Four Blister

Germ Killer

Healing Lotion
PURPURA HEMORRHAGICA.

R No. 145.

Physic Ball

Fever Paste

Horse Tonic

Badger Balm

Healing Oil

Healing Lotion

QUITTOR.

R No. 146.

Germ Killer

Antiseptic Poultice

Healing Lotion

RING BONE.

R No. 147.

Bone Blister

RING WORM.

R No. 148.

Physic Ball

Hor'se 'Tonic

Germ Killer

Skin Ointment

ROARING.

R No. 149.

Lucky Four Blister

RUPTURE.

K No. 150.

Healing Oil

SCALDS AND BURNS.

R No. 151.

Badger Balm

Antiseptic Poultice

SCRATCHES.

R No. 152.

Physic Ball

Germ Killer

Badger Balm

Antiseptic Poultice

SHOE BOILS.

R No. 94.

Absorbent

Lucky Four Blister

SKIN DISEASE.

R No. 111.

Physic Ball

Horse Tonic

Germ Killer

Skin Ointment

SORES.

R No. 153.

Germ Killer

Healing Lotion

Healing Oil

SORE THROAT. R No. 154.

White Liniment

Fever Paste

Horse Tonic 
SPAVIN.

R No. 85.

Absorbent for Bog Sparin

R No. 86

Bone Blister for Bone Spavin

\section{SPEEDY CRACK.}

R No. 152.

Phrsic Ball

Horse Tonic

Germ Killer

Badger Balm

Antiseptic Poultice

SPLINTS.

R No. 155.

Bone Blister

SPRAINS.

R No. 156.

Antiseptic Poultice

Absorbent

Lucky Four Blister

STERILITY.

R No. 83.

Breeding Tonic

Antisepto

Flushing Outfit

ITRANGLES.

P No. 97.

Physic Ball

White Liniment

Antiseptic Poultice

Fever Paste

Horse Tonic

Germ Killer

\section{STRING HALT.}

R No. 157.

Physic Ball

Horse Tonic

SUNSTROKE.

R No. 158.

Fever Paste

Whiskey

SWELLING.

R No. 159.

Physic Ball

Horse Toric

Badger Balm

Antiseptic Poultice

SWEENY.

R No. 160.

Lucky Four Blister

White Liniment

\section{SYNOVITIS.}

P No. 161.

Badger Balm

Antiseptic Poultice

Lucky Four Blister
TENDON SORE.

R No. 162.

Badger Balm

Antiseptic Poultice

Lucky Four Blister

THOROUGHPINS.

R No. 163.

Absorbent

THRUSH IN FEET.

R No. 164.

Antiseptic Poultice

Germ Killer

Physic Ball

Horse Tonic

Germ Killer

TUMOR.

R No. 165.

Absorbent

ULCERS.

R No. 166.

Germ Killer

Healing Lotion

Absorbent

URINE RETAINED.

R No. 167.

Catheter

Colic Cure

WARTS.

R No. 168.

Wartine

WIND BROKEN.

R No. 81.

Physic Ball

Horse 'Tonic

Heave Powder

WIND GALLS.

R No. 169.

Absorbent

WIRE CUTS.

R No. 170.

Germ Killer

Healing Oil

Absorbent

WORMS.

R No. 171.

Worm Powder

Physic Ball

Germ Killer

\section{WOUNDS.}

R No. 172.

Germ Killer

Healing Oil

Healing Lotion 


\section{SWINE}

CASTRATION.

R No. 173.

Healing Oil

ABORTION IN SOWS.

R No. 174.

Breeding Tonic

Antisepto

Disinfectall

Flushing Outfit

DIARRHOEA.

R No. 175.

Disinfectall

Calf Cholera Remedy
HOG CHOLERA.

R No. 176.

Hog Tonic

Disinfectall

THUMPS.

R No. 177.

Hog Tonic

WORMS.

R No. 178.

Hog Tonic

Worm Powder

LICE ON HOGS.

R No. 179.

Disinfectall

Diolice

\section{SHEEP}

DISTEMPER.

R No. 180.

Sheep Tonic

Disinfectall

\section{GRUBS IN THE HEAD OF} SHEEP.

R No. 181.

Sheep Tonic

Disinfectall
INDIGESTION.

R No. 182.

Sheep Tonic

INTESTINAL WORMS.

R No. 183.

Worm Powder

LUNG WORMS.

R No. 184.

Worm Powder

Disinfectall

\section{POULTRY}

CATARR
ROUP.

R No. 185.

Roup Cure

Disinfectall

Poultry Tonic

BRONCHIAL ROUP.

R No. 186.

Roup Cure

\section{CANKER.}

R No. 187.

Roup Cure

Disinfectall

\section{CHICKEN POX.}

R No. 188.

Disinfectall

Roup Cure

\section{CHOLERA.}

R No. 189.

Poultry Cholera Cure

Poultry Tonic
CROP BOUND.

R No. 190.

Poultry Tonic

DIARRHOEA.

R No. 191.

Poultry Cholera Cure

GAPES.

R No. 192.

Poultry Tonic

LEG WEAKNESS.

R No. 193.

Oil of Camphor

Iodide Potassium

Poultry Tonic

LICE.

R No. 194.

Disinfectall

Diolice 
PRESCRIPTIONS.

MOULTING.

R No. 195.

Poultry Tonic

PIP.

R No. 196.

Tincture of Aconite

Roup Cure

Disinfectall
ROUP.

R No. 197.

Disinfectall

Poultry Tonic

Roup Cure

\section{WORMS.}

R No. 198.

Worm Powder

Epsom Salts 
DR. DAVID ROBERTS

\section{Anti-Abortion Treatment Outfit}

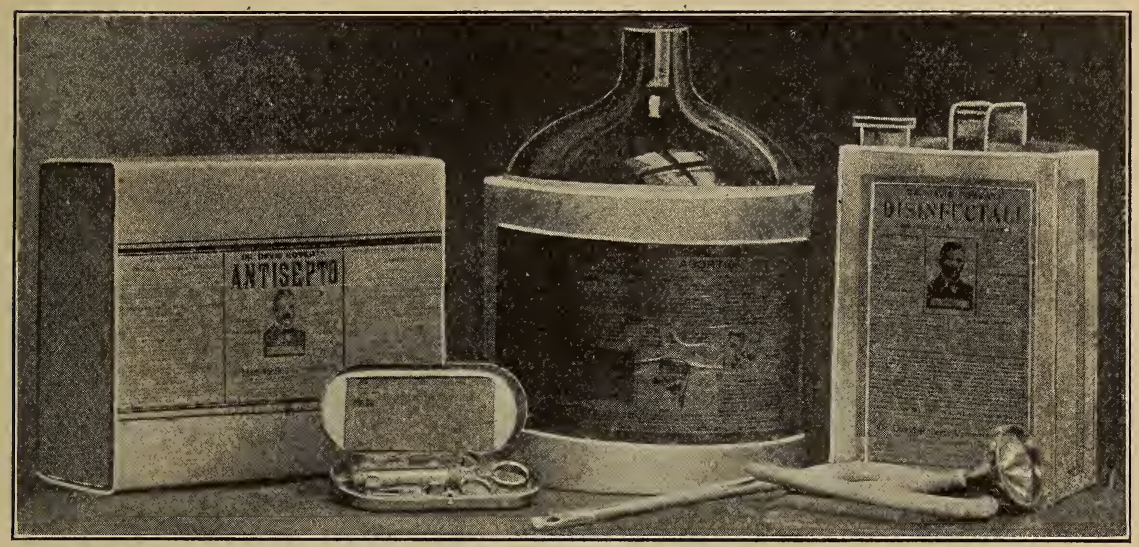

See Article on Abortion in Cows.

FOR THE PREVENTION AND CURE OF ABORTION IN CATTLE.

What Dr. David Roberts' Anti-Abortion Treatment Is.

It is scientifically prepared by a cattle specialist and graduate of one of the leading veterinary colleges of America.

It has been tried and tested by veterinarians and stock raisers in all parts of the United States, Canada, Mexico and Europe and has stood the test.

It is the cheapest, simplest and easiest method of stamping abortion out of a herd.

It will positively prevent and cure abortion in cows, and thereby wipe it out of any herd, no matter of how long standing.

It will convert a diseased, rotten, filthy herd into a perfectly clean, healthy one, and by so doing increase the value of the herd.

It does not cost one cent to use it, as the increased flow of milk (due to a healthy herd) will more than pay for the treatment.

It is profitable to use it, as you will have a lot of strong, healthy calves for sale instead of a few sickly, diseased ones.

The "SERUM" does not in any manner interfere with the regular flow of milk, except as it destroys the germs and renders a herd free from disease, consequently the cows will naturally increase their flow of milk, and the results are a healthy herd, strong, live calves, and an extra amount of milk, which will pay for the treatment, while the calves are a clear gain instead of a dead loss.

A cow that has aborted will be out of condition for a long time, her milk will be short in quantity and poor in quality; she will undoubtedly abort next year and is more susceptible to other diseases, such as barrenness, etc., unless the germ of abortion is destroyed. Dr David Roberts Anti-Abortion treatment is the only SURE way to combat Abortion.

This treatment is not sold through dealers on account of the personal services rendered the stockman while herd is under treatment.

Write direct to us for further information and special prices.

In writing state number of cows, heifers, calves and bulls owned. 


\section{DR. DAVID ROBERTS}

\section{Antisepto}

One Pound Can

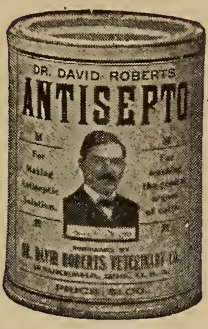

Price $\$ 1.00$

This Will Make 16 Gallons of Antiseptic Solution.

For Washing the Genital Organs of Cattle. Destroying Germs, Thus Preventing Infection. Indispensable to the Cattle Owner Who Guards the Health of His Animals.

All cows and heifers having an unnatural or catarrhal discharge from the vagina should have their genital organs washed out with the antiseptic solution until all discharge ceases.

The sheath of the herd bull should be washed out after each service; this will prevent him from becoming infected, and in case he is infected will prevent him from infecting cows and heifers bred to him.

The Antiseptic solution prevents and destroys germs, soothes and heals the inflamed mucous membrane of the genital organs, thus preventing the formation of germs and the spread of abortion.

This Antiseptic solution is also good for washing the genital organs of mares, ewes and sows.

Put up in air-tight cans with friction tops, which preserves contents and makes if easy to remove. 


\section{DR. DAVID ROBERTS}

\section{Breeding Tonic}

\section{Pound Can}

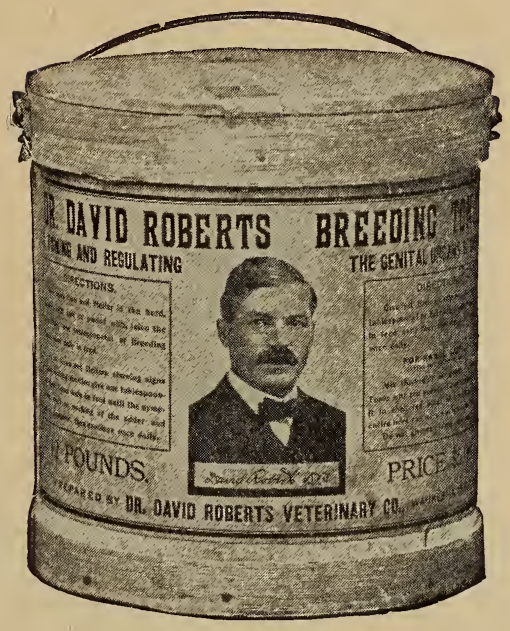

Price $\$ 5.00$

\section{For Toning and Regulating the Genital Organs of Cattle.}

\section{Thus Enabling Cows and Heifers to Carry Their Calves Full Time.}

Dr. David Roberts' Breeding Tonic, which is prepared especially for pregnant cows and heifers, should be fed to pregnant cows in small quantities in their feed during the period of pregnancy. This will keep their genital organs in a strong, healthy condition, thereby enabling them to give birth to a strong, healthy calf in the proper manner, at the same time preventing retention of the afterbirth, catarrhal discharge and barrenness, thereby enabling the cow to ward off many diseases that she is liable to contract at this critical period. The feeding of this Breeding Tonic to pregnant cows strengthens and invigorates the muscles and all of their genital organs to such an extent that they have no trouble in calving and expelling the afterbirth as nature intended they should.

This BREEDING Tonic is also invaluable for other pregnant animals, mares, ewes and sows. Same dose for mares as for cattle; half the amount for ewes and sows.

For sows it may be given in the slops or swill.

\section{BARRENNESS}

in

\section{Cows, Mares, Sows and Ewes.}

Breeding Tonic is unexcelled to tone up the genital organs and place the animal in breeding condition. 


\section{DR. DAVID ROBERTS}

\section{Cow Cleaner}

\section{See page 51 \\ for additional information}

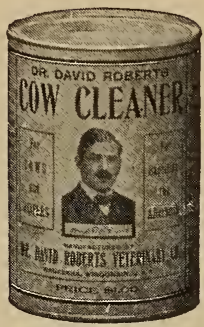

Price $\$ 1.00$

\section{An Indispensable Compound for Expelling the Afterbirth in Cows and Heifers.}

Thus preventing catarrhal discharges which often produce infectious abortion in cattle, also barrenness.

Put up in air-tight cans with friction top, which preserves contents and makes it easy to remove.

An afterbirth that can be removed without force or injury to the cow is in a condition to come away of its own accord.

In removing the afterbirth by main force it is only the body of it and such buttons as are torn off that come away, thus leaving many serious conditions. If the cotyledons or buttons are forcibly torn off there is great danger of serious internal hemorrhage, as well as leaving a lot of clotted blood in the womb to decompose.

The parts of the afterbirth attached to the buttons are retained and undergo putrefaction, and the buttons torn from the womb leave raw sores which become infected by the rotting, decomposing, irritating masses of foreign matter, of which a large per cent. is absorbed by the system.

This is liable to produce barrenness and infectious abortion, and the cow by absorbing a large portion of this matter dries up on her milk, grows thin rapidly and is liable to become a victim of tuberculosis; and if she contracts it, is then in condition to expose the entire herd.

\section{NOTICE.}

A cow that has retained the afterbirth should be placed in a well bedded box-stall. Give her warm drinks, boiled oats and hot bran mashes. If in cold weather, place a blanket over her.

A cow that retains the afterbirth will be out of condition for a long time.

Her milk will be short in quantity, poor in quality and unfit for human use.

Avoid this danger by having the Cow Cleaner on hand and giving as directed 


\section{Calf Cholera Remedy}

OR SCOUR MEDICINE.

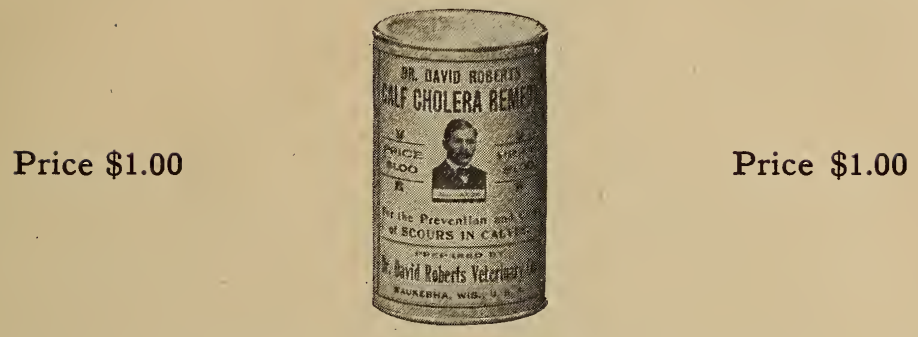

For the Prevention and Cure of Scours in all Live Stock.
A Valuable Remedy for the Prevention and Cure of Scours in Calves, Calf Cholera, White Scours, Diarrhoea, Bloody Flux, Dysentery and Indigestion.

The most important factor in the raising of cattle is their care while young.

Do not think that you are doing the correct thing if you are only managing to keep the life in a calf until it is three months old and then have it get fat on grass before the winter comes. If you do this you are apt to have a lot of "scrawns" with their digestive organs destroyed and which will never make strong, healthy steers or cows and will not be good for either dairy, beef or breeding animals.

\section{SPECIAL CARE OF CALVES UNDER TREATMENT.}

Stable should be thoroughly cleaned, disinfected with Disinfectall, and well drained, allowing plenty of sunlight and good ventilation.

The hind quarters and tail should be washed with a solution of Disinfectall.

The Calf Cholera Remedy is invaluable in overcoming all stomach and bowel troubles in calves, colts, lambs and pigs.

Calvès should be fed sparingly while under treatment.

This remedy is put up in air-tight cans with friction top, which preserves the contents and makes it easy to remove. 


\section{Badger Balm}

\section{See Cattle and Horse Section for additional information}

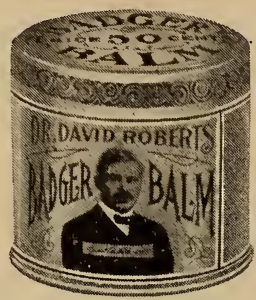

\section{Price 50 Cents}

\section{UNEXCELLED FOR}

Sore Teats, Cow Pox, Caked or Inflamed Udder in Cows, Galls, Scratches, Cracked Heels, Sore Neck, Cuts, Wounds, Inflamed Swelling and all kinds of diseases in Cattle and Horses.

An excellent Healing Balm for general family use in the following Skin Diseases: Piles, Saltrheum, Eczema, Erysipelas, Scrofulous Ulcers, Ringworm, Wounds, Cuts, Bruises, Boils, Chaps, Sunburn, Chilblains, Frostbites and bites of poisonous insects.

Use Badger Balm freely. It is soothing and healing. It should be in every household.

\section{DR. DAVID ROBERTS}

\section{Milk Fever Outfit}

See page 69

for additional information

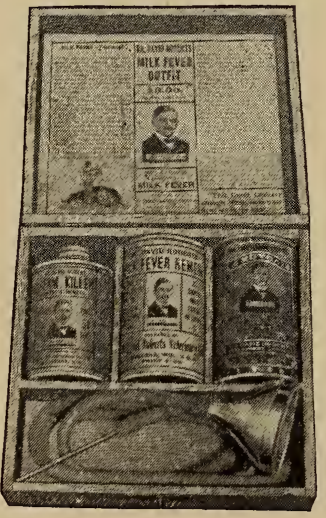

Price $\$ 3.00$

\section{A Tried, Tested and Positive Cure for Milk Fever.}

This outfit contains sufficient of the treatment to save from six to ten cows.

Every owner of a cow should have a Milk Fever Outfit on hand to insure him against loss of his best cows by milk fever, as none but the best are liable to be affected.

Put up in air-tight cans with friction top, which preserves contents and makes it easy to remove. 


\section{DR. DAVID ROBERTS}

\section{Laxotonic}

See Cattle

Section for additional information

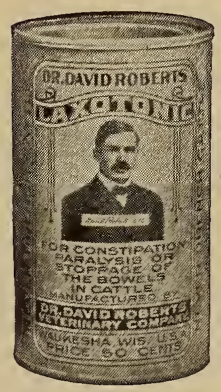

\section{Price \\ 50 Cents}

\section{A Laxative and Nerve Tonic}

\section{To Overcome Constipation, Paralysis or Stoppage of the Bowels of Cattle. Also to Prevent and Overcome Bloat.}

LAxotonic is administered in small doses dry on the tongue, and the danger of drenching is thus avoided.

Never give a cow a physic, such as salts or oil, for if the bowels are paralyzed, these will produce inflammation and death will follow.

\section{WARNING! \\ NEVER DRENCH CATTLE.}

It is absolutely dangerous to administer a physic to cattle by drenching, on account of the great liability of part of the drench-passing down the windpipe into the lungs.

Many a valuable animal has been thus killed outright, or so injured as to linger in an unhealthy condition for many months and finally die of lung trouble.

For this reason our LAXXTONIC, which is an invaluable powdered compound, was prepared to overcome constipation and paralysis.

Put up in air-tight cans with friction top, which preserves contents and makes it easy to remove. 


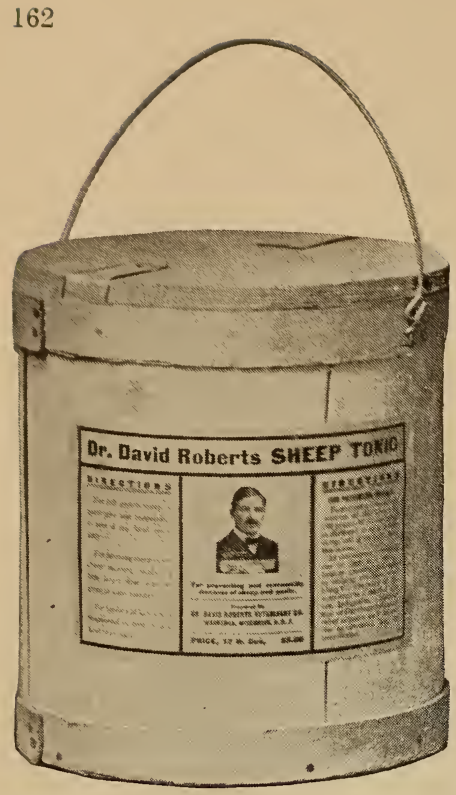

DR. DAVID ROBERTS

\section{Sheep .Tonic}

\section{See page 127 for additional information}

\section{Price, $12 \mathrm{lb}$. Can, $\$ 5.00$}

Sheep Tonic should be used in preventing and overcoming all diseases of sheep and goats.

It is a great deal easier to prevent disease than it is to cure it, and at a small expense with the use of this Tonic, sheep and goats can be kept in a healthy condition and will ward off such diseases as Catarrhal Fever, Indigestion, and will regulate the bowels.

DR. DAVID ROBERTS

\section{Cow Tonic}

\section{See Cattle Section}

for additional information

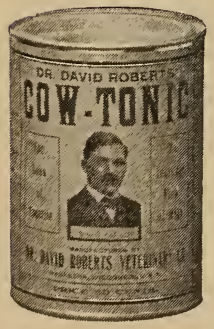

One Pound Can, Price $50 \mathrm{Cts}$.

12 Pound Can, Price $\$ 5.00$

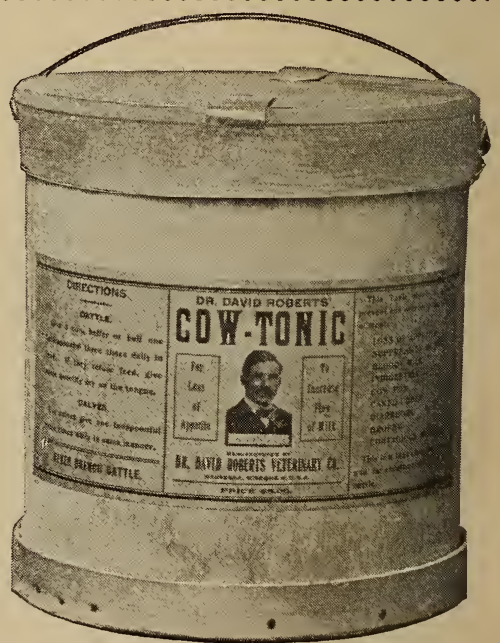

A Valuable Tonic to Have on Hand for Following Ailments : Depraved Appetite Catarrhal Fever Lump Jaw Loss of Appetite Caked Udder Inflamed Womb Bloody Urine Diarrhœa Bloody Milk Cow Pox Suppression of Milk Indigestion.

Dropsy of Abdomen Itching of the Skin Contagious Mammitis Lung Fever

This is a high-class general Tonic, and is excellent for fitting Show Cattle and preparing cows and heifers for the advanced registry, as it improves the appetite and increases the flow of milk. Put up in air-tight cans with friction top, which preserves contents and makes it easy to remove. 


\section{DR. DAVID ROBERTS}

\section{Germ Killer}

One bottle sufficient to make an eight gallon solution

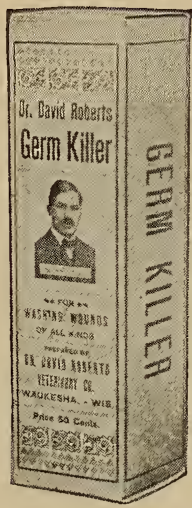

Price $50 \mathrm{Cts}$.

\section{FOR WASHING WOUNDS OF ALL KINDS}

\section{Use for Washing:}

Wire Cuts

Broken Knees

Open Joints

Collar Boils

Poll Evil

Fistula Withers
Pus Cavities

Quarter Cracks

Quittor

Gravel in Foot

Sore Neck
Sore Back

'Thrush in Horses' Feet

Foot Rot in Sheep

Roots of Tail and Maine

Sore Feet in Cattle

Exterminates Fleas on Dogs, Flies, Germs.

NOTICE!

NEVER USE SOAP in washing wounds.

\section{DR. DAVID ROBERTS \\ Skin Ointment}

Can contains

$11 / 4$ pounds

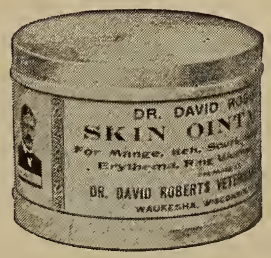

Price $\$ 1.00$

\section{An Invaluable Remedy for Mange}

Also an excellent skin tonic and healer for skin diseases of all nature, such as Itch, Eczema, Erythema, Scab, Ringworm, Dandruff and Scruf.

It also prevents the spread of Skin Diseases, which is oftentimes catching, such as Mange. 


\section{DR. DAVID ROBERTS}

\section{Antiseptic Poultice}

\section{Contents of this Can makes ten pounds of poultice}

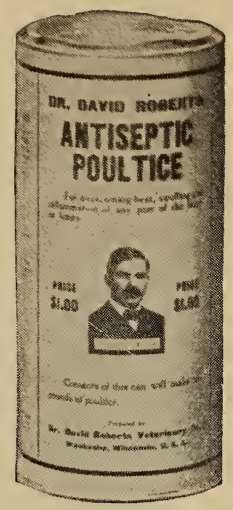

Price $\$ 1.00$

AN ABSOLUTELY RELIABLE ANTISEPTIC POULTICE. INVALUABLE IN OVERCOMING heat, swelling and inflammation of any part of the body or limbs of live stock, AND SHOULD BE USED FOR POULTICING THE FOLLOWING AILMENTS:

Sore or swollen throat in horses or cattle,

Sore, hot or inflamed feet in horses or cattle,

Swollen hocks,

Swollen knees,

Swollen or inflamed tendons,

Hot, swollen or inflamed joints,

Foot rot or cracked claws in cattle,

Poll Evil or Fistulas,
Nail pricks, Quittor, Corns, or Founder in horses, Sore Backs or Necks, Caked or inflamed udder in cows, Bruises or Boils, Pneumonia in cattle or horses, Kicks and Bruises, Cracked Heels, Scratches and all inflammation.

This Antiseptic poultice is not to be compared with any vegetable poultice (such as flaxseed), and it never sours and is always free from germs. Is cooling, soothing and healing.

On account of its freedom from germs is often used in human practice with the best of results.

Put up in air-tight can: with friction top, which preserves contents and makes it easy to remove.

It would be well to have a can on hand for emergency cases. 


\section{DR. DAVID ROBERTS}

\section{Worm Powder}

\section{One Pound Can}

\section{Price 50 Cents}

\section{An Effective Remedy for Expelling and Freeing Animals of Stomach and Intestinal Worms of all Kinds.}

Put up in air-tight cans with friction top, which preserves contents and makes it easy to remove.

\section{SYMPTOMS.}

Slight colicky pains are noticed at times, or there may be only switching of the tail, frequent passage of manure, itching of the anus, or rubbing of the tail or rump against the stall or fences. The horse is in poor condition; does not shed his coat; is hide-bound and pot-bellied; the appetite is depraved, licking the walls, biting the woodwork of the stalls, licking parts of the bed; eating earth, being particularly fond of salt; the bowels are irregular and constipated or diarrhœa being noticed. Adherence of dried, whitish substance about the anus and turning up of the upper lip.

(A symptom is a sign used by a dumb brute in trying to make his keeper understand that he is in need of medical aid, and should have it rather than stand the untold torture he undergoes while infested with worms.)

\section{DR. DAVID ROBERTS}

\section{Eye Lotion}

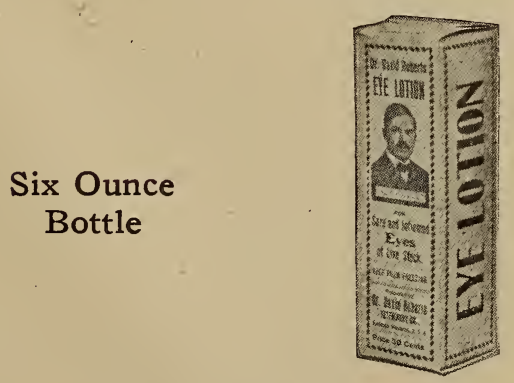

\section{Price 50 Cents}

An Unequaled Remedy for Sore and Inflamed Eyes. of all Descriptions in all Kinds of Live Stock.

Very Valuable in Pink Eye and Catarrhal Affections of the Eye. 
DR. DAVID ROBERTS.

White Liniment

\author{
Price 50 Cents
}

For Man or Beast. An Old, Tried and True Liniment That Never Fails.

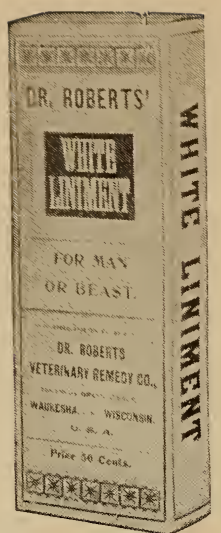

Gives Quick Relief in Cases of Rheumatism. Once Used, Always Used.

For All Sprains, Bruises, Sore Throat, Lung Fever, Etc., Etc.

This Liniment is Excellent for Garget, Caked or Inflamed Udder in Cows.

Family Use.-Chronic and Inflammatory Rheumatism.

Strained Ligaments and Joints, Contracted Cords, Muscular Soreness, Sciatica, Lumbago, Pleurisy, Side Ache, Lame Back, Sore Throat and Chest, and all Neuralgia Pains.

\section{Veterinary Use.-Sweeney, Sprained Tendons.}

Muscular and Ligamentary Lameness, Shoulder, Stifle and Hip Joint Lameness, Swollen Glands, Sore Throat with Distemper or Influenza, and Congestion or Inflammation of the Lungs.

DR. DAVID ROBERTS.

\section{Absorbent}

\section{Price $\$ 1.00$}

See Cattle and Horse Section for additional information.

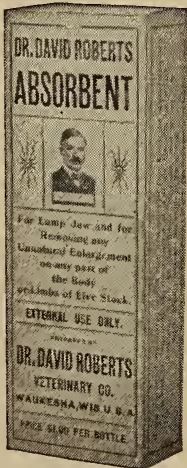

The Best Remedy Known for Lump Jaw and for Removing any Unnatural Enlargement on any Part of the Body or Limbs of Live Stock.

For External Use Only.

Dr. David Roberts' ABSORBENT is especially prepared to remove by absorbing, any unnatural ailment or enlargment of any part of the body or limbs, such as:

LUMP JAW,
SPLINTS, CURBS,
SIDEBONES, RINGBONE,
THOROUGHPIN,
BOG SPAVIN,
CHAPPED HOCK,
SHOEBOILS, WINDPUFFS,

CALLOUS COLLAR GALLS, POLL EVIL, FISTULA WITHERS, COLD ABSCESS, ENLARGED GLANDS, such as Goiters, Lump Jaw and Enlargements due to Kicks, Bruises, Cuts, Etc.

If the owner of an animal would stop and consider how much the appearance of it would be improved by the removal of a single blemish, he would undoubtedly have all blemishes removed, and in so doing greatly increase the value of the animal. 


\section{DR. DAVID ROBERTS}

\section{Wartine}

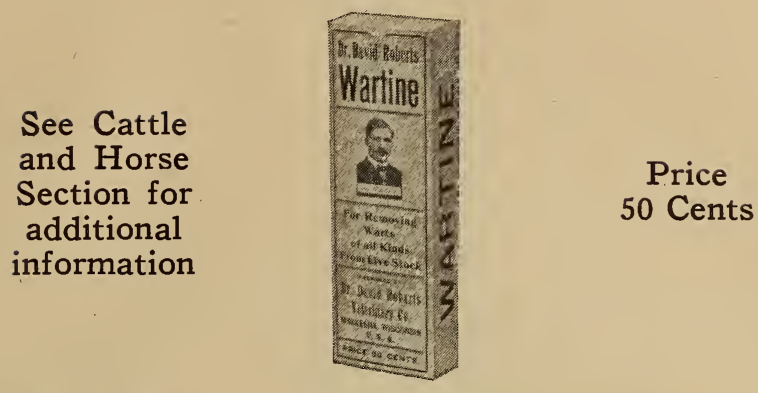

A harmless and painless treatment for removing warts of all kinds on livestock.

\section{DR. DAVID ROBERTS}

\section{Umbilicure}

See Navel Disease in Colts and Calves; also Foaling and Calving

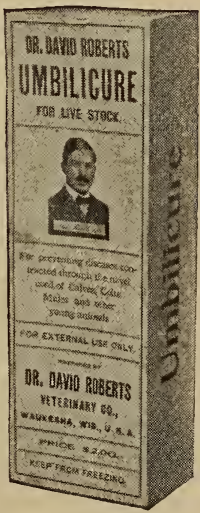

\section{For Preventing}

Diseases

Contracted through the Navel Cord of Calves, Colts, Mules and other Young Animals

The death of 75 per cent. of the young animals which die at birth may be attributed to diseases contracted through the navel cord, such as heat, swelling, lameness and gathering in any joints of the body, usually that of the ankle, hock, knee or stifle, which gathers, breaks and discharges a large amount of pus. Death soon follows unless properly treated; for this reason it is necessary and very important to not only examine, but to treat the navel cord at birth to prevent the death of the young animal.

\section{NOTICE.}

All apartments where an animal is placed to bring forth its young should be thoroughly cleaned, bedded, ventilated and disinfected. An attendant should be present and the navel cord of all colts and calves should be cut six inches long and tied with a string soaked in Umbilicure and then apply Umbilicure to navel cord as directed. In this manner many a young animal can be saved which would otherwise die withou* the cause being known to the owner. 


\section{DR. DAVID ROBERTS}

\section{Fever Paste}

\section{See Cattle and Horse Sections for additional information}

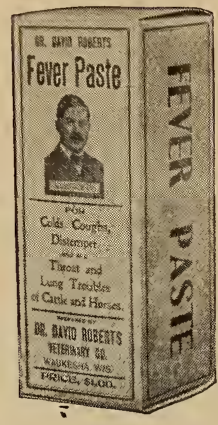

Price $\$ 1.00$

A Quick and Ready Relief for Coughs, Colds, Distemper and all Throat and Lung Troubles in Cattle and Horses.

\section{FOR}

Colds
Cough
Sore Throat
Distemper
Influenza
Laryngitis
Pharyngitis
Bronchitis
Pleurisy

Lung Fever Climatic Fever Catarrhal Fever Inflammation of Lungs Congestion of Lungs Stockyard Distemper Asthma And all Throat and Lung Troubles

\section{NOTICE!}

\section{Sore Throat or Lung Trouble.}

A sick animal should be placed in a well-bedded box stall and blanketed. Allow plenty of water and fresh air, but no draught.

The stall should be thoroughly disinfected and kept clean. Give animal Fever Paste according to directions.

Never drench a horse while suffering from distemper, sore throat or lung trouble. Have Fever Paste in the house for immediate use. 
DR. DAVID ROBERTS

\section{Healing Lotion}

12 Ounce

Bottle

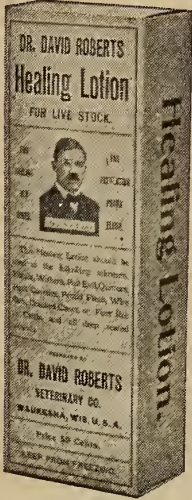

Price 50 Cents

For live stock, healing old sores and preventing proud flesh.

This healing lotion should be used in the following ailments, and ought to be in every stock raiser's home.

Fistulas, Withers, Quittors,

Proud Flesh,
Wire Cuts, Poll Evil, Pus Cavities,
Cracked claws in cattle, And all deep seated wounds.

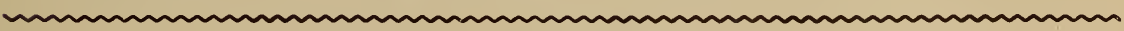

DR. DAVID ROBERTS

Heave Powder

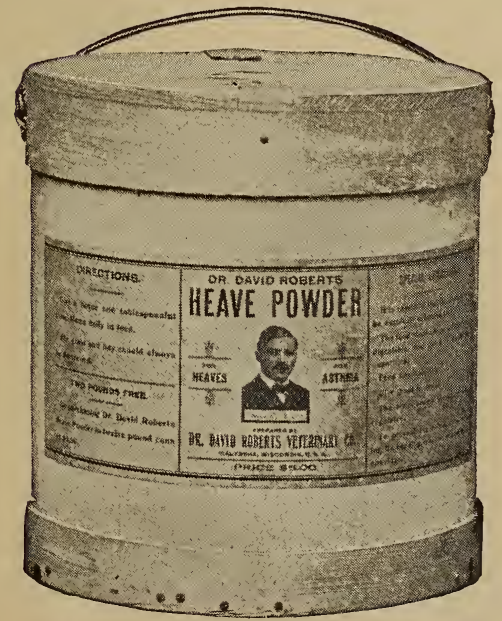

See page 101 for additional information

1 Pound Can

Price 50 Cents

\section{Pound Can} Price $\$ 5.00$

An Invaluable Tonic for Heaves, Asthma and Broken Wind in Horses. This Treatment Always Gives Relief and Cures if Directions Are Followed.

Put up in air-tight, friction-top, one-pound cans, which preserves the contents and makes it easy to remove; also in 12-pound wood jacket cans. 


\section{DR. DAVID ROBERTS}

\section{Horse Tonic}

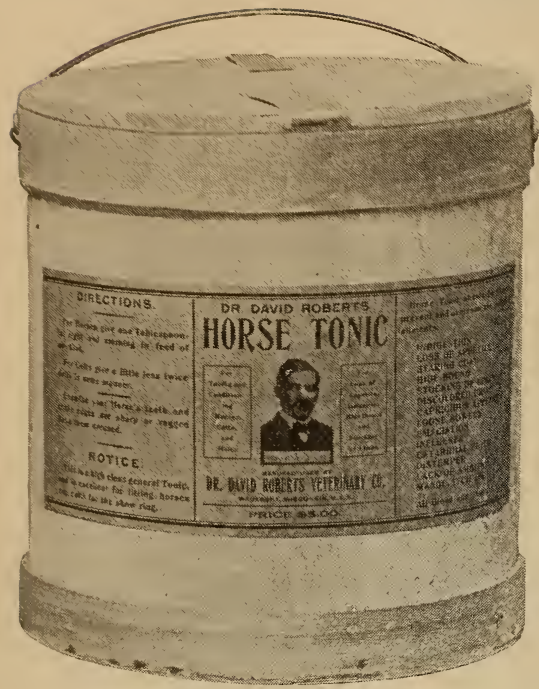

See Horse Section for additional information

One Pound Can

Price 50 Cents

12 Pound Can

Price $\$ 5.00$

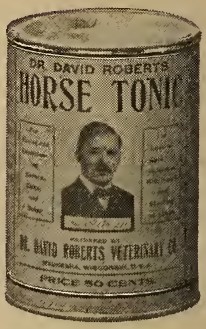

This HORSE TONIC is an effective stimulant, and should be given to prevent and overcome the following ailments in horses, colts and mules:

$\begin{array}{ll}\begin{array}{l}\text { Indigestion, } \\ \text { Loss of Appetite, }\end{array} & \begin{array}{l}\text { Loose Bowels, } \\ \text { Mange, } \\ \text { Staring Coat, }\end{array} \\ \text { Hide Bound, } & \text { Emaciation, } \\ \text { Lack of Ambition, } & \text { Distemper, } \\ \text { Stocking of Limbs, } & \text { Itch, } \\ \text { Capricious Appetite, } & \end{array}$

And all Blood and Skin Diseases.

Put up in air-tight cans with friction top which preserves contents and makes it easy to remove; also in 12-pound wood jacket cans.

\section{NOTICE!}

This HORSE TONIC is excellent for conditioning horses and colts for the show ring.

Examine your horses' teeth, and if the edges are sharp or ragged, have them dressed. 


\section{DR. DAVID ROBERTS}

\section{Colic Cure}

See Horse • Section for additional information

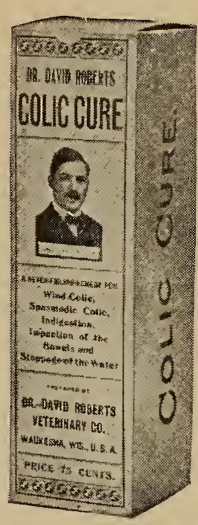

\section{Price \\ 75 Cents}

A Never Failing Remedy for Wind Colic, Spasmodic Colic, Indigestion, Impaction of the Bowels, and Stoppage of the Water.

\section{HOW TO KNOW COLIC.}

In the first stage the horse will begin to be uneasy, looks around, raises up his hind feet towards his belly, steps around from one side of the stall to the other, stops eating, will curl as if to lie down. In the second stage, he lies down and gets up again after lying perhaps a couple of minutes. In the third stage, he rolls, kicks, sweats profusely, has a haggard countenance, is inclined to turn upon his back, and remain so. If it does not leave off in the course of half an hour, it is apt to run into enteritis and kill him.

Every horse owner should have a bottle of Colic Cure on hand for an emergency case. Failure to give prompt relief may mean the loss of an animal.

\section{HOW TO DRENCH A HORSE.}

Back the animal into a single stall, place a clothes line around his upper teeth and pass. it over a beam, pull him up gently and give one swallow at a time. (See page 95.) 


\section{DR. DAVID ROBERTS \\ Physic Ball for Horses}

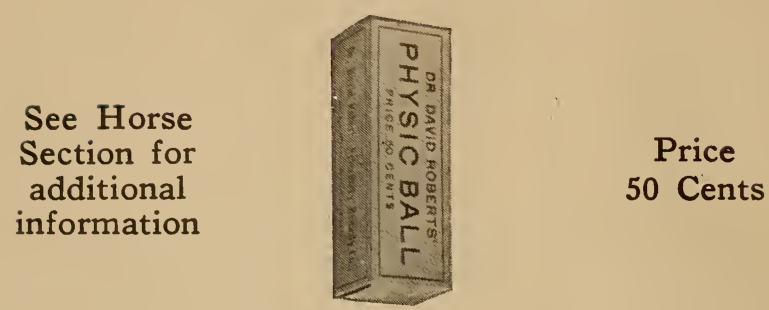

A PHYSIC BALL should be given every two weeks to all horses and colts (except mares with foal) afflicted with the following ailments:

Out of Condition,

Loss of Appetite,

Hide bound, Worms,
Skin Diseases,

Swollen Sheath,

Depraved Appetite,

Heaves and Constipation.
Indigestion,

Staring Coat,

Swollen Limbs,

Give a PHYSIC BALL every three months to horses apparently in good condition, as it will keep them in good health and spirit.

All horses that are not turned out to pasture should be given a PHYSIC BALL occasionally to stimulate the liver, aid digestion, expel parasites, sleeken the coat, and keep the animal in a good working condition.

A few of these Physic Balls should be kept on hand at all times for use in emergency cases.

\section{DR. DAVID ROBERTS Healing Oil}

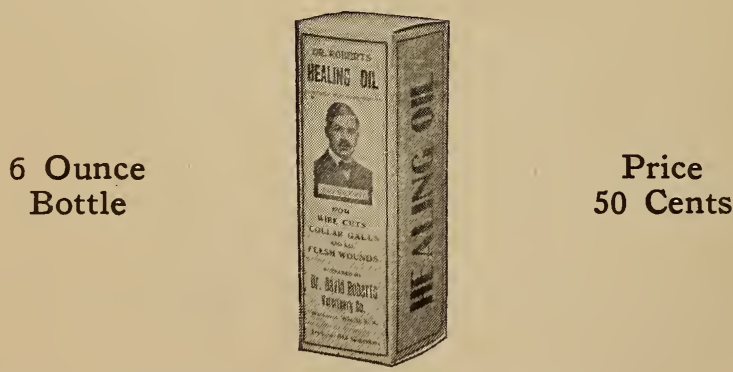

A Positive Gall Cure, also a Valuable Preparation at a Healer for

Sore Backs,

Shoe Boils,

Wire Cuts,
Collar Boils,

Broken Knees,

Fistula Withers,

Poll Evil and all Flesh Wounds.

In castrating colts, pigs, lambs, calves or other farm animals, use HEALING OIL freely on parts after the operation. This will prevent any bad results and insure prompt healing.

A bottle of this Oil should be kept handy and applied when needed. 
DR. DAVID ROBERTS

\section{Hoof Remedy}

See Horse Section for additional information

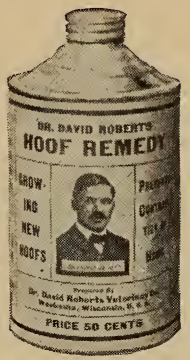

Price

50 Cents

Positively the Best Treatment for the Prevention and Cure of - Contracted Hoofs.

And to Overcome Such Ailments as Corns, Founder, Soreness, and all Ailments of the Feet.

\section{DR. DAVID ROBERTS \\ Lucky Four Blister}

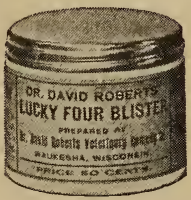

See Horse Section for additional information.

\section{Price 50 Cents.}

This Blister should be used in the treatment of all cases requiring a good penetrating, stimulating Blister, including Lameness of Shoulder, Stifle, Tendons, Hip Joints, also Sweeny.

For Contracted Hoofs apply a little of the Blister, to cornet, at the same time applying the Hoof Remedy to the outside and bottom of hoof.

\section{DR. DAVID ROBERTS}

\section{Bone Blister}

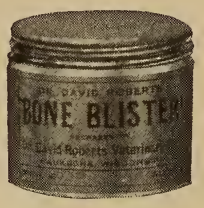

See Horse section for additional information.

\section{Price $\$ 1.00$.}

This Blister should be used in the treatment of the following ailments:

Bone Spavin Splint

Ring Bone Curb

Side Bone Capped Hock 
DR. DAVID ROBERTS

\section{Poultry Cholera Cure}

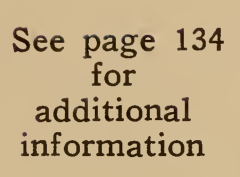

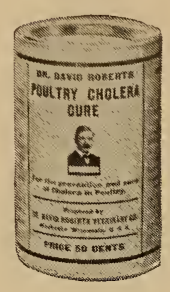

\author{
Price \\ 50 Cents
}

For the Prevention and Cure of Cholera in Poultry.

This remedy is put up in an air-tight can with friction top, which preserves contents and makes it easy to remove.

To prevent Cholera among poultry a can should be kept on hand and used when first symptoms of disease are shown.

\section{DR. DAVID ROBERTS}

\section{Kidney Cure}

\section{See Cattle and Horse Sections for additional information}

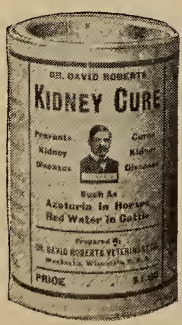

Price $\$ 1.00$

For the Preventing and Cure of Kidney Disease in Horses and Red Water in Cattle.

This remedy is put up in air-tight can with friction top which preserves contents and makes it easy to remove.

A can of this remedy should be kept on hand at all times for sudden cases of that dreaded disease Azoturia, for which it is the best cure known.

Red Water in cows is also speedily cured with this remedy. 


\section{DR. DAVID ROBERTS}

\section{Fly Oil}

Price,

1 Gal. $\$ 1.25$

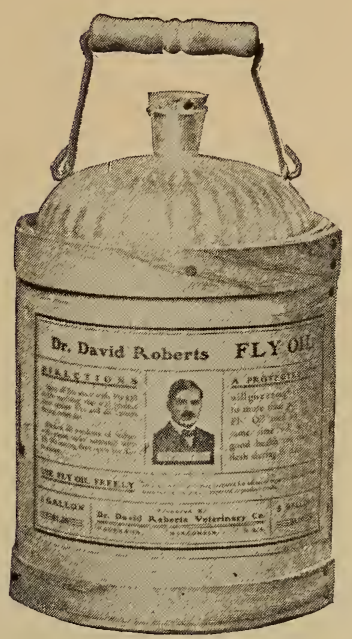

Price,

5 Gal. $\$ 5.00$

\section{Use Fly Oil Freely.}

Animals sprayed in the morning with Fly Oil will be protected from flies and insects for the entire day.

\section{DR. DAVID ROBERTS}

\section{Horn Killer}

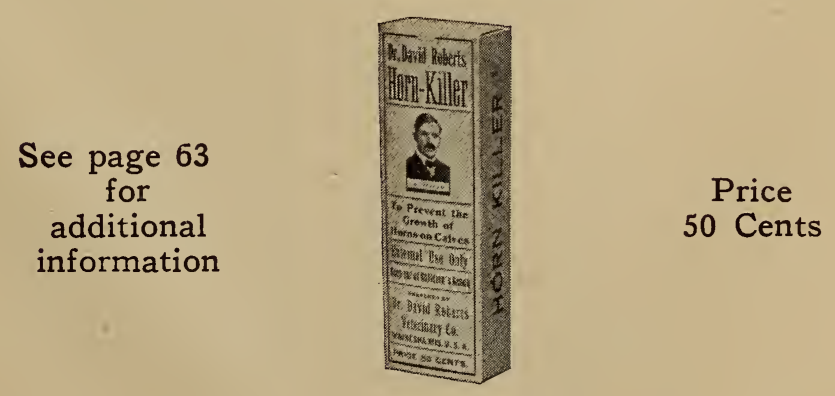

A powerful solution for stopping the growth of horns on calves.

The dangerous, painful and cruel process of "sawing horns can be avoided by the use of this preparation, which is certain and painless. 


\section{DR. DAVID ROBERTS}

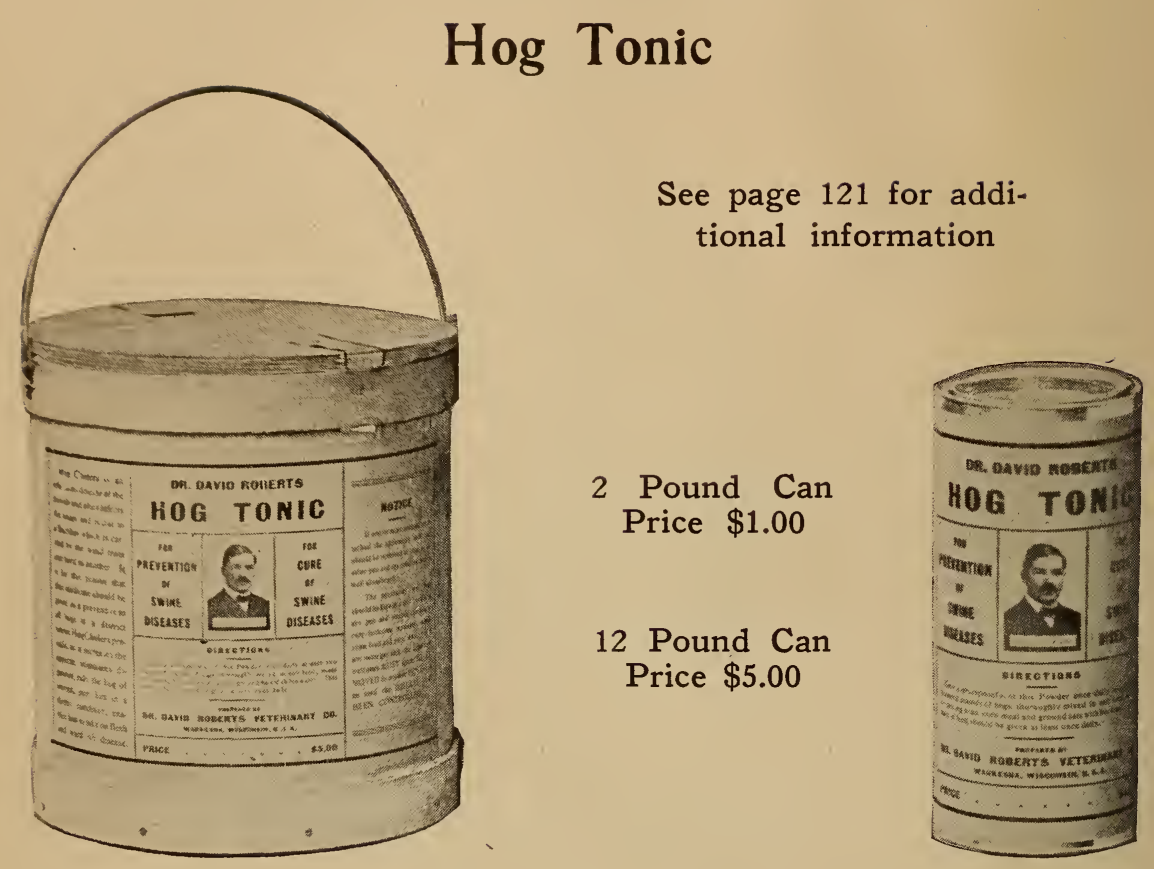

Hog Cholera is an infectious disease of the bowels, and often infects the lungs, and is due to a bacillus which is carried by the wind from one herd to another. It is for this reason that this medicine should be given as a preventive, to all hogs in a district where Hog Cholera prevails, as it increases the appetite, stimulates digestion, rids the hog of worms, puts him in a thrifty condition, enables him to take on flesh and ward off diseases.

Use Hog Tonic freely, it means better results.

\section{NOTICE!}

If one or more animals are attacked, the apparently well ones should be removed at once to another pen, and the infected pen be well disinfectd with DISINFECTALL.

The apparently well hogs should be kept in a well ventilated, dry pen, and receive the best of care, Hog Tonic, wholesome food and pure water, and if any more get sick, the apparently well ones MUST again be REMOVED to another pen, and so on until the DISEASE HAS BEEN CONTROLLED. 


\section{DR. DAVID ROBERTS}

\section{Poultry Tonic}

\section{See Poultry Section for additional information}

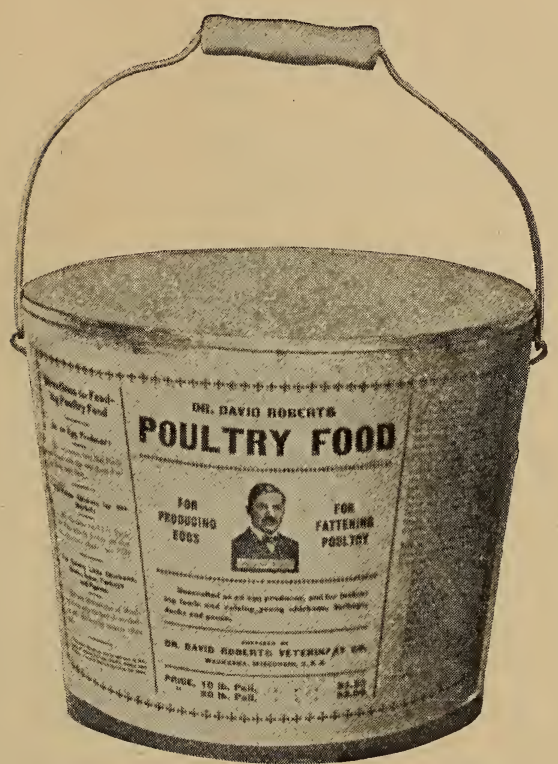

12 Pound Pail Price $\$ 1.25$ 30 Pound Pail Price $\$ 3.00$

Unexcelled as an Egg Producer, and for Fattening Fowls and Raising Young Chickens, Turkeys, Ducks and Geese.

Poultry fattens quickly if the proper conditions exist. Profit can be more than doubled. All fowls must be healthy to fatten. The blood must be in good condition, the bowels regular and the digestive organs in good order.

The only quick, positive and reliable method to do this is by the use of a GOOD POULTRY TONiC. It not only enriches the regular food, but it is an excellent flesh producer, and aids poultry to put on flesh so quickly as to make the most tender and juicy eating.

Fowls respond to this food promptly.

POULTRY TONIC will not only make hens lay, but it will ward off and prevent many diseases that poultry is subject to, such as:

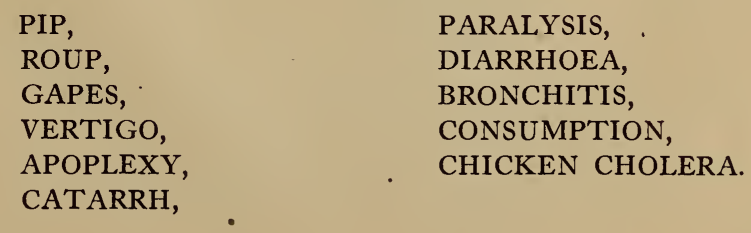

Try it on half your flock and compare results. 


\section{Diolice}

\section{$11 / 2$ Pound Air Tight Sifting Top Package}

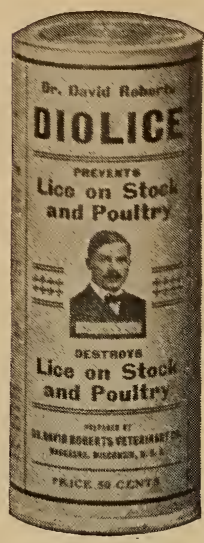

Price 50 Cents

\section{An Unequaled Powdered Louse Killer}

\section{For Destroying Lice on all Live Stock and Poultry.}

Diolice may be used at all seasons of the year, especially during the winter months, when it is unsafe to use liquids on account of the danger of stock taking cold.

\section{IMPORTANT !}

Fowls cannot gain flesh or lay as they should if annoyed by lice. Setting hens will leave their eggs. DIOLICE should be used thoroughly during the hatching season. It will insure the lives of many little chickens that would otherwise succumb to disease by being worried and weakened by lice. Growing chickens must not waste their time in picking lice from themselves when they should be finding food and putting on flesh. These precautions will keep poultry free from lice and mites, and thereby make the poultry business profitable.

\section{DR. DAVID ROBERTS Roup Cure}

\section{See page 136 for additional information}

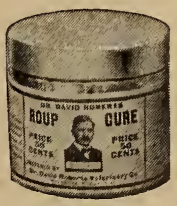

\section{Price 50 Cents}

\section{Prevents and Cures Roup in Poultry.}

\section{HOW TO KNOW ROUP.}

Sneezing, discharge at nostrils, wheezing, rattling at throat and a bad odor about the nostrils or mouth.

Fowl wants to sleep most of the time with head under wing. 


\section{DR. DAVID ROBERTS \\ Condensed Stock Tonic}
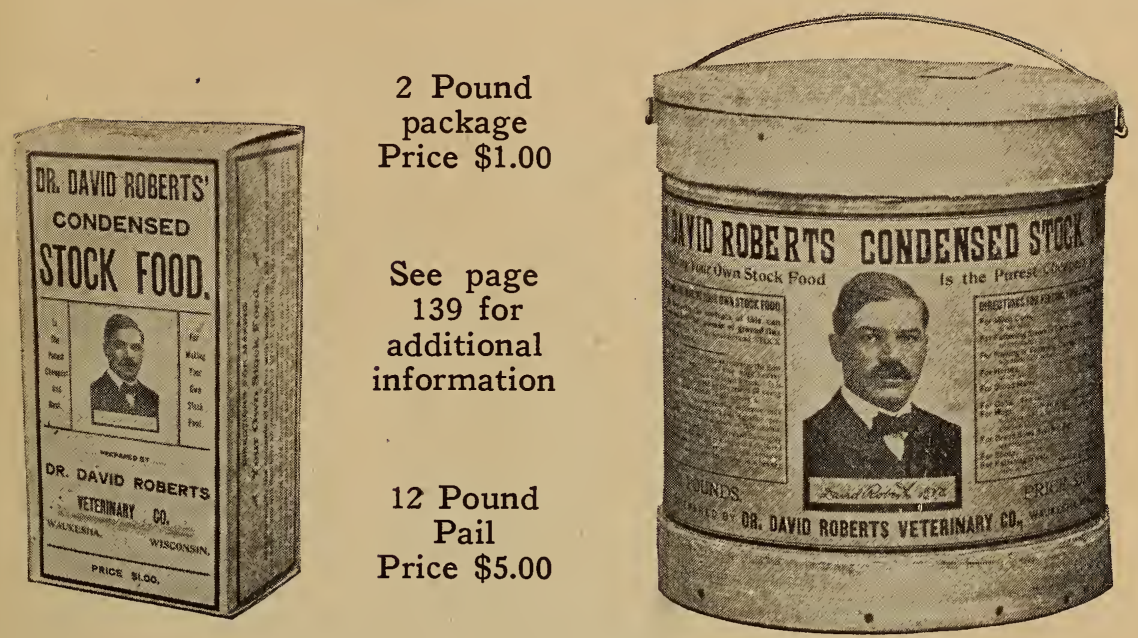

AN ADVANCED IDEA IN STOCK TONIC.

Our Condensed STOCK Tonic contains nothing but the purest of ground roots and herbs necessary to stimulate and tone up the digestive organs of all live stock.

It is put up in this way to save freight.

\section{DIRECTIONS FOR MAKING YOUR OWN STOCK TONIC.}

Mix thoroughly 2 pounds of Condensed Stock Tonic to every 25 pounds of ground flaxseed. You will then have an unadulterated STock Tonic that has no equal.

This STOCK TonIC will aid digestion, increase the flow of milk, save milk in raising calves, keep hogs healthy and fatten them quickly, sleeken and fatten horses. It is a bone and muscle builder, and for this reason all young stock as well as matured animals should receive it.

To be successful in the breeding of cattle, and especially show cattle, much attention should be given in order to produce strong, robust, healthy, superior individuals. In order to expect this the calf from the moment that it drops should receive proper care and such food as will be digested and assimilated, so as not to overtax the digestive organs. To avoid this, such ingredients should be added to the feed as will aid digestion and assimilation, thus causing rapid development of bone and muscle, and the result will be a perfect animal.

Profit can be made easy and saved by the regular use of a good Stock Tonic, in the form of a pure, unadulterated Stock Food, which you can make at home and know positively that it is absolutely pure.

Two pounds of CONDENSED STOCK Tonic mixed thoroughly with every 25 pounds of salt and put in troughs in a sheltered place where the cows can have free access to it in passing to and from the pasture will keep them in a healthy condition.

Stock raisers should mix their own Stock Tonic and know it is clean and pure. Try a can and see the difference between prepared Stock Tonic and that which you mix yourself. 


\section{DR. DAVID ROBERTS}

\section{Disinfectall}

\section{(Strictly a Live Stock Preparation)}

Price $\$ 1.25$ per gallon

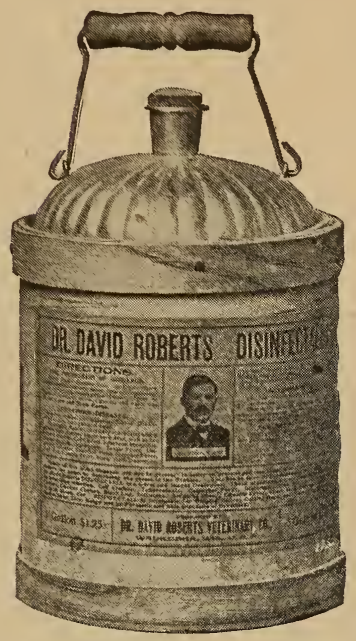

5 gallons

$\$ 5.00$

Nearly all live stock diseases are due to germs, and in order to prevent and cure them it is absolutely necessary to remove the cause, by destroying the germs in the stables.

This can be done by the liberal use of Disinfectall.

Dr. David Roberts' Disinfectall is a germ and insect destroyer, and as these organisms are the cause of such diseases as Infectious Abortion, Calf Cholera, Tuberculosis, Texas Fever, Hog Cholera, Chicken Cholera, Anthrax, Catarrhal Fevers, Distemper, Pink Eye, Blackleg, Influenza, Shipping Fever, Climatic Fever, Stock Yards Distemper, Glanders, Scabs in Sheep, etc., Disinfectall is invaluable for dipping Sheep, Cattle, Hogs and Horses, for destroying Scabs, Ticks, Lice, Mange and all Parasitic and Skin Diseases of Live Stock.

Use Disinfectall freely throughout the stables and prevent the spread of diseases by killing the germs in the air. It is easier to prevent than to cure.

\section{IMPORTANT !}

Sixty drops equal one teaspoonful.

One drachm equals one teaspoonful.

Four teaspoonfuls equal one tablespoonful.

Two tablespoonfuls equal one ounce.

Sixteen ounces equal one pint.

For dipping live stock use one gallon of Disinfectall to 50 gallons of water. 


\section{Test Your Herd}

This Outfit Complete for Testing Cattle for Tuberculosis.

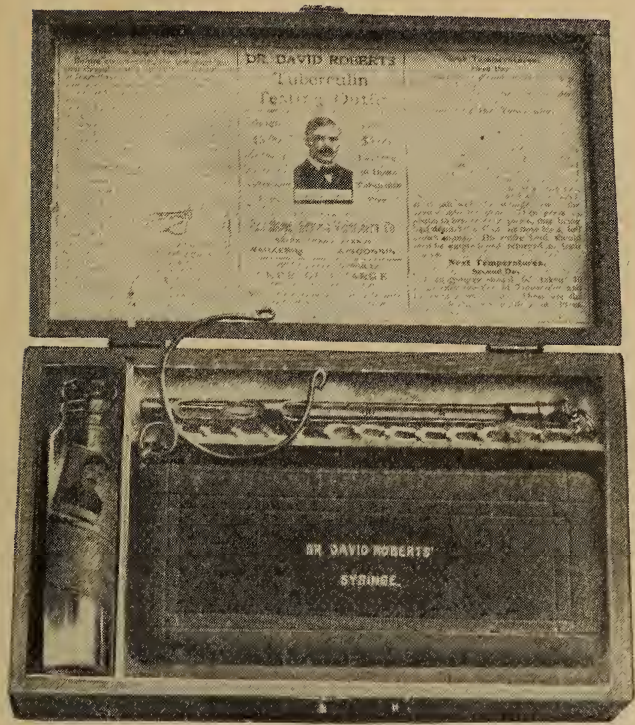

\section{Price $\$ 5.00$}

Including Tuberculin Sufficient to Test Ten Head.

On all herds over 10 head figure 15 cents per head additional

See page 75

How to Apply Test.

DELIVERED BY MAIL POSTPAID.

I supply charts for recording temperatures, and also

\section{ADVISE YOU FREE OF CHARGE}

exact condition of your herd, after chart is returned to me.

Order an Outfit today and Test Your Own Herd, and be on the Safe Side. 


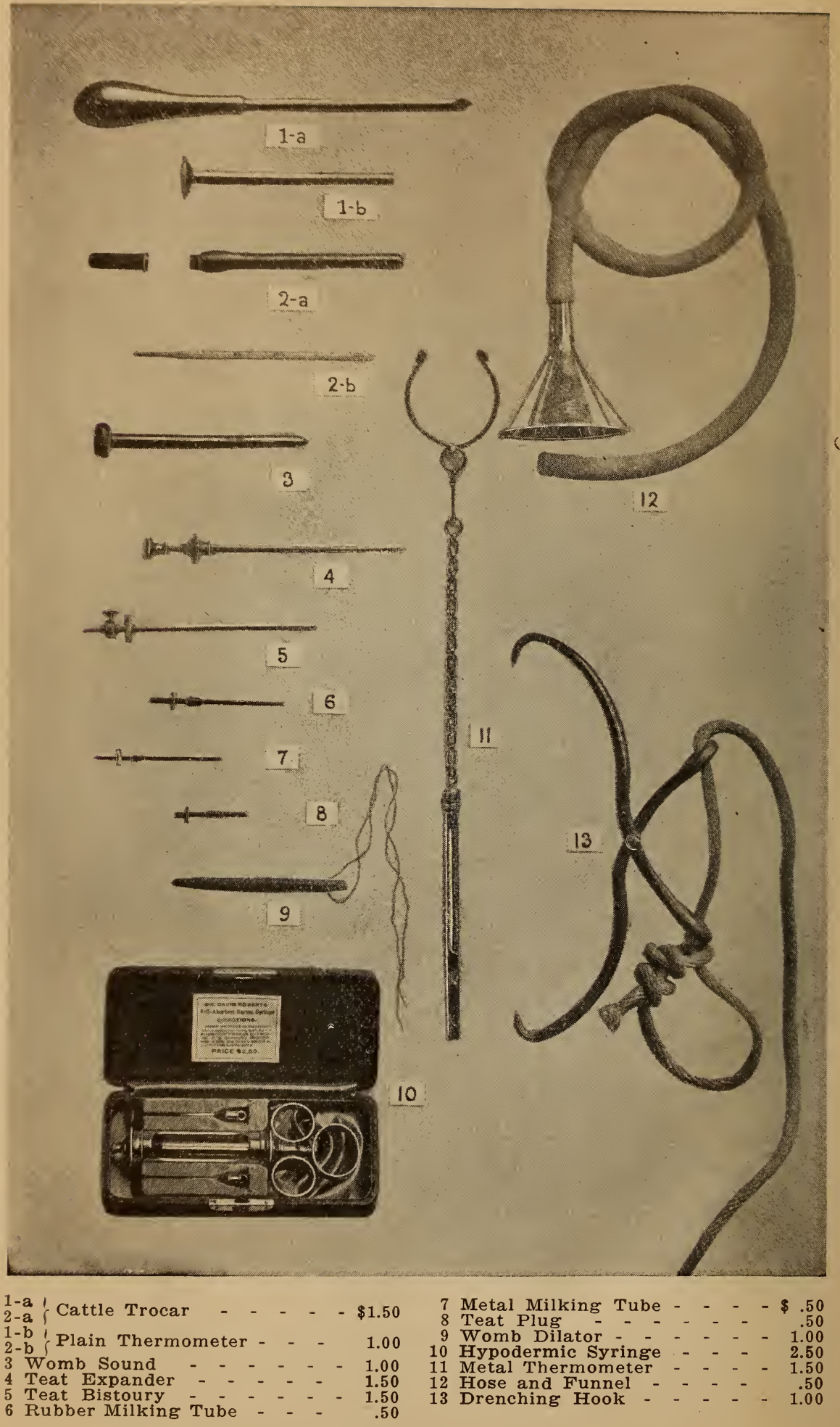




\section{IN CONCLUSION}

We desire to emphasize in the strongest possible terms our desire to be of practical assistance to the owners and breeders of Live Stock.

We will consider it a privilege to answer by personal correspondence any questions relating to the care and management of Cattle, Horses, Swine, Sheep and Poultry. Dr. David Roberts himself will reply to all inquiries regarding diseases of live stock and their treatment.

We guarantee our Veterinary Remedies and Condensed Stock Tonic, when used according to directions.

We guarantee the genuineness of every testimonial appearing in this book.

In all cases where it is desired that Dr. David Roberts visit the herd, we will be pleased to arrange for such a visit, to any point in the United States or Canada, as soon as his other professional engagements will permit.

It is impossible to cover in this condensed treatise all of the diseases of live stock. To do this would require many volumes.

No matter from what disease your stock may suffer, if you will write us fully regarding same, Dr. David Roberts will write you personally, advising you as to the proper treatment and the method of administering same.

In a word, the aim of this company is to render valuable service to owners and breeders of live stock everywhere.

We desire to thank our friends for their patronage and generous indorsement of cur medicines and other products, and to extend to them our sincerest good wishes for their continued prosperity and success in raising the standard of their flocks and herds.

Faithfully yours,

Dr. David Roberts Veterinary Co., Waukesha, Wis., U. S. A.

\section{HOW TO ORDER.}

Purchase medicines from our dealer in your town. If you have no dealer and no order sheet write plainly the name of medicine wanted and make remittance either by Post Office Order, Express Order or Bank Draft on Chicago or New York to Dr. David Roberts Veterinary Co., Waukesha, Wis., U. S. A.

Remittance must accompany order, otherwise medicine will be sent C. O. D. 
PRINTED BY

AMER-KRASSELT CO

\section{THE CRAMER-KRASSE
MILWAUKEE}



LIBRARY OF CONGRESS

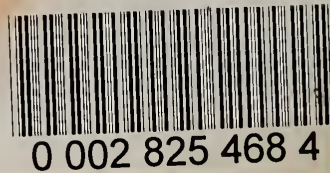

